\title{
Tree growth and water use efficiency during the twentieth century: from global trends to local drivers
}

Justin Michael Mathias

West Virginia University, jmathia6@mix.wvu.edu

Follow this and additional works at: https://researchrepository.wvu.edu/etd

Part of the Terrestrial and Aquatic Ecology Commons

\section{Recommended Citation}

Mathias, Justin Michael, "Tree growth and water use efficiency during the twentieth century: from global trends to local drivers" (2020). Graduate Theses, Dissertations, and Problem Reports. 7610.

https://researchrepository.wvu.edu/etd/7610

This Dissertation is protected by copyright and/or related rights. It has been brought to you by the The Research Repository @ WVU with permission from the rights-holder(s). You are free to use this Dissertation in any way that is permitted by the copyright and related rights legislation that applies to your use. For other uses you must obtain permission from the rights-holder(s) directly, unless additional rights are indicated by a Creative Commons license in the record and/ or on the work itself. This Dissertation has been accepted for inclusion in WVU Graduate Theses, Dissertations, and Problem Reports collection by an authorized administrator of The Research Repository @ WVU.

For more information, please contact researchrepository@mail.wvu.edu. 

Tree growth and water use efficiency during the 20th century: from
global trends to local drivers

\author{
Justin M. Mathias
}

Dissertation submitted to the Eberly College of Arts and Sciences at West Virginia University

in partial fulfillment of the requirements for the degree of

\author{
Doctor of Philosophy \\ in \\ Biology
}

\author{
Richard B. Thomas, Ph.D., Chair \\ William T. Peterjohn, Ph.D. \\ Jonathan R. Cumming, Ph.D. \\ Edward R. Brzostek, Ph.D. \\ David M. Nelson, Ph.D.
}

Department of Biology
Morgantown, West Virginia
2020

Keywords: tree ring; stable isotope; intrinsic water use efficiency; tree growth Copyright 2020 Justin M. Mathias 


\section{Abstract \\ Tree growth and intrinsic water use efficiency during the $20^{\text {th }}$ century: from global trends to local drivers}

Justin M. Mathias

The frequency and severity of extreme environmental conditions will continue to increase under global environmental change. How terrestrial plants respond to prolonged, and often novel environmental stressors, will have profound impacts on, and feedbacks with, the Earth climate system at local to continental scales. Central to these feedbacks are plant stomata, actively regulated pores on the leaves of plants that act as a control valve over the fluxes of carbon dioxide $\left(\mathrm{CO}_{2}\right)$ into the leaf during photosynthesis and water vapor $\left(\mathrm{H}_{2} \mathrm{O}\right)$ out of the leaf during transpiration. Importantly, changes in stomatal aperture do not affect the fluxes of $\mathrm{CO}_{2}$ and $\mathrm{H}_{2} \mathrm{O}$ equally, tipping the balance between $\mathrm{CO}_{2}$ uptake and $\mathrm{H}_{2} \mathrm{O}$ loss, or water use efficiency (WUE), from the leaf to the canopy scale. Understanding the environmental factors driving changes in leaf physiology is of paramount concern under climate change as small changes in tree WUE can have major effects on biogeochemical processes over large geographical areas. In this dissertation, I use a dendroisotopic approach to investigate the drivers of tree growth and intrinsic water use efficiency (iWUE) over the twentieth century, a period of rapid environmental change. I begin by synthesizing tree ring carbon and oxygen isotope data from published literature to examine how changes in the underlying component parts, photosynthesis and stomatal conductance to water, have driven changes in iWUE since the early twentieth century. I then focus my analysis to the Central Appalachian Mountains in the eastern United States, where I investigate how moderate climate change, along with reductions in acidic air pollution, have affected the growth and physiology of red spruce, a tree species that has been historically sensitive to acidic pollution. Finally, I expand my analyses of the environmental drivers of growth and physiology to two of the most common broadleaf deciduous tree species in the eastern United States, northern red oak and tulip poplar. This research suggests at the global scale, most tree species have shown increasing iWUE since the early 1900s, which positively accelerated in 1963, and has largely been a result of stimulated photosynthesis. At a more local scale, I found reductions in acidic pollution, alongside increases in atmospheric $\mathrm{CO}_{2}$ concentrations, led to increased growth and iWUE of red spruce trees since $c a$. 1989. Lastly, I found the tree species studied exhibit a range of sensitivity to acidic pollution-while red spruce trees were highly sensitive, the two studied broadleaf deciduous trees were less so, highlighting the nuance and complexity behind tree responses to environmental change. Overall, these results showcase the active physiological response of trees to environmental change consistent with physiological theory and will help guide decisions regarding the importance of environmental factors in future model development and parameterization. 


\section{Acknowledgements}

This accomplishment would not have been possible without the myriad individuals who helped me along the way. I would first like to express my utmost gratitude to my friend and mentor, Dr. Richard Thomas, for your unwavering support throughout my graduate studies. I am beyond grateful for your guidance, advice, and most of all, friendship as I navigated my Ph.D. I would, without question, not be where I am today without your direction. Your compassion as a leader, and your integrity as a scientist and person are unparalleled. To my family, I cannot thank you enough for your endless love and support—each day of this journey was made easier because of you. I especially thank you for always supporting my decisions and providing sage advice when I most needed to hear it and for encouraging my curiosity and pursuit of knowledge throughout my entire life. I also have to thank Dr. Kenny Smith—you showed me the ropes and to this day remain one of my closest friends and colleagues. To Olivia, I could not have done this without your continual support - thank you for always being a source of positivity and encouragement. To all of my remaining committee members, Drs. William Peterjohn, Edward Brzostek, Jonathan Cumming, and David Nelson, thank you for challenging me to think critically and for providing me with the tools and expertise that helped me achieve this goal. I also owe a great deal of gratitude to the US Forest Service for access to study locations, without which this research would not have been possible, and I would specifically like to thank Stephanie Connolly for her expertise regarding red spruce ecosystems. Last, I would like thank the many students that have helped me in the lab and field - specific mention goes to Benjamin Russell, Kristin Lantz, Marvin Wright, Afsoon Sabet, and Keanan Allen. 


\section{Table of Contents}

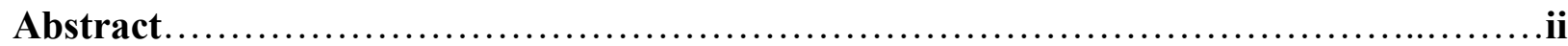

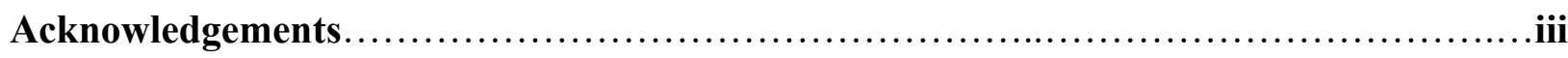

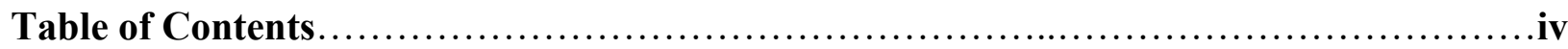

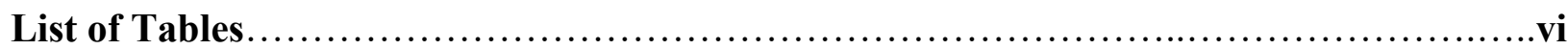

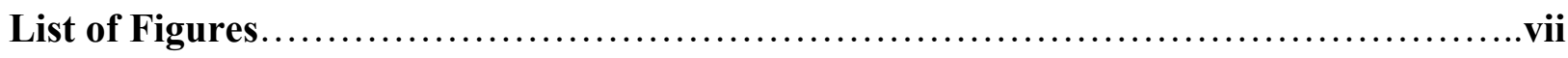

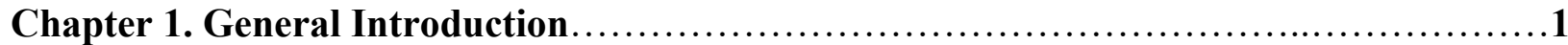

1.1. Research Overview................................................................

1.2. Study area and Plot Descriptions............................................ 6

1.3. Study Objectives.............................................................. 8

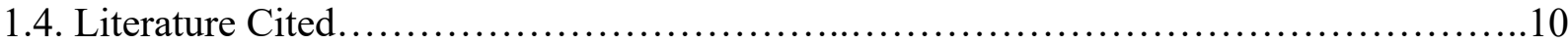

Chapter 2. A global meta-analysis of historical changes in intrinsic water use efficiency of

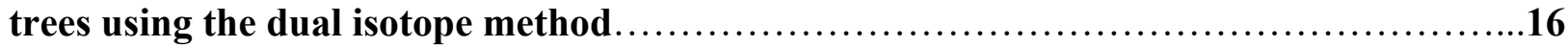

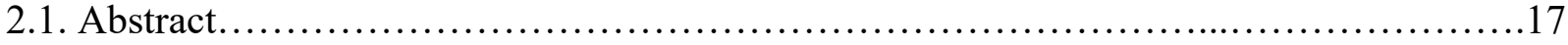

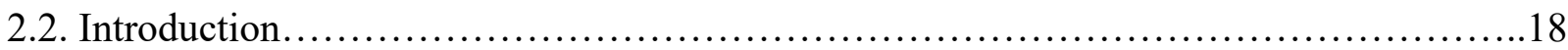

2.3. Methods ............................................................... 20

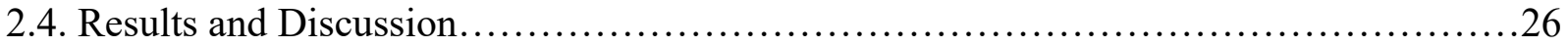

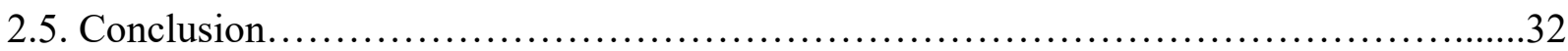

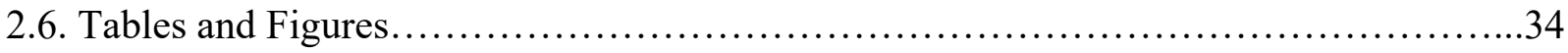

2.7. Literature Cited ............................................................... 39

Chapter 3. Disentangling the effects of acidic air pollution, atmospheric $\mathrm{CO}_{2}$, and climate change on recent growth of red spruce trees in the Central Appalachian Mountains......46

3.1. Abstract............................................................ 47

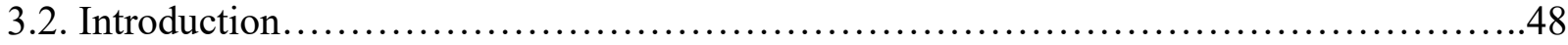

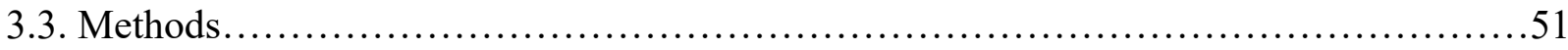

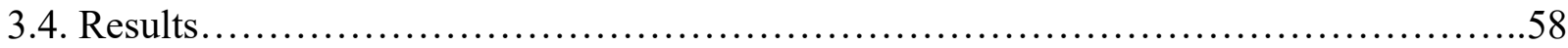

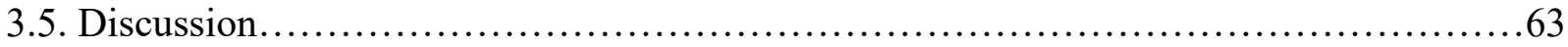

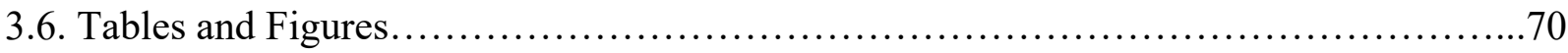

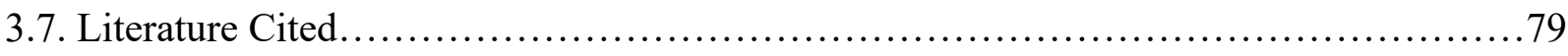

Chapter 4. Air pollution and climate interact to influence the growth and water use efficiency of Quercus rubra and Liriodendron tulipifera in the Central Appalachian Mountains.... 


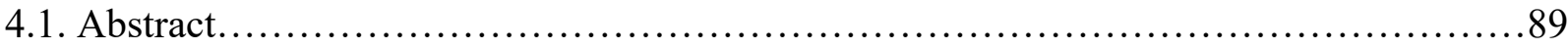

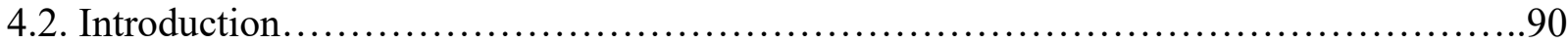

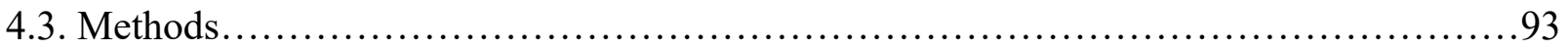

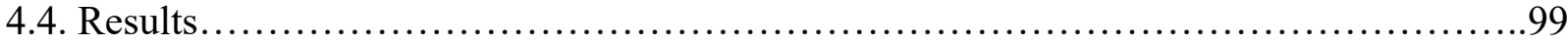

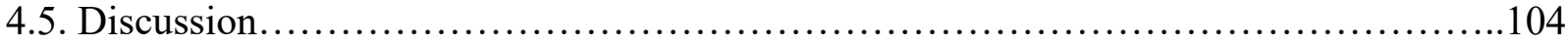

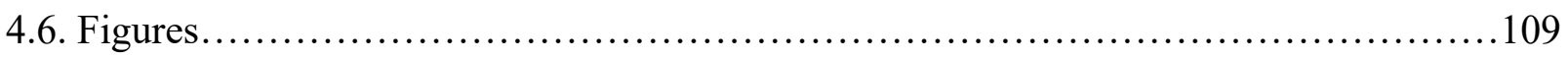

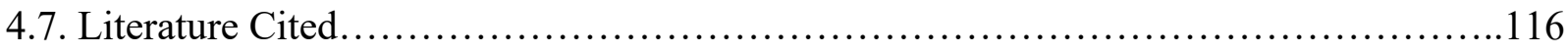

Chapter 5. General conclusions about the trends and drivers of tree growth and intrinsic

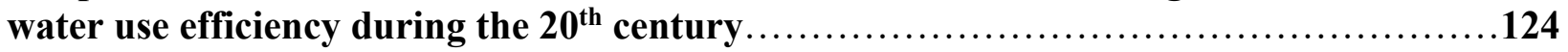

5.1. General Conclusions................................................... 125

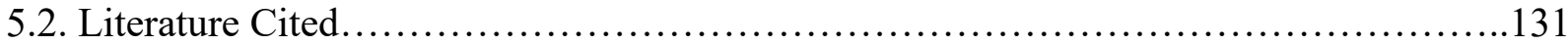

Appendix. Supplementary Tables and Figures....................................... 


\section{List of Tables.}

Table 2.1. Linear mixed effect model results and attributes for the best model (lowest AICc) examining the drivers of tree ring derived iWUE for the period 1963 - 2015 when only considering environmental factors climate and $\mathrm{CO}_{2}$ ( $2^{\text {nd }}$ column), including wood type as a fixed effect with no interactions in the model ( $3^{\text {rd }}$ column), and when including leaf type as a fixed effect with no interactions in the model ( $4^{\text {th }}$ column). Intercept values for each model represent the value of iWUE when each numerical environmental factor included in the model is at its mean value during the study period. Leaf and wood type parameter estimates indicate the difference from the original intercept value for each respective variable, with comparisons made with " $100 \%$ tracheids" at the base level for wood type and "needleleaf evergreen" as the base level for leaf type. The marginal $\mathrm{R}^{2}$ describes the goodness of model fit given fixed effects only, while the conditional $\mathrm{R}^{2}$ describes the goodness of model fit including fixed and random effects (tree species nested within site). Model parameter significance is denoted by an asterisk where denotes $\mathrm{p}<0.06$, $*$ denotes $\mathrm{p}<0.05, * *$ denotes $\mathrm{p}<0.01$, and $* * *$ denotes $\mathrm{p}<0.001$, while ${ }^{\mathrm{ns}}$ denotes not significant.

Table 3.1. Estimated breakpoints ( \pm standard errors) where a directional change in the 19402014 chronologies of red spruce basal area increment (BAI), $\Delta^{13} \mathrm{C}$, and $\delta^{15} \mathrm{~N}$ occurred for McGowan Mountain (MCG), Span Oak Run (SOR) and Cranberry Glades (CGL). At each site, $\mathrm{N}=20-25$ red spruce trees. The overall breakpoint, defined as the average breakpoint at all 3 sites and all 3 proxies, was the year $1989 \pm 1.5$ years.

Table 3.2. Kendall's rank correlation coefficients $(\tau)$ between environmental parameters and the regional chronologies from 1989 to 2014 of basal area increment (BAI), $\Delta^{13} \mathrm{C}$, seasonally integrated net photosynthesis $(A)$, and seasonally integrated stomatal conductance $\left(g_{c}\right)$ of red spruce trees from three locations in the central Appalachian Mountains. Environmental parameters included national $\mathrm{SO}_{2}$ and $\mathrm{NO}_{x}$ emissions (Lefohn et al., 1999; EPA, 2015), atmospheric $\mathrm{CO}_{2}$ concentrations (Keeling, Piper, Bollenbacher, \& Walker, 2015), and monthly, growing season, and annual precipitation and temperatures (WV Climate Division 4, NOAA, 2017). $\tau$ is shown for significant correlations only, and $*$ denotes $\mathrm{p}<0.01$, ** denotes $\mathrm{p}<0.001$, while $* * *$ denotes $\mathrm{p}<0.0001$.

Table 3.3. Mean sensitivity ( \pm standard errors) of BAI to each environmental parameter determined to be significant by the average model for the 1989 to 2014 period. Sensitivities are defined as the change in BAI $\left(\mathrm{cm}^{2}\right)$ to a one-unit change for each of the environmental factors listed and were determined by dividing the contribution of each factor to BAI by the respective trend of each factor over 1989-2014. Units for environmental factors are in parentheses. 


\section{List of Figures.}

Figure 2.1. Tree locations from which chronologies of iWUE and $\Delta^{18} \mathrm{O}_{\mathrm{lw}}$ were developed (a) and group mean-centered iWUE by species within site over the period $1901-2015$. The color of data points in (a) and (b) correspond to the biome from which trees were growing, while the size of the circle in (a) corresponds to the number of trees used in the development of each carbon and oxygen isotope-derived chronology, respectively. The vertical dashed line in (b) occurs at the year 1963 where the rate of change in iWUE increases. The solid lines in (b) denote the average trend in iWUE for the period before $(1901$ - 1963) and after $(1963$ - 2015) the identified breakpoint.

Figure. 2.2. Visualization of the nature of the interaction between growing season vapor pressure deficit and atmospheric $\mathrm{CO}_{2}$ (a) and growing season vapor pressure deficit and $\mathrm{CO}_{2}$ (b) on iWUE during the period $1963-2015$. The interactions shown represent a given value of iWUE throughout the range experienced by each group mean-centered environmental factor since 1963. Parameter estimates for each interaction are listed in Table 2.1.

Figure 2.3. Visualization of the nature of the interaction between atmospheric $\mathrm{CO}_{2}$ and growing season precipitation ( $\mathrm{PPT}_{\text {growing }}$ ) on iWUE for needleleaf evergreen (a), needleleaf deciduous (b), and broadleaf deciduous (c) tree species, and between atmospheric $\mathrm{CO}_{2}$ and growing season VPD (VPD $\left.{ }_{\text {grw }}\right)$ for broadleaf evergreen trees (d). The interactions shown represent a given value of iWUE throughout the range experienced by each group mean-centered environmental factor since 1963.

Figure 2.4. Standardized chronologies of $\operatorname{iWUE}(\mathrm{a}, \mathrm{b}, \mathrm{c})$ and $\Delta^{18} \mathrm{O}_{\mathrm{lw}}(\mathrm{d}, \mathrm{e}, \mathrm{f})$ binned by the individual site $\Delta^{18} \mathrm{O}_{\mathrm{lw}}$ trend for the period 1963 - 2015. Red data points (a,d) contain individual chronologies with decreasing $\Delta^{18} \mathrm{O}_{\mathrm{lw}}$, blue data points $(\mathrm{b}, \mathrm{e})$ contain individual chronologies with constant $\Delta^{18} \mathrm{O}_{\mathrm{lw}}$, and green data points (c,f) contain individual chronologies with increasing $\Delta^{18} \mathrm{O}_{\mathrm{lw}}$. The respective slope for iWUE and $\Delta^{18} \mathrm{O}_{\mathrm{lw}}$ for each category (decreasing, constant, increasing $\left.\Delta^{18} \mathrm{O}_{\mathrm{lw}}\right)$ is listed in each respective panel, along with the $\mathrm{p}$ value with the corresponding LME model fit where species chronology is nested within site as a random factor. The solid black line in each panel represent the average trend across all data points.

Figure 3.1. Average basal area increment (BAI) of red spruce trees from three forest sites in the Central Appalachian Mountains from 1900-2014 ( $\mathrm{N}=20-25$ trees for each site). Open circles indicate the juvenile growth phase after logging in the early $20^{\text {th }}$ Century, whereas closed circles represent the mature growth phase.

Figure 3.2. Chronology of carbon isotope discrimination (a), $\Delta^{13} \mathrm{C}$, and wood $\delta^{15} \mathrm{~N}$ for red spruce trees $(\mathrm{N}=5$ per site) from three forest sites in the central Appalachian Mountains (b). The $\Delta^{13} \mathrm{C}$ chronology in (a) includes $1940-2014$, while the $\delta^{15} \mathrm{~N}$ chronology in (b) includes 19402013. The vertical dashed lines in (a) and (b) are at 1989, the average critical year for the region determined via breakpoint analysis where a directional shift in BAI, $\Delta^{13} \mathrm{C}$, and $\delta^{15} \mathrm{~N}$ occurred. 
Figure 3.3. Chronology of seasonally integrated photosynthesis modeled using $\Delta^{13} \mathrm{C}$ for red spruce trees $(\mathrm{N}=5$ per site) from three forest sites in the central Appalachian Mountains from 1940-2014 (a), seasonally integrated stomatal conductance modeled using $\Delta^{13} \mathrm{C}$ (b), and intrinsic water use efficiency ( $i$ WUE) derived from the chronologies of $\Delta^{13} \mathrm{C}(\mathrm{c})$. The vertical dashed lines in (a) and (b) are at 1989, the average critical year for the region determined via breakpoint analysis where a directional shift in BAI, $\Delta^{13} \mathrm{C}$, and $\delta^{15} \mathrm{~N}$ occurred. The vertical dashed line in (c) is at 1995, the critical year where a directional shift in $i$ WUE occurred. The three red spruce forest sites are McGowan Mountain (MCG), Span Oak Run (SOR), and Cranberry Glades (CGL).

Figure 3.4. Relationships between seasonally integrated photosynthesis (a) and basal area increment with mean April temperatures (b) before and after 1989. ANCOVA was used to determine if the response of seasonally integrated photosynthesis or basal area increment to April temperatures were different before and after 1989, the average critical year for the region determined via breakpoint analysis where a directional shift in BAI, $\Delta^{13} \mathrm{C}$, and $\delta^{15} \mathrm{~N}$ occurred. Climate data are from West Virginia Division 4, which is the region that contains the three red spruce stands in this study (WV Climate Division 4, NOAA, 2017).

Figure 3.5. Relationships between carbon isotope discrimination (a), seasonally integrated photosynthesis (b), seasonally integrated stomatal conductance (c), and basal area increment with wood $\delta^{15} \mathrm{~N}(\mathrm{~d})$ at each red spruce site $(\mathrm{N}=5$ trees per site) from 1989-2013. In each panel, correlation coefficients are from top to bottom, McGowan Mountain (MCG), Span Oak Run (SOR), and Cranberry Glades (CGL).

Figure 3.6. Contribution of atmospheric $\mathrm{CO}_{2}, \mathrm{NO}_{x}$ emissions, $\mathrm{SO}_{2}$ emissions, and mean April temperatures to the change in BAI each year predicted by the GLMM average model for 19892014 (a), and the contribution of $\mathrm{CO}_{2}, \mathrm{NO}_{\mathrm{x}}$ emissions, $\mathrm{SO}_{2}$ emissions, and mean April temperatures to the total change in BAI over 1989-2014 (b). Numbers in brackets indicate the direction and magnitude of changes in environmental parameters. Numbers in brackets in panel (a) represent the trend in each respective environmental parameter over 1989-2014, while numbers in brackets in panel (b) represent the total change in each respective environmental parameter over 1989-2014. Units for $\mathrm{CO}_{2}$ and $\mathrm{April} \mathrm{T}_{\text {mean }}$ are $\mathrm{ppm}$ and ${ }^{\circ} \mathrm{C}$, respectively, while units for $\mathrm{NO}_{\mathrm{x}}$ and $\mathrm{SO}_{2}$ are $10^{6}$ metric tons. Unknown contributions in (a) were calculated as the difference between the observed change and all known contributions. Models with $\triangle \mathrm{AICc}<4$ were included in the average model (see Table S3 for model structure). Asterisks $\left(^{*}\right.$ ) indicate significance at the $\alpha=0.05$ level.

Figure 4.1. Chronologies of basal area increment from 1920 - 2015 for Quercus rubra (a, c) and Liriodendron tulipifera (b, d) from Watershed 10 (a, b) and Watershed 13 (c, d) in the Fernow Experimental Forest, Parsons, West Virginia, USA. Individual tree growth in each panel is denoted by light gray lines, while the average chronology is denoted by the bold purple and orange lines for Quercus rubra and Liriodendron tulipifera, respectively. The vertical dashed lines at 1960 in each panel represent the beginning of the mature growth phase of each chronology. The slope of the average growth trend from 1960-2015 (solid black trendline) is denoted for each respective panel below the expressed population signal (eps), a measure of how 
well the sampled trees reflect a chronology developed from an infinite population (Wigley et al., 1984).

Figure 4.2. Chronologies of leaf-corrected carbon isotope discrimination $(a, b)$ and intrinsic water use efficiency (c,d) for the period 1960 - 2015 for Quercus rubra (a,c; purple) and Liriodendron tulipifera (b,d; orange) in Watershed 10 (circles) and Watershed 13 (triangles) at the Fernow Experimental Forest, Parsons, WV, USA. For each year, iWUE was derived from leaf-corrected $\Delta^{13} \mathrm{C}$ from Quru and Litu trees in each of the two study locations. Data points in gray represent measurements from each tree, while purple and orange represent mean values within a given site for a given year for each chronology. The solid black trendline in each panel is the average trend from $1960-2015$.

Figure 4.3. Contour plots depicting the interactive effects among environmental factors on BAI $(\mathrm{a}, \mathrm{b})$ and iWUE (c, d, e) of Quercus rubra in the Fernow Experimental Forest, Parsons, WV, U.S during the 1960 - 2015 study period. Interactions were determined from the best (lowest $\mathrm{AIC}_{\mathrm{c}}$ ) linear mixed effects model for each response variable and include the sum of June and July precipitation of the current year $\left(\mathrm{JJ}_{\mathrm{ppt}}\right)$, minimum growing season temperature (Growing ${ }_{\mathrm{Tmin}}$ ), and U.S. emissions of $\mathrm{SO}_{2}\left(\mathrm{SO}_{2}\right.$ Emissions) and $\mathrm{NO}_{\mathrm{x}}\left(\mathrm{NO}_{\mathrm{x}}\right.$ Emissions). Units for $\mathrm{NO}_{\mathrm{x}}$ and $\mathrm{SO}_{2}$ emissions are $10^{6}$ metric tons, while $\mathrm{JJ}_{\mathrm{ppt}}$ are in $\mathrm{mm}$, Growing ${ }_{\mathrm{Tmin}}$ are in ${ }^{\circ} \mathrm{C}$, and atmospheric $\mathrm{CO}_{2}$ are in ppm. Each interaction is plotted across the range experienced by each respective environmental parameter, with the value of the response variable (BAI or iWUE) corresponding to the respective color hue (moving from light green toward dark blue indicates increasing BAI, while moving from dark blue toward dark red indicates increasing iWUE).

Figure 4.4. Contributions of multiple environmental factors to the observed changes in BAI (A) and iWUE (B) for the period 1960 - 2015 for Quercus rubra (purple) and Liriodendron tulipifera (orange) in Watershed 10 and Watershed 13 in the Fernow Experimental Forest, Parsons, WV, U.S. Numbers in parentheses beside each environmental factor denote the direction and magnitude of the respective average yearly change (i.e. slope) for the period $1960-$ 2015. Units for Atmospheric $\mathrm{CO}_{2}$, Growing ${ }_{\mathrm{Tmin}}$, and $\mathrm{JJ}_{\mathrm{ppt}}$ are $\mathrm{ppm},{ }^{\circ} \mathrm{C}$, and $\mathrm{mm}$, respectively, while units for both $\mathrm{SO}_{2}$ Emissions and $\mathrm{NO}_{\mathrm{x}}$ Emissions are $10^{6}$ metric tons. Unknown contributions were determined by subtracting all known contributions from the observed change during the 1960 - 2015 study period. Model summaries for linear mixed effects models for BAI and iWUE of Quru and Litu used in the calculation of contributions are listed in Table S3.

Figure 4.5. Contour plots depicting the nature of the interactions among environmental factors on BAI (A) and iWUE (B, C, D) of Liriodendron tulipifera in the Fernow Experimental Forest, Parsons, WV, U.S during the 1960 - 2015 study period. Interactions were determined from the best (lowest $\mathrm{AIC}_{\mathrm{c}}$ ) linear mixed effects model for each response variable and include the sum of June and July precipitation of the current year $\left(\mathrm{JJ}_{\mathrm{ppt}}\right)$, minimum growing season temperature (Growing ${ }_{\text {Tmin }}$ ), and U.S. emissions of $\mathrm{SO}_{2}\left(\mathrm{SO}_{2}\right.$ Emissions) and $\mathrm{NO}_{\mathrm{x}}\left(\mathrm{NO}_{\mathrm{x}}\right.$ Emissions). Units for $\mathrm{NO}_{\mathrm{x}}$ and $\mathrm{SO}_{2}$ emissions are $10^{6}$ metric tons, while $\mathrm{JJ}_{\mathrm{ppt}}$ are in $\mathrm{mm}$, Growing ${ }_{\mathrm{Tmin}}$ are in ${ }^{\circ} \mathrm{C}$, and atmospheric $\mathrm{CO}_{2}$ are in ppm. Each interaction is plotted across the range experienced by each respective environmental parameter, with the value of the response variable (BAI or iWUE) corresponding to the respective color hue (moving from light green toward dark blue indicates increasing BAI, while moving from dark blue toward dark red indicates increasing iWUE). 
Figure 4.6. Modelled BAI using the final models for Quercus rubra (a) and Liriodendron tulipifera (b) under observed (Quru, purple line; Litu, orange line) and high $\mathrm{SO}_{2}$ emissions (red lines) scenarios. $\mathrm{BAI}$ under high $\mathrm{SO}_{2}$ (red lines in a and $b$ ) was predicted using the average $\mathrm{SO}_{2}$ emissions level from 1970 - 1990 (24.4 metric tons) forced during the entire period from 1991 to 2015. Cumulative basal area increment for each scenario was then converted to diameter at breast height (DBH), and species specific allometric equations between DBH and aboveground biomass (AGBM) (Chojnacky et al., 2014) were used to determine total aboveground biomass carbon at 2015 for each scenario after accounting for $\% \mathrm{C}$ in wood $\left(\mathrm{AGBM}^{*} 0.5\right)$. The gray shaded area in a and $\mathrm{b}$ represents the calculated integrated difference in basal area between the two scenarios, with the percent difference in carbon stored in AGBM listed in each panel, and the corresponding basal area on the bottom right corner of each panel.

Figure 4.7. Modeled changes of Quercus rubra (a) and Liriodendron tulipifera (b) intrinsic water use efficiency under hypothetical future environmental change predicted using the final model. Data points represent iWUE for each year in the period $2030-2050$ as climatic factors linearly approach a $\pm 25 \%$ change from their previous 30 -year averages by the year 2050 and atmospheric $\mathrm{CO}_{2}$ concentrations increase according to the RCP 4.5 scenario (IPCC, 2014). Horizontal dashed lines represent observed iWUE in 2015 for each species, respectively. 
Chapter 1. General Introduction. 


\subsection{Research Overview.}

Since the onset of the industrial revolution there has been significant global changeconcentrations of atmospheric $\mathrm{CO}_{2}$ have risen by ca. 34\% (Keeling, Piper, Bollenbacher, \& Walker, 2016), global temperatures have increased by $c a .0 .8^{\circ} \mathrm{C}$ (of which, more than $60 \%$ occurred during the past four decades) (Hansen et al., 2010), acidic air pollution has become increasingly pervasive, particularly in developing countries (WHO, 2016), and the frequency and severity of extreme weather events such as drought is increasing (Trenberth et al., 2014). How terrestrial plants respond to these prolonged, and often novel environmental stressors will have profound impacts on, and feedbacks with, the Earth climate system at local to continental scales (Swann et al., 2016; Kooperman et al., 2018). As such, there has been substantial progress in understanding the role of forest ecosystems in this rapidly changing environment through experimental manipulation of environmental conditions (Hendrey et al., 1999; Dickson et al., 2000; Miglietta et al., 2001; Norby et al., 2001; Hanson et al., 2017), development and benchmarking of coupled atmosphere-biosphere process-based models (Zaehle et al., 2014; De Kauwe et al., 2014; Walker et al., 2015), and assessment of data generated from Forest Inventory and Analysis (FIA) plots (Jenkins et al., 2001; Thomas et al., 2010).

Groundbreaking studies investigating the effects of elevated atmospheric $\mathrm{CO}_{2}$ on trees in unmanaged forest stands used a Free-Air $\mathrm{CO}_{2}$ Enrichment (FACE) approach whereby ambient $\mathrm{CO}_{2}$ concentrations were maintained at levels predicted by the end of the $21^{\text {st }}$ century (Hendrey et al., 1999; Dickson et al., 2000; Miglietta et al., 2001; Norby et al., 2001). After roughly a decade of forest exposure to elevated $\mathrm{CO}_{2}$, major FACE results revealed plants, on average, responded by increasing rates of maximum and diurnal leaf photosynthesis, decreasing stomatal conductance, and increasing leaf level water use efficiency (iWUE) (Ainsworth \& Long, 2004; Ainsworth \& Rogers, 2007). A recent synthesis of data generated across multiple FACE experiments has also highlighted the stimulatory effect of increased atmospheric $\mathrm{CO}_{2}$ on longterm plant growth, showing a nearly $30 \%$ increase in woody biomass over a decade of treatment (Walker et al., 2019). Importantly, these results from FACE studies have provided a testable framework for guiding hypotheses regarding expected changes in plant physiology under increasing atmospheric $\mathrm{CO}_{2}$ in the future.

More recent large-scale experiments have expanded upon FACE studies by incorporating a warming component, such as the Spruce and Peatland Responses Under Changing 
Environments (SPRUCE) in northern Minnesota (Hanson et al., 2017), as increases in atmospheric $\mathrm{CO}_{2}$ ultimately lead to warmer temperatures at the Earth's surface (IPCC, 2014). SPRUCE and similar experiments have shown that warming may increase rates of litter decomposition (Butenschoen et al., 2011) and emissions of trace gases such as $\mathrm{CO}_{2}$ and $\mathrm{CH}_{4}$ (Gill et al., 2017), as well as reduce the size of soil carbon pools through increased respiratory losses (Wilson et al., 2016; Melillo et al., 2017). Moreover, these experiments have provided critical information on aboveground plant processes, showing that warming and elevated $\mathrm{CO}_{2}$ can lead to a longer growing season for vegetation, but also result in a greater vulnerability to frost damage (Richardson et al., 2018).

In addition to releasing $\mathrm{CO}_{2}$, fossil fuel burning contributes to the emissions of oxidized forms of nitrogen and sulfur, which undergo various reactions and return to the biosphere as strong acids (i.e. sulfuric acid, nitric acid) (Driscoll et al., 2001; Elliott et al., 2007). Though much progress has been made in reducing acidic pollution in the United States due to the Clean Air Act and subsequent amendments (EPA, 2015), acid deposition remains a pervasive problem in many areas globally (WHO, 2016). Whole watershed acidification experiments, such as in the Fernow Experimental Forest in Parsons, West Virginia (Lanning et al., 2019), offer a unique opportunity to examine how consistently high levels of simulated acidic deposition may influence ecosystem processes. For example, under prolonged exposure to high acid deposition rates, soils experience reductions in buffering capacity (Bowman et al., 2008), leach essential base cations such as calcium and magnesium (DeHayes et al., 1999; Driscoll et al., 2001), and mobilize toxic metals such as aluminum (Driscoll et al., 2001), which have the potential to reduce forest growth and productivity (Engel et al., 2016). The effects of acid deposition may also extend to the water cycle through the effects on tree physiological responses, as has been documented in the Fernow Experimental Forest where trees have been shown to use more water under acidic conditions (Lanning et al., 2019).

Importantly, precipitation is expected to become more variable under future environmental change, with droughts becoming more extreme (Trenberth et al., 2014) and rain events increasing in both frequency and severity (Zhang et al., 2013; Stott, 2016). Drought experiments, especially when coupled with modelling techniques are invaluable for understanding forest responses to environmental change from the plant to global scale (McDowell et al., 2013) and have guided the development of demography based vegetation 
models, such as the Ecosystem Demography model Version 2 (Medvigy et al., 2009), that have been used to examine the importance of water availability in constraining estimates of various fluxes in the global carbon cycle (Trugman et al., 2017).

Though each of the aforementioned experiments and techniques have been invaluable for understanding the effects of a given environmental factor on tree growth and physiology, it is critical to consider the integrated effect of many factors under ambient conditions. For example, Forest Inventory and Analysis (FIA) plots, established in the $20^{\text {th }}$ century, undergo periodic resampling of standing biomass, tree mortality, and recruitment and, over time, have been used to examine forest responses to nitrogen and sulfur deposition (Thomas et al., 2010; Horn et al., 2018) and drought (Shaw et al., 2005), among many other factors. Additionally, process-based models that incorporate fundamental physiological relationships of plants can simulate plant responses to a variety of ecosystem perturbations (Aber \& Federer, 1992; Parton et al., 1992) and aid in hypothesis development and testing, particularly when model results do not match observed ecosystem responses (Zaehle et al., 2014; De Kauwe et al., 2014; Walker et al., 2015). Like FACE, warming, acid deposition, and precipitation/drought experiments, FIA plots and modeling studies have led to valuable insights regarding ecosystem functioning, but critically, often lack the ability to evaluate historical ecosystem changes beyond a few decades, largely due to time span or model parameterization constraints.

Dendroecology fills this knowledge gap and provides a powerful lens to examine the factors driving tree growth and physiology over time, as the integrated response of trees to environmental change is archived in woody biomass increment each year. A dendroecological approach can be particularly useful in remote areas where it is difficult to establish long-term monitoring plots or eddy-covariance towers but are representative of larger geographical areas that play major roles in the global carbon and water cycles (Levesque et al., 2019). Importantly, changes in growth (i.e. tree ring widths) can be used to estimate annual aboveground biomass increment through the use of species-specific allometric relationships, providing an assessment of annual changes in carbon sequestration (Dye et al., 2016). Further, when coupled with relative basal area and relative abundance of each tree species, ecosystem-scale carbon cycling dynamics can be resolved at fine-scale temporal resolution (Teets et al., 2018), allowing a more accurate overview of the role of a given forest in the context of environmental change. 
Extending dendroecological work to the analysis of tree ring stable isotopes has become increasingly common, providing information on processes related to photosynthesis (A) (Mathias \& Thomas, 2018; Thomas, Spal, Smith, \& Nippert, 2013), stomatal conductance ( $\left.g_{s}\right)$ (Grams, Kozovits, Häberle, Matyssek, \& Dawson, 2007; Rossella Guerrieri et al., 2019; Mathias \& Thomas, 2018; Scheidegger, Saurer, Bahn, \& Siegwolf, 2000; Thomas et al., 2013), and tree intrinsic water use efficiency (iWUE) (Frank et al., 2015; Rossella Guerrieri et al., 2019; Thomas et al., 2013), as well as nitrogen cycling and availability (Evans, 2001; Smith et al., 2016; Burnham et al., 2016; Sabo et al., 2020). As such, changes in the tree ring stable isotope signature of carbon $\left(\delta^{13} \mathrm{C}\right)$, oxygen $\left(\delta^{18} \mathrm{O}\right)$, and nitrogen $\left(\delta^{15} \mathrm{~N}\right)$ are most widely, and often simultaneously, used in studies examining tree responses to environmental change. Briefly, the $\delta^{13} \mathrm{C}$ signature of tree rings serves as a record of the diffusional and biochemical properties of photosynthesis, whereby increasing $\delta^{13} \mathrm{C}$ is indicative of a reduction in the concentration of leaf intercellular $\mathrm{CO}_{2}\left(\mathrm{C}_{\mathrm{i}}\right)$, which can occur through increased photosynthetic rates or reduced stomatal conductance (Farquhar et al., 1982, 1989). On the other hand, tree ring $\delta^{18} \mathrm{O}$ signatures are not related to changes in leaf photosynthesis, but are sensitive to changes in stomatal conductance (Barbour, 2007; Ubierna and Farquhar, 2014), such that coupling tree ring $\delta^{13} \mathrm{C}$ and $\delta^{18} \mathrm{O}$ can aid in partitioning changes in iWUE between its component parts, photosynthesis and stomatal conductance (Scheidegger et al., 2000; Grams et al., 2007; Bögelein et al., 2012; Guerrieri et al., 2019). Lastly, tree ring $\delta^{15} \mathrm{~N}$ may serve as an index of ecosystem nitrogen (N) availability, where through various mechanisms, enrichment in tree ring ${ }^{15} \mathrm{~N}$ (more positive $\delta^{15} \mathrm{~N}$ ) is indicative of a more open ecosystem $\mathrm{N}$ cycle (i.e. $\mathrm{N}_{\text {supply }}>\mathrm{N}_{\text {demand }}$ ) (Aber et al., 1998; Evans, 2001, 2007; Pardo et al., 2002; Craine et al., 2009; Lovett \& Goodale, 2011; Gerhart \& McLauchlan, 2014). Given the central role of trees in regulating the global cycles of carbon and water (Pan et al., 2011; Schlesinger \& Jasechko, 2014) in a period of rapid environmental change, the overall aim of this research is to use a multiproxy dendroecological approach to identify the long-term drivers of tree growth and physiology in the context of environmental change. 


\subsection{Study Area and Plot Descriptions.}

This research project was conducted under two broad themes - the first theme represents a meta-analysis of tree ring carbon and oxygen isotope chronologies from 84 sites globally where I examine the underlying component parts driving global iWUE. The sites included in the metaanalysis span 10 biomes and include tree species growing in 1) temperate broadleaf and mixed forests, 2) temperate conifer forests, 3) montane grasslands and shrublands, 4) Mediterranean forests, woodlands and scrub, 5) tundra, 6) temperate grasslands, savannas, and shrublands, 7) boreal forests and taiga, 8) deserts and xeric shrublands, 9) tropical and subtropical moist broadleaf forests, and 10) tropical and subtropical coniferous forests. As such, large differences in soil, vegetation, and parent material exist among sites. Mean growing season temperatures ranged from $2.84{ }^{\circ} \mathrm{C}$ to $32.70{ }^{\circ} \mathrm{C}$, while total growing season precipitation ranged from $0.62 \mathrm{~mm}$ to $1693.02 \mathrm{~mm}$ across all 84 sites. The large range in temperature and precipitation among sites resulted in large differences in growing season vapor pressure deficit, which ranged from $71.8 \mathrm{~Pa}$ to 3,213.6 Pa. The sampled trees included in this analysis range from $c a$. 70 to $c a$. 550 years old and represent 36 unique tree species across a spectrum of leaf and wood types.

The second theme of this research project was field-based and was conducted in the Monongahela National Forest throughout the state of West Virginia. I selected five study locations, of which three were previously established in 2011 as part of a carbon balance and soil nitrogen cycling study (Smith et al., 2016) and contain red spruce (Picea rubens Sarg.) as codominant canopy trees. The remaining two sites are reference watersheds located within the Fernow Experimental Forest in Parsons, West Virginia and are largely dominated by broadleaf deciduous trees including the two study species, red oak (Quercus rubra) and tulip poplar (Liriodendron tulipifera).

The three red spruce stands are located along a 100-km long north-south transect in the Central Appalachian Mountains. The northernmost site is located on McGowan Mountain $\left(\mathrm{MCG} ; 38^{\circ} 58^{\prime} \mathrm{N}, 79^{\circ} 41^{\prime} \mathrm{W}\right.$ ) and is positioned within the Appalachian Plateau physiographic province, while Span Oak Run (SOR; 38 37' N, 7946’ W), and Cranberry Glades (CGL; 38 12' $\mathrm{N}, 80^{\circ} 17^{\prime} \mathrm{W}$ ) are located in the Allegheny Mountain Section physiographic province of West Virginia (USGS, 1946). Each site is $\geq 900$ meters in elevation and has a southwest aspect with slopes ranging from $0-10 \%$. The mean annual temperature for this region in West Virginia was $9.5^{\circ} \mathrm{C}$ over the last 75 years (WV Climate Division 4 , NOAA, 2017). The annual total 
precipitation over the last 75 years was $1229.6 \mathrm{~mm} \mathrm{yr}^{-1}$, with $47 \%$ of the precipitation during the growing season from May to September (WV Climate Division 4, NOAA, 2017). Soils at each of the three red spruce dominated sites consist of a thick organic layer containing litter from by red spruce, eastern hemlock (Tsuga candadensis), yellow birch (Betula alleghaniensis), and red maple (Acer rubrum) which are the dominant canopy species. These sites are mature closed canopy stands with no evidence of anthropogenic or natural disturbance, such as logging or fire, since logging events in the early 1900's.

The two additional study locations containing broadleaf deciduous trees are located in the Fernow Experimental Forest, Parsons, WV. Both Watershed 10 (WS10; $39.0566^{\circ} \mathrm{N}$, $\left.79.6789^{\circ} \mathrm{W}\right)$ and Watershed $13\left(\mathrm{WS} 13 ; 39.0617^{\circ} \mathrm{N},-79.6805^{\circ} \mathrm{W}\right)$ are located within the Appalachian Plateau physiographic province (USGS 1946) and are considered reference watersheds for the Fernow, since they have remained free from disturbance since the early 1900s. In addition to the two study species, red oak and tulip poplar, tree species including American beech (Fagus grandifolia), red maple (Acer rubrum), and sugar maple (Acer saccharum) are commonly found in each watershed. The mean elevation of WS10 and WS13 is $\sim 725$ and $\sim 694$ meters above sea level, respectively. The topography at WS10 and WS13 is relatively steep, with $26 \%$ and $25 \%$ slopes, respectively, and while WS10 has a southerly aspect, WS13 has a northerly aspect. Soils at WS10 and WS13 consist of a relatively thin organic layer with litter primarily contributed from the genera Quercus and Liriodendron, as well as Acer and Fagus. Over the past 75 years mean annual temperature (MAT) at WS10 and WS13 was $9.0^{\circ} \mathrm{C}$ and $9.2^{\circ} \mathrm{C}$, respectively, ranged on average from $2.6^{\circ} \mathrm{C}$ to $20^{\circ} \mathrm{C}$ across the year, and increased by $0.75^{\circ} \mathrm{C}$ at both watersheds. Mean annual precipitation (MAP) at WS10 and WS13 was $1314 \mathrm{~mm}$ and $1310 \mathrm{~mm}$, respectively, with the majority of precipitation occurring in July $(10.2 \pm 0.2 \%$ of total annual precipitation) and the least amount of precipitation occurring in October $(6.8 \pm 0.2 \%$ of total annual precipitation) (PRISM Climate Group, 2004). Mean annual precipitation increased during the study period and was driven largely by precipitation during June and July (+ $0.75 \mathrm{~mm} \mathrm{yr}^{-1}$ ) (PRISM Climate Group, 2004). 


\subsection{Study Objectives.}

This research project that included a meta-analysis of previously published research as well as a field-based component across five forested study locations in the Central Appalachian Mountains had three main aims:

In Chapter 2, I synthesized tree ring carbon and oxygen isotope data from previously published articles in a new, physiologically meaningful way to examine the trends and drivers of tree intrinsic water use efficiency (iWUE) over the twentieth century. To do this, I performed a literature search on Web of Science using the phrase "tree ring, carbon, oxygen, isotope". From articles that met strict selection criteria, I digitally extracted dendroisotopic data from highquality figures published in each article, after which I developed species-level chronologies of iWUE and leaf water oxygen isotope enrichment above the source water $\left(\Delta^{18} \mathrm{O}_{\mathrm{lw}}\right)$ for each site. I then used linear mixed effects models to identify those factors (i.e. atmospheric $\mathrm{CO}_{2}$, temperature, etc.) most important in driving iWUE over the twentieth century at the global scale, after which I coupled iWUE and $\Delta^{18} \mathrm{O}_{\mathrm{lw}}$ chronologies to examine whether changes in iWUE were primarily driven by leaf photosynthesis or stomatal conductance.

In Chapter 3, I focused my analysis of the factors driving changes in iWUE to red spruce trees at three study locations in the Central Appalachians. Each study location is downwind of the highly industrialized Ohio River Valley and experienced some of the highest, most pervasive, levels of acid deposition in the eastern United States before the Amendments to the Clean Air Act in 1990. I hypothesized that reductions in acidic deposition, along with increasing atmospheric $\mathrm{CO}_{2}$ concentrations would positively affect the growth of red spruce trees. To test this hypothesis, I collected increment cores from at least 20 randomly sampled red spruce trees for growth and carbon isotope analysis at each study location. I also measured the response of leaf photosynthesis to increasing atmospheric $\mathrm{CO}_{2}$ (i.e. A- $\mathrm{C}_{\mathrm{i}}$ curve) to reconstruct leaf physiology through time using $\mathrm{C}_{\mathrm{i}}$ derived from tree ring carbon isotope signatures. I then used linear mixed effects models to determine the factors driving growth and iWUE, in addition to the specific temporal contribution and sensitivity to growth of each factor since 1940.

In Chapter 4, I expanded my analysis of the drivers of tree growth and physiology to two of the most ecologically important broadleaf deciduous tree species in the eastern United States, northern red oak and tulip poplar. Similar to Chapter 3, I collected increment cores from at least 20 trees at two study locations in the Fernow Experimental Forest in Parsons, West Virginia. I 
also developed $\mathrm{A}-\mathrm{C}_{\mathrm{i}}$ curves for each tree species for upper and lower canopy leaves from at least five trees of each species at each study location. I hypothesized broadleaf deciduous trees would be sensitive to acidic air pollution, but also sensitive to climate change that has occurred in this region. I used linear mixed effects models to test this hypothesis and identify those factors important in driving growth and iWUE over time, as well as to predict potential changes in iWUE under future climate scenarios. 


\subsection{Literature Cited.}

Aber JD, Federer CA. 1992. A generalized, lumped-parameter model of photosynthesis, evaporation and net primary production in temperate and boreal forest ecosystems. Oecologia 92: 463-474.

Aber J, McDowell W, Nadelhoffer K, Magill A, Berntson G, Kamakea M, McNulty S, Currie W, Rustad L, Fernandez I. 1998. Nitrogen Saturation in Temperate Forest Ecosystems. BioScience 48: 921-934.

Ainsworth EA, Long SP. 2004. What have we learned from 15 years of free-air $\mathrm{CO}_{2}$ enrichment (FACE)? A meta-analytic review of the responses of photosynthesis, canopy properties and plant production to rising $\mathrm{CO}_{2}$. New Phytologist 165: 351-372.

Ainsworth EA, Rogers A. 2007. The response of photosynthesis and stomatal conductance to rising $\left[\mathrm{CO}_{2}\right]$ : mechanisms and environmental interactions. Plant, Cell \& Environment 30: $258-270$.

Barbour MM. 2007. Stable oxygen isotope composition of plant tissue: a review. Functional Plant Biology 34: 83.

Bögelein R, Hassdenteufel M, Thomas FM, Werner W. 2012. Comparison of leaf gas exchange and stable isotope signature of water-soluble compounds along canopy gradients of cooccurring Douglas-fir and European beech. Plant, Cell \& Environment 35: 1245-1257.

Bowman WD, Cleveland CC, Halada Ĺ, Hreško J, Baron JS. 2008. Negative impact of nitrogen deposition on soil buffering capacity. Nature Geoscience 1: 767-770.

Burnham MB, McNeil BE, Adams MB, Peterjohn WT. 2016. The response of tree ring $\delta^{15} \mathrm{~N}$ to whole-watershed urea fertilization at the Fernow Experimental Forest, WV. Biogeochemistry 130: 133-145.

Butenschoen O, Scheu S, Eisenhauer N. 2011. Interactive effects of warming, soil humidity and plant diversity on litter decomposition and microbial activity. Soil Biology and Biochemistry 43: 1902-1907.

Craine JM, Elmore AJ, Aidar MPM, Bustamante M, Dawson TE, Hobbie EA, Kahmen A, Mack MC, McLauchlan KK, Michelsen A, et al. 2009. Global patterns of foliar nitrogen isotopes and their relationships with climate, mycorrhizal fungi, foliar nutrient concentrations, and nitrogen availability. New Phytologist 183: 980-992.

Core Writing Team RKP and LAM (eds. ). 2014. IPCC, 2014: Climate Change 2014: Synthesis Report. Contribution of Working Groups I, II, and III to the Fifth Assessment Report of the Intergovernmental Panel on Climate Change.

DeHayes DH, Schaberg PG, Hawley GJ, Strimbeck GR. 1999. Acid Rain Impacts on Calcium Nutrition and Forest Health. BioScience 49: 789. 
Dickson RE, Lewin KF, Isebrands JG, Coleman MD, Heilman WE, Riemenschneider DE, Sober J, Host GE, Zak DR, Hendrey GR, et al. 2000. Forest Atmosphere Carbon Transfer and Storage (FACTS-II ) The Aspen Free-air $\mathrm{CO}_{2}$ and $\mathrm{O}_{3}$ Enrichment (FACE) Project : An Overview. Gen. Tech. NC-214. St. Paul MN: U.S. Department of Agriculture, Forest Service, North Central Research Station.: 68.

Driscoll CT, Lawrence GB, Bulger AJ, Butler TJ, Cronan CS, Eagar C, Lambert KF, Likens GE, Stoddard JL, Weathers KC. 2001. Acidic Deposition in the Northeastern United States: Sources and Inputs, Ecosystem Effects, and Management Strategies. BioScience 51: 180.

Dye A, Barker Plotkin A, Bishop D, Pederson N, Poulter B, Hessl A. 2016. Comparing tree-ring and permanent plot estimates of aboveground net primary production in three eastern U.S. forests. Ecosphere 7: e01454.

Elliott EM, Kendall C, Wankel SD, Burns DA, Boyer EW, Harlin K, Bain DJ, Butler TJ. 2007. Nitrogen Isotopes as Indicators of $\mathrm{NO}_{\mathrm{x}}$ Source Contributions to Atmospheric Nitrate Deposition Across the Midwestern and Northeastern United States. Environmental Science \& Technology 41: 7661-7667.

Engel BJ, Schaberg PG, Hawley GJ, Rayback SA, Pontius J, Kosiba AM, Miller EK. 2016. Assessing relationships between red spruce radial growth and pollution critical load exceedance values. Forest Ecology and Management 359: 83-91.

Evans RD. 2001. Physiological mechanisms influencing plant nitrogen isotope composition. Trends in Plant Science 6: 121-126.

Evans RD. 2007. Soil nitrogen isotope composition. In: Stable isotopes in ecology and environmental science. 83-98.

Farquhar GD, Ehleringer JR, Hubick KT. 1989. Carbon Isotope Discrimination and Photosynthesis. Annual Review of Plant Physiology and Plant Molecular Biology 40: 503537.

Farquhar G, O’Leary M, Berry J. 1982. On the relationship between carbon isotope discrimination and the intercellular carbon dioxide concentration in leaves. Australian Journal of Plant Physiology 9: 121-137.

Frank DC, Poulter B, Saurer M, Esper J, Huntingford C, Helle G, Treydte K, Zimmermann NE, Schleser GH, Ahlström A, et al. 2015. Water-use efficiency and transpiration across European forests during the Anthropocene. Nature Climate Change 5: 579-583.

Gerhart LM, McLauchlan KK. 2014. Reconstructing terrestrial nutrient cycling using stable nitrogen isotopes in wood. Biogeochemistry 120: 1-21. 
Gill AL, Giasson MA, Yu R, Finzi AC. 2017. Deep peat warming increases surface methane and carbon dioxide emissions in a black spruce-dominated ombrotrophic bog. Global Change Biology 23: 5398-5411.

Grams TEE, Kozovits AR, Häberle KH, Matyssek R, Dawson TE. 2007. Combining $\delta^{13} \mathrm{C}$ and $\delta^{18} \mathrm{O}$ analyses to unravel competition, $\mathrm{CO}_{2}$ and $\mathrm{O}_{3}$ effects on the physiological performance of different-aged trees. Plant, Cell and Environment 30: 1023-1034.

Guerrieri R, Belmecheri S, Ollinger S V, Asbjornsen H, Jennings K, Xiao J, Stocker BD, Martin M, Hollinger DY, Bracho-Garrillo R, et al. 2019. Disentangling the role of photosynthesis and stomatal conductance on rising forest water-use efficiency. Proceedings of the National Academy of Sciences: 201905912.

Hansen J, Ruedy R, Sato M, Lo K. 2010. Global surface temperature change. Rev. Geophys. 48: RG4004.

Hanson PJ, Riggs JS, Nettles WR, Phillips JR, Krassovski MB, Hook LA, Gu L, Richardson AD, Aubrecht DM, Ricciuto DM, et al. 2017. Attaining whole-ecosystem warming using air and deep-soil heating methods with an elevated $\mathrm{CO}_{2}$ atmosphere. Biogeosciences 14: 861-883.

Hendrey GR, Ellsworth DS, Lewin KF, Nagy J. 1999. A free-air enrichment system for exposing tall forest vegetation to elevated atmospheric $\mathrm{CO}_{2}$. Global Change Biology 5: 293-309.

Horn KJ, Thomas RQ, Clark CM, Pardo LH, Fenn ME, Lawrence GB, Perakis SS, Smithwick EAH, Baldwin D, Braun S, et al. 2018. Growth and survival relationships of 71 tree species with nitrogen and sulfur deposition across the conterminous U.S. (D Loustau, Ed.). PLOS ONE 13: e0205296.

Jenkins JC, Birdsey RA, Pan Y. 2001. Biomass and NPP estimation for the Mid-Atlantic region (USA) using plot-leve forest inventory data. Ecological Applications 11: 1174-1193.

De Kauwe MG, Medlyn BE, Zaehle S, Walker AP, Dietze MC, Wang Y-P, Luo Y, Jain AK, ElMasri B, Hickler T, et al. 2014. Where does the carbon go? A model-data intercomparison of vegetation carbon allocation and turnover processes at two temperate forest free-air $\mathrm{CO}_{2}$ enrichment sites. New Phytologist 203: 883-899.

Keeling RF, Piper SC, Bollenbacher AF, Walker SJ. 2016. Scripps $\mathrm{CO}_{2}$ Program.

Kooperman GJ, Fowler MD, Hoffman FM, Koven CD, Lindsay K, Pritchard MS, Swann ALS, Randerson JT. 2018. Plant Physiological Responses to Rising $\mathrm{CO}_{2}$ Modify Simulated Daily Runoff Intensity With Implications for Global-Scale Flood Risk Assessment. Geophysical Research Letters 45: 12,457-12,466.

Lanning M, Wang L, Scanlon TM, Vadeboncoeur MA, Adams MB, Epstein HE, Druckenbrod D. 2019. Intensified vegetation water use under acid deposition. Science Advances 5: eaav5168. 
Levesque M, Andreu-hayles L, Smith WK, Allred BW, Pederson N, Williams AP, Hobi ML. 2019. productivity dynamics at the biome scale. Nature Communications: 1-10.

Lovett GM, Goodale CL. 2011. A New Conceptual Model of Nitrogen Saturation Based on Experimental Nitrogen Addition to an Oak Forest. Ecosystems 14: 615-631.

Mathias JM, Thomas RB. 2018. Disentangling the effects of acidic air pollution, atmospheric $\mathrm{CO}_{2}$, and climate change on recent growth of red spruce trees in the Central Appalachian Mountains. Global Change Biology.

McDowell NG, Fisher RA, Xu C, Domec JC, Hölttä T, Mackay DS, Sperry JS, Boutz A, Dickman L, Gehres N, et al. 2013. Evaluating theories of drought-induced vegetation mortality using a multimodel-experiment framework. New Phytologist 200: 304-321.

Medvigy D, Wofsy SC, Munger JW, Hollinger DY, Moorcroft PR. 2009. Mechanistic scaling of ecosystem function and dynamics in space and time: Ecosystem Demography model version 2. Journal of Geophysical Research 114: G01002.

Melillo JM, Frey SD, DeAngelis KM, Werner WJ, Bernard MJ, Bowles FP, Pold G, Knorr MA, Grandy AS. 2017. Long-term pattern and magnitude of soil carbon feedback to the climate system in a warming world. Science 358: 101-105.

Miglietta F, Peressotti A, Vaccari FP, Zaldei A, DeAngelis P, Scarascia-Mugnozza G. 2001. Free-air $\mathrm{CO}_{2}$ enrichment (FACE) of a poplar plantation: the POPFACE fumigation system. New Phytologist 150: 465-476.

NOAA National Centers for Environmental Information, West Virginia climate region 4 meteorological data 1895-2016. 2017.

Norby RJ, Todd DE, Fults J, Johnson DW. 2001. Allometric determination of tree growth in a CO2-enriched sweetgum stand. New Phytologist 150: 477-487.

Pan Y, Birdsey R a, Fang J, Houghton R, Kauppi PE, Kurz W a, Phillips OL, Shvidenko A, Lewis SL, Canadell JG, et al. 2011. A Large and Persistent Carbon Sink in the World's Forests. Science 333: 988-993.

Pardo LH, Hemond HF, Montoya JP, Fahey TJ, Siccama TG. 2002. Response of the natural abundance of $15 \mathrm{~N}$ in forest soils and foliage to high nitrate loss following clear-cutting. Canadian Journal of Forest Research 32: 1126-1136.

Parton W, Ojima D, Schimel D, Kittel T. 1992. Development of simplified ecosystem models for applications in earth system studies: the CENTURY experience. Modeling the Earth System: 281-302.

PRISM Climate Group, Oregon State University. 2004. : http://prism.oregonstate.edu. 
Richardson AD, Hufkens K, Milliman T, Aubrecht DM, Furze ME, Seyednasrollah B, Krassovski MB, Latimer JM, Nettles WR, Heiderman RR, et al. 2018. Ecosystem warming extends vegetation activity but heightens vulnerability to cold temperatures. Nature 560: 368-371.

Sabo RD, Elmore AJ, Nelson DM, Clark CM, Fisher T, Eshleman KN. 2020. Positive correlation between wood $\delta^{15} \mathrm{~N}$ and stream nitrate concentrations in two temperate deciduous forests. Environmental Research Communications 2: 025003.

Scheidegger Y, Saurer M, Bahn M, Siegwolf R. 2000. Linking stable oxygen and carbon isotopes with stomatal conductance and photosynthetic capacity: a conceptual model. Oecologia 125: 350-357.

Schlesinger WH, Jasechko S. 2014. Transpiration in the global water cycle. Agricultural and Forest Meteorology 189-190: 115-117.

Shaw JD, Steed BE, DeBlander LT. 2005. Forest Inventory and Analysis (FIA) annual inventory answers the question: What is happening to pinyon-juniper woodlands? Journal of Forestry 103: $280-285$.

Smith KR, Mathias JM, McNeil BE, Peterjohn WT, Thomas RB. 2016. Site-level importance of broadleaf deciduous trees outweighs the legacy of high nitrogen $(\mathrm{N})$ deposition on ecosystem N status of Central Appalachian red spruce forests. Plant and Soil.

Stott P. 2016. How climate change affects extreme weather events. Science 352: 1517-1518.

Swann ALS, Hoffman FM, Koven CD, Randerson JT. 2016. Plant responses to increasing $\mathrm{CO}_{2}$ reduce estimates of climate impacts on drought severity. Proceedings of the National Academy of Sciences 113: 10019-10024.

Teets A, Fraver S, Weiskittel AR, Hollinger DY. 2018. Quantifying climate-growth relationships at the stand level in a mature mixed-species conifer forest. Global Change Biology 24: 3587-3602.

Thomas RQ, Canham CD, Weathers KC, Goodale CL. 2010. Increased tree carbon storage in response to nitrogen deposition in the US. Nature Geoscience 3: 13-17.

Thomas RB, Spal SE, Smith KR, Nippert JB. 2013. Evidence of recovery of Juniperus virginiana trees from sulfur pollution after the Clean Air Act. Proceedings of the National Academy of Sciences 110: 15319-15324.

Trenberth KE, Dai A, van der Schrier G, Jones PD, Barichivich J, Briffa KR, Sheffield J. 2014. Global warming and changes in drought. Nature Clim. Change 4: 17-22.

Trugman AT, Medvigy D, Mankin JS, Anderegg WRL, Materials S, Note S. 2017. Soil moisture drought as a major driver of carbon cycle uncertainty. Supplementary Materials. : 1-22. 
U.S. Environmental Protection Agency, Air Emissions Inventory, Air Pollution Emissions Trends Data. 2015.

Ubierna N, Farquhar GD. 2014. Advances in measurements and models of photosynthetic carbon isotope discrimination in $\mathrm{C}_{3}$ plants. Plant, Cell \& Environment 37: 1494-1498.

US Geological Survey (1946) Physiographic divisions of the conterminous U.S.

Walker AP, De Kauwe MG, Medlyn BE, Zaehle S, Iversen CM, Asao S, Guenet B, Harper A, Hickler T, Hungate BA, et al. 2019. Decadal biomass increment in early secondary succession woody ecosystems is increased by $\mathrm{CO}_{2}$ enrichment. Nature Communications 10: 454.

Walker AP, Zaehle S, Medlyn BE, De Kauwe MG, Asao S, Hickler T, Parton W, Ricciuto DM, Wang Y-P, Wårlind D, et al. 2015. Predicting long-term carbon sequestration in response to $\mathrm{CO}_{2}$ enrichment: How and why do current ecosystem models differ? Global

Biogeochemical Cycles 29: 476-495.

WHO. 2016. Global Health Observatory data repository.

Wilson RM, Hopple AM, Tfaily MM, Sebestyen SD, Schadt CW, Pfeifer-Meister L, Medvedeff C, McFarlane KJ, Kostka JE, Kolton M, et al. 2016. Stability of peatland carbon to rising temperatures. Nature Communications 7: 13723.

Zaehle S, Medlyn BE, De Kauwe MG, Walker AP, Dietze MC, Hickler T, Luo Y, Wang Y-P, El-Masri B, Thornton P, et al. 2014. Evaluation of 11 terrestrial carbon-nitrogen cycle models against observations from two temperate Free-Air $\mathrm{CO}_{2}$ Enrichment studies. New Phytologist 202: 803-822.

Zhang X, Wan H, Zwiers FW, Hegerl GC, Min SK. 2013. Attributing intensification of precipitation extremes to human influence. Geophysical Research Letters 40: 5252-5257. 
Chapter 2. A global meta-analysis of historical changes in intrinsic water use efficiency of trees using the dual isotope method.

In preparation for submission to Nature Climate Change as: Mathias, J.M. and R.B. Thomas.

2020. A global meta-analysis of historical changes in intrinsic water use efficiency of trees using the dual isotope method. 


\subsection{Abstract.}

Multiple lines of evidence point to increasing tree intrinsic water use efficiency (iWUE), or the ratio of net photosynthesis $\left(A_{n e t}\right)$ to stomatal conductance $\left(g_{s}\right)$, over the last century. Rising atmospheric $\mathrm{CO}_{2}\left(\mathrm{C}_{\mathrm{a}}\right)$ is often directly linked to increasing iWUE, though whether this predominantly occurs through stimulated $A_{\text {net }}$ or reduced $g_{s}$ has remained elusive. Moreover, whether $\mathrm{C}_{\mathrm{a}}$ interacts with climate, and if tree physiological responses are different among functional types remains an open question. Synthesizing data from 113 unique tree ring chronologies across the globe, we show a widespread ca. $40 \%$ increase in iWUE over the twentieth century. A dual carbon-oxygen isotope approach revealed that stimulated $A_{n e t}$ dominated iWUE in $c a .90 \%$ of examined cases, whereas reductions in $g_{s}$ occurred in the remaining $c a$. $10 \%$, of which the overwhelming majority $(>90 \%)$ were broadleaf deciduous trees. Our study showcases the active physiological response of trees to environmental change is remarkably consistent with physiological theory and will help guide decisions regarding the importance of factors in model parameterization. 


\subsection{Introduction.}

The frequency and severity of extreme environmental conditions will continue to increase under global environmental change (Zhang et al., 2013; Cai et al., 2015; Stott, 2016; Cohen et al., 2018). How terrestrial plants respond to prolonged, and often novel environmental stressors, will have profound impacts on, and feedbacks with, the Earth climate system at local to continental scales (Swann et al., 2016; Kooperman et al., 2018). Central to these feedbacks are plant stomata, actively regulated pores on the leaves of plants that act as a control valve over the fluxes of carbon dioxide $\left(\mathrm{CO}_{2}\right)$ into the leaf during photosynthesis and water vapor $\left(\mathrm{H}_{2} \mathrm{O}\right)$ out of the leaf during transpiration. Importantly, changes in stomatal aperture do not affect the fluxes of $\mathrm{CO}_{2}$ and $\mathrm{H}_{2} \mathrm{O}$ equally, as the sum of resistances for the diffusion of $\mathrm{CO}_{2}$ from the atmosphere to Rubisco are much greater than those for $\mathrm{H}_{2} \mathrm{O}$ from the surface of leaf mesophyll cells to the atmosphere (Nobel, 1991). Indeed, as stomatal aperture changes, so does water use efficiency (WUE), or the ratio of $\mathrm{CO}_{2}$ uptake to $\mathrm{H}_{2} \mathrm{O}$ released from the leaf to canopy scale (Keenan et al., 2013). Consequently, understanding the environmental factors driving changes in leaf physiology is of paramount concern under climate change as small changes in tree WUE can have major effects on biogeochemical processes such as continental runoff, over large geographical areas (Lemordant et al., 2018; Kooperman et al., 2018).

Approaches using tree ring carbon isotopes (Peñuelas et al., 2011; van der Sleen et al., 2015; Frank et al., 2015; Guerrieri et al., 2019), eddy-flux measurement analysis (Keenan et al., 2013; Knauer et al., 2016; Guerrieri et al., 2019), atmospheric composition analysis (Keeling et al., 2017), and Earth system modeling techniques (Ito \& Inatomi, 2012; Knauer et al., 2016; Keeling et al., 2017; Cernusak et al., 2019; Guerrieri et al., 2019) have shown trends of recently increasing WUE. These increases can occur by stimulation of leaf photosynthetic rates $\left(A_{n e t}\right)$ (Ainsworth \& Long, 2004; Ainsworth \& Rogers, 2007), reduced stomatal conductance to water $\left(g_{s}\right)$ (Ainsworth \& Long, 2004; Ainsworth \& Rogers, 2007), or some combination of the two. A fundamental physiological response found in numerous $\mathrm{CO}_{2}$ enrichment experiments is that WUE of many plants is improved as a result of increasing $\mathrm{CO}_{2}\left(\mathrm{C}_{\mathrm{a}}\right)$ stimulating photosynthesis and causing partial stomatal closure (Ainsworth \& Rogers, 2007; Franks et al., 2013). Yet, environmental factors distinct from $\mathrm{C}_{\mathrm{a}}$ have independent effects on $A_{\text {net }}$ and $g_{s}$ and, therefore, may modulate the response of WUE to rising $\mathrm{CO}_{2}$, especially across functionally distinct plant groups with differences in wood (Guerrieri et al., 2019) and leaf morphology (Rumman et al., 
2018). Despite this, few studies have thoroughly examined the effects of multiple factors over controls of WUE, and even fewer have considered the underlying component parts, $A_{\text {net }}$ and $g_{s}$ (Cernusak et al., 2019; Rossella Guerrieri et al., 2019; Mathias \& Thomas, 2018; Rumman et al., 2018; Thomas et al., 2013; G. Xu, Liu, Belmecheri, et al., 2018). This has, in part, been due to the complexity of partitioning $\mathrm{H}_{2} \mathrm{O}$ gas fluxes at ecosystem scales (Scanlon et al., 2019), in addition to the difficulty in attributing changes in isotopically derived intrinsic water use efficiency (iWUE; the ratio of $A_{n e t}$ to stomatal conductance to water, $g_{s}$ ) to $A_{\text {net }}$ or $g_{s}$ without the accompaniment of physiological measurements (Mathias \& Thomas, 2018; Thomas et al., 2013).

An emerging technique of coupling isotopically derived estimates of iWUE with oxygen isotope leaf water enrichment above source water $\left(\Delta^{18} \mathrm{O}_{\mathrm{lw}}\right.$; derived from tree ring $\left.\delta^{18} \mathrm{O}\right)$ allows a qualitative attribution of changes in iWUE to underlying $A_{\text {net }}$ and $g_{s}$ (Boettger, Haupt, Friedrich, \& Waterhouse, 2014a; Bögelein et al., 2012; Grams et al., 2007; Rossella Guerrieri et al., 2019; Scheidegger et al., 2000; G. Xu, Liu, Belmecheri, et al., 2018). As $\Delta^{18} \mathrm{O}_{\mathrm{lw}}$ is inversely related to $g_{s}$ (Farquhar et al., 2007), increasing iWUE accompanied by constant or decreasing $\Delta^{18} \mathrm{O}_{\mathrm{lw}}$ is necessarily driven by increases in $A_{n e t}$, while increasing $\Delta^{18} \mathrm{O}_{\mathrm{lw}}$ coinciding with increasing iWUE results from a reduced $g_{s}$ or a combination of reduced $g_{s}$ and increased $A_{\text {net }}$ (Bögelein et al., 2012; Graham D. Farquhar et al., 2007; Rossella Guerrieri et al., 2019). As such, there currently exists a wealth of previously untapped long-term records of tree physiological responses to environmental change within numerous dendrochronological studies from around the world, providing a historical view of how iWUE has changed globally over the last century. In this analysis we 1) synthesize published data from tree ring carbon and oxygen isotope chronologies to examine global trends in tree-ring derived intrinsic water use efficiency, 2) identify those environmental factors, and their interactions, that best explain multi-decadal to centurial trends in iWUE, and 3) investigate the potential underlying changes in $A_{\text {net }}$ and $g_{s}$ through an analysis of coupled tree ring derived iWUE and $\Delta^{18} \mathrm{O}_{\mathrm{lw}}$ over time (Bögelein et al., 2012; Grams et al., 2007; Rossella Guerrieri et al., 2019; Scheidegger et al., 2000; G. Xu, Liu, Belmecheri, et al., 2018). 


\subsection{Methods.}

\section{Data Collection and Extraction}

We compiled a dataset comprised of 113 unique tree ring stable isotope chronologies from 36 tree species at 84 sites across the globe. Data were collected from published articles resulting from a literature search on Web of Science using the search phrase "tree ring, carbon, oxygen, isotope." Articles published prior the search date (7/15/19) were identified for potential use in our global analysis, and of the 378 candidate articles resulting from the search, 49 met all selection criteria for inclusion, which were: 1) present raw, uncorrected $\delta^{13} \mathrm{C}$ or $\delta^{13} \mathrm{C}$-derived variables (i.e. $\Delta^{13} \mathrm{C}$, iWUE) and $\delta^{18} \mathrm{O}$ stable isotope signatures from absolutely dated tree ring chronologies, 2) provide identification information regarding tree species sampled and the respective tree ages, 3) include geographic coordinates of each study location, 4) contain high quality figures from which the isotope data could be extracted or be accompanied by a publicly available supplemental data file, 5) contain meta-data regarding the type of tree ring sample used (i.e. $\alpha$-cellulose, bulk wood), and 6) be sampled from mature trees ( $>50$ years) that were not subject to experimental treatments.

We used WebPlotDigitizer, a semi-automated data extraction application with built-in tools to extract data from a variety of plot types, with the ability to save files in TAR or JSON format (Rohatgi, 2019), to retrieve $\delta^{13} \mathrm{C}$-derived and $\delta^{18} \mathrm{O}$ isotope data from published figures. Briefly, from each article that met the selection criteria, we first captured a high-quality image file for each relevant figure in TIFF format and assigned numerical values to the $x$-axis and $y$ axis, respectively. This was accomplished by assigning values to the known endpoints of each axis, in turn, and linearly interpolating values between the points. We then identified each unique data point on a given figure, after which the abscissa and ordinate were automatically calculated. This was performed for each tree- or species-specific chronology within a given site. Typically, species-averaged chronologies for $\delta^{13} \mathrm{C}$-derived and $\delta^{18} \mathrm{O}$ isotope data of all sampled trees were

presented in published literature; however, in cases where individual tree chronologies were presented, we first extracted data for each year at the tree level before calculating a species-level mean for a given species within a given site, for direct comparison among observations across all studies.

Environmental factors examined as potential drivers of tree physiology in this study include atmospheric $\mathrm{CO}_{2}\left(\mathrm{C}_{\mathrm{a}}, \mathrm{ppm}\right)$, as well as climate factors temperature $\left(\mathrm{TMP},{ }^{\circ} \mathrm{C}\right)$, 
precipitation (PPT, $\mathrm{mm}$ ), and vapor pressure deficit (VPD, $\mathrm{kPa}$ ) given their relevance to large scale controls over the carbon and hydrologic cycles (Knapp et al., 2004; Xu et al., 2019; Zhang et al., 2019; Cernusak et al., 2019). Annual $C_{a}$ concentrations were obtained the from Scripps Institute of Oceanography ice-core merged data product (Keeling et al., 2015; MacFarling Meure et al., 2006), while climate data were obtained from the Climatic Research Unit (CRU TS4.03) global gridded data product (Harris \& Jones, 2019). Climate data from the CRU TS4.03 data product are provided at a $0.5^{\circ} \times 0.5^{\circ}$ spatial resolution at monthly time-step from $1901-2018$ and are validated using local observations from ground-based meteorological stations. From the CRU TS4.03, we extracted TMP, PPT, and vapor pressure (VAP, in hPa) for each of the 84 unique study locations, and calculated VPD from VAP and TMP using methods from Allen (Allen et al., 1998). We calculated annual $\left(x_{\mathrm{ann}}\right)$ and growing season $\left(x_{\mathrm{grw}}\right)$ values for each climate variable over the period $1901-2015$ using means for TMP and VPD, while using sums for PPT. The range of months over which the growing season occurs at each site was determined based on information provided in each published article.

Lastly, we compiled characteristics unique to each site and chronology included in this analysis such as biome type, tree ring type, and tree phenology type (Table S2.1). Biome type was determined based on GPS coordinates provided for each unique site coupled with a global geographical biome classification database outlined in Dinerstein et al. (2017), while tree ring type was determined based upon known ring morphology confirmed using the The Xylem Database (Schweingruber \& Landolt, 2010).

\section{Carbon Isotope Calculations}

The extracted $\delta^{13} \mathrm{C}$-derived chronologies fell into four distinct categories-raw tree ring $\delta^{13} \mathrm{C}\left(\delta^{13} \mathrm{C}_{\text {raw }}, \mathrm{N}=45\right)$, atmospheric $\mathrm{CO}_{2}$-corrected $\delta^{13} \mathrm{C}\left(\delta^{13} \mathrm{C}_{\text {cor }}, \mathrm{N}=36\right)$, carbon isotope discrimination $\left(\Delta^{13} \mathrm{C}, \mathrm{N}=25\right.$ ), and intrinsic water use efficiency (iWUE, $\mathrm{N}=7$ ). While there is a consistent post-photosynthetic fractionation $(\sim 2 \%)$ between leaf organic matter and carbon assimilated into woody biomass (Badeck et al., 2005; Gessler et al., 2014; Frank et al., 2015), in addition to fractionation related to photorespiration (Ubierna \& Farqhuar, 2014), none of the published studies identified in our analysis took this into account when presenting values of $\delta^{13} \mathrm{C}_{\mathrm{cor}}, \Delta{ }^{13} \mathrm{C}$, or iWUE. As such, all published values of $\delta^{13} \mathrm{C}_{\mathrm{cor}}, \Delta^{13} \mathrm{C}$, and iWUE were first converted to $\delta^{13} \mathrm{C}_{\text {raw }}$ before calculation of $\delta^{13} \mathrm{C}$-derived chronologies that included these effects 
following Lavernge et al. (2019). We calculated $\delta^{13} \mathrm{C}_{\text {raw }}$ when values of atmospheric $\delta^{13} \mathrm{CO}_{2}$ corrected $\delta^{13} \mathrm{C}$ were given using

$$
\delta^{13} \mathrm{C}_{\text {raw }}=\delta^{13} \mathrm{C}_{\text {cor }}+\left(\delta^{13} \mathrm{C}_{\mathrm{atm}}+6.4\right),
$$

and when discrimination, $\Delta{ }^{13} \mathrm{C}$, was presented using

$$
\delta^{13} C_{\text {raw }}=-\frac{1000 * \Delta^{13} C-1000 * \delta^{13} C_{\text {atm }}}{1000+\Delta^{13} C},
$$

where $\delta^{13} \mathrm{C}_{\text {atm }}$ is the carbon isotopic signature of atmospheric $\mathrm{CO}_{2}$ on the year of ring formation (-6.4 \%o being the $\delta^{13} \mathrm{C}_{\text {atm }}$ signature prior to the industrial revolution) (Farquhar et al., 1982;

McCarroll \& Loader, 2004). In cases where intrinsic water use efficiency was presented, we first calculated $\Delta{ }^{13} \mathrm{C}$ using

$$
\Delta{ }^{13} C=\frac{\frac{-i W U E_{*}}{0.625} *(b-a)+C_{a^{*}}(b-a)}{C_{a}}+a,
$$

where $a(4.4 \%)$ is the fractionation associated with the diffusion of $\mathrm{CO}_{2}$ (Craig, 1953; Farquhar et al. , 1982), $b$ (28\%) is the mean fractionation related to the preferential utilization of ${ }^{12} \mathrm{CO}_{2}$ over ${ }^{13} \mathrm{CO}_{2}$ during carboxylation by Rubisco (G. Farquhar et al., 1982; Ubierna \& Farqhuar, 2014), and $\mathrm{C}_{\mathrm{a}}$ is the atmospheric $\mathrm{CO}_{2}$ concentration during the year of ring formation (Keeling et al., 2015; MacFarling Meure et al., 2006). We then used Equation 2 to calculate $\delta^{13} \mathrm{C}_{\text {raw }}$ from $\Delta^{13} \mathrm{C}$ (Farquhar et al., 1982, 1989). To calculate iWUE from $\delta^{13} \mathrm{C}_{\text {raw }}$ including photorespiration and post-photosynthetic fractionation effects, we first calculated leaf internal $\mathrm{CO}_{2}\left(\mathrm{C}_{\mathrm{i}}\right)$ using

$$
C_{i}=\frac{\frac{\left(\delta^{13} c_{a t m^{-}}\left(\delta^{13} c_{p}-d\right)\right)}{\left(1+\frac{\left(\delta^{13} c_{p}-d\right)}{1000}\right)}-a-f *\left(\frac{\Gamma^{*}}{p C_{a}}\right)}{b-a} * C_{a},
$$

where $\delta^{13} C_{p}$ is the isotopic signature of the tree ring, $d$ accounts for the carbon isotope fractionation from leaf to wood (bulk wood $=1.9 \%$, cellulose $=2.1 \%$ ) (Badeck et al., 2005; Frank et al., 2015), $f$ is the isotopic fractionation associated with photorespiration (12 \%o) (Ubierna \& Farqhuar, 2014), ${ }_{p} C_{a}$ is the partial pressure of atmospheric $\mathrm{CO}_{2}(\mathrm{~Pa})$, and $\Gamma^{*}$ is the $\mathrm{CO}_{2}$ compensation point in the absence of dark respiration (Pa) (Lavergne et al., 2019b). We calculated $\Gamma^{*}$ according to

$$
\Gamma^{*}=\Gamma_{25}^{*} *\left(\frac{P_{a t m}}{P_{0}}\right) * e^{\left(\frac{\Delta H_{a} *(T-298)}{R T * 298}\right)},
$$

where $\Delta H_{a}$ is the energy of activation (37830 $\mathrm{J} \mathrm{mol}^{-1}$ ) (Bernacchi et al., 2001), $T$ is the leaf temperature $\left({ }^{\circ} \mathrm{C}\right), R$ is the molar gas constant $\left(8.314 \mathrm{~J} \mathrm{~mol}^{-1} \mathrm{~K}\right), P_{\text {atm }}$ is the ambient atmospheric pressure $(\mathrm{Pa}), P_{0}$ is the atmospheric pressure at sea level $(101325 \mathrm{~Pa})$, and $\Gamma_{25}^{*}$ is the $\mathrm{CO}_{2}$ 
compensation point at $25^{\circ} \mathrm{C}(4.332 \mathrm{~Pa})$ (Bernacchi et al., 2001; Stocker et al., 2019). We assumed $T$ reflects the mean air temperature over the growing season. We then calculated iWUE $\left(\mathrm{mmol} \mathrm{CO} \mathrm{mol}^{-1} \mathrm{H}_{2} \mathrm{O}\right.$ ) as

$$
i W U E=\left(C_{a}-C_{i}\right) * 0.625 \text {. }
$$

For each of the preceding calculations we assumed leaf structure, mesophyll conductance $\left(g_{m}\right)$, and mesophyll $\mathrm{CO}_{2}$ fractionation remained unchanged throughout the length of each of the chronologies (Seibt et al., 2008); however, we do realize minor species differences in leaf morphology or small changes over time due to environmental influences could have minor influences over $g_{m}$, and thusly $\delta^{13} \mathrm{C}$-derived chronologies (Flexas et al., 2008). Although it could increase uncertainty around our estimates of $C_{i}$, and thus iWUE, this assumption is nevertheless standard across dendroisotopic studies reconstructing iWUE from tree ring carbon isotopes (Frank et al., 2015; Rossella Guerrieri et al., 2019; Lavergne, Voelker, et al., 2019; Mathias \& Thomas, 2018; Peñuelas et al., 2011; Thomas et al., 2013).

\section{Oxygen Isotope Calculations}

We calculated tree ring ${ }^{18} \mathrm{O}$ enrichment above the source water $\left(\Delta^{18} \mathrm{O}_{\text {tr }}\right)$ from raw tree ring $\delta^{18} \mathrm{O}\left(\delta^{18} \mathrm{O}_{\text {tr }}\right)$ using

$$
\Delta^{18} O_{t r}=\frac{\delta^{18} O_{t r}-\delta^{18} O_{p}}{1+\left(\frac{1^{18} O_{p}}{1000}\right)}
$$

where $\delta^{18} \mathrm{O}_{\mathrm{p}}$ is the oxygen isotopic composition of precipitation during ring formation (Cheesman \& Cernusak, 2016). Given the lack of long-term records of $\delta^{18} \mathrm{O}_{\mathrm{p}}$ at the study locations, we estimated site-specific $\delta^{18} \mathrm{O}_{\mathrm{p}}$ over the length of each respective chronology following methods from Guerrieri et al. (2019) using

$$
\delta^{18} O_{p}=0.52 * T_{a}-0.006 * T_{a}^{2}+2.42 * P_{a}-1.43 * P_{a}^{2}-0.046 * \sqrt{E}-13,
$$

where $\mathrm{T}_{\mathrm{a}}$ is the mean annual temperature $\left({ }^{\circ} \mathrm{C}\right), \mathrm{P}_{\mathrm{a}}$ is total annual precipitation $(\mathrm{m})$, and $\mathrm{E}$ is the elevation (m) of the study location above sea level (Barbour et al., 2001). Finally, from $\Delta^{18} \mathrm{O}_{\text {tr }}$ we calculated the enrichment of leaf water ${ }^{18} \mathrm{O}$ above source water $\left(\Delta^{18} \mathrm{O}_{\mathrm{lw}}\right)$ using

$$
\Delta^{18} O_{l w}=\frac{\Delta^{18} O_{t r}-\varepsilon_{w c}}{1-p_{x} p_{e x}}
$$

where $\varepsilon_{\mathrm{wc}}(27 \%)$ is the fractionation associated with carbonyl oxygen atoms exchanging with water during wood (i.e. cellulose) synthesis (Sternberg et al., 1986; Cheesman \& Cernusak, 
2016) and $p_{x}$ is the fraction of stem water at the site of cellulose synthesis, of which a given proportion of oxygen atoms, $p_{e x}$, are exchanged. While $p_{x} \approx 1$, a value in the range of $0.20-0.42$ is typically used for $p_{\text {ex }}$ (Cernusak et al., 2005; Sternberg \& Ellsworth, 2011; Belmecheri et al., 2018), with higher values of $p_{\mathrm{ex}}$ often observed in more arid sites (Cheesman \& Cernusak, 2016). For this study, we used a conservative value (0.40) for $\mathrm{p}_{\mathrm{x}} \mathrm{p}_{\mathrm{ex}}$ (Sternberg \& Ellsworth, 2011).

\section{Statistical analyses}

To examine long-term trends in iWUE, we fit a linear mixed effects (LME) model using the R package nlme (Pinheiro et al., 2018) including year as the sole fixed effect with tree species nested within site as random factors. In this analysis, we examined trends in iWUE across the entire chronology for which climate data were available (full: 1901 -2015), in addition to two unique periods (pre: 1901 - 1963, post: 1963 - 2015) after we identified a breakpoint in the full iWUE chronology (across all sites and species) using the segmented package in R(Muggeo, 2008). Additionally, we used generalized least squares (GLS) regression to examine trends in isotope-derived response variables (iWUE, $\Delta^{18} \mathrm{O}_{\mathrm{lw}}$, etc.) separately for each species within a given site, as well as for environmental factors (PPT, TMP, etc.) at a given site for each time period (i.e. full, pre, post) using the R package nlme (Pinheiro et al., 2018). Each LME and GLS model used to determine temporal trends were fit via restricted maximum likelihood and included a first-order autocorrelation structure to account for temporal autocorrelation in the chronologies.

We further used LME models to identify which environmental factors were most responsible in driving the observed changes in iWUE over the last 115 years using the R package nlme (Pinheiro et al., 2018). We used the dredge() function from the MuMIn R package (Barton, 2017) to examine all possible model LME model combinations $(\mathrm{N}=113)$ that included the environmental factors $\mathrm{C}_{\mathrm{a}}, \mathrm{TMP}_{\mathrm{grw}}, \mathrm{PPT}_{\mathrm{grw}}$, VPD $\mathrm{V}_{\mathrm{grw}}$, wood type, and leaf type as independent variables, as well as interactions up to order 2 . We identified the top candidate model as having the lowest corrected Akaike information criterion $\left(\mathrm{AIC}_{\mathrm{c}}\right)$ for subsequent parameter inference. Prior to this analysis continuous environmental factors were grouped by each unique chronology and centered to their mean to reduce multicollinearity (Schielzeth, 2010; Guerrieri et al., 2019). Each LME model examined included a temporal autocorrelation structure of order 1, as well as species nested within site as a random factor, and were fit via maximum likelihood for 
comparison of models with different fixed effects. The top candidate model was then refit via restricted maximum likelihood. We used the R package visreg (Breheny \& Burchett, 2017) to visualize the nature of significant interactions between environmental factors on iWUE over the range experienced by each factor.

As a complement to LME model parameter inference, we examined the independent effects of each environmental factor included as a fixed effect in the final model on iWUE through hierarchical partitioning using the R package hier.part (Mac Nally \& Walsh, 2004). Hierarchical partitioning does not consider potential interactions between factors, but instead determines the contribution of a given environmental factor to iWUE through an examination of every possible model structure containing a given predictor variable. By doing so, hierarchical partitioning avoids enhancing or diminishing the variance explained by any given predictor variable, and circumvents issues related to multicollinearity among predictor variables(Murray \& Conner, 2009). To do this, we used the rand.hp() function, which randomizes the matrices containing response and predictor variables and computes independent effects, set at 1,000 repetitions to determine variable contributions to iWUE.

We performed ANCOVA to examine differences in the rate of change of iWUE and $\Delta^{18} \mathrm{O}_{\mathrm{lw}}$ over time depended upon leaf type, wood type, or biome, and performed ANOVA to compare iWUE means between leaf type, wood type, and biome. Further, we used the R package emmeans (Lenth, 2019) to test for pairwise differences among groups from ANCOVA model fits, and used the R package multcomp (Hothorn et al., 2008) to generate connecting letters reports from Tukey's HSD post hoc test for multiple comparisons of means from ANOVA model fits. We have made all data and code supporting this analysis publicly available on github.com/justinmathias. 


\subsection{Results and Discussion.}

Using 113 unique tree ring carbon and oxygen isotope chronologies comprising 36 different species across 84 sites globally (Fig. 2.1a), we show tree-level iWUE increased, on average, by ca. 40\% (iWUE $=0.23^{*}$ year - 369.16) over the last century $(1901-2015)($ Fig. 2.1b). We identified a breakpoint in the combined iWUE chronology at 1963, after which iWUE increased linearly at a rate of $0.39 \pm 0.01 \mu \mathrm{mol} \mathrm{CO} \mathrm{mol}^{-1} \mathrm{H}_{2} \mathrm{O}$ year ${ }^{-1}\left(1.67 \%\right.$ year $\left.{ }^{-1}\right)$, or approximately 3.9 times faster than the previous 63 years $(F=207.14, p<0.0001)$ (Fig. 2.1b). When considering individual chronologies, the increases in iWUE were widespread, with 93\% (105 of 113 chronologies) of those examined having positive trends over 1901 - 2015 and 84\% (95 of 113) of those examined having positive trends over 1963 - 2015 (Table S2.1). These data reinforce reports of increasing iWUE in the United States (Guerrieri et al., 2019) and Europe (Peñuelas et al., 2011; Frank et al., 2015), and showcase the active long-term regulation of tree physiology during the Anthropocene from trees spanning 10 biomes in six continents that represent a spectrum of leaf and wood types (Table S2.1).

Globally, differences in vegetation physiognomy may have large impacts on iWUE, and despite much work examining plant physiological processes within biomes, there have been few largescale comparisons of historical tree iWUE across biomes at a global scale (Peñuelas et al., 2011; Ito \& Inatomi, 2012; Frank et al., 2015; Guerrieri et al., 2019). In this study, we found the rate of increase of iWUE from 1963 to 2015 differed among the 10 biomes represented $(\mathrm{F}=$ 7.21, $p<0.001$ ) and ranged between $0.101 \pm 0.07 \mu \mathrm{mol} \mathrm{CO}_{2} \mathrm{~mol}^{-1} \mathrm{H}_{2} \mathrm{O}$ year ${ }^{-1}$ for trees growing in deserts and xeric shrublands to $0.611 \pm 0.07 \mu \mathrm{mol} \mathrm{CO}_{2} \mathrm{~mol}^{-1} \mathrm{H}_{2} \mathrm{O}$ year ${ }^{-1}$ for Mediterranean forests, woodlands and scrub (Fig. S2.1a, Table S2.2). Like deserts and xeric shrublands, the rate of iWUE increase since 1963 for trees growing in the tundra and in temperate grasslands, savannas, and shrublands was low, with a mean across the three biomes of $0.131 \mu \mathrm{mol} \mathrm{CO}_{2} \mathrm{~mol}^{-1}$ $\mathrm{H}_{2} \mathrm{O}$ year $^{-1}$. All other biomes exhibit mean rates of iWUE increase after 1963 greater than 0.409 $\mu$ mol $\mathrm{CO}_{2}$ mol $^{-1} \mathrm{H}_{2} \mathrm{O}$ year-1 (Table S2.2). Further, mean iWUE over 1963 - 2015 ranged from a low of $59.9 \mu \mathrm{mol} \mathrm{CO} \mathrm{mol}^{-1} \mathrm{H}_{2} \mathrm{O}$ in tropical and subtropical moist broadleaf forests to a high of $91.5 \mu \mathrm{mol} \mathrm{CO} \mathrm{Col}^{-1} \mathrm{H}_{2} \mathrm{O}$ in temperate conifer forests (Fig. S2.1a). However, we found no relationship between the rate of iWUE increase and mean iWUE in each biome $(p=0.67)$.

When considering changes in iWUE since 1963 with respect to plant functional traits, the rate of iWUE increase was ca. 21\% higher for those tree species with $100 \%$ tracheids relative to 
diffuse porous trees $(p=0.022)$, but we found no difference in the rate of iWUE increase between trees with $100 \%$ tracheids and ring porous trees $(p=0.61)$ or between diffuse porous trees and ring porous trees $(p=0.27$ ) (Fig. S2.2a). Our results are similar to iWUE trends from tree rings presented by Frank et al. (2015) in European forests, but are in contrast to work by Saurer et al. (2014) and Wang et al. (2018) using tree rings and flux tower measurements, respectively, who showed broadleaf deciduous trees (i.e. ring porous and diffuse porous) in the Northern hemisphere having greater rates of increase in iWUE than trees with $100 \%$ tracheids over the last century. Additionally, we found mean iWUE during 1963 - 2015 was different among all wood types $(\mathrm{F}=782.96, p<0.001)$, being the highest in those species with $100 \%$ tracheids and lowest in ring porous species (Fig. S2.2b), consistent with recent findings from 12 tree species at 8 forested sites in the United States (Guerrieri et al., 2019). Further, patterns in mean iWUE for each wood type fall intuitively along a gradient of hydraulic conductivity, with those species with $100 \%$ tracheids being more similar to valves, while ring porous trees are akin to pipes (Sperry, 2003). There were no differences in the rate of iWUE increase among trees with different leaf functional types since $1963(\mathrm{~F}=1.05, p=0.37)$ (Fig. S2.2c). However, mean iWUE was different among trees with different leaf types, with needleleaf evergreen trees being the highest, followed by needleleaf deciduous trees, broadleaf evergreen trees, and finally broadleaf deciduous trees (Fig. S2.2d).

Changes in climate and $\mathrm{C}_{\mathrm{a}}$ have strong effects on vegetation function from the leaf (Ainsworth \& Long, 2004; Ainsworth \& Rogers, 2007) to global scale (Cornwell et al., 2018; Cernusak et al., 2019; Haverd et al., 2020), yet how environmental change has influenced iWUE across large spatial scales over the last century is not fully resolved. Guerrieri et al. (2019) recently showed increasing $\mathrm{C}_{\mathrm{a}}$ and climate change led to increased iWUE in tree species across the United States, but whether this response is conserved across biomes experiencing a much larger range in climate is still unknown. To address this knowledge gap, we used linear mixed effects (LME) models to examine the importance of environmental factors in driving leaf physiology. Across all species and study locations, LME model results indicated that iWUE from 1963 - 2015 was strongly, positively related to $C_{a}$ and growing season vapor pressure deficit $\left(\mathrm{VPD}_{\text {grw }}\right)$, and was negatively related to growing season precipitation $\left(\mathrm{PPT}_{\text {grw }}\right)$, although a large proportion of the total variance was attributed to differences among sites (Table 2.1). Further, when extending this analysis to changes in iWUE over the last 115 years (1901 - 2015), LME 
model main effects were remarkably consistent with data from 1963 - 2015, with the exception of growing season temperature $\left(\mathrm{TMP}_{\text {grw }}\right)$ having a marginally positive effect on iWUE across the 115-year chronology (Table S2.4). As a complement to our analysis of the effects of $\mathrm{C}_{\mathrm{a}}$, $\mathrm{PPT}_{\mathrm{grw}}$, $\mathrm{TMP}_{\text {grw }}$, and $\mathrm{VPD}_{\text {grw }}$ on tree iWUE, we used hierarchical partitioning (HP), which alleviates potential problems due to multicollinearity, to estimate the individual contribution of a given environmental parameter to tree iWUE. For the period 1901 - 2015, HP indicated that of the $42 \%$ variance in iWUE explained by our model, $\mathrm{C}_{\mathrm{a}}$ accounted for $59.6 \%(\mathrm{z}=1,375.49, p<$ 0.05), more than any other factor considered. We found $\mathrm{VPD}_{\text {grw }} \mathrm{TMP}_{\text {grw }}$, and $\mathrm{PPT}_{\text {grw }}$ contributed $23.6 \%(\mathrm{z}=501.33, p<0.05), 16.2 \%(\mathrm{z}=340.07, p<0.05)$, and $0.6 \%(\mathrm{z}=12.64, p<0.05)$, respectively. Of the $31 \%$ variance in iWUE explained in our model over the period $1963-2015$, the influence of $\mathrm{C}_{\mathrm{a}}$ declined to $45.2 \%(\mathrm{z}=455.58, p<0.05)$ and the influence of TMP $\mathrm{grw}_{\mathrm{w}}$ increased to $28.0 \%(\mathrm{z}=357.20, p<0.05)$, whereas the contributions of $\mathrm{VPD}_{\text {grw }}$ and PPT grw were similar to the 1963 - 2015 chronology with $26.1 \%(\mathrm{z}=269.66, p<0.05)$ and $0.7 \%(\mathrm{z}=6.42, p<$ $0.05)$, respectively.

Vapor pressure deficit, or dryness of the atmosphere, regulates stomatal conductance, and therefore, both photosynthesis and transpiration (Grossiord et al., 2020). Air temperature drives VPD (Grossiord et al., 2020), but also affects leaf metabolism, including the ratio of photosynthesis to photorespiration (Dusenge et al., 2019). Precipitation is a proxy for soil moisture content and, thus, the amount of water that can be taken up by plant roots. Increasing atmospheric $\mathrm{CO}_{2}$ may affect both stomatal conductance and photosynthesis (Ainsworth \& Long, 2004; Ainsworth \& Rogers, 2007). Therefore, the individual effects of VPD, precipitation, air temperature, and atmospheric $\mathrm{CO}_{2}$ on our observations of iWUE over the last 115-years are grounded in well-established plant physiology. Here, we show that these environmental drivers interact to regulate tree iWUE and are dependent on leaf and wood functional types, demonstrating the complexity and nuance of tree responses to environmental change. Across all chronologies, the response of tree iWUE to VPD $_{\text {grw }}$ after 1963 was dependent upon both $\mathrm{C}_{\mathrm{a}}$ and $\mathrm{TMP}_{\text {grw }}$ (Table 2.1), such that the effect of $\mathrm{VPD}_{\text {grw }}$ on iWUE was diminished under higher $\mathrm{C}_{\mathrm{a}}$

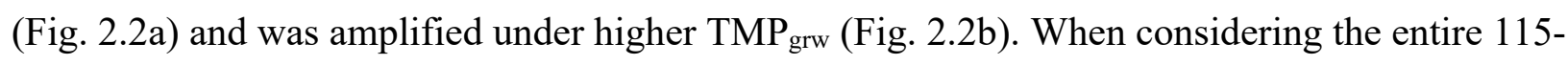
year period, increasing $\mathrm{C}_{\mathrm{a}}$ not only ameliorated the effect of $\mathrm{VPD}_{\text {grw }}$ (Fig. S2.3a), but also the

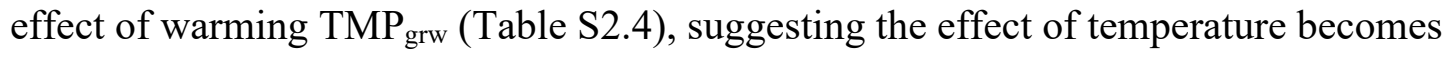
increasingly important after 1963 (Fig. S2.3b). Furthermore, we found increasing $\mathrm{C}_{\mathrm{a}}$ led to larger 
increases in iWUE in those tree species that had 100\% tracheids, with respect to trees that were diffuse porous or ring porous, and the effect of $\mathrm{C}_{\mathrm{a}}$ was diminished in broadleaf deciduous trees relative needleleaf evergreen trees (Table S2.3). When considering leaf type, we found interactions between $\mathrm{C}_{\mathrm{a}}$ and $\mathrm{PPT}_{\text {grw }}$ where the effects of increasing $\mathrm{C}_{\mathrm{a}}$ on $\mathrm{iWUE}$ were greatest with low $\mathrm{PPT}_{\text {grw }}$ and diminished at high $\mathrm{PPT}_{\text {grw }}$ for needleleaf evergreen (Fig. 2.3a), and needleleaf deciduous (Fig. 2.3b), in contrast to broadleaf deciduous trees where the effect of increasing $\mathrm{C}_{\mathrm{a}}$ offset the negative effects of high PPT $\mathrm{Prw}_{\text {on }}$ iWUE (Fig. 2.3c). Interestingly, we found no interaction between $\mathrm{C}_{\mathrm{a}}$ and $\mathrm{PPT}_{\text {grw }}$ on $\mathrm{iWUE}$ of broadleaf evergreen trees, which instead showed an interaction between $C_{a}$ and $V P D_{\text {grw }}$ on iWUE (Fig. 2.3d). When considering functional wood types, we found more complex interactions, where there were interactions between $\mathrm{TMP}_{\text {grw }}$ and $\mathrm{PPT}_{\text {grw }}$ on iWUE of tree species with $100 \%$ tracheids and diffuse porous trees, where the greatest iWUE in trees with 100\% tracheids was at low TMP grw and low $\mathrm{PPT}_{\text {grw }}$ (Fig. S2.4a) and the greatest iWUE in diffuse porous trees was at high $\mathrm{TMP}_{\text {grw }}$ and low $\mathrm{PPT}_{\text {grw }}$ (Fig. S2.4b). On the other hand, ring porous trees showed an interaction between VPD grw and $\mathrm{PPT}_{\text {grw }}$, where iWUE was greatest at high VPD grw and low PPT grw (Fig. S2.4c). These results underscore the intricate interplay between $\mathrm{C}_{\mathrm{a}}$, temperature, precipitation and evaporative water demand on tree physiology, highlight important differences in tree responses to environmental change across tree functional traits, and may have important implications for tree iWUE as climate changes and $C_{a}$ continues to rise (Zhang et al., 2019; Grossiord et al., 2020).

Annually resolved, canopy-integrated iWUE chronologies reconstructed from tree ring carbon isotope signatures clearly show a positive trend over the twentieth century explained, in part, by interactions between $\mathrm{C}_{\mathrm{a}}, \mathrm{PPT}_{\text {grw }}, \mathrm{VPD}_{\text {grw }}$, and $\mathrm{TMP}_{\text {grw }}$. Yet, whether the increases in iWUE were due to underlying stimulated $A_{n e t}$, reduced $g_{s}$, or some combination thereof, cannot be explained using carbon isotope signatures alone. Therefore, we combined analyses of the chronologies of iWUE with those of $\Delta^{18} \mathrm{O}_{\mathrm{lw}}$ to qualitatively partition the increases in iWUE between independent changes in $A_{n e t}$ and $g_{s}$. Of all chronologies showing an increase in iWUE since 1963 , we found $18.6 \%(\mathrm{~N}=21)$ of the studies showed decreasing $\Delta^{18} \mathrm{O}_{\mathrm{lw}}$ (Fig. 2.4a), indicating increased $g_{s}$ across the 53-year period, $71.7 \%(\mathrm{~N}=81)$ showed constant $\Delta^{18} \mathrm{O}_{\mathrm{lw}}($ Fig. $2.4 \mathrm{~b})$, indicating no change in $g_{s}$, and $9.7 \%(\mathrm{~N}=11)$ showed increasing $\Delta^{18} \mathrm{O}_{\mathrm{lw}}$ (Fig. 2.4c), reflecting a decrease in $g_{s}$ despite consistent increases in iWUE (Fig. 2.4d,e,f). Trends in $\Delta^{18} \mathrm{O}_{\mathrm{lw}}$ over time were not different among wood types $(\mathrm{F}=1.81, p=0.16)$ (Fig. S2.5a), although there 
were differences due to leaf type $(\mathrm{F}=2.97, p=0.03)$, with broadleaf deciduous trees showing slightly increasing $\Delta^{18} \mathrm{O}_{\mathrm{lw}}$, and all other leaf types being no different from each other and having either a nonsignificant slope or a negative slope (Fig. S2.5b). There were no relationships between the trends in $\Delta^{18} \mathrm{O}_{\mathrm{lw}}$ and mean $\mathrm{TMP}_{\text {grw }}$, mean PPT grw, or mean VPD grw across all chronologies since 1963 (Fig. S2.6a,b,c), nor was there a relationship between the trend in $\Delta^{18} \mathrm{O}_{\mathrm{lw}}$ and the trend in $\mathrm{TMP}$ grw $\left(\right.$ Fig. S2.6d). $\Delta^{18} \mathrm{O}_{\mathrm{lw}}$ trends did, however, become more negative (corresponding to increased $g_{s}$ ) in sites becoming wetter since 1963 (Fig. S2.6e) and more positive (corresponding to reduced $g_{s}$ ) in sites where VPD was increasing (Fig. S2.6f), although the variability in $\Delta^{18} \mathrm{O}_{\mathrm{lw}}$ trends explained by $\mathrm{PPT}_{\text {grw }}$ trends and $\mathrm{VPD}_{\text {grw }}$ trends was only $15 \%$ and $6 \%$, respectively. These findings are similar to Guerrieri et al. (2019) who showed negative or constant $\Delta^{18} \mathrm{O}_{\mathrm{lw}}$ trends in wetter sites.

Stimulated $A_{n e t}$ driving increased iWUE may have large effects on the carbon cycle through increased carbon sequestration, while increasing iWUE due to reduced $g_{s}$ may have large effects on the hydrologic cycle, through reductions in transpiration. Where iWUE increased from 1963 to 2015 (Fig. 2.4a,b,c), the temporal analysis of $\Delta^{18} \mathrm{O}_{\mathrm{lw}}$ suggests $g_{s}$ increased in 18.6 $\%$ of all examined chronologies (Fig. 2.4d), whereas $g_{s}$ remained constant in $71.7 \%$ (Fig. 2.4e) and decreased in $9.7 \%$ (Fig. 2.4f), as $\Delta^{18} \mathrm{O}_{\mathrm{lw}}$ is inversely related to $g_{s}$ (Barbour, 2007; Bögelein et al., 2012; Graham D. Farquhar et al., 2007; Grams et al., 2007; Scheidegger et al., 2000). This points to enhanced $A_{\text {net }}$ overwhelming increases in $g_{s}$ where $\Delta^{18} \mathrm{O}_{1 \mathrm{w}}$ declined (Fig. 2.4a,d), as well as driving increasing iWUE under constant $g_{s}$ where $\Delta^{18} \mathrm{O}_{\mathrm{lw}}$ remained constant (Fig. 2.4b,e), such that increasing iWUE was driven by stimulated $A_{n e t}$ in $c a .90 \%$ of chronologies examined. As such, this suggests reductions in $g_{s}$ alone where $\Delta^{18} \mathrm{O}_{\mathrm{lw}}$ increased, or in combination with increasing $A_{\text {net }}$, occurred in less than 10\% those chronologies examined (Fig. 2.4c,f). The widespread increase in $A_{\text {net }}$ underscored by the combined analysis of iWUE and $\Delta^{18} \mathrm{O}_{\text {lw }}$ is in line with global observations of increasing vegetation productivity as $\mathrm{C}_{\mathrm{a}}$ has been increasing (Cernusak et al., 2019; Haverd et al., 2020), and builds upon recent observations showing widespread stimulated $A_{n e t}$ resulting in increased iWUE in the United States (Guerrieri et al., 2019). Moreover, the rate at which iWUE increased was highest in those chronologies with increasing $\Delta^{18} \mathrm{O}_{\mathrm{lw}}\left(\right.$ reduced $g_{s}$ ) (Fig. 2.4c), followed by those with constant $\Delta^{18} \mathrm{O}_{\mathrm{lw}}$ (constant $g_{s}$ ) (Fig. 2.4b), and finally those with decreasing $\Delta^{18} \mathrm{O}_{\mathrm{lw}}$ (increased $g_{s}$ ) (Fig. 2.4a). This again highlights the importance of stimulated $A_{n e t}$ in driving increasing iWUE in all cases and supports 
reductions in $g_{s}$, inferred through increasing $\Delta^{18} \mathrm{O}_{\mathrm{lw}}$, exacerbating realized increases in iWUE. Finally, those chronologies that showed no trend in iWUE since $1963(\mathrm{~N}=18)$ had constant $(\mathrm{N}=$ 14) or decreasing $\Delta^{18} \mathrm{O}_{\mathrm{lw}}(\mathrm{N}=4)$, suggesting any potential increases in $A_{\text {net }}$ were not sufficient to offset the increase or constant $g_{s}$. 


\subsection{Conclusion.}

Our coupled analysis of iWUE and $\Delta^{18} \mathrm{O}_{\mathrm{lw}}$ highlights the importance of stimulated $A_{\text {net }}$ as the main driver behind increasing iWUE over the last 115 years, although some proportion of iWUE is still unexplained by factors not included in this study. Through the analysis of tree rings, we cannot exclude potential effects of changes in leaf area index (Frank et al., 2015), tree level photosynthesis or hydraulic conductivity with age which may reduce both $A_{\text {net }}$ and $g_{s}$ (Ewers et al., 2005; Ryan et al., 2000), or height or size effects on carbon isotope discrimination (Brienen et al., 2017). Further, we cannot examine air pollution effects over the study period due to the paucity of available data for the study locations, which could influence iWUE (Boettger et al., 2014a; Holmes, 2014; Mathias \& Thomas, 2018). Nevertheless, these data represent a variety of tree ages and types with unique overlap among different time periods throughout the analysis and present a strong case for $\mathrm{C}_{\mathrm{a}}, \mathrm{PPT}_{\text {grw }}$, and $\mathrm{VPD}_{\text {grw }}$ as drivers of the consistently observed global trends in iWUE.

This study using tree ring chronologies representing 34 species across 10 biomes presents clear evidence of a $\sim 40 \%$ increase in tree iWUE over the $20^{\text {th }}$ century (Fig. 2.1 ), similar in magnitude to the $\sim 34 \%$ increase in $\mathrm{C}_{\mathrm{a}}$ which occurred over the same time (Keeling et al., 2015). Importantly, coupling iWUE with $\Delta^{18} \mathrm{O}_{\mathrm{lw}}$ revealed stimulated $A_{\text {net }}$ as a consistent driver behind increasing iWUE across $\sim 90 \%$ of the examined chronologies, while reduced $g_{s}$, or a combination of increasing $A_{n e t}$ and reduced $g_{s}$, was responsible for increases in iWUE in the remaining $\sim 10 \%$ (Fig 2.4). The rate at which iWUE increased more than tripled after 1963 and occurred within 5 years of a similar breakpoint in $\mathrm{C}_{\mathrm{a}}$ (Fig. S2.7). Furthermore, we identified $\mathrm{C}_{\mathrm{a}}$ as a main factor in driving increases in iWUE, which may simultaneously stimulate $A_{n e t}$ and reduce $g_{s}$ (Ainsworth \& Long, 2004; Ainsworth \& Rogers, 2007), although generally $\mathrm{C}_{\mathrm{a}}$ stimulated $\mathrm{iWUE}$ to a greater degree on those trees containing $100 \%$ tracheids. The widespread patterns of stimulated $A_{\text {net }}$ from this study are in line with recent findings of a $31 \%$ increase in global photosynthetic carbon gain over the $20^{\text {th }}$ century (Haverd et al., 2020), and directly track increasing $\mathrm{C}_{\mathrm{a}}$ (Cernusak et al., 2019; Haverd et al., 2020). However, these data also show the dependency of iWUE on climate factors and suggest trees in areas that experience future increases in $\mathrm{PPT}_{\text {grw }}$, or lower $\mathrm{VPD}_{\text {grw, }}$ may have lower realized iWUE than those areas experiencing drier conditions, or lower evaporative demand, in turn (Table 2.1). Nevertheless, these data showing increased iWUE over the $20^{\text {th }}$ century encompass a spectrum of tree functional types across a broad geographic area, 
highlight the complexity of tree responses to environmental change, and reinforce the importance of stimulated photosynthesis, and not reductions in leaf $g_{s}$, as the primary driver in global increases in iWUE. 


\subsection{Tables and Figures.}

Table 2.1. Linear mixed effect model results and parameters for the best model (lowest AICc) examining the drivers of tree ring derived iWUE for the period 1963-2015 when only considering environmental factors climate and $\mathrm{CO}_{2}\left(2^{\text {nd }}\right.$ column), including wood type as a fixed effect with no interactions in the model ( $3^{\text {rd }}$ column), and when including leaf type as a fixed effect with no interactions in the model $\left(4^{\text {th }}\right.$ column). Intercept values for each model represent the value of iWUE when each numerical environmental factor included in the model is at its mean value during the study period. Leaf and wood type parameter estimates indicate the difference from the original intercept value for each respective variable, with comparisons made with " $100 \%$ tracheids" at the base level for wood type and "needleleaf evergreen" as the base level for leaf type. The marginal $\mathrm{R}^{2}$ describes the goodness of model fit given fixed effects only, while the conditional $\mathrm{R}^{2}$ describes the goodness of model fit including fixed and random effects (tree species nested within site). Model parameter significance is denoted by an asterisk where denotes $\mathrm{p}<0.06,{ }^{*}$ denotes $\mathrm{p}<0.05,{ }^{* *}$ denotes $\mathrm{p}<0.01$, and ${ }^{* * *}$ denotes $\mathrm{p}<0.001$, while ${ }^{\text {ns }}$ denotes not significant.

\begin{tabular}{|c|c|c|c|}
\hline Parameter & $1963-2015$ & $1963-2015_{\text {wood }}$ & $1963-2015_{\text {leaf }}$ \\
\hline Intercept $\left(\mu \mathrm{mol} \mathrm{mol}{ }^{-1}\right)$ & $83.078 \pm 1.401^{* * *}$ & $87.297 \pm 1.292^{* * *}$ & $87.592 \pm 1.326^{* * *}$ \\
\hline $\mathrm{C}_{\mathrm{a}}(\mathrm{ppm})$ & $0.238 \pm 0.007^{* * *}$ & $0.238 \pm 0.007^{* * *}$ & $0.238 \pm 0.007^{* * *}$ \\
\hline $\operatorname{PPT}_{\text {grw }}(\mathrm{mm})$ & $-0.010 \pm 0.001^{* * *}$ & $-0.010 \pm 0.001^{* * *}$ & $-0.010 \pm 0.001^{* * *}$ \\
\hline $\mathrm{TMP}_{\text {grw }}\left({ }^{\circ} \mathrm{C}\right)$ & $0.246 \pm 0.135^{\mathrm{ns}}$ & $0.245 \pm 0.135^{\mathrm{ns}}$ & $0.245 \pm 0.135^{\mathrm{ns}}$ \\
\hline $\operatorname{VPD}_{\text {grw }}(\mathrm{kPa})$ & $13.141 \pm 1.476^{* * *}$ & $13.131 \pm 1.477^{* * *}$ & $13.131 \pm 1.477^{* * *}$ \\
\hline $\mathrm{CO}_{2}: \mathrm{TMP}_{\mathrm{grw}}$ & $0.012 \pm 0.007^{\mathrm{ns}}$ & $0.012 \pm 0.007^{\mathrm{ns}}$ & $0.012 \pm 0.007^{\mathrm{ns}}$ \\
\hline $\mathrm{CO}_{2}: \mathrm{VPD}_{\text {grw }}$ & $-0.175 \pm 0.073^{*}$ & $-0.172 \pm 0.073^{*}$ & $-0.172 \pm 0.073^{*}$ \\
\hline $\mathrm{TMP}_{\text {grw }}: \mathrm{VPD}_{\text {grw }}$ & $1.919 \pm 0.915^{*}$ & - & $1.936 \pm 0.915^{*}$ \\
\hline Diffuse Porous & - & $-17.641 \pm 2.851^{* * *}$ & - \\
\hline Ring Porous & - & $-18.321 \pm 2.727^{* * *}$ & - \\
\hline Needleleaf Deciduous & - & - & $-3.064 \pm 2.667^{\mathrm{ns}}$ \\
\hline Broadleaf Evergreen & - & - & $-10.720 \pm 7.954^{\mathrm{ns}}$ \\
\hline Broadleaf Deciduous & - & - & $-18.952 \pm 2.285^{* * *}$ \\
\hline Marginal $\mathrm{R}^{2}$ & 0.12 & 0.38 & 0.39 \\
\hline Conditional $\mathrm{R}^{2}$ & 0.88 & 0.89 & 0.89 \\
\hline
\end{tabular}


Figure 2.1. Tree locations from which chronologies of iWUE and $\Delta^{18} \mathrm{O}_{\mathrm{lw}}$ were developed (a) and group mean-centered iWUE by species within site over the period $1901-2015$. The color of data points in (a) and (b) correspond to the biome from which trees were growing, while the size of the circle in (a) corresponds to the number of trees used in the development of each carbon and oxygen isotope-derived chronology, respectively. The vertical dashed line in (b) occurs at the year 1963 where the rate of change in iWUE increases. The solid lines in (b) denote the average trend in iWUE for the period before $(1901$ - 1963) and after $(1963-2015)$ the identified breakpoint.

a

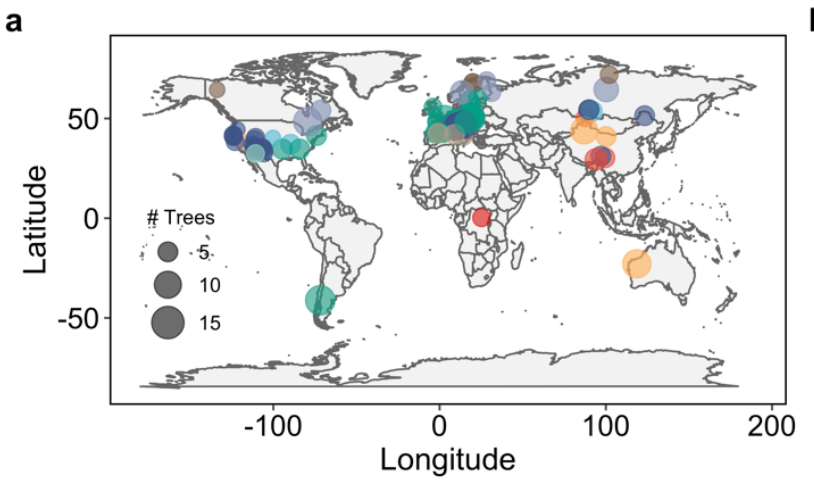

- Boreal Forests/Taiga

- Temperate Broadleaf \& Mixed Forests

Deserts \& Xeric Shrublands

- Mediterranean Forests, Woodlands \& Scrub

- Montane Grasslands \& Shrublands

Temperate Conifer Forests

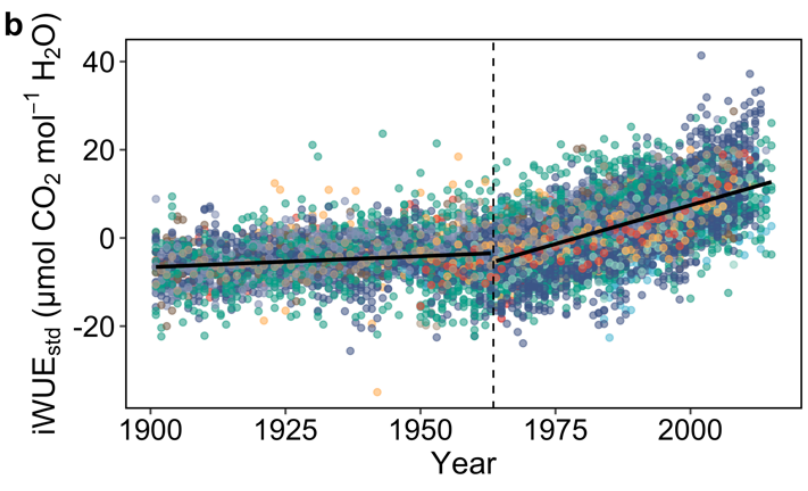

Temperate Grasslands, Savannas \& Shrublands

- Tropical \& Subtropical Coniferous Forests

- Tropical \& Subtropical Moist Broadleaf Forests

- Tundra 
Figure 2.2. Visualization of the nature of the interaction between growing season vapor pressure deficit and atmospheric $\mathrm{CO}_{2}$ (a) and growing season vapor pressure deficit and $\mathrm{CO}_{2}$ (b) on iWUE during the period $1963-2015$. The interactions shown represent a given predicted value of iWUE throughout the range experienced by each group mean-centered environmental factor since 1963. Values listed for each environmental factor represent its value with respect to the mean during the study period. Parameter estimates for each interaction are listed in Table 2.1.

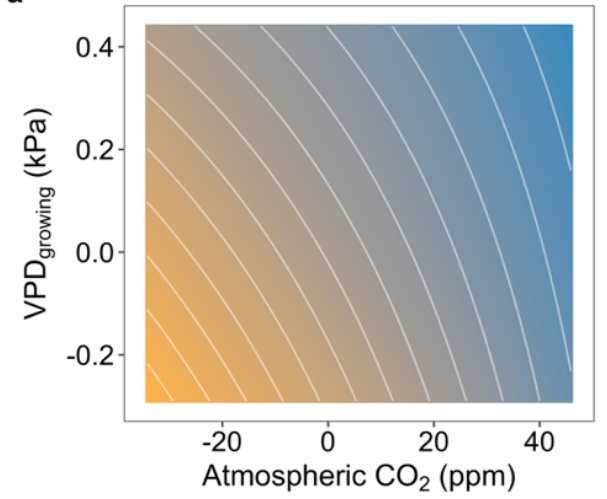

b

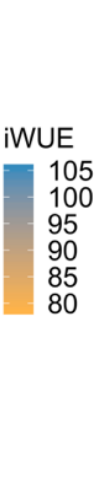

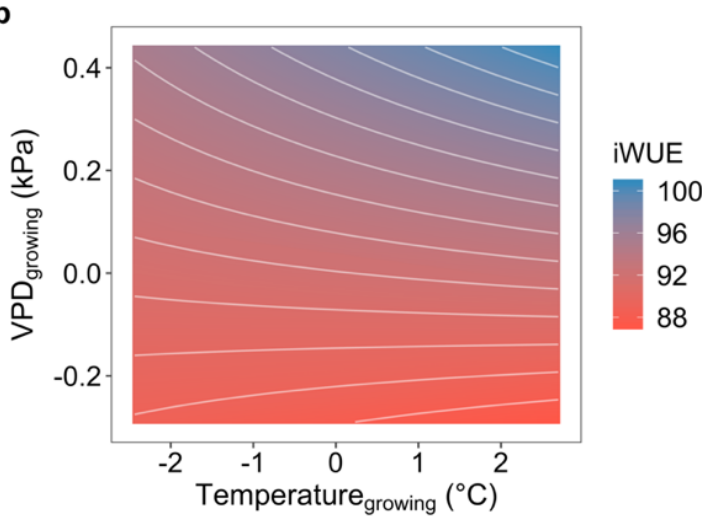


Figure 2.3. Visualization of the nature of the interaction between atmospheric $\mathrm{CO}_{2}$ and growing season precipitation ( $\mathrm{PPT}_{\text {growing}}$ ) on iWUE for needleleaf evergreen (a), needleleaf deciduous (b), and broadleaf deciduous (c) tree species, and between atmospheric $\mathrm{CO}_{2}$ and growing season VPD (VPD grw) for broadleaf evergreen trees (d). The interactions shown represent a given predicted value of iWUE throughout the range experienced by each group mean-centered environmental factor since 1963. Values listed for each environmental factor represent its value with respect to the mean during the study period.

a

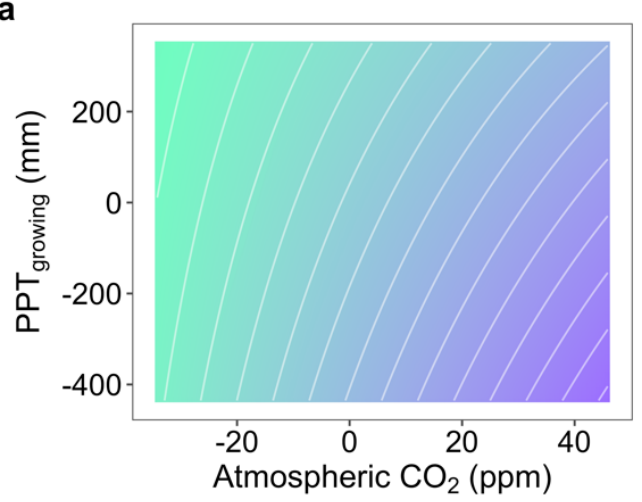

c

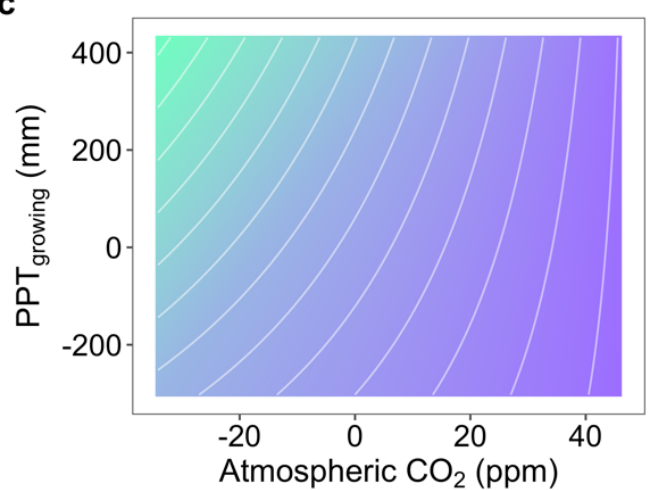

b

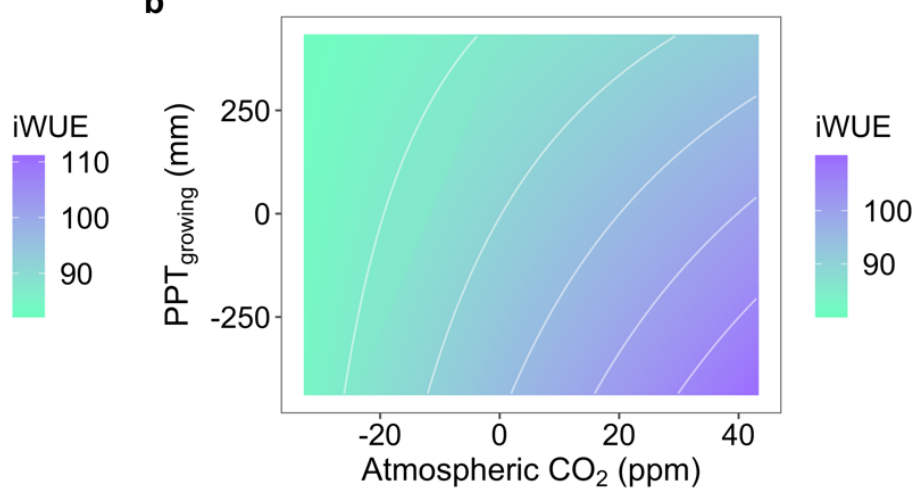

d

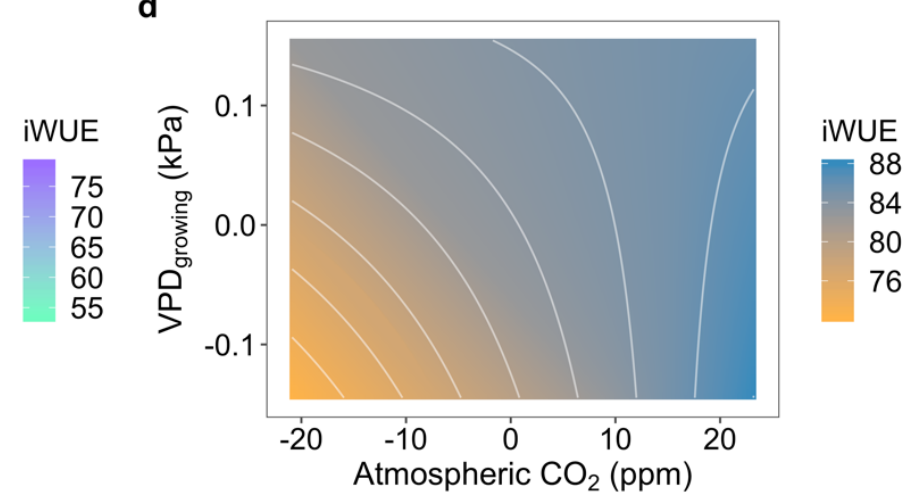


Figure 2.4. Standardized chronologies of $\operatorname{iWUE~}(\mathrm{a}, \mathrm{b}, \mathrm{c})$ and $\Delta^{18} \mathrm{O}_{\mathrm{lw}}(\mathrm{d}, \mathrm{e}, \mathrm{f})$ binned by the individual site $\Delta^{18} \mathrm{O}_{\mathrm{lw}}$ trend for the period 1963 - 2015. Red data points (a,d) contain individual chronologies with decreasing $\Delta^{18} \mathrm{O}_{\mathrm{lw}}$, blue data points $(\mathrm{b}, \mathrm{e})$ contain individual chronologies with constant $\Delta^{18} \mathrm{O}_{\mathrm{lw}}$, and green data points (c,f) contain individual chronologies with increasing $\Delta^{18} \mathrm{O}_{\mathrm{lw}}$. The respective slope for iWUE and $\Delta^{18} \mathrm{O}_{\mathrm{lw}}$ for each category (decreasing, constant, increasing $\Delta^{18} \mathrm{O}_{\mathrm{lw}}$ ) is listed in each respective panel, along with the $\mathrm{p}$ value with the corresponding LME model fit where species chronology is nested within site as a random factor. The solid black line in each panel represent the average trend across all data points.
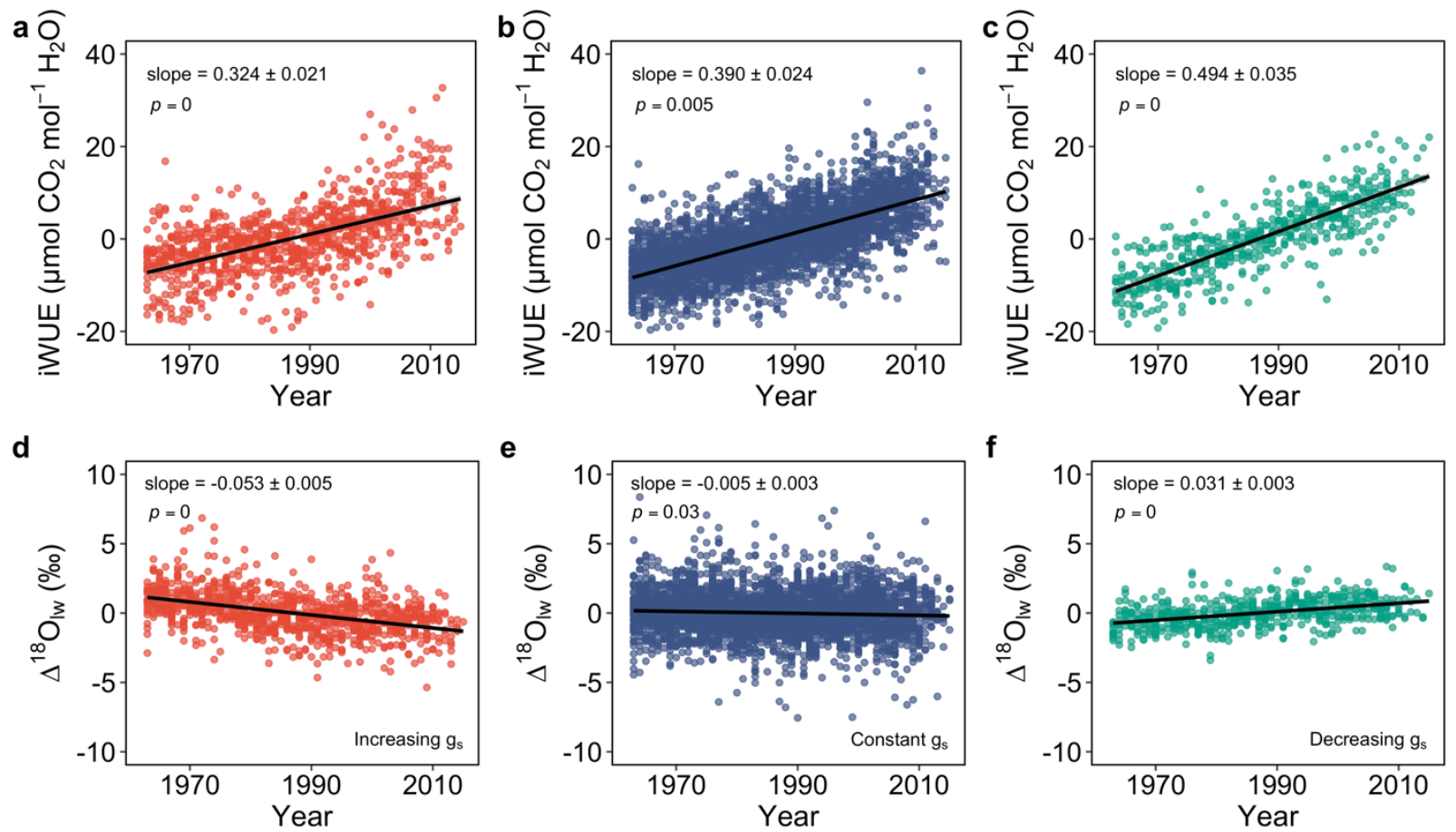


\subsection{Literature Cited.}

Ainsworth EA, Long SP. 2004. What have we learned from 15 years of free-air CO2 enrichment (FACE)? A meta-analytic review of the responses of photosynthesis, canopy properties and plant production to rising $\mathrm{CO}_{2}$. New Phytologist 165: 351-372.

Ainsworth EA, Rogers A. 2007. The response of photosynthesis and stomatal conductance to rising $\left[\mathrm{CO}_{2}\right]$ : mechanisms and environmental interactions. Plant, Cell \& Environment 30: $258-270$.

Allen RG, Pereira LS, Raes D, Smith M, Ab W. 1998. Fao,1998. Irrigation and Drainage Paper No. 56, FAO: 300.

Badeck F-W, Tcherkez G, Nogués S, Piel C, Ghashghaie J. 2005. Post-photosynthetic fractionation of stable carbon isotopes between plant organs - a widespread phenomenon. Rapid Communications in Mass Spectrometry 19: 1381-1391.

Barbour MM. 2007. Stable oxygen isotope composition of plant tissue: a review. Functional Plant Biology 34: 83.

Barbour MM, Andrews TJ, Farquhar GD. 2001. Correlations between oxygen isotope ratios of wood constituents of Quercus and Pinus samples form around the world. Australian Journal of Plant Physiology 28: 335-348.

Bartoń K. 2017. MuMIn: Multi-Model Inference. R package version 1.40.0.

Belmecheri S, Wright WE, Szejner P, Morino KA, Monson RK. 2018. Carbon and oxygen isotope fractionations in tree rings reveal interactions between cambial phenology and seasonal climate. Plant, Cell \& Environment 41: 2758-2772.

Bernacchi CJ, Singsaas EL, Pimentel C, Portis Jr AR, Long SP. 2001. Improved temperature response functions for models of Rubisco-limited photosynthesis. Plant, Cell and Environment 24: 253-259.

Boettger T, Haupt M, Friedrich M, Waterhouse JS. 2014. Reduced climate sensitivity of carbon, oxygen and hydrogen stable isotope ratios in tree-ring cellulose of silver fir (Abies alba Mill.) influenced by background $\mathrm{SO}_{2}$ in Franconia (Germany, Central Europe). Environmental Pollution 185: 281-294.

Bögelein R, Hassdenteufel M, Thomas FM, Werner W. 2012. Comparison of leaf gas exchange and stable isotope signature of water-soluble compounds along canopy gradients of cooccurring Douglas-fir and European beech. Plant, Cell \& Environment 35: 1245-1257.

Breheny P, Burchett W. 2017. Package 'visreg' : Visualization of Regression Models. The R Journal 9: 56-71. 
Brienen RJW, Gloor E, Clerici S, Newton R, Arppe L, Boom A, Bottrell S, Callaghan M, Heaton T, Helama S, et al. 2017. Tree height strongly affects estimates of water-use efficiency responses to climate and $\mathrm{CO}_{2}$ using isotopes. Nature Communications 8: 288.

Cai W, Wang G, Santoso A, Mcphaden MJ, Wu L, Jin FF, Timmermann A, Collins M, Vecchi $\mathrm{G}$, Lengaigne $\mathrm{M}$, et al. 2015. Increased frequency of extreme La Niña events under greenhouse warming. Nature Climate Change 5: 132-137.

Cernusak LA, Farquhar GD, Pate JS. 2005. Environmental and physiological controls over oxygen and carbon isotope composition of Tasmanian blue gum, Eucalyptus globulus. Tree Physiology 25: 129-146.

Cernusak LA, Haverd V, Brendel O, Le Thiec D, Guehl J-M, Cuntz M. 2019. Robust Response of Terrestrial Plants to Rising $\mathrm{CO}_{2}$. Trends in Plant Science: 1-9.

Cheesman AW, Cernusak LA. 2016. Infidelity in the outback: climate signal recorded in $\Delta^{18} \mathrm{O}$ of leaf but not branch cellulose of eucalypts across an Australian aridity gradient (F Meinzer, Ed.). Tree Physiology 37: 554-564.

Cohen J, Pfeiffer K, Francis JA. 2018. Warm Arctic episodes linked with increased frequency of extreme winter weather in the United States. Nature Communications 9: 1-12.

Cornwell WK, Wright IJ, Turner J, Maire V, Barbour MM, Cernusak LA, Dawson T, Ellsworth D, Farquhar GD, Griffiths H, et al. 2018. Climate and soils together regulate photosynthetic carbon isotope discrimination within $\mathrm{C}_{3}$ plants worldwide. Global Ecology and Biogeography 27: 1056-1067.

Craig H. 1953. The geochemistry of the stable carbon isotopes. Geochimica et Cosmochimica Acta 3: 53-92.

Dinerstein E, Olson D, Joshi A, Vynne C, Burgess ND, Wikramanayake E, Hahn N, Palminteri S, Hedao P, Noss R, et al. 2017. An Ecoregion-Based Approach to Protecting Half the Terrestrial Realm. BioScience 67: 534-545.

Dusenge ME, Duarte AG, Way DA. 2019. Plant carbon metabolism and climate change: elevated $\mathrm{CO}_{2}$ and temperature impacts on photosynthesis, photorespiration and respiration. New Phytologist 221: 32-49.

Ewers BE, Gower ST, Bond-Lamberty B, Wand CK. 2005. Effects of stand age and tree species on canopy transpiration and average stomatal conductance of boreal forests. Plant, Cell and Environment 28: 660-678.

Farquhar GD, Cernusak LA, Barnes B. 2007. Heavy Water Fractionation during Transpiration. Plant Physiology 143: 11-18. 
Farquhar GD, Ehleringer JR, Hubick KT. 1989. Carbon Isotope Discrimination and Photosynthesis. Annual Review of Plant Physiology and Plant Molecular Biology 40: 503537.

Farquhar G, O’Leary M, Berry J. 1982. On the relationship between carbon isotope discrimination and the intercellular carbon dioxide concentration in leaves. Australian Journal of Plant Physiology 9: 121-137.

Flexas J, Ribas-Carbo M, Diaz-Espejo A, Galmes J, Medrano H. 2008. Mesophyll conductance to $\mathrm{CO}_{2}$ : current knowledge and future prospects. Plant, Cell \& Environment 31: 602-621.

Frank DC, Poulter B, Saurer M, Esper J, Huntingford C, Helle G, Treydte K, Zimmermann NE, Schleser GH, Ahlström A, et al. 2015. Water-use efficiency and transpiration across European forests during the Anthropocene. Nature Climate Change 5: 579-583.

Franks PJ, Adams MA, Amthor JS, Barbour MM, Berry JA, Ellsworth DS, Farquhar GD, Ghannoum O, Lloyd J, McDowell N, et al. 2013. Sensitivity of plants to changing atmospheric $\mathrm{CO} 2$ concentration: from the geological past to the next century. New Phytologist 197: 1077-1094.

Gessler A, Ferrio JP, Hommel R, Treydte K, Werner RA, Monson RK. 2014. Stable isotopes in tree rings: towards a mechanistic understanding of isotope fractionation and mixing processes from the leaves to the wood. Tree Physiology 34: 796-818.

Grams TEE, Kozovits AR, Häberle KH, Matyssek R, Dawson TE. 2007. Combining $\delta^{13} \mathrm{C}$ and $\delta^{18} \mathrm{O}$ analyses to unravel competition, $\mathrm{CO}_{2}$ and $\mathrm{O}_{3}$ effects on the physiological performance of different-aged trees. Plant, Cell and Environment 30: 1023-1034.

Grossiord C, Buckley TN, Cernusak LA, Novick KA, Poulter B, Siegwolf RTW, Sperry JS, McDowell NG. 2020. Plant responses to rising vapor pressure deficit. New Phytologist: nph.16485.

Guerrieri R, Belmecheri S, Ollinger S V, Asbjornsen H, Jennings K, Xiao J, Stocker BD, Martin M, Hollinger DY, Bracho-Garrillo R, et al. 2019. Disentangling the role of photosynthesis and stomatal conductance on rising forest water-use efficiency. Proceedings of the National Academy of Sciences: 201905912.

Harris IC, Jones PD. 2019. CRU TS4.03: Climatic Research Unit (CRU) Time-Series (TS) version 4.03 of high resolution gridded data of month-by-month variation in climate (Jan. 1901-Dec. 2018). Centre for Environmental Data Analysis.

Haverd V, Smith B, Canadell JG, Cuntz M, Mikaloff-Fletcher S, Farquhar G, Woodgate W, Briggs PR, Trudinger CM. 2020. Higher than expected $\mathrm{CO}_{2}$ fertilization inferred from leaf to global observations. Global Change Biology: gcb.14950.

Holmes CD. 2014. Air pollution and forest water use. Nature 507: E1-E2. 
Hothorn T, Bretz F, Westfall P. 2008. Simultaneous Inference in General Parametric Models. Biometrical Journal 50: 346-363.

Ito A, Inatomi M. 2012. Water-Use Efficiency of the Terrestrial Biosphere: A Model Analysis Focusing on Interactions between the Global Carbon and Water Cycles. Journal of Hydrometeorology 13: 681-694.

Keeling RF, Graven HD, Welp LR, Resplandy L, Bi J, Piper SC, Sun Y, Bollenbacher A, Meijer HAJ. 2017. Atmospheric evidence for a global secular increase in carbon isotopic discrimination of land photosynthesis. Proceedings of the National Academy of Sciences 114: $10361-10366$.

Keeling RF, Piper SC, Bollenbacher AF, Walker SJ. 2015. Scripps $\mathrm{CO}_{2}$ Program. Scripps Institution of Oceanography, University of California - San Diego, USA 92093-0244.

Keenan TF, Hollinger DY, Bohrer G, Dragoni D, Munger JW, Schmid HP, Richardson AD. 2013. Increase in forest water-use efficiency as atmospheric carbon dioxide concentrations rise. Nature 499: 324-327.

Knapp AK, Haddad BM, Williams DG, Tissue DT, Small EE, Koch GW, Weltzin JF, Harte J, Zak JC, Shaw MR, et al. 2004. Convergence across biomes to a common rain-use efficiency. Nature 429: 651-654.

Knauer J, Zaehle S, Reichstein M, Medlyn BE, Forkel M, Hagemann S, Werner C. 2016. The response of ecosystem water-use efficiency to rising atmospheric $\mathrm{CO}_{2}$ concentrations: sensitivity and large-scale biogeochemical implications. New Phytologist: n/a-n/a.

Kooperman GJ, Fowler MD, Hoffman FM, Koven CD, Lindsay K, Pritchard MS, Swann ALS, Randerson JT. 2018. Plant Physiological Responses to Rising CO2 Modify Simulated Daily Runoff Intensity With Implications for Global-Scale Flood Risk Assessment. Geophysical Research Letters 45: 12,457-12,466.

Lavergne A, Voelker S, Csank A, Graven H, de Boer HJ, Daux V, Robertson I, Dorado-Liñán I, Martínez-Sancho E, Battipaglia G, et al. 2019. Historical changes in the stomatal limitation of photosynthesis: empirical support for an optimality principle. New Phytologist $\mathrm{n} / \mathrm{a}$ : nph.16314.

Lemordant L, Gentine P, Swann AS, Cook BI, Scheff J. 2018. Critical impact of vegetation physiology on the continental hydrologic cycle in response to increasing $\mathrm{CO}_{2}$. Proceedings of the National Academy of Sciences 115: 4093-4098.

Lenth R. 2019. emmeans: Estimated Marginal Means, aka Least-Squares means. R package version 1.4.3.01. 
MacFarling Meure C, Etheridge D, Trudinger C, Steele P, Langenfelds R, van Ommen T, Smith A, Elkins J. 2006. Law Dome $\mathrm{CO}_{2}, \mathrm{CH}_{4}$ and $\mathrm{N}_{2} \mathrm{O}$ ice core records extended to 2000 years BP. Geophysical Research Letters 33: L14810.

Mathias JM, Thomas RB. 2018. Disentangling the effects of acidic air pollution, atmospheric $\mathrm{CO}_{2}$, and climate change on recent growth of red spruce trees in the Central Appalachian Mountains. Global Change Biology.

McCarroll D, Loader NJ. 2004. Stable isotopes in tree rings. Quaternary Science Reviews 23: 771-801.

Muggeo VMR. 2008. segmented: an R Package to Fit Regression Models with Broken-Line Relationships. : 20-25.

Murray K, Conner MM. 2009. Methods to quantify variable importance: Implications for the analysis of noisy ecological data. Ecology 90: 348-355.

Mac Nally R, Walsh CJ. 2004. Hierarchical partitioning public-domain software. Biodiversity and Conservation 13: 659-660.

Nobel PS. 1991. Physiochemical and Environmental Plant Physiology. Academic Press.

Peñuelas J, Canadell JG, Ogaya R. 2011. Increased water-use efficiency during the 20th century did not translate into enhanced tree growth. Global Ecology and Biogeography 20: 597-608.

Pinheiro J, Bates D, DebRoy S, Sarkar D, Team RC. 2018. nlme: Linear and Nonlinear Mixed Effects Models. R package version 3.1-131.1.

Rohatgi A. 2019. WebPlotDigitizer: Web based tool to extract data from plots, images, and maps. Version 4.2.

Rumman R, Atkin OK, Bloomfield KJ, Eamus D. 2018. Variation in bulk-leaf ${ }^{13} \mathrm{C}$ discrimination, leaf traits and water-use efficiency-trait relationships along a continentalscale climate gradient in Australia. Global Change Biology 24: 1186-1200.

Ryan MG, Bond BJ, Law BE, Hubbard RM, Woodruff D, Cienciala E, Kucera J. 2000. Transpiration and whole-tree conductance in ponderosa pine trees of different heights. Oecologia 124: 553-560.

Saurer M, Spahni R, Frank DC, Joos F, Leuenberger M, Loader NJ, Mccarroll D, Gagen M, Poulter B, Siegwolf RTW, et al. 2014. Spatial variability and temporal trends in water-use efficiency of European forests. Global Change Biology 20: 3700-3712.

Scanlon TM, Schmidt DF, Skaggs TH. 2019. Correlation-based flux partitioning of water vapor and carbon dioxide fluxes: Method simplification and estimation of canopy water use efficiency. Agricultural and Forest Meteorology 279: 107732. 
Scheidegger Y, Saurer M, Bahn M, Siegwolf R. 2000. Linking stable oxygen and carbon isotopes with stomatal conductance and photosynthetic capacity: a conceptual model. Oecologia 125: 350-357.

Schielzeth H. 2010. Simple means to improve the interpretability of regression coefficients. Methods in Ecology and Evolution 1: 103-113.

Schweingruber F, Landolt W. 2010. The Xylem Database: a web product of the Swiss Federal Research Institute WSL.

Seibt U, Rajabi A, Griffiths H, Berry JA. 2008. Carbon isotopes and water use efficiency: sense and sensitivity. Oecologia 155: 441-454.

van der Sleen P, Groenendijk P, Vlam M, Anten NPR, Boom A, Bongers F, Pons TL, Terburg G, Zuidema PA. 2015. No growth stimulation of tropical trees by 150 years of $\mathrm{CO}_{2}$ fertilization but water-use efficiency increased. Nature Geoscience 8: 24-28.

Sperry JS. 2003. Evolution of Water Transport and Xylem Structure. International Journal of Plant Sciences 164: S115-S127.

Sternberg LDSL, Deniro MJ, Savidge RA. 1986. Oxygen Isotope Exchange between Metabolites and Water during Biochemical Reactions Leading to Cellulose Synthesis. Plant Physiology 82: 423-427.

Sternberg L, Ellsworth PFV. 2011. Divergent Biochemical Fractionation, Not Convergent Temperature, Explains Cellulose Oxygen Isotope Enrichment across Latitudes (HYH Chen, Ed.). PLOS ONE 6: e28040.

Stocker B, Wang H, Smith N, Harrison S, Keenan T, Sandoval D, Davis T, Prentice IC. 2019. Pmodel v1.0: An optimality-based light use efficiency model for simulating ecosystem gross primary production. Geoscientific Model Development Discussions 37: 1-59.

Stott P. 2016. How climate change affects extreme weather events. Science 352: 1517-1518.

Swann ALS, Hoffman FM, Koven CD, Randerson JT. 2016. Plant responses to increasing $\mathrm{CO}_{2}$ reduce estimates of climate impacts on drought severity. Proceedings of the National Academy of Sciences 113: 10019-10024.

Thomas RB, Spal SE, Smith KR, Nippert JB. 2013. Evidence of recovery of Juniperus virginiana trees from sulfur pollution after the Clean Air Act. Proceedings of the National Academy of Sciences 110: 15319-15324.

Ubierna N, Farquhar GD. 2014. Advances in measurements and models of photosynthetic carbon isotope discrimination in $\mathrm{C}_{3}$ plants. Plant, Cell \& Environment 37: 1494-1498. 
Wang M, Chen Y, Wu X, Bai Y. 2018. Forest-Type-Dependent Water Use Efficiency Trends Across the Northern Hemisphere. Geophysical Research Letters 45: 8283-8293.

Xu G, Liu X, Belmecheri S, Chen T, Wu G, Wang B, Zeng X, Wang W. 2018. Disentangling Contributions of $\mathrm{CO}_{2}$ Concentration and Climate to Changes in Intrinsic Water-Use Efficiency in the Arid Boreal Forest in China's Altay Mountains. Forests 9: 642.

Xu C, McDowell NG, Fisher RA, Wei L, Sevanto S, Christoffersen BO, Weng E, Middleton RS. 2019. Increasing impacts of extreme droughts on vegetation productivity under climate change. Nature Climate Change.

Zhang Q, Ficklin D, Manzoni S, Wang L, Way D, Phillips R, Novick KA. 2019. Response of ecosystem intrinsic water use efficiency and gross primary productivity to rising vapor pressure deficit. Environmental Research Letters.

Zhang X, Wan H, Zwiers FW, Hegerl GC, Min SK. 2013. Attributing intensification of precipitation extremes to human influence. Geophysical Research Letters 40: 5252-5257. 
Chapter 3. Disentangling the effects of acidic air pollution, atmospheric $\mathrm{CO}_{2}$, and climate change on recent growth of red spruce trees in the Central Appalachian Mountains.

Published as: Mathias, J.M. and R.B. Thomas. 2018. Disentangling the effects of acidic air pollution, atmospheric $\mathrm{CO}_{2}$, and climate change on recent growth of red spruce trees in the Central Appalachian Mountains. Global Change Biology. DOI: 10.1111/gcb.14273. 


\subsection{Abstract.}

In the 45 years after legislation of the Clean Air Act, there has been tremendous progress on reducing acidic air pollutants in the Eastern U.S., yet limited evidence exists that cleaner air has improved forest health. Here, we investigate the influence of recent environmental changes on the growth and physiology of red spruce (Picea rubens Sarg.) trees, a key indicator species of forest health, spanning three locations along a $100 \mathrm{~km}$ transect in the Central Appalachian Mountains. We incorporated a multi-proxy approach using 75-year tree ring chronologies of basal tree growth, carbon isotope discrimination $\left(\Delta^{13} \mathrm{C}\right.$, a proxy for leaf gas exchange) and $\delta^{15} \mathrm{~N}$ (a proxy for ecosystem $\mathrm{N}$ status) to examine tree and ecosystem level responses to environmental change. Results reveal the two most important factors driving increased tree growth since $c a$. 1989 are reductions in acidic sulfur pollution and increases in atmospheric $\mathrm{CO}_{2}$, while reductions in pollutant emissions of $\mathrm{NO}_{\mathrm{x}}$ and warmer springs played smaller, but significant roles. Tree ring $\Delta^{13} \mathrm{C}$ signatures increased significantly since 1989 , concurrently with significant declines in tree ring $\delta^{15} \mathrm{~N}$ signatures. These isotope chronologies provide strong evidence that simultaneous changes in $\mathrm{C}$ and $\mathrm{N}$ cycling, including greater photosynthesis and stomatal conductance of trees and increases in ecosystem $\mathrm{N}$ retention, were related to recent increases in red spruce tree growth and are consequential to ecosystem recovery from acidic pollution. Intrinsic water use efficiency ( $i \mathrm{WUE}$ ) of the red spruce trees increased by $\sim 51 \%$ across the 75 -year chronology, and was driven by changes in atmospheric $\mathrm{CO}_{2}$ and acid pollution, but $i$ WUE was not linked to recent increases in tree growth. This study documents the complex environmental interactions that have contributed to the recovery of red spruce forest ecosystems from pervasive acidic air pollution beginning in 1989, about 15 years after acidic pollutants started to decline in the U.S. 


\subsection{Introduction.}

Recent observations of enhanced tree growth in temperate forest ecosystems of the northern hemisphere have raised questions about the underlying causal mechanisms (Boisvenue \& Running, 2006; Engel et al., 2016; Fang et al., 2014; S. E. Johnson \& Abrams, 2009; McMahon, Parker, \& Miller, 2010; Thomas et al., 2013). Is this increased productivity a consequence of forest regrowth following disturbance, or is tree growth being enhanced by environmental changes, such as $\mathrm{CO}_{2}$ fertilization and climate change (Schimel et al., 2000; Joos et al., 2002)? These are critical questions because forest ecosystems are a significant part of the terrestrial carbon (C) sink that removes nearly $30 \%$ of anthropogenic $\mathrm{C}$ emissions each year, providing a negative feedback that moderates climate change (Le Quéré et al., 2017). Yet, a large amount of uncertainty exists about the continued capacity of forests to sequester $\mathrm{C}$ emissions (Friedlingstein et al., 2006). Initially, forest regrowth after disturbance provides a large $\mathrm{C}$ sink, but this sink may not persist as forest productivity slows during the late stages of stand development, thereby limiting the capacity of the C sink (Caspersen et al., 2000; Fang et $a l ., 2014)$. The persistence of the effects of increased $\mathrm{CO}_{2}$ and climate change on forest $\mathrm{C}$ sequestration are harder to predict and are likely to interact with the dynamics of forest recovery, possibly resulting in either positive or negative feedbacks on the $\mathrm{C}$ sink (Anderson-Teixeira et al., 2013). In order to partition the relative contributions by these sets of drivers, and how their complex interactions affect forest $\mathrm{C}$ sinks, we need a deeper understanding of how simultaneous changes in key environmental variables affect long-term $\mathrm{C}$ cycling in forest ecosystems.

For decades, temperate forests in the eastern U.S. have experienced anthropogenic disturbance, including pervasive levels of acidic air pollution from fossil fuel combustion (Greaver et al., 2012). Before environmental legislation designed to curb pollutant emissions became effective, national levels of $\mathrm{SO}_{2}$ and $\mathrm{NO}_{\mathrm{x}}$ emissions were as high as 29.6 and 25.6 million metric tons annually (Lefohn et al., 1999; EPA, 2015) (Figure S3.1a,b). Since the Clean Air Act and subsequent amendments, $\mathrm{SO}_{2}$ and $\mathrm{NO}_{\mathrm{x}}$ emissions have fallen from their highest levels by $84 \%$ and 56\%, respectively (Lefohn et al., 1999; EPA, 2015). Although significant progress has been made in understanding $\mathrm{C}$ cycling following many types of disturbance in forest ecosystems (Liu et al., 2011), mechanisms that govern recovery from acid deposition following reductions in acidic air pollution are still poorly understood. It has been projected that the recovery of terrestrial ecosystems following long-term acid deposition takes decades (Likens 
et al., 1996; Driscoll et al., 2001), and now over four decades after the Clean Air Act of 1970, there remains scant evidence of forest ecosystem recovery from the long history of disturbance by acid deposition in the Eastern U.S. (Engel et al., 2016; Lawrence et al., 2015; Li et al., 2010; Thomas et al., 2013).

In addition to the declines in acidic air pollution since the Clean Air Act, there have been substantial increases in atmospheric $\mathrm{CO}_{2}$ concentrations (Figure S1c), along with significant changes in climate (Figure S3.1d). Increasing atmospheric $\mathrm{CO}_{2}$ concentrations stimulate forest productivity, thereby enhancing carbon storage (Norby et al., 2005; Fernández-Martínez et al., 2017); however, these responses are often modulated by changes in temperature or precipitation (Granda et al., 2014; Jennings et al., 2016), in addition to acid pollutants (Fernández-Martínez et al., 2017). It is therefore critical to understand how each of these factors contribute to the recovery of trees from acid pollution and the extent, and nature, of any interactive effects between tree recovery and environmental change.

Tree ring growth and isotope chronologies have become important proxies used to examine historical changes in productivity, plant physiology, and ecosystem processes in a rapidly changing environment (Dye et al., 2016; McLauchlan et al., 2017; Thomas et al., 2013). While tree ring chronologies provide an opportunity to examine changes in forest productivity (Dye et al., 2016), these datasets are strengthened by linking observed changes in growth to underlying physiology (Belmecheri et al., 2014; Thomas et al., 2013). In particular, carbon isotope signatures of tree rings provide information regarding the diffusive and biochemical processes of photosynthesis (Farquhar et al., 1982, 1989). Nitrogen isotope signatures $\left(\delta^{15} \mathrm{~N}\right)$ of tree rings record changes in ecosystem $\mathrm{N}$ status, although the exact mechanisms have yet to be fully reconciled (Evans, 2001; Gerhart \& McLauchlan, 2014). It has been postulated that tree ring $\delta^{15} \mathrm{~N}$ reflects pollutant emissions and deposition of oxidized $\mathrm{N}$ compounds (Elliott et al., 2007; Hietz et al., 2010; Gurmesa et al., 2017); however, there is also abundant evidence that $\delta^{15} \mathrm{~N}$ reflects ecosystem N cycling dynamics (Nadelhoffer \& Fry, 1994; Evans, 2001, 2007; Craine et al., 2009, 2015; Hobbie \& Högberg, 2012; Burnham et al., 2016; McLauchlan et al., 2017). These proxies become more informative when an integrative approach is taken, combining multiple indicators of ecosystem status in order to track long term changes in 
ecosystem function (Choi et al., 2005; Kwak et al., 2011; Leonelli et al., 2012; Zeng et al., 2014).

For this study, we incorporated a multi-proxy approach, using tree ring basal area increment (BAI), $\Delta{ }^{13} \mathrm{C}$ and $\delta^{15} \mathrm{~N}$, to explore the drivers of recent growth and physiological changes of red spruce trees (Picea rubens Sarg.), an economically and ecologically important conifer species in temperate forests of the eastern U.S. and a key indicator species of forest disturbance by acidic air pollution (Siccama et al., 1982; Johnson \& Siccama, 1983; Hamburg \& Cogbill, 1988). Our objectives were to $(i)$ identify those factors most related to proximate increases in red spruce growth in the Central Appalachian Mountains; (ii) examine the relationships between tree growth, reconstructed seasonally-integrated leaf physiology, including $i$ WUE, and environmental factors; and (iii) explore the use of tree ring $\delta^{15} \mathrm{~N}$ as an integrator of historical ecosystem $\mathrm{N}$ cycling. To meet these objectives, we examined red spruce tree growth using tree rings at three forest locations spanning a $100 \mathrm{~km}$ transect in the Central Appalachian Mountains where we have previously examined drivers of ecosystem $\mathrm{N}$ availability (Smith et al., 2016). We used Kendall's rank correlation analyses and generalized linear mixed models (GLMMs) to disentangle the multiple environmental effects and their sensitivities on red spruce tree growth into discreet components. 


\subsection{Methods.}

\section{Study locations and red spruce tree growth analyses}

Three red spruce forest stands were chosen along a north-south transect of $100 \mathrm{~km}$ along the Central Appalachian Mountains. McGowan Mountain (MCG; 38 $58^{\prime}$ N, $79^{\circ} 41^{\prime} \mathrm{W}$ ) is positioned within the Appalachian Plateau physiographic province, while Span Oak Run (SOR; $\left.38^{\circ} 37^{\prime} \mathrm{N}, 79^{\circ} 46^{\prime} \mathrm{W}\right)$, and Cranberry Glades (CGL; 38 $12^{\prime} \mathrm{N}, 80^{\circ} 17^{\prime} \mathrm{W}$ ) are located in the Allegheny Mountain Section physiographic province of West Virginia (USGS, 1946). Each site is $\geq 900$ meters in elevation and has a southwest aspect with slopes ranging from $0-10 \%$. The mean annual temperature for this region in West Virginia was $9.5^{\circ} \mathrm{C}$ over the period of 19402014 (WV Climate Division 4, NOAA, 2017). The annual total precipitation across this time period was $1229.6 \mathrm{~mm} \mathrm{yr}^{-1}$, with $47 \%$ of the precipitation during the growing season from May to September (WV Climate Division 4, NOAA, 2017). Soils at each of the three sites consist of a thick organic layer with litter contributed by red spruce (Picea rubens Sarg.), eastern hemlock (Tsuga candadensis), yellow birch (Betula alleghaniensis), and red maple (Acer rubrum) as dominant canopy species. These sites are mature closed canopy stands with no evidence of anthropogenic or natural disturbance, such as logging or fire, since logging events in the early 1900's. Overall tree density at MCG, SOR, and CGL was 534, 617, and 675 trees ha-1, with red spruce contributing $c a .23 \%, 25 \%$, and $48 \%$ of the trees, respectively. Soils at MCG are classified as ernest and are moderately well to poorly drained, very deep, and have parent material that is colluvium derived from acid shale, siltstone, and sandstone (USDA, 2015). SOR and CGL are snowdog series soils and are very deep, moderately well drained, and colluvium derived from acid sandstone, siltstone, and shale (USDA, 2015). The underlying geology at MCG and CGL consists of Pennsylvanian Pottsville sandstone, while SOR is underlain by Devonian Chemung Shale (WVGES, 1968). Thus, the soil buffering capacities are different at each site with MCG having the lowest buffering capacity and CGL having the greatest buffering capacity.

At each site, 20-25 red spruce trees, greater than $10 \mathrm{~cm}$ diameter at breast height $(1.4 \mathrm{~m}$ aboveground), were cored using a $5.15 \mathrm{~mm}$ increment borer (Haglöf Inc., Madison, MS). Trees were randomly selected to avoid any potential biases during growth analyses, and cores were taken perpendicular to the slope to avoid compression and expansion wood. Twenty cores from MCG were harvested at the end of the 2013 growing season, with five additional cores harvested 
after the 2014 growing season. At SOR and CGL, all tree cores were collected at the end of the 2014 growing season. Cores were returned to lab where they were processed according to standard dendrochronological techniques, as described by Stokes and Smiley (Stokes \& Smiley, 1996). Chronologies were crossdated using WinDENDRO (Regent Instruments, Inc.), and statistically confirmed using dplR (Bunn et al., 2015), after which an individual calendar year was assigned to each growth ring. The average age of sampled red spruce trees from the 3 locations was $109 \pm 27$ years (mean \pm s.d.). The early portion of the tree ring chronologies represented growth release of saplings after logging in the early 1900's and therefore, the focus of this study was the time period after juvenile growth, 1940 to 2014 . The expressed population signals (EPS), a measure of the common variance in a chronology, for each red spruce site across years 1940-2014 were all greater than 0.85, indicating that our sample size adequately represents the tree population (Wigley et al., 1984). Raw ring widths of each year were converted to basal area increment (BAI) to better characterize tree growth and to minimize the effects of tree size and age on annual growth trends using

$$
B A I=\pi\left(R_{n}^{2}-R_{n-1}^{2}\right)
$$

where $R$ is the radius of the tree at a given year of ring formation, $n$. At each site, BAI was averaged for each year using the 20-25 red spruce trees at each location to develop site-level chronologies, which we treated as replicates $(\mathrm{N}=3)$ in this study.

\section{Isotopic analysis of tree rings}

A subset of 5 randomly chosen tree cores were selected from each location to develop C and $\mathrm{N}$ isotope chronologies for the red spruce trees. As with BAI, $\mathrm{C}$ and $\mathrm{N}$ isotopes were averaged for similar years and forest site was a replicate $(\mathrm{N}=3)$. Samples were analyzed for their stable $\mathrm{C}$ or $\mathrm{N}$ isotope composition with a ThermoFisher Delta $\mathrm{V}+$ isotope ratio mass spectrometer interfaced with a Carlo Erba NC 2500 Elemental Analyzer. For these analyses, tree

cores were dissected under microscope by scalpel into individual growth rings at the boundary of earlywood and latewood for years 1940-2014. Tree ring whole wood from each individual year was then finely chopped to homogenize the sample, and $1 \pm 0.2 \mathrm{mg}$ was packed into tin capsules for $\mathrm{C}$ isotopic analysis. Carbon isotope composition was measured as $\delta^{13} \mathrm{C}(\%)$ using

$$
\delta^{13} \mathrm{C}(\%)=\left(\mathrm{R}_{\text {sample }} / \mathrm{R}_{\text {standard }}-1\right) * 1000,
$$

where $R_{\text {sample }}$ is the ratio of ${ }^{13} \mathrm{C}:{ }^{12} \mathrm{C}$ in the wood sample and $\mathrm{R}_{\text {standard }}$ is the ratio of ${ }^{13} \mathrm{C}:{ }^{12} \mathrm{C}$ in the standard PeeDee belemnite (PDB) from the PeeDee River Formation in Hemingway, South 
Carolina. The conversion of leaf carbohydrate to wood was then accounted for by subtracting $3 \%$ from the wood $\delta^{13} \mathrm{C}$ (Leavitt \& Long, 1982; Thomas et al., 2013). Leaf-corrected $\delta^{13} \mathrm{C}$ values were converted to isotope discrimination $\left(\Delta^{13} \mathrm{C}\right)$ to account for the progressive depletion in atmospheric $\delta^{13} \mathrm{CO}_{2}$ due to fossil fuel burning using

$$
\Delta^{13} C=\left(\frac{{ }^{13} C_{\text {air }}-\delta^{13} C_{\text {plant }}}{1+\frac{\delta^{13} C_{\text {plant }}}{1000}}\right),
$$

where $\delta^{13} \mathrm{C}_{\text {air }}$ and $\delta^{13} \mathrm{C}_{\text {plant }}$ are the stable carbon isotope compositions of the atmosphere and plant, respectively (Farquhar et al., 1982). Atmospheric $\delta^{13} \mathrm{C}$ values for a given year up to 2004 used to calculate $\Delta^{13} \mathrm{C}$ were interpolated using the high precision records of atmospheric $\delta^{13} \mathrm{C}$ obtained from Antarctic ice cores (Francey et al., 1999) by McCarroll and Loader (2004). After 2004, atmospheric $\delta^{13} \mathrm{C}$ was calculated as the average change per year (-0.0199\%) during the 1940 - 2004 period (Keeling, Piper, Bollenbacher, \& Walker, 2010). For this study, needle structure, mesophyll conductance and mesophyll $\mathrm{CO}_{2}$ fractionation of red spruce trees were assumed to have not changed across the 75-year tree ring chronology (Seibt et al., 2008).

For $\mathrm{N}$ isotope samples, whole wood for three consecutive years was combined (e.g. 1941, 1942, and 1943 comprise 1942) to ensure an adequate sample mass for analysis ( $\sim 10 \mathrm{mg})$ given the low $\mathrm{N}$ concentration in wood and, therefore, represent a wood $\mathrm{N}$ isotope signal integrated over 3 years. Wood nitrogen isotope composition was measured as $\delta^{15} \mathrm{~N}(\%)$ using

$$
\delta^{15} \mathrm{~N}(\%)=\left(\mathrm{R}_{\text {sample }} / \mathrm{R}_{\text {standard }}-1\right) * 1000,
$$

where $R_{\text {sample }}$ is the ratio of ${ }^{15} \mathrm{~N}:{ }^{14} \mathrm{~N}$ in the wood sample and $\mathrm{R}_{\text {standard }}$ is the ratio of ${ }^{15} \mathrm{~N}:{ }^{14} \mathrm{~N}$ in atmospheric $\mathrm{N}_{2}$.

Reconstruction of photosynthetic parameters across the chronology

In order to simulate changes in seasonally-integrated photosynthesis $(A)$, stomatal conductance $\left(g_{c}\right)$, and intrinsic water use efficiency ( $i$ WUE) across the tree ring chronology from 1940-2014, field measurements of the relationship between $A$ and leaf intercellular $\mathrm{CO}_{2}\left(C_{i}\right)(A-$ $C_{i}$ curves) were coupled with the $\Delta^{13} \mathrm{C}$ chronology, following the methods of (Thomas et al., 2013). First, $\Delta^{13} \mathrm{C}$ was converted to $C_{i} / C a$, the ratio of leaf intercellular $\mathrm{CO}_{2}$ to atmospheric $\mathrm{CO}_{2}$, using

$$
\frac{C_{i}}{C_{a}}=\frac{\Delta^{13} C-a}{b-a},
$$

where $a$ is the diffusional fractionation of $\mathrm{CO}_{2}$ through the stomata (4.4\%) and $b$ is the 
biochemical fractionation of $\mathrm{CO}_{2}$ by Rubisco (27\%) (Farquhar et al., 1982). For each individual year of the chronology, the respective $C_{i} / C_{a}$ was multiplied by the atmospheric $\mathrm{CO}_{2}$ concentration (Keeling et al., 2015) to determine $C_{i}$. Values of isotopically-derived $C_{i}$ were then used to predict the seasonally integrated $A$ using $A-C_{i}$ relationships derived from measurements at each of our three sites. Stomatal conductance was calculated using methods from (Farquhar \& Sharkey, 1982) using

$$
g_{c}=\left|\frac{0-A}{C_{a}-C_{i}}\right|,
$$

where $A$ is seasonally-integrated photosynthesis, $C a$ is the atmospheric $\mathrm{CO}_{2}$ concentration and $C_{i}$ is the leaf intercellular $\mathrm{CO}_{2}$ concentration.

For the calculation of $A$ and $g_{c}$, we measured $A-C_{i}$ response curves from at least three red spruce trees per site during June, July, and August 2014. Between 0900 and 1600 EST, we harvested small branches containing intact sun needles from the upper canopy and immediately placed them into water picks to maintain the transpiration stream. $A-C_{i}$ curves were measured using an open-flow gas exchange system with red/blue LED lights (LI6400XT, Li-Cor, Inc., Lincoln, NE) by placing intact needles into the cuvette at saturating light (1500 $\mu \mathrm{mol}$ photons $\mathrm{m}^{-}$ ${ }^{2} \mathrm{~s}^{-1}$ ). After $\mathrm{ca} .5 \mathrm{~min}$ equilibration in the cuvette, rates of photosynthesis were measured at nine ambient $\mathrm{CO}_{2}$ concentrations between $50-1200 \mu \mathrm{L} \mathrm{CO}_{2} \mathrm{~L}^{-1}$ air beginning at ambient $\mathrm{CO}_{2}(400$ $\mathrm{ppm})$ at the time of the study. After gas-exchange analyses, all needles were taken to the laboratory and scanned to determine projected leaf area, and gas exchange of red spruce was expressed on a total leaf area basis.

Intrinsic water use efficiency was calculated using $C_{i}$ and $C_{a}$ where

$$
i \mathrm{WUE}=\frac{A}{g_{s}}=\left(C_{a}-C_{i}\right) * 0.625,
$$

whereby Fick's law of diffusion of $\mathrm{CO}_{2}$ into the leaf is solved for the quantity $\frac{A}{g_{c}}$ and $g_{c}$ is converted to stomatal conductance to water $\left(g_{s}\right)$ by accounting for the different diffusivities of $\mathrm{H}_{2} \mathrm{O}$ and $\mathrm{CO}_{2}$ (Farquhar et al., 1989).

\section{Statistical analyses}

Breakpoint analyses were performed using the R package 'segmented' (Muggeo, 2008) with the red spruce chronologies of BAI, $\Delta^{13} \mathrm{C}$, and $\delta^{15} \mathrm{~N}$ to determine specific critical years where significant directional shifts in the $1940-2014$ chronologies of BAI, $\Delta{ }^{13} \mathrm{C}$, and $\delta^{15} \mathrm{~N}$ occurred. For all further analyses used to examine environmental effects on these proxies of tree 
growth, photosynthetic physiology and ecosystem N status, we used 1989 as the critical year where this directional shift occurred, which was determined as the average breakpoint of BAI, $\Delta^{13} \mathrm{C}$, and $\delta^{15} \mathrm{~N}$ chronologies (Table 1). We used linear mixed effects (LME) models using the 'nlme' package in R (Pinheiro et al., 2018) with year as the single predictor variable, accounting for temporal autocorrelation with an $\operatorname{AR}(1,0)$ structure, and including site as a random factor, to examine temporal trends in BAI, $A, g_{c}$, and $\delta^{15} \mathrm{~N}$ for before (1940-1989) and after (1989-2014) the critical year. We also used breakpoint analysis to identify a critical directional shift that occurred in the $i$ WUE chronology and used the same LME model structure to determine changes in $i$ WUE before and after this year.

Initially, we performed exploratory bootstrapped Pearson's correlations using the $\mathrm{R}$ package 'treeclim' (Zang \& Biondi, 2015) to examine the relationships between annual, growing season (May - September), and monthly mean, maximum, and minimum temperatures, precipitation, and Palmer Drought Severity Index (PDSI) and red spruce tree-ring chronologies from 1940-2014 (WV Climate Division 4, NOAA, 2017). All chronologies were prewhitened prior to these analyses to remove first order autocorrelation.

Kendall's rank correlation, a nonparametric correlation analysis (Sokal \& Rohlf, 2011), was used to examine the relationships between potential explanatory environmental parameters and the dependent variables BAI, $\Delta^{13} \mathrm{C}, A$, and $g_{c}$ over the 1940-2014 chronology, as well as the period 1989-2014. For these analyses, environmental parameters included U.S. emissions of $\mathrm{SO}_{2}$ and $\mathrm{NO}_{\mathrm{x}}$ (Lefohn et al., 1999; EPA, 2015), atmospheric $\mathrm{CO}_{2}$ concentrations (Keeling et al., 2015), and climate variables (annual, growing season, and monthly mean temperatures, and precipitation) (WV Climate Division 4, NOAA, 2017). We also examined the potential effects of wet deposition of $\mathrm{SO}_{4}{ }^{2-}$ and $\mathrm{NO}_{3}{ }^{-}$in precipitation (WV18; NADP, 2015); however, since NADP measurements only partially covered our 1940-2014 chronology, and because the trends of pollutant emissions and trends of atmospheric wet deposition were strongly related (Figure $\mathrm{S} 1 \mathrm{a}, \mathrm{b}$ ), we only used pollutant emissions in these analyses. For $\delta^{15} \mathrm{~N}$, we used Pearson productmoment correlation to examine the relationships between wood $\delta^{15} \mathrm{~N}$, U.S. $\mathrm{NO}_{\mathrm{x}}$ emissions (EPA, 2015), and $\mathrm{NO}_{3}{ }^{-}$deposition (NADP, 2015), as well as the relationships between $\delta^{15} \mathrm{~N}$ and $\Delta^{13} \mathrm{C}$, seasonally integrated $A, g_{c}$, and BAI of the red spruce trees.

Whereas trends in pollutant emissions and $\mathrm{CO}_{2}$ were clear across the 75-year chronology, changes in climate variables were less clear due to the high interannual variability of temperature 
and precipitation that occurs in this region of the Central Appalachian Mountains. Thus, to carefully examine the potential influences of temperature and precipitation on the chronologies of BAI, $\Delta^{13} \mathrm{C}, A$, and $g_{c}$, we first examined the linear trends of annual, growing season and monthly climate variables to determine if significant changes across 1940 to 2014 had occurred. Second, we used analysis of covariance (ANCOVA) to determine whether trends in temperature or precipitation were different before and after 1989. Third, we used analysis of variance (ANOVA) to determine if climate variables during the period 1940-1989 were different from 1989-2014. Finally, ANCOVA was used to determine whether changes in the responses of BAI, $A$, and $g_{c}$ to temperature or precipitation were different before and after 1989.

To examine the influence and interactions of environmental parameters on red spruce BAI from 1940-2014 and 1989-2014, we utilized generalized linear mixed models (GLMMs) and model averaging using the R packages 'nlme' and 'MuMIn' (Bartoń, 2017; Pinheiro et al., 2018). Models differing by less than four AICc units, with respect to the best model, were averaged to identify the nature of the relationship between predictor variables and BAI (Fernández-Martínez et al., 2017). The environmental parameters included in this analysis were selected a priori based on their known importance to tree growth and physiology and informed by the results of the initial Kendall's rank correlation and bootsrapped Pearson's correlations. For this analysis, we included atmospheric $\mathrm{CO}_{2}$, national emissions of $\mathrm{SO}_{2}$, national emissions of $\mathrm{NO}_{\mathrm{x}}$, and mean April temperatures as predictor variables, exploring all possible combinations of models, including interactions. We also used combinations of other environmental factors in the GLMM averaging, but the four factors listed above consistently provided the best model fit, capturing the greatest variation in BAI while minimizing the unidentified biotic or abiotic contributions to the temporal variation in BAI, determined as an 'unknown' residual effect from the consensus model. In the GLMMs, we accounted for temporal autocorrelation using an $\operatorname{AR}(1,0)$ structure, and included environmental parameters as fixed effects, while site was included as a random effect.

The average model was used to identify the relative effect each parameter had on BAI for the 1989-2014 period (Fernández-Martínez et al., 2017). To do this, we first used the average model to predict BAI for a given year. We then ran the model to predict BAI holding a given environmental parameter constant at its respective median value for the region over 1989-2014 (atmospheric $\mathrm{CO}_{2}: 371.5$ ppm, $\mathrm{NO}_{x}$ emissions: 20.52 million metric tons, $\mathrm{SO}_{2}$ emissions: 14.04 
million metric tons, mean April temperature: $10.08{ }^{\circ} \mathrm{C}$ ), while letting all other parameters change as observed. The difference in slope between BAI predicted from the original model and BAI predicted when holding a particular environmental parameter constant was the contribution of that parameter to predicted BAI. The sensitivity of BAI to each parameter was then determined by dividing the contribution of given parameter to BAI by its own trend over 1989-2014. Finally, we determined the total contribution each environmental parameter had on the total change in BAI over 1989-2014 by multiplying the sensitivity of BAI to each respective environmental parameter by that parameter's total change over 1989-2014 (atmospheric $\mathrm{CO}_{2}:+46.8 \mathrm{ppm}, \mathrm{NO}_{\mathrm{x}}$ emissions: -13.78 million metric tons, $\mathrm{SO}_{2}$ emissions: -19.50 million metric tons, mean April temperature: $+1.82{ }^{\circ} \mathrm{C}$ ). Standard errors were propagated throughout all calculations using the $\mathrm{R}$ package 'propagate' (Spiess, 2017).

Significance was assigned at the $\alpha=0.05$ level for all analyses. All statistical analyses were performed using JMP software for Macintosh v.12.0 (SAS Institute, Cary NC) or R Version 3.3.3 (R Foundation for Statistical Computing, Vienna, Austria). 


\subsection{Results.}

Tree ring chronology breakpoints and trends in BAI, $\Delta^{13} C$ and $\delta^{15} \mathrm{~N}$

Breakpoint analysis of the 1900-2014 red spruce BAI chronology revealed two distinct breakpoints, with the first at $1941 \pm 2.1$ years, marking the end of the juvenile growth phase of the red spruce trees (Figure 3.1). The second breakpoint in BAI was $1988 \pm 2.4$ years, where a directional shift from declining BAI to increasing BAI was observed (Figure 3.1, Table 3.1). Breakpoints in 1940-2014 chronologies of $\Delta^{13} \mathrm{C}$ and $\delta^{15} \mathrm{~N}$ exhibit directional changes in the late $20^{\text {th }}$ century that were contemporaneous with those in BAI. Breakpoint analysis for tree ring $\Delta^{13} \mathrm{C}$ indicates a directional shift in tree ring $\Delta^{13} \mathrm{C}$ signatures at $1991 \pm 1.5$ years (Figure 3.2a, Table 3.1). For tree ring $\delta^{15} \mathrm{~N}$, breakpoint analysis shows a directional shift in tree ring $\delta^{15} \mathrm{~N}$ signatures at $1987 \pm 3.8$ years when averaged over the three sites (Figure 3.2b, Table 3.1). Oneway ANOVA indicated breakpoint years were not significantly different for a given response variable $\left(\mathrm{BAI}, \Delta^{13} \mathrm{C}\right.$, or $\left.\delta^{15} \mathrm{~N}\right)$ across sites $(\mathrm{F}=0.74, \mathrm{p}=0.52)$, nor for a given site $(\mathrm{MCG}, \mathrm{SOR}$, or CGL) across response variable $(F=0.83, \mathrm{p}=0.53)$. Thus, the overall average year where directional changes were observed in the 1940-2014 chronologies of BAI, $\Delta^{13} \mathrm{C}$, and $\delta^{15} \mathrm{~N}$ at all 3 sites was $1989 \pm 1.5$ years.

Using 1989 as the overall breakpoint year, red spruce BAI showed a $0.16 \mathrm{~cm}^{2} \mathrm{yr}^{-1}$ decline, or a total reduction of 48.9\%, between 1940-1989 ( $\mathrm{p}<0.0001)$, but a $0.34 \mathrm{~cm}^{2} \mathrm{yr}^{-1}$ increase, or a total increase of 105.8\%, from 1989-2014, $(\mathrm{p}<0.0001)$ (Figure 1). Tree ring $\Delta^{13} \mathrm{C}$ signatures declined by $17 \%$ between $1940-1989$ from $20.7 \%$ to $17.7 \%$ (p $<0.0001)$, after which $\Delta^{13} \mathrm{C}$ signatures increased steadily by $0.070 \%$ each year from $1989-2014(\mathrm{p}<0.0001)$ (Figure 3.2a). Growth rates following the 1989 breakpoint were not different than growth rates during the juvenile period from 1908 to 1941 (ANCOVA, $F=2.92, p=0.09$; Figure 3.1). In addition, tree ring $\Delta^{13} \mathrm{C}$ signatures for the year 2013 were not different from those for the year 1941 (ANOVA, $F=0.652, \mathrm{p}=0.47$; Figure 3.2a).

Analysis of the nitrogen isotope composition in whole wood of red spruce tree rings for the 48 years prior to 1989 revealed a mean $\delta^{15} \mathrm{~N}$ signature of $0.404 \%$, but no trend between 1940-1989 ( $\mathrm{p}=0.23$; Figure 3.2b). After 1989, however, the $\delta^{15} \mathrm{~N}$ chronology shows an abrupt, significant depletion in the heavier $\mathrm{N}$ isotope in all three red spruce locations as $\delta^{15} \mathrm{~N}$ progressively declined, on average, by $0.083 \%$ each year from the mean $\delta^{15} \mathrm{~N}$ signatures of $0.404 \%$ before $1989(\mathrm{p}<0.0001$; Figure 3.2b). The average $\mathrm{N}$ concentrations in red spruce tree 
rings were $32 \%$ greater after 1989 (0.059\%) compared to wood $\mathrm{N}$ concentrations before 1989 $(0.045 \%)(\mathrm{F}=47.37, \mathrm{p}<0.0001)$.

Changes in environmental factors across the 1940-2014 tree ring chronology

We examined whether there were changes that occurred near 1989 for one or more environmental factors that could possibly explain the observed near simultaneous changes in BAI, tree ring $\Delta^{13} \mathrm{C}$ and $\delta^{15} \mathrm{~N}$ signatures. From 1940-1989, $\mathrm{SO}_{2}$ emissions in the U.S. averaged 23.13 million metric tons $\mathrm{yr}^{-1}$, but declined by 0.73 million metric tons $\mathrm{yr}^{-1}$ from 1989-2014 (Figure S3.1a; ANCOVA, F = 129.7, p < 0.001) (Lefohn et al., 1999; EPA, 2015). From 19401989, $\mathrm{NO}_{\mathrm{x}}$ emissions in the U.S. increased by 0.92 million metric tons $\mathrm{yr}^{-1}\left(\mathrm{R}^{2}=0.92, \mathrm{p}<0.01\right)$, but declined by 0.56 million metric tons $\mathrm{yr}^{-1}$ from 1989-2014 (Figure S3.1b; $\mathrm{R}^{2}=0.91, \mathrm{p}<$ 0.001) (EPA, 2015). On average, atmospheric $\mathrm{CO}_{2}$ concentration increased from $311 \mathrm{ppm}$ in

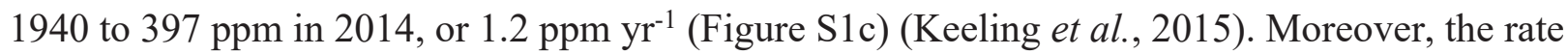
at which atmospheric $\mathrm{CO}_{2}$ concentration increased was $1.0 \mathrm{ppm} \mathrm{yr}^{-1}$ greater during the 19892014 period than during 1940-1989 (ANCOVA, $\mathrm{F}=136.5, \mathrm{p}<0.01$ ) (Keeling et al., 2015).

Mean annual temperatures in this region have increased significantly over the past 75 years by $0.50^{\circ} \mathrm{C}$ (WV Climate Division 4, NOAA, 2017) (Figure S3.2a; $\mathrm{R}^{2}=0.04, \mathrm{p}=0.04$ ). In contrast, there were no significant changes in mean annual precipitation (Figure S3.2b), growing season temperature (Figure S3.2c), or growing season precipitation from 1940-2014 (Figure S3.2d) (WV Climate Division 4, NOAA, 2017). With the exception of April mean temperatures, temperature and precipitation in this region have not changed significantly at or around 1989 in a

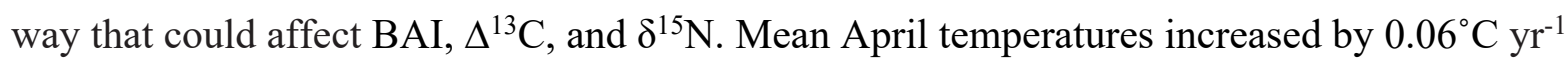
from 1989-2014, but showed no trend prior to 1989 (Figure S3.1d; ANCOVA, F = 3.90, p = 0.05), and therefore, mean April temperatures were $0.72^{\circ} \mathrm{C}$ warmer during 1989-2014 than during 1940-1989 (ANOVA, $\mathrm{F}=4.10, \mathrm{p}=0.05$ ). Assessing environmental influences on seasonally integrated leaf physiology

Chronologies of seasonally integrated leaf physiology modeled using $\Delta^{13} \mathrm{C}$ revealed an $11 \%$ reduction in $A(\mathrm{p}<0.0001$; Figure $3.3 \mathrm{a})$ in red spruce and a $47 \%$ reduction in $g_{c}(\mathrm{p}<$ 0.0001; Figure 3.3b) from 1940-1989. From 1989-2014, there was a 43\% increase in $A(\mathrm{p}<$ 0.0001; Figure 3.3a) and a 67\% increase in $g_{c}(\mathrm{p}<0.0001$; Figure 3.3b). Using historical monthly, seasonal, and annual climate variables (WV Climate Division 4, NOAA, 2017), atmospheric $\mathrm{CO}_{2}$ concentrations (Keeling et al., 2015), and U.S. $\mathrm{SO}_{2}$ and $\mathrm{NO}_{\mathrm{x}}$ emissions (Lefohn 
et al., 1999; EPA, 2015) to examine environmental influences on $A$ and $g_{c}$ of red spruce trees, Kendall's rank correlation revealed that $A$ across the entire 1940-2014 chronology was negatively correlated with $\mathrm{SO}_{2}(\tau=-0.39, \mathrm{p}<0.0001)$ and $\mathrm{NO}_{\mathrm{x}}(\tau=-0.27, \mathrm{p}<0.0001)$ and positively correlated with atmospheric $\mathrm{CO}_{2}(\tau=0.20, \mathrm{p}<0.0001)$, mean annual temperatures $(\tau$ $=0.22, \mathrm{p}<0.0001)$, and mean April temperatures $(\tau=0.17, \mathrm{p}=0.0002)$. Across the entire chronology, $g_{c}$ was negatively correlated with $\mathrm{NO}_{\mathrm{x}}$ emissions $(\tau=-0.66, \mathrm{p}<0.0001)$ and atmospheric $\mathrm{CO}_{2}(\tau=-0.43, \mathrm{p}<0.0001)$ and positively correlated with May temperatures $(\tau=$ $0.13, \mathrm{p}<0.01)$, June temperatures $(\tau=0.15, \mathrm{p}<0.01)$, and June precipitation $(\tau=0.14, \mathrm{p}<$ $0.01)$. Increases in $A$ from 1989-2014 are correlated with increases in atmospheric $\mathrm{CO}_{2}(\tau=0.73$, $\mathrm{p}<0.0001)$, increases in April temperatures $(\tau=0.23, \mathrm{p}<0.01)$ and reductions in pollutant emissions of $\mathrm{SO}_{2}(\tau=-0.72, \mathrm{p}<0.0001)$ and $\mathrm{NO}_{\mathrm{x}}(\tau=-0.69, \mathrm{p}<0.0001)$. Furthermore, the temperature response of $A$ was higher for a given April temperature during 1989-2014 than during 1940-1989 (ANCOVA; $\mathrm{F}=8.94, \mathrm{p}=0.003$ ) (Figure 3.4a). Increases in $g_{c}$ from 19892014 are correlated with increases in atmospheric $\mathrm{CO}_{2}(\tau=0.63, \mathrm{p}<0.0001)$, increases in April temperatures $(\tau=0.21, \mathrm{p}<0.01)$ and May temperatures $(\tau=0.21, \mathrm{p}<0.01)$, as well as reductions in pollutant emissions of $\mathrm{SO}_{2}(\tau=-0.62, \mathrm{p}<0.0001)$ and $\mathrm{NO}_{\mathrm{x}}(\tau=-0.59, \mathrm{p}<0.0001)$. These environmental factors were the most important influences on $A$ and $g_{c}$ and complete Kendall's rank correlation analyses are shown in in Table S3.1 for 1940-2014 and in Table 3.2 for 1989-2014.

In this study, there was a 58\% increase in seasonally integrated $i$ WUE across the 75 -year red spruce chronology ( $\mathrm{p}<0.0001$; Figure 3.3c), where $i$ WUE was positively correlated with $A$ $(\mathrm{r}=0.25, \mathrm{p}=0.0002)$ and negatively correlated with $g_{c}(\mathrm{r}=-0.83, \mathrm{p}<0.0001)$. There was, however, a breakpoint in $i$ WUE averaged across the 3 sites at $1995 \pm 2.5$ years, where $i$ WUE declined $13 \%$ after that year $(\mathrm{p}<0.0001$; Figure 3.3c). Across the 75-year chronology, BAI of red spruce trees was not correlated with $i$ WUE $(\mathrm{p}=0.10)$, but BAI was positively correlated with $A(\mathrm{r}=0.52, \mathrm{p}<0.0001)$ and $g_{c}(\mathrm{r}=0.39, \mathrm{p}<0.0001)$. Kendall's rank correlation revealed that $i$ WUE during 1940-1995 was positively correlated with atmospheric $\mathrm{CO}_{2}(\tau=0.71, \mathrm{p}<0.0001)$, $\mathrm{NO}_{\mathrm{x}}(\tau=0.61, \mathrm{p}<0.0001)$, mean March temperatures $(\tau=0.14, \mathrm{p}=0.006)$, and mean November temperatures $(\tau=0.13, \mathrm{p}=0.013)$. There was a negative correlation between $i$ WUE during 19401995 with June precipitation $(\tau=-0.16, \mathrm{p}=0.002)$, mean May temperatures $(\tau=-0.13, \mathrm{p}=$ $0.015)$, and mean June temperatures $(\tau=-0.15, p=0.006)$, mean October temperatures $(\tau=$ - 
$0.13, \mathrm{p}=0.015)$, and mean growing season temperatures $(\tau=-0.10, \mathrm{p}=0.05)$. After the 1995 breakpoint, after which $i$ WUE declined, Kendall's rank correlation indicated that $i$ WUE was not significantly correlated with any of the environmental factors that we examined.

Tree ring nitrogen isotope composition

Reductions in tree ring $\delta^{15} \mathrm{~N}$ after 1989 were synchronous with increases in tree ring $\Delta^{13} \mathrm{C}$ (Figure 5a; MCG, $\mathrm{r}=-0.98, \mathrm{p}=0.005$; SOR, $\mathrm{r}=-0.96, \mathrm{p}=0.01 ; \mathrm{CGL}, \mathrm{r}=-0.99, \mathrm{p}<0.001$ ), and strongly correlated with increases in $A$ (Figure 3.5b; MCG, $\mathrm{r}=-0.99, \mathrm{p}=0.002$; SOR, $\mathrm{r}=-0.97$, $\mathrm{p}=0.007 ; \mathrm{CGL}, \mathrm{r}=-0.99, \mathrm{p}=0.002)$ and $g_{c}($ Figure 3.5c; MCG, $\mathrm{r}=-0.98, \mathrm{p}=0.004 ; \mathrm{SOR}, \mathrm{r}=-$ $0.95, \mathrm{p}=0.01 ; \mathrm{CGL}, \mathrm{r}=-0.99, \mathrm{p}<0.001)$ at each red spruce site, although the correlations between tree ring $\delta^{15} \mathrm{~N}$ and red spruce growth were more variable (Figure 3.5d; MCG r $=-0.87$, p $=0.056 ;$ SOR $r=-0.93, p=0.02 ;$ CGL $r=-0.60, p=0.28)$. The proximate reduction of $\delta^{15} \mathrm{~N}$ after 1989 was positively correlated with the decline in national emissions of $\mathrm{NO}_{\mathrm{x}}(\mathrm{r}=0.92, \mathrm{p}<$ 0.0001; Figure S3.3a) and local wet deposition of $\mathrm{NO}_{3}^{-}(\mathrm{r}=0.86, \mathrm{p}<0.0001$; Figure $\mathrm{S} 3.3 \mathrm{~b})$. Assessing environmental influences on BAI

We first used bootstrapped Pearson's correlations to explore the relationships between current year ring width indices at each red spruce location and monthly mean temperature and precipitation of the current and previous year (Figure S3.4, Table S3.2) (WV Climate Division 4, NOAA, 2017). We found no significant correlations between radial growth and these climate variables, except for a weak positive correlation with the previous year's July precipitation at one red spruce location $(\mathrm{SOR})(\mathrm{r}=0.18, \mathrm{p}<0.05)$. There were no significant correlations between tree radial growth and maximum monthly temperature, minimum monthly temperature, or PDSI at our red spruce study locations (Table S3.2).

Kendall's rank correlation revealed that BAI of red spruce trees from 1940-2014 declined as atmospheric $\mathrm{CO}_{2}$ increased $(\tau=-0.14, \mathrm{p}=0.002)$, as pollutant emissions of $\mathrm{NO}_{\mathrm{x}}(\tau=-0.34, \mathrm{p}$ $<0.0001)$ and $\mathrm{SO}_{2}$ increased $(\tau=-0.12, \mathrm{p}=0.01)$ (Table S3.1). GLMMs identified only a negative relationship between $\mathrm{NO}_{\mathrm{x}}$ emissions and BAI over 1940-2014 (p<0.001, $-0.353 \pm 0.05$ slope estimate \pm standard error), with no other models with a $\triangle \mathrm{AICc}<4$. Kendall's rank correlation showed increases in BAI from 1989-2014 were correlated with increases in atmospheric $\mathrm{CO}_{2}(\tau=0.41, \mathrm{p}<0.0001)$, increases in April temperatures $(\tau=0.26, \mathrm{p}<0.001)$ and reductions in pollutant emissions of $\mathrm{SO}_{2}(\tau=-0.42, \mathrm{p}<0.0001)$ and $\mathrm{NO}_{\mathrm{x}}(\tau=-0.36, \mathrm{p}<0.0001)$. Additionally, the temperature response of BAI to April temperatures was greater during 1989- 
2014 than during 1940-1989 (ANCOVA; $F=6.96, p=0.009$ ) (Figure 3.4b).

In order to specifically examine the recent increases in BAI from 1989-2014, model averaging of the best models ( $\triangle \mathrm{AICc}<4$ from the best model; hereafter referred to as 'average model') determined by GLMMs indicated the importance of mean April temperatures, a negative interaction between $\mathrm{SO}_{2}$ and $\mathrm{NO}_{\mathrm{x}}$ emissions, a positive interaction between atmospheric $\mathrm{CO}_{2}$ and $\mathrm{SO}_{2}$ emissions, and a positive interaction between atmospheric $\mathrm{CO}_{2}$ and $\mathrm{NO}_{\mathrm{x}}$ emissions (Table S3.3). We found that over the 1989-2014 period the average model predicts an increase in BAI of $0.29 \pm 0.02 \mathrm{~cm}^{2} \mathrm{yr}^{-1}(\mathrm{t}=15.60, \mathrm{p}<0.001)$ (Figure 3.6a), in close agreement with observed BAI $\left(\mathrm{R}^{2}=0.85, \mathrm{p}<0.001\right)$ (Figure $\left.\mathrm{S} 3.5\right)$. Of the $0.29 \mathrm{~cm}^{2} \mathrm{yr}^{-1}$ increase in BAI, increasing atmospheric $\mathrm{CO}_{2}$ contributed to a $0.17 \pm 0.02 \mathrm{~cm}^{2} \mathrm{yr}^{-1}$ increase of BAI $(\mathrm{t}=96.05, \mathrm{p}<0.01)$. Reductions in national emissions of $\mathrm{SO}_{2}$ contributed to a $0.11 \pm 0.02 \mathrm{~cm}^{2} \mathrm{yr}^{-1}$ increase of BAI (t $=17.18, \mathrm{p}<0.01)$, while decreasing emissions of $\mathrm{NO}_{\mathrm{x}}$ reduced BAI by $0.06 \pm 0.02 \mathrm{~cm}^{2} \mathrm{yr}^{-1}(\mathrm{t}=-$ $7.68, \mathrm{p}<0.01)$. Higher April temperatures contributed to a small increase in BAI by $0.04 \pm 0.03$ $\mathrm{cm}^{2} \mathrm{yr}^{-1}(\mathrm{t}=3.65, \mathrm{p}<0.01)$ (Figure 3.6a). Unknown contributions due to unidentified biotic or abiotic factors were calculated as the difference between the observed change and all known contributions and accounted for $0.04 \pm 0.05 \mathrm{~cm}^{2} \mathrm{yr}^{-1}(\mathrm{t}=1.08, \mathrm{p}=0.28)$. Sensitivity analysis of GLMM results revealed that over 1989-2014 average BAI was the most sensitive to increases in April temperatures and reductions in $\mathrm{SO}_{2}$ emissions, followed by reductions in $\mathrm{NO}_{\mathrm{x}}$, and increases in atmospheric $\mathrm{CO}_{2}$ (Table 3.3).

These results indicate that increasing atmospheric $\mathrm{CO}_{2}$ was responsible for the largest change in basal area of the red spruce trees, producing a $4.38 \pm 0.6 \mathrm{~cm}^{2}$ increase between 19892014. Reductions in national $\mathrm{SO}_{2}$ emissions were the second most important factor, contributing to a $2.96 \pm 0.52 \mathrm{~cm}^{2}$ increase in basal area (Figure 3.6b). Lastly, reductions in national emissions of $\mathrm{NO}_{\mathrm{x}}$ negatively impacted basal area by $-1.70 \pm 0.52 \mathrm{~cm}^{2}$, while increases in mean April temperatures contributed positively to a $1.01 \pm 0.80 \mathrm{~cm}^{2}$ increase in basal area (Figure 3.6b). 


\subsection{Discussion.}

A synchronous change in three tree ring proxy indicators, BAI, $\Delta^{13} \mathrm{C}$ and $\delta^{15} \mathrm{~N}$, identified 1989 as the average year that three forest stands of red spruce trees, spanning $100 \mathrm{~km}$ in the Central Appalachian Mountains, began a 25-year period of accelerated tree growth (Table 3.1). Prior to 1989, there was a 49-year period of declining tree growth, characteristic of reduced growth of red spruce trees exposed to high levels of acidic air pollution and deposition in the eastern U.S. (Cook et al., 1987; Johnson et al., 1988; Eager \& Adams, 1992). Our observations of recent increases in growth of red spruce trees are similar to observations of increased growth of red spruce in the northeastern U.S. (Engel et al., 2016) and other tree species in the eastern U.S. (Johnson \& Abrams, 2009; McMahon et al., 2010; Thomas et al., 2013; Fang et al., 2014). In our study, GLMM model averaging used to examine the environmental influences on growth of red spruce from 1989-2014 indicated recovery from reduced acidic air pollution, a fertilization effect of increased atmospheric $\mathrm{CO}_{2}$, and a positive influence of early spring temperatures, thus highlighting the importance of multiple environmental factors on the proximate increases in red spruce tree growth in the Central Appalachian Mountains.

Since the Clean Air Act of 1970 and subsequent amendments, pollutant emissions in the U.S. have dropped considerably. From 1940-1989, $\mathrm{SO}_{2}$ emissions averaged 23.13 million metric tons $\mathrm{yr}^{-1}$, but declined by 0.73 million metric tons $\mathrm{yr}^{-1}$ from 1989-2014 (Figure S3.1a) (Lefohn et al., 1999; EPA, 2015). Kendall's rank correlation placed the decline in $\mathrm{SO}_{2}$ emissions as the topmost environmental factor contributing to the observed growth increases in red spruce trees since 1989 (Table 3.2). GLMM model averaging also pointed to a strong effect of decreasing $\mathrm{SO}_{2}$ emissions on tree growth across 1989-2014, as well as a high sensitivity to these pollutant reductions (Figure 3.6, Table 3.3). The changes in the red spruce $\Delta^{13} \mathrm{C}$ chronology, a proxy indicator for photosynthetic physiology, further support recovery of these trees from acid pollution. The decrease in $\Delta^{13} \mathrm{C}$ in the red spruce tree rings from 1940 to 1989 , corresponding to reductions in $A$ and $g_{c}$, has been shown in many studies examining the effects of acidic sulfur pollution on the $\mathrm{C}$ isotope signatures of trees (Savard et al., 2004; Santruckova et al., 2007; Rinne et al., 2010; Boettger et al., 2014b; Kwak et al., 2016), including species from the eastern U.S. (Li et al., 2010; Thomas et al., 2013). The increase in $\Delta^{13} \mathrm{C}$, corresponding to increases in $A$ and $g_{c}$, that we observed after 1989 as $\mathrm{SO}_{2}$ emissions declined has also been found in studies as a function of decreasing pollution (Boettger et al., 2014b; Li et al., 2010; Thomas et al., 2013), and 
is opposite from observations of reduced tree ring $\Delta^{13} \mathrm{C}$ with increased tree height or as trees get older (Mcdowell et al., 2011; Brienen et al., 2017). Thus, our data are consistent with the hypothesis that reductions in acidic air pollution and deposition from the historically high totals in the 1970s reached a critical level around 1989 that red spruce trees were better able to tolerate, thereby beginning the recovery of tree growth and photosynthetic physiology of red spruce trees in the Central Appalachian Mountains that has persisted for 25 years as pollution levels continued to decline.

Our study suggests that increases in growth and $A$ after 1989 were likely enhanced by increases in atmospheric $\mathrm{CO}_{2}$ concentrations, which have increased substantially over the last 75 years and have increased by $c a$. 13\% from 1989-2014 (Keeling et al., 2015). Although numerous experiments using large square-wave increases in $\mathrm{CO}_{2}$, such as FACE experiments, often show increased tree growth (Norby et al., 2005), an effect of increasing $\mathrm{CO}_{2}$ on growth is rarely observed in tree ring studies, possibly because the annual step changes in $\mathrm{CO}_{2}$ are small and any changes in growth are masked by other environmental factors positively or negatively contributing to growth. In our study, both Kendall's rank correlation and GLMM model averaging indicate strong effects of increasing $\mathrm{CO}_{2}$ on red spruce growth from 1989-2014 (Figure 3.6). In addition, if $A$ is considered a diffusive process, where $A=\left(C_{a}-C_{i}\right)^{*} g_{c}$, then the 43\% increase in $A$ of red spruce trees after 1989 is likely produced by the combination of the $13 \%$ increase in $C_{a}$ and the $67 \%$ increase in $g_{c}$ as acidic pollution declines. Our data suggesting a $\mathrm{CO}_{2}$ enhancement of growth and $A$ of red spruce trees since 1989 are consistent with flux tower observations of increased forest productivity from 23 forest sites in the U.S. and Europe from 1995 to 2011, where increases in atmospheric $\mathrm{CO}_{2}$ were shown to stimulate GPP and NEP (Fernández-Martínez et al., 2017).

Both $\mathrm{SO}_{4}{ }^{2-}$ deposition and elevated $\mathrm{CO}_{2}$ reduce $g_{c}$ experimentally (Borer et al., 2005; Ainsworth \& Rogers, 2007) and, thus, the combined effects of acid deposition and increasing atmospheric $\mathrm{CO}_{2}$ are likely responsible for the $47 \%$ decline in $g_{c}$ of red spruce trees from 19401989. If we assume that the increase in $g_{c}$ after 1989 represents a complete recovery from acid deposition, then the 15\% reduction in $g_{c}$ from 1940-2014 reflects only the effect of increasing $\mathrm{CO}_{2}$ on $g_{c}$ of the red spruce trees (Figure S3.6a) and is more in line with observed reductions in $g_{c}$ per ppm $\mathrm{CO}_{2}$ increase from elevated $\mathrm{CO}_{2}$ experiments using trees (Ainsworth \& Rogers, 2007). Under this assumption, our data indicate that acidic air pollution is a $3.7 \mathrm{x}$ greater forcing 
factor on $g_{c}$ of red spruce trees than increasing $\mathrm{CO}_{2}$ (Figure S3.6a). Numerous experiments, as well as dendroisotopic studies, have shown that $i \mathrm{WUE}$, the ratio of $A$ to stomatal conductance of water, of many plants is improved as a result of a combination of increasing $\mathrm{CO}_{2}$ stimulating $A$ and causing partial stomatal closure (Ainsworth \& Rogers, 2007; Franks et al., 2013; Keenan et al., 2013; Knauer et al., 2016), and this has been hypothesized to be an important mechanism leading to increased forest productivity. Over the 1940-2014 tree ring chronology, $i$ WUE of red spruce trees increased $51 \%$, or $+0.68 \% \mathrm{yr}^{-1}$, as $A$ increased by $27 \%$ and $g_{c}$ declined by $15 \%$ from 1940-2014. If we use the Ball-Berry model to predict the theoretical change in $i$ WUE if impacted by changes in $\mathrm{CO}_{2}$ alone, using a constant $C_{i} / C_{a}$ ratio of 0.72 (mean at 1940), then $i \mathrm{WUE}$ increases by $30 \%$ over the tree ring chronology (Figure S6b), tracking the increase in atmospheric $\mathrm{CO}_{2}$ (Knauer et al., 2016). If we model $i$ WUE using the decline in $g_{c}$ attributed to increasing $\mathrm{CO}_{2}$ for red spruce trees in this study (-15\%, Figure S3.6a) and an increase in $A$ that is predicted from $\mathrm{CO}_{2}$ enrichment studies using trees (Ainsworth \& Rogers, 2007), scaled over the range of $\mathrm{CO}_{2}$ during our study (9.3\% increase in $A$ from 1940-1989), then $i$ WUE increases by $41 \%$ over the tree ring chronology (Figure S3.6b). Both of these examples, point to the much greater sensitivity of $g_{c}$ to acidic sulfur pollution than to $\mathrm{CO}_{2}$ and the subsequent role of pollution in the observed increases of $i$ WUE. In addition, several analyses have observed that increases in $i$ WUE do not always translate into greater tree growth (Silva et al., 2010; Peñuelas et al., 2011; Lévesque et al., 2014). In our study, BAI declined 48.9\% from 1940-1989 as $i$ WUE increased 67.2\%; From 1989-1995, BAI increased 63.6\% as $i$ WUE increased 0.6\%; And, from 1995-2014, BAI increased $37.4 \%$ as $i$ WUE decreased $9.8 \%$. Thus, our study agrees with these analyses that $i$ WUE is a poor predictor of tree growth, especially in mesic environments, such as our red spruce forest locations in the Central Appalachian Mountains.

From 1940-1989, $\mathrm{NO}_{\mathrm{x}}$ emissions increased by 0.92 million metric tons $\mathrm{yr}^{-1}$, but declined by 0.56 million metric tons $\mathrm{yr}^{-1}$ from 1989-2014 (EPA, 2015). GLMM model averaging indicated that tree growth of red spruce across 1989-2014 was negatively impacted by reductions in $\mathrm{NO}_{\mathrm{x}}$ emissions after 1989 (Figure 3.6). This result was surprising given that Kendall's rank correlation identified strong negative correlations between $\mathrm{NO}_{\mathrm{x}}$ emissions and BAI, $\Delta^{13} \mathrm{C}, A$ and $g_{c}$ after 1989 (Table 2), as well as across the entire 1940-2014 chronology (Table S3.1). These contradictory results highlight the uncertainty associated with the effects of $\mathrm{N}$ deposition on tree growth since $\mathrm{N}$ deposition may act as a source of soil acidity and negatively impact tree growth 
or may act as a fertilizer source of $\mathrm{N}$ and positively impact tree growth (Thomas et al., 2010; Jennings et al., 2016).

The negative correlations between tree ring $\delta^{15} \mathrm{~N}$ and BAI, $\Delta^{13} \mathrm{C}, A$ and $g_{c}$ after 1989 add to the difficulty of interpreting the $\mathrm{NO}_{\mathrm{x}}$ emissions results from our GLMM model averaging, as our $\delta^{15} \mathrm{~N}$ chronology would suggest red spruce tree growth and photosynthesis increased as ecosystem $\mathrm{N}$ availability declined. However, even with the dramatic declines in $\mathrm{N}$ deposition in this region, an examination of $\mathrm{N}$ cycling at these three red spruce forest sites suggests that these ecosystems are not strongly N-limited (Smith et al., 2016). Given the close relationship between tree ring $\delta^{15} \mathrm{~N}$ and declines in national emissions of $\mathrm{NO}_{\mathrm{x}}$ and local wet deposition of $\mathrm{NO}_{3}{ }^{-}$(Figure S3.3), one may hypothesize that the $\delta^{15} \mathrm{~N}$ signatures in the red spruce tree ring chronologies reflect changes in the $\delta^{15} \mathrm{~N}$ signatures of pollutant sources, since $\mathrm{NO}_{3}{ }^{-}$produced from fossil fuel combustion is enriched in ${ }^{15} \mathrm{~N}$ relative to biogenic sources (Felix et al., 2012). However, the evidence that tree ring $\delta^{15} \mathrm{~N}$ reflects $\delta^{15} \mathrm{~N}$ from fossil fuel sources is limited (Gerhart $\&$ McLauchlan, 2014), and although the source $\delta^{15} \mathrm{~N}$ signature of $\mathrm{N}$ deposition over the tree-ring chronology is unknown at our locations, our data do not support this hypothesis given the constant wood $\delta^{15} \mathrm{~N}$ prior to 1989 when $\mathrm{NO}_{\mathrm{x}}$ emissions were increasing dramatically (Figure 3.2b, Figure S3.1).

An alternative hypothesis is that $\delta^{15} \mathrm{~N}$ in plant tissues, including tree rings, reflects ecosystem $\mathrm{N}$ supply relative to demand, where a more open $\mathrm{N}$ cycle, defined as a scenario where $\mathrm{N}$ supply exceeds plant demand, typically results in greater rates of net nitrate production (a process that strongly fractionates against ${ }^{15} \mathrm{~N}$ ) followed by the loss of isotopically light nitrate by leaching and/or denitrification (Gerhart \& McLauchlan, 2014). The loss of ${ }^{15} \mathrm{~N}$-depleted nitrate enriches the residual pool of plant available $\mathrm{N}$ that, in turn, leads to elevated values of $\delta^{15} \mathrm{~N}$ in plant tissue (Pardo et al., 2002). Following this line of reasoning, the red spruce tree-ring $\delta^{15} \mathrm{~N}$ chronology between 1940 and 1989 may reflect a more open $\mathrm{N}$ cycle resulting from declining tree growth rates and, therefore, a reduced plant demand for $\mathrm{N}$ by red spruce trees. Likewise, the decrease in wood $\delta^{15} \mathrm{~N}$ after 1989 may have resulted from a tighter, more closed $\mathrm{N}$ cycle, as increased tree growth created a greater demand for $\mathrm{N}$ during a time of reductions in $\mathrm{N}$ deposition (Figure 3.1, Figure S3.1b). In addition, N concentrations in wood were 32\% greater after 1989 compared to before 1989, and this, along with greater tree growth, further suggests that plant $\mathrm{N}$ uptake and retention increased after 1989. Our $\delta^{15} \mathrm{~N}$ data reflect observations of declining tree 
ring $\delta^{15} \mathrm{~N}$ signatures across the continental U.S. in recent decades (Elmore et al. 2016; McLauchlan et al., 2017) and support the patterns found in the European NITREX studies where experimental removal of $\mathrm{N}$ deposition from throughfall led to rapid ecosystem recovery and a more closed $\mathrm{N}$ cycle as losses of gaseous $\mathrm{N}$ through denitrification and $\mathrm{NO}_{3}{ }^{-}$leaching declined (Bredemeier et al., 1998; Corre \& Lamersdorf, 2004). Thus, the $\delta^{15} \mathrm{~N}$ chronology found in these red spruce trees has broad implications for regional forest ecosystem recovery to pollution, as well as increased water quality and fewer occurrences of eutrophication, since it is likely that less $\mathrm{N}$ is lost into stream runoff as $\mathrm{N}$ inputs from pollution decline, as has been shown in this region by Eshleman et al. (2013).

Changes in historical climate were the least influential environmental variables affecting BAI, $\Delta{ }^{13} \mathrm{C}$, and seasonally integrated $A$ and $g_{c}$ of red spruce trees after 1989 , possibly due to the high interannual variability of temperature and precipitation in the Central Appalachian region (WV Climate Division 4, NOAA, 2017). Precipitation at our study locations did not significantly change over the study period. Precipitation was not different before and after 1989 (Figure S2b,d), and thus, was not identified by either Kendall's rank correlation or GLMMs as having an influence on BAI, $\Delta^{13} \mathrm{C}, A$ or $g_{c}$ from 1989 to 2014. Our results are contrary to Levesque et al. (2017), who concluded that increasing water availability after 1984, and not increases in $\mathrm{CO}_{2}$ or reductions in acid pollution, has been the primary factor driving increases in BAI, $A$ and $g_{c}$ of two broadleaf species, Quercus rubra and Liriodendron tulipifera, at Black Rock, NY, where annual precipitation increased 4\% and growing season precipitation increased 19\% during 19842014 compared to 1950-1983 (PRISM Climate Group, 2017).

On the other hand, mean annual temperatures in this Central Appalachian region have significantly increased by $0.50^{\circ} \mathrm{C}$ over the past 75 years, that was largely contributed to by a $0.72^{\circ} \mathrm{C}$ increase in mean April temperatures during 1989-2014 compared to 1940-1989 (WV Climate Division 4, NOAA, 2017). Our tree ring data point to changes in early spring phenology of red spruce trees due to these warmer temperatures after 1989 that are manifested as greater tree growth. First, Kendall's rank correlation identified a strong positive correlation between mean April temperatures and BAI, $A$ and $g_{c}$ of red spruce trees during 1989-2014. Second, the GLMM average model indicated a main effect of April temperatures on BAI of red spruce during 1989-2014 that contributed to tree growth increases, and showed a very high sensitivity, suggesting that even small changes in spring temperatures can affect tree growth. Finally, 
ANCOVA indicated that greater mean April temperatures after 1989 translated to greater seasonally integrated $A$ and, a subtle, but significant, increase in $B A I$ of red spruce trees compared to 1940-1989 (Figure 3.4). Our observations of an accelerated early spring phenology of red spruce trees due to higher spring temperatures are similar to observations of other tree species globally (Black et al., 2000; Piao et al., 2007), as well as in the eastern U.S (Richardson et al., 2009; Dragoni et al., 2011; Elmore et al., 2016).

A large number of elevated $\mathrm{CO}_{2}$ experiments have generated critical information on how the $\mathrm{C}$ cycle is changing in the world's ecosystems (Long et al., 2004; Norby et al., 2005). However, isolating the effects of increasing $\mathrm{CO}_{2}$ on tree growth in forest ecosystems has been difficult to confirm due to the small annual step-changes in $\mathrm{CO}_{2}$ and the myriad of interacting environmental factors known to affect whole-tree growth over multi-decadal time spans (Luo \& Reynolds, 1999; Hyvönen et al., 2007a). This study provides evidence for increasing $\mathrm{CO}_{2}$ having a positive effect on tree growth, but also indicates a broad range of complexity as red spruce forest ecosystems recover from decades of acidic air pollution and the realization that none of the environmental factors that are examined here act in isolation. Although declines in acidic air pollution and increases in atmospheric $\mathrm{CO}_{2}$ have contributed to increases in red spruce tree growth after 1989, climate change during the early spring also has occurred, which in turn, positively affected the growth of the red spruce trees. It remains unclear how long the increases in growth of these red spruce stands will be sustained. Plant available $\mathrm{N}$ will likely be important to maintain this increase in productivity (Luo et al., 2004) and, despite evidence of increased $\mathrm{N}$ uptake and retention by the red spruce trees, $\mathrm{N}$ inputs from anthropogenic sources are clearly declining. Although the purpose of our study was to examine the timing and physiological basis of recent growth by red spruce trees in the Central Appalachian Mountains, a simple scaling exercise using our tree growth data, red spruce allometry (Whittaker et al., 1974; Siccama et al., 1994), and forest inventory biomass data (Kellndorfer et al., 2012) coupled with forest land cover estimates (Homer et al., 2015) (Figure S3.7) suggests the carbon sink in the Northeastern temperate forest could have been reduced by as much as $0.79 \mathrm{Pg} \mathrm{C}$ since 1940 due to acid deposition (Table S4), or roughly equivalent to $12 \%$ of anthropogenic growth in global atmospheric C in 2016 (Le Quéré et al., 2017), if all species responded the same as red spruce trees. While this back of the envelope estimate clearly needs refinement using a range of species sensitivities to acidic pollution, our assessment suggests that a significant portion of the increases 
in the temperate forest carbon sink in the U.S. observed by Pan et al. (2011) could be explained by recovery of trees from decades of acid deposition. This highlights the necessity to better quantify the influence of acidic air pollution on forest ecosystems globally in order to accurately resolve the contribution of forests to the global carbon cycle. 


\subsection{Tables and Figures.}

Table 3.1. Estimated breakpoints ( \pm standard errors) where a directional change in the 19402014 chronologies of red spruce basal area increment (BAI), $\Delta^{13} \mathrm{C}$, and $\delta^{15} \mathrm{~N}$ occurred for McGowan Mountain (MCG), Span Oak Run (SOR) and Cranberry Glades (CGL). At each site, $\mathrm{N}=20-25$ red spruce trees. The overall breakpoint, defined as the average breakpoint at all 3 sites and all 3 proxies, was the year $1989 \pm 1.5$ years.

\begin{tabular}{cccc}
\hline Site & BAI & $\Delta^{13} \mathrm{C}$ & $\delta^{15} \mathrm{~N}$ \\
\hline MCG & $1985 \pm 1.8$ & $1990 \pm 0.8$ & $1985 \pm 2.4$ \\
SOR & $1993 \pm 2.3$ & $1992 \pm 0.9$ & $1981 \pm 1.8$ \\
CGL & $1987 \pm 2.2$ & $1993 \pm 1.0$ & $1994 \pm 7.4$ \\
\hline
\end{tabular}


Table 3.2. Kendall's rank correlation coefficients $(\tau)$ between environmental parameters and the regional chronologies from 1989 to 2014 of basal area increment (BAI), $\Delta^{13} \mathrm{C}$, seasonally integrated net photosynthesis $(A)$, and seasonally integrated stomatal conductance $\left(g_{c}\right)$ of red spruce trees from three locations in the central Appalachian Mountains. Environmental parameters included national $\mathrm{SO}_{2}$ and $\mathrm{NO}_{x}$ emissions (Lefohn et al., 1999; EPA, 2015), atmospheric $\mathrm{CO}_{2}$ concentrations (Keeling et al., 2015), and monthly, growing season, and annual precipitation and temperatures (WV Climate Division 4, NOAA, 2017). $\tau$ is shown for significant correlations only, and $*$ denotes $\mathrm{p}<0.01, * *$ denotes $\mathrm{p}<0.001$, while $* * *$ denotes $\mathrm{p}<$ 0.0001 .

\begin{tabular}{ccccc}
\hline Environmental Parameter & $\mathrm{BAI}$ & $\Delta^{13} \mathrm{C}$ & $A$ & $g_{c}$ \\
\hline $\mathrm{NO}_{\mathrm{x}}$ & $-0.364^{* * *}$ & $-0.326^{* * *}$ & $-0.689^{* * *}$ & $-0.594^{* * *}$ \\
$\mathrm{SO}_{2}$ & $-0.422^{* * *}$ & $-0.338^{* * *}$ & $-0.718^{* * *}$ & $-0.618^{* * *}$ \\
Atmospheric $\mathrm{CO}_{2}$ & $0.414^{* * *}$ & $0.343^{* * *}$ & $0.727^{* * *}$ & $0.625^{* * *}$ \\
MGT & & & \\
January temperature & & 0.207 & 0.193 \\
February temperature & & -0.203 & $-0.215^{*}$ \\
April temperature & $0.263^{* *}$ & & -0.175 & -0.171 \\
May temperature & & $0.233^{*}$ & $0.210^{*}$ \\
February precipitation & -0.154 & & 0.190 & $0.211^{*}$ \\
March precipitation & & -0.186 & \\
December precipitation & & -0.165 & 0.157 \\
\hline
\end{tabular}


Table 3.3. Mean sensitivity ( \pm standard errors) of BAI to each environmental parameter determined to be significant by the average model for the 1989 to 2014 period. Sensitivities are defined as the change in BAI $\left(\mathrm{cm}^{2}\right)$ to a one-unit change for each of the environmental factors listed and were determined by dividing the contribution of each factor to BAI by the respective trend of each factor over 1989-2014. Units for environmental factors are in parentheses.

\begin{tabular}{cc}
\hline Factor & Sensitivity \\
\hline Atmospheric $\mathrm{CO}_{2}(\mathrm{ppm})$ & $0.093 \pm 0.013$ \\
$\mathrm{SO}_{2}$ emissions $\left(10^{6}\right.$ metric tons $)$ & $-0.152 \pm 0.029$ \\
$\mathrm{NO}_{\mathrm{x}}$ emissions $\left(10^{6}\right.$ metric tons $)$ & $0.123 \pm 0.040$ \\
April temperature $\left({ }^{\circ} \mathrm{C}\right)$ & $0.556 \pm 0.521$ \\
\hline
\end{tabular}


Figure 3.1. Average basal area increment (BAI) of red spruce trees from three forest sites in the Central Appalachian Mountains from 1900-2014 ( $\mathrm{N}=20-25$ trees for each site). Open circles indicate the juvenile growth phase after logging in the early $20^{\text {th }}$ Century, whereas closed circles represent the mature growth phase.
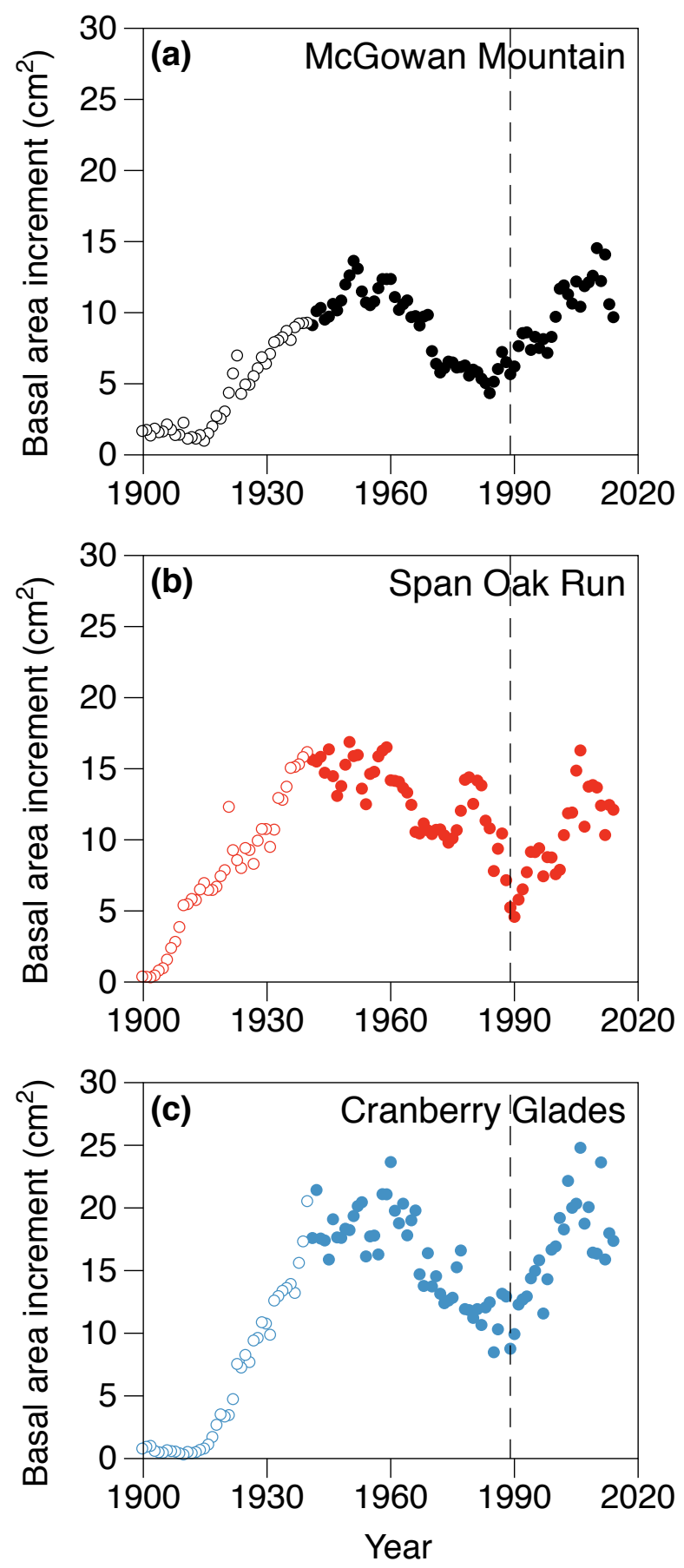
Figure 3.2. Chronology of carbon isotope discrimination, $\Delta^{13} \mathrm{C}$, (a) and (b) wood $\delta^{15} \mathrm{~N}$ for red spruce trees $(\mathrm{N}=5$ per site) from three forest sites in the central Appalachian Mountains. The $\Delta^{13} \mathrm{C}$ chronology in (a) includes $1940-2014$, while the $\delta^{15} \mathrm{~N}$ chronology in (b) includes 19402013. The vertical dashed lines in (a) and (b) are at 1989, the average critical year for the region determined via breakpoint analysis where a directional shift in BAI, $\Delta^{13} \mathrm{C}$, and $\delta^{15} \mathrm{~N}$ occurred. The three red spruce forest sites are McGowan Mountain (MCG), Span Oak Run (SOR), and Cranberry Glades (CGL).
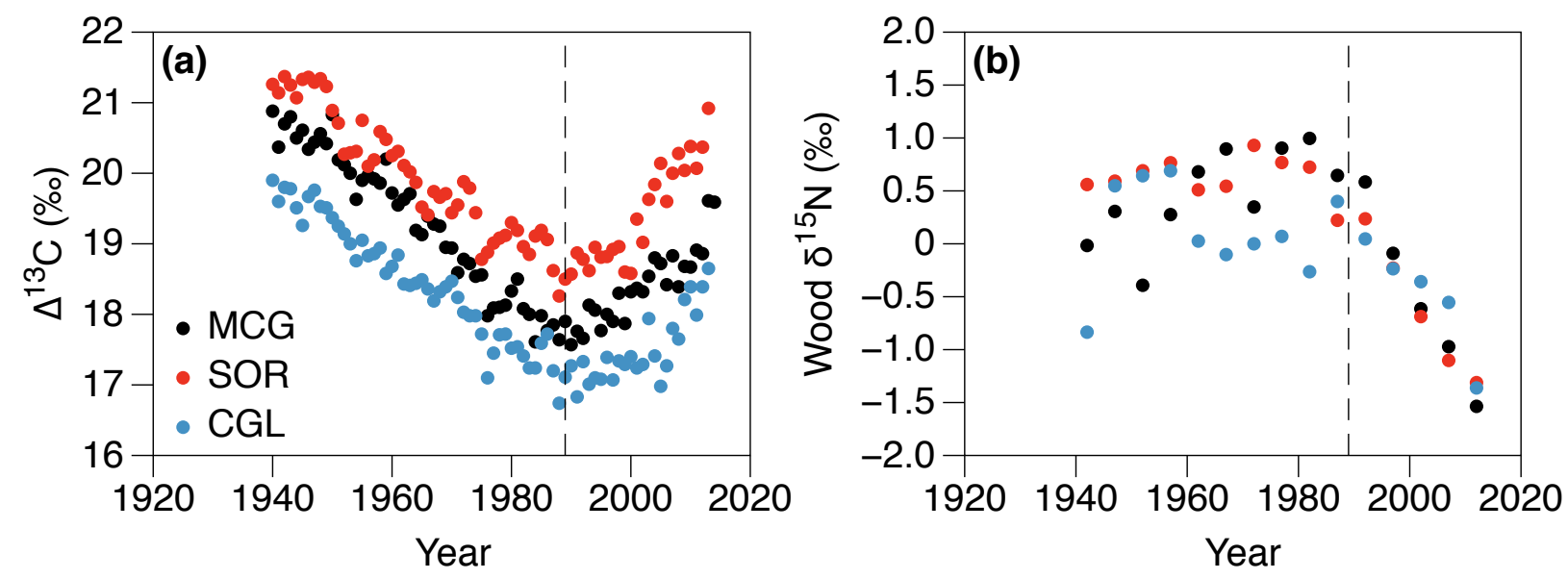
Figure 3.3. Chronology of seasonally integrated photosynthesis modeled using $\Delta^{13} \mathrm{C}$ for red spruce trees $(\mathrm{N}=5$ per site) from three forest sites in the central Appalachian Mountains from 1940-2014 (a), seasonally integrated stomatal conductance modeled using $\Delta^{13} \mathrm{C}(\mathrm{b})$, and intrinsic water use efficiency $(i \mathrm{WUE})$ derived from the chronologies of $\Delta^{13} \mathrm{C}(\mathrm{c})$. The vertical dashed lines in (a) and (b) are at 1989, the average critical year for the region determined via breakpoint analysis where a directional shift in BAI, $\Delta^{13} \mathrm{C}$, and $\delta^{15} \mathrm{~N}$ occurred. The vertical dashed line in (c) is at 1995, the critical year where a directional shift in $i$ WUE occurred. The three red spruce forest sites are McGowan Mountain (MCG), Span Oak Run (SOR), and Cranberry Glades (CGL).
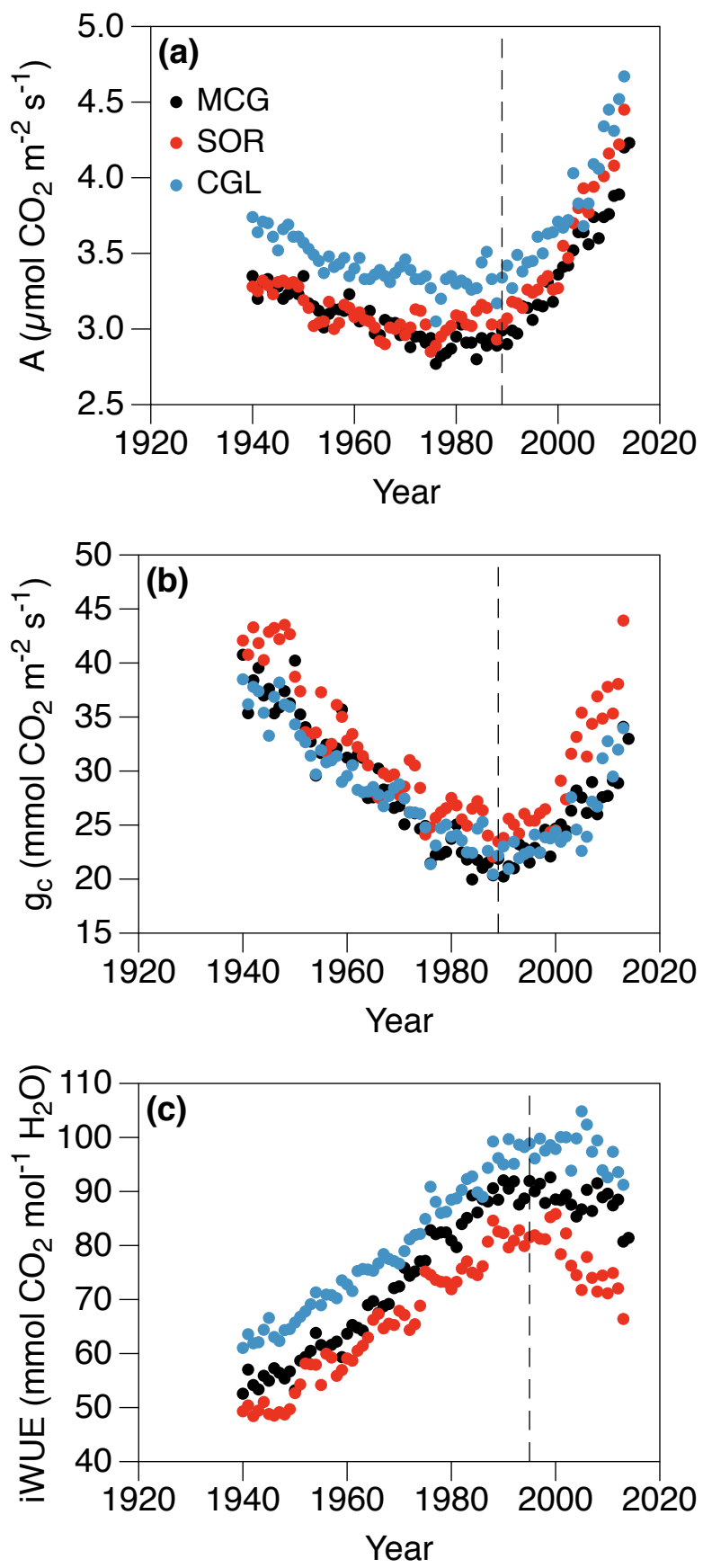
Figure 3.4. Relationships between seasonally integrated photosynthesis (a) and basal area increment with mean April temperatures (b) before and after 1989. ANCOVA was used to determine if the response of seasonally integrated photosynthesis or basal area increment to April temperatures were different before and after 1989, the average critical year for the region determined via breakpoint analysis where a directional shift in BAI, $\Delta^{13} \mathrm{C}$, and $\delta^{15} \mathrm{~N}$ occurred. Climate data are from West Virginia Division 4, which is the region that contains the three red spruce stands in this study (WV Climate Division 4, NOAA, 2017).
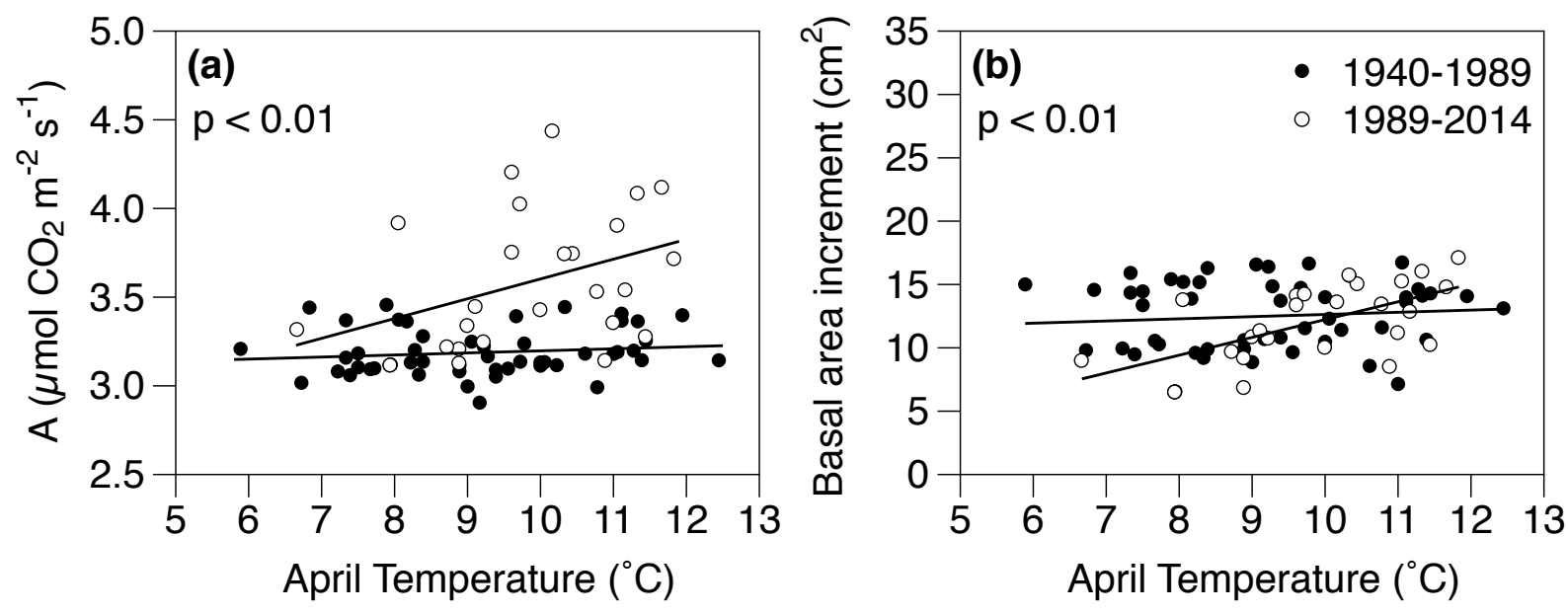
Figure 3.5. Relationships between carbon isotope discrimination (a), seasonally integrated photosynthesis (b), seasonally integrated stomatal conductance (c), and basal area increment with wood $\delta^{15} \mathrm{~N}(\mathrm{~d})$ at each red spruce site $(\mathrm{N}=5$ trees per site) from 1989-2013. In each panel, correlation coefficients are from top to bottom, McGowan Mountain (MCG), Span Oak Run (SOR), and Cranberry Glades (CGL).
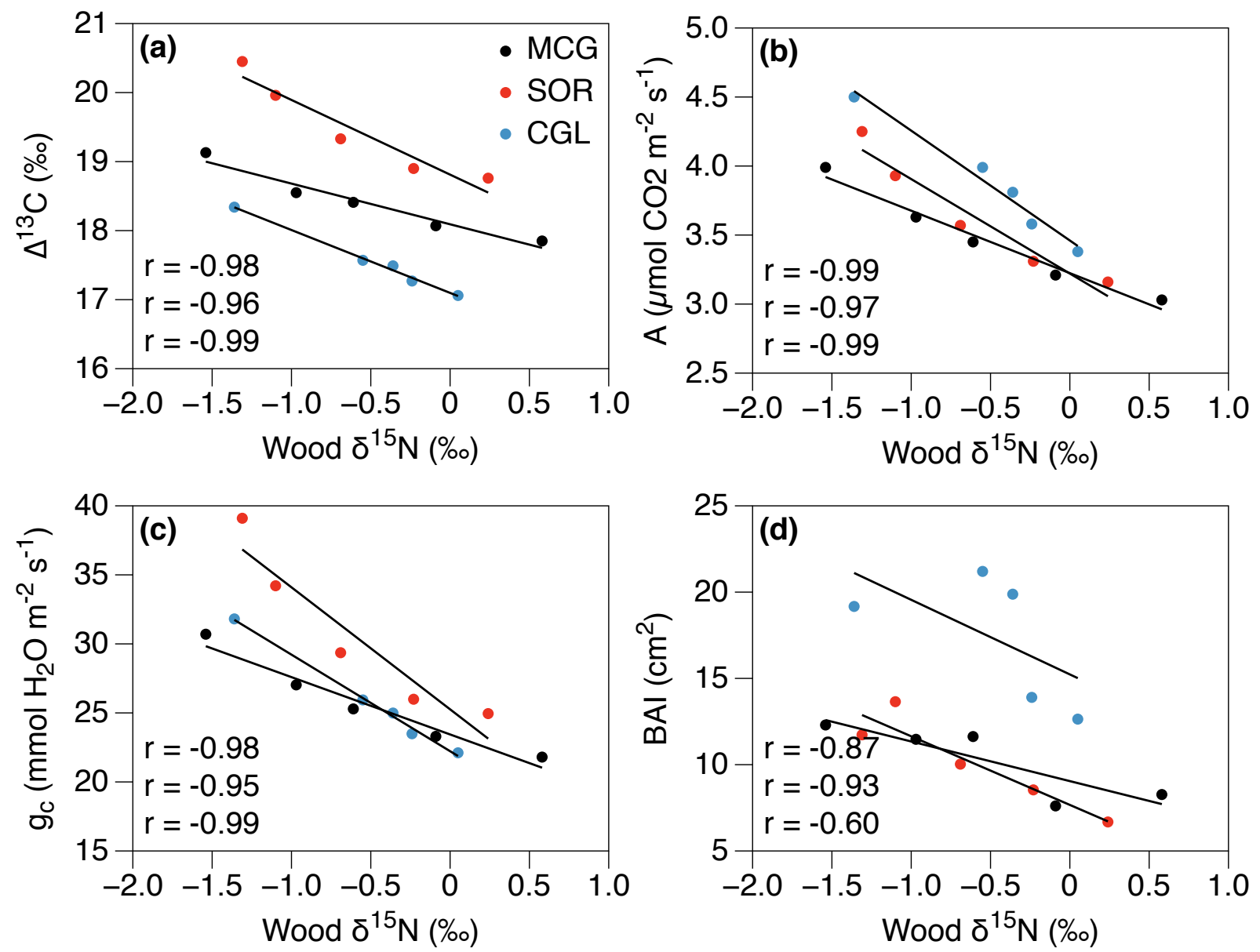
Figure 3.6. Contribution of atmospheric $\mathrm{CO}_{2}, \mathrm{NO}_{x}$ emissions, $\mathrm{SO}_{2}$ emissions, and mean April temperatures to the change in BAI each year predicted by the GLMM average model for 19892014 (a), and the contribution of $\mathrm{CO}_{2}, \mathrm{NO}_{\mathrm{x}}$ emissions, $\mathrm{SO}_{2}$ emissions, and mean April temperatures to the total change in BAI over 1989-2014 (b). Numbers in brackets indicate the direction and magnitude of changes in environmental parameters. Numbers in brackets in panel (a) represent the trend in each respective environmental parameter over 1989-2014, while numbers in brackets in panel (b) represent the total change in each respective environmental parameter over 1989-2014. Units for $\mathrm{CO}_{2}$ and April $\mathrm{T}_{\text {mean }}$ are ppm and ${ }^{\circ} \mathrm{C}$, respectively, while units for $\mathrm{NO}_{\mathrm{x}}$ and $\mathrm{SO}_{2}$ are $10^{6}$ metric tons. Unknown contributions in (a) were calculated as the difference between the observed change and all known contributions. Models with $\triangle \mathrm{AICc}<4$ were included in the average model (see Table S3 for model structure). Asterisks (*) indicate significance at the $\alpha=0.05$ level.
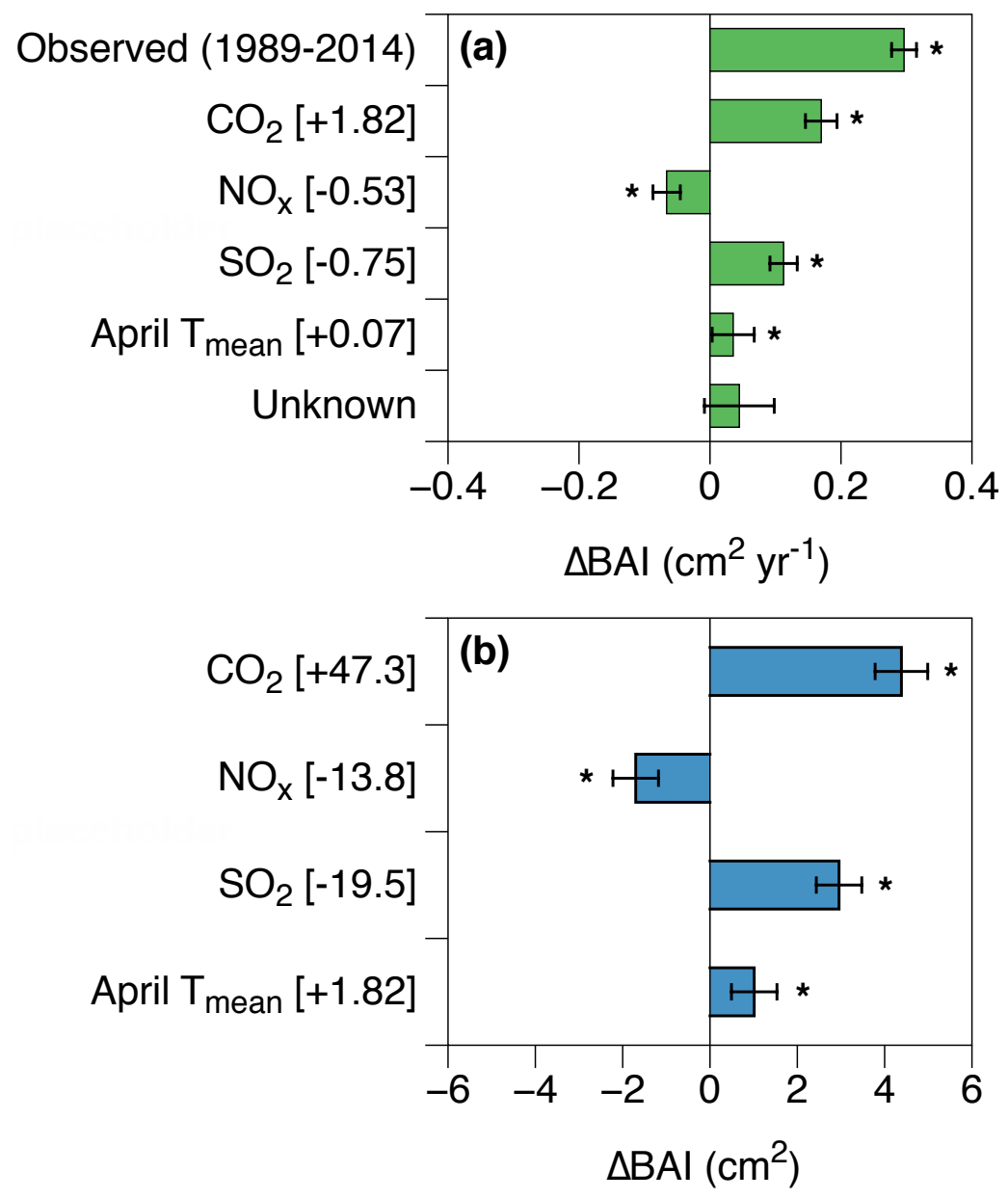


\subsection{Literature Cited.}

Ainsworth EA, Rogers A. 2007. The response of photosynthesis and stomatal conductance to rising $\left[\mathrm{CO}_{2}\right]$ : mechanisms and environmental interactions. Plant, Cell \& Environment 30: $258-270$.

Anderson-Teixeira KJ, Miller AD, Mohan JE, Hudiburg TW, Duval BD, DeLucia EH. 2013. Altered dynamics of forest recovery under a changing climate. Global Change Biology 19: 2001-2021.

Bartoń K. 2017. MuMIn: Multi-Model Inference. R package version 1.40.0.

Belmecheri S, Maxwell RS, Taylor AH, Davis KJ, Freeman KH, Munger WJ. 2014. Tree-ring $\delta^{13} \mathrm{C}$ tracks flux tower ecosystem productivity estimates in a NE temperate forest. Environmental Research Letters 9: 074011.

Black TA, Chen WJ, Barr AG, Arain MA, Chen Z, Nesic Z, Hogg EH, Neumann HH, Yang PC. 2000. Increased carbon sequestration by a boreal deciduous forest in years with a warm spring. Geophysical Research Letters 27: 1271-1274.

Boettger T, Haupt M, Friedrich M, Waterhouse JS. 2014. Reduced climate sensitivity of carbon, oxygen and hydrogen stable isotope ratios in tree-ring cellulose of silver fir (Abies alba Mill.) influenced by background $\mathrm{SO}_{2}$ in Franconia (Germany, Central Europe). Environmental Pollution 185: 281-294.

Boisvenue C, Running SW. 2006. Impacts of climate change on natural forest productivity evidence since the middle of the 20th century. Global Change Biology 12: 862-882.

Borer CH, Schaberg PG, DeHayes DH. 2005. Acidic mist reduces foliar membrane-associated calcium and impairs stomatal responsiveness in red spruce. Tree Physiology 25: 673-680.

Bredemeier M, Blanck K, Xu Y-J, Tietema A, Boxman AW, Emmett B, Moldan F, Gundersen P, Schleppi P, Wright RF. 1998. Input-output budgets at the NITREX sites. Forest Ecology and Management 101: 57-64.

Brienen RJW, Gloor E, Clerici S, Newton R, Arppe L, Boom A, Bottrell S, Callaghan M, Heaton T, Helama S, et al. 2017. Tree height strongly affects estimates of water-use efficiency responses to climate and $\mathrm{CO}_{2}$ using isotopes. Nature Communications 8: 288.

Bunn A, Korpela M, Biondi F, Campelo F, Merian P, Qeadan F, Zang C, Buras A, Cecile J, Mudelsee M, et al. 2015. Dendrochronology Program LIbrary in R. R package version 1.6.3.

Burnham MB, McNeil BE, Adams MB, Peterjohn WT. 2016. The response of tree ring $\delta^{15} \mathrm{~N}$ to whole-watershed urea fertilization at the Fernow Experimental Forest, WV.

Biogeochemistry 130: 133-145. 
Caspersen JP, Pacala SW, Jenkins JC, Hurtt GC, Moorcroft PR, Birdsey RA. 2000.

Contributions of land-use history to carbon accumulation in U.S. forests. Science 290: 1148-1151.

Choi W-J, Lee S-M, Chang SX, Ro H. 2005. Variations of $\delta^{13} \mathrm{C}$ AND $\delta^{15} \mathrm{~N}$ in Pinus Densiflora Tree-Rings and their Relationship to Environmental Changes in Eastern Korea. Water, Air, and Soil Pollution 164: 173-187.

Cook ER, Johnson AH, Blasing TJ. 1987. Forest decline: modeling the effect of climate in tree rings. Tree Physiology 3: 27-40.

Corre MD, Lamersdorf NP. 2004. Reversal of nitrogen saturation after long-term deposition reduction: impact on soil nitrogen cycling. Ecology 85: 3090-3104.

Craine JM, Brookshire ENJ, Cramer MD, Hasselquist NJ, Koba K, Marin-Spiotta E, Wang L. 2015. Ecological interpretations of nitrogen isotope ratios of terrestrial plants and soils. Plant and Soil 396: 1-26.

Craine JM, Elmore AJ, Aidar MPM, Bustamante M, Dawson TE, Hobbie EA, Kahmen A, Mack MC, McLauchlan KK, Michelsen A, et al. 2009. Global patterns of foliar nitrogen isotopes and their relationships with climate, mycorrhizal fungi, foliar nutrient concentrations, and nitrogen availability. New Phytologist 183: 980-992.

Dragoni D, Schmid HP, Wayson CA, Potter H, Grimmond CSB, Randolph JC. 2011. Evidence of increased net ecosystem productivity associated with a longer vegetated season in a deciduous forest in south-central Indiana, USA. Global Change Biology 17: 886-897.

Driscoll CT, Lawrence GB, Bulger AJ, Butler TJ, Cronan CS, Eagar C, Lambert KF, Likens GE, Stoddard JL, Weathers KC. 2001. Acidic Deposition in the Northeastern United States: Sources and Inputs, Ecosystem Effects, and Management Strategies. BioScience 51: 180.

Dye A, Barker Plotkin A, Bishop D, Pederson N, Poulter B, Hessl A. 2016. Comparing tree-ring and permanent plot estimates of aboveground net primary production in three eastern U.S. forests. Ecosphere 7: e01454.

Eager C, Adams MB. 1992. Ecology and Decline of Red Spruce in the Eastern United States. Ecological Studies 96. New York: Springer-Verlag.

Elliott EM, Kendall C, Wankel SD, Burns DA, Boyer EW, Harlin K, Bain DJ, Butler TJ. 2007. Nitrogen Isotopes as Indicators of $\mathrm{NO}_{\mathrm{x}}$ Source Contributions to Atmospheric Nitrate Deposition Across the Midwestern and Northeastern United States. Environmental Science \& Technology 41: 7661-7667.

Elmore AJ, Nelson DM, Craine JM. 2016. Earlier springs are causing reduced nitrogen availability in North American eastern deciduous forests. Nature Plants 2: 1-5. 
Engel BJ, Schaberg PG, Hawley GJ, Rayback SA, Pontius J, Kosiba AM, Miller EK. 2016. Assessing relationships between red spruce radial growth and pollution critical load exceedance values. Forest Ecology and Management 359: 83-91.

Eshleman KN, Sabo RD, Kline KM. 2013. Surface water quality is improving due to declining atmospheric N deposition. Environmental Science and Technology 47: 12193-12200.

Evans RD. 2001. Physiological mechanisms influencing plant nitrogen isotope composition. Trends in Plant Science 6: 121-126.

Evans RD. 2007. Soil nitrogen isotope composition. In: Stable isotopes in ecology and environmental science. 83-98.

Fang J, Kato T, Guo Z, Yang Y, Hu H, Shen H, Zhao X, Kishimoto-Mo AW, Tang Y, Houghton R. 2014. Evidence for environmentally enhanced forest growth. Proceedings of the National Academy of Sciences 111: 9527-9532.

Farquhar GD, Ehleringer JR, Hubick KT. 1989. Carbon Isotope Discrimination and Photosynthesis. Annual Review of Plant Physiology and Plant Molecular Biology 40: 503537.

Farquhar G, O’Leary M, Berry J. 1982. On the relationship between carbon isotope discrimination and the intercellular carbon dioxide concentration in leaves. Australian Journal of Plant Physiology 9: 121-137.

Farquhar GD, Sharkey TD. 1982. Stomatal Conductance and Photosynthesis. Annual Review of Plant Physiology 33: 317-345.

Felix JD, Elliott EM, Shaw SL. 2012. Nitrogen Isotopic Composition of Coal-Fired Power Plant NOx : Influence of Emission Controls and Implications for Global Emission Inventories. Environmental Science \& Technology 46: 3528-3535.

Fernández-Martínez M, Vicca S, Janssens IA, Ciais P, Obersteiner M, Bartrons M, Sardans J, Verger A, Canadell JG, Chevallier F, et al. 2017. Atmospheric deposition, $\mathrm{CO}_{2}$, and change in the land carbon sink. Scientific Reports 7: 9632.

Francey RJ, Allison CE, Etheridge DM, Trudinger CM, Enting IG, Leuenberger M, Langenfelds RL, Michel E, Steele LP. 1999. A 1000-year high precision record of $\delta^{13} \mathrm{C}$ in atmospheric $\mathrm{CO}_{2}$. Tellus B 51: 170-193.

Franks PJ, Adams MA, Amthor JS, Barbour MM, Berry JA, Ellsworth DS, Farquhar GD, Ghannoum O, Lloyd J, McDowell N, et al. 2013. Sensitivity of plants to changing atmospheric $\mathrm{CO}_{2}$ concentration: from the geological past to the next century. New Phytologist 197: 1077-1094. 
Friedlingstein P, Cox P, Betts R, Bopp L, von Bloh W, Brovkin V, Cadule P, Doney S, Eby M, Fung I, et al. 2006. Climate-Carbon Cycle Feedback Analysis: Results from the C4 MIP Model Intercomparison. Journal of Climate 19: 3337-3353.

Gerhart LM, McLauchlan KK. 2014. Reconstructing terrestrial nutrient cycling using stable nitrogen isotopes in wood. Biogeochemistry 120: 1-21.

Granda E, Rossatto DR, Camarero JJ, Voltas J, Valladares F. 2014. Growth and carbon isotopes of Mediterranean trees reveal contrasting responses to increased carbon dioxide and drought. Oecologia 174: 307-317.

Greaver TL, Sullivan TJ, Herrick JD, Barber MC, Baron JS, Cosby BJ, Deerhake ME, Dennis RL, Dubois J-JB, Goodale CL, et al. 2012. Ecological effects of nitrogen and sulfur air pollution in the US: what do we know? Frontiers in Ecology and the Environment 10: 365372.

Gurmesa GA, Lu X, Gundersen P, Fang Y, Mao Q, Hao C, Mo J. 2017. Nitrogen input 15N signatures are reflected in plant $15 \mathrm{~N}$ natural abundances in subtropical forests in China. Biogeosciences 14: 2359-2370.

Hamburg SP, Cogbill C V. 1988. Historical decline of red spruce populations and climatic warming. Nature 331: 428-431.

Hietz P, Dünisch O, Wanek W. 2010. Long-Term Trends in Nitrogen Isotope Composition and Nitrogen Concentration in Brazilian Rainforest Trees Suggest Changes in Nitrogen Cycle. Environmental Science \& Technology 44: 1191-1196.

Hobbie EA, Högberg P. 2012. Nitrogen isotopes link mycorrhizal fungi and plants to nitrogen dynamics. New Phytologist 196: 367-382.

Homer CG, Dewitz JA, Yang L, Jin S, Danielson P, Xian G, Coulston J, Herold ND, Wickham JD, Megown K. 2015. Completion of the 2011 National Land Cover Database for the conterminous United States-Representing a decade of land cover change information. Photogrammetric Engineering and Remote Sensing 81: 345-354.

Hyvönen R, Ågren GI, Linder S, Persson T, Cotrufo MF, Ekblad A, Freeman M, Grelle A, Janssens I a, Jarvis PG, et al. 2007. The likely impact of elevated $\left[\mathrm{CO}_{2}\right]$, nitrogen deposition, increased temperature and management on carbon sequestration in temperate and boreal forest ecosystems: a literature review. New Phytologist 173: 463-480.

Jennings KA, Guerrieri R, Vadeboncoeur MA, Asbjornsen H. 2016. Response of Quercus velutina growth and water use efficiency to climate variability and nitrogen fertilization in a temperate deciduous forest in the northeastern USA. Tree Physiology 36: 428-443.

Johnson SE, Abrams MD. 2009. Age class, longevity and growth rate relationships: protracted growth increases in old trees in the eastern United States. Tree Physiology 29: 1317-1328. 
Johnson AH, Cook ER, Siccama TG. 1988. Climate and red spruce growth and decline in the northern Appalachians. Proceedings of the National Academy of Sciences 85: 5369-5373.

Johnson AH, Siccama TG. 1983. Acid deposition and forest decline. Environmental Science and Technology 17: A294-A305.

Joos F, Prentice IC, House JI. 2002. Growth enhancement due to global atmospheric change as predicted by terrestrial ecosystem models: consistent with US forest inventory data. Global Change Biology 8: 299-303.

Keeling RF, Piper SC, Bollenbacher AF, Walker SJ. 2010. Monthly atmospheric ${ }^{13} \mathrm{C} /{ }^{12} \mathrm{C}$ isotopic ratios for 11 SIO stations. Trends: A Compendium of Data on Global Change (Carbon Dioxide Information Analysis Center, Oak Ridge National Laboratory, US Department of Energy, Oak Ridge, TN).

Keeling RF, Piper SC, Bollenbacher AF, Walker SJ. 2015. Scripps CO2 Program. Scripps Institution of Oceanography, University of California - San Diego, USA 92093-0244.

Keenan TF, Hollinger DY, Bohrer G, Dragoni D, Munger JW, Schmid HP, Richardson AD. 2013. Increase in forest water-use efficiency as atmospheric carbon dioxide concentrations rise. Nature 499: 324-327.

Kellndorfer J, Walker W, Kirsch K, Fiske G, Bishop J, LaPoint L, Hoppus M, Westfall J. 2012. NACP Aboveground Biomass and Carbon Baseline Data (NBCD 2000).

Knauer J, Zaehle S, Reichstein M, Medlyn BE, Forkel M, Hagemann S, Werner C. 2016. The response of ecosystem water-use efficiency to rising atmospheric $\mathrm{CO}_{2}$ concentrations: sensitivity and large-scale biogeochemical implications. New Phytologist: n/a-n/a.

Kwak J-H, Lim S-S, Chang SX, Lee K-H, Choi W-J. 2011. Potential use of $\delta^{13} \mathrm{C}, \delta^{15} \mathrm{~N}, \mathrm{~N}$ concentration, and $\mathrm{Ca} / \mathrm{Al}$ of Pinus densiflora tree rings in estimating historical precipitation pH. Journal of Soils and Sediments 11: 709-721.

Kwak J-H, Lim S-S, Lee K-S, Viet HD, Matsushima M, Lee K-H, Jung K, Kim H-Y, Lee S-M, Chang SX, et al. 2016. Temperature and air pollution affected tree ring $\delta 13 \mathrm{C}$ and water-use efficiency of pine and oak trees under rising $\mathrm{CO}_{2}$ in a humid temperate forest. Chemical Geology 420: 127-138.

Lawrence GB, Hazlett PW, Fernandez IJ, Ouimet R, Bailey SW, Shortle WC, Smith KT, Antidormi MR. 2015. Declining Acidic Deposition Begins Reversal of Forest-Soil Acidification in the Northeastern U.S. and Eastern Canada. Environmental Science and Technology 49: 13103-13111.

Leavitt SW, Long A. 1982. Evidence for ${ }^{13} \mathrm{C} /{ }^{12} \mathrm{C}$ fractionation between tree leaves and wood. Nature 298: 742-744. 
Lefohn AS, Husar JD, Husar RB. 1999. Estimating historical anthropogenic global sulfur emission patterns for the period 1850-1990. Atmospheric Environment 33: 3435-3444.

Leonelli G, Battipaglia G, Siegwolf RTW, Saurer M, Morra di Cella U, Cherubini P, Pelfini M. 2012. Climatic isotope signals in tree rings masked by air pollution: A case study conducted along the Mont Blanc Tunnel access road (Western Alps, Italy). Atmospheric Environment 61: 169-179.

Levesque M, Andreu-Hayles L, Pederson N. 2017. Water availability drives gas exchange and growth of trees in northeastern US, not elevated $\mathrm{CO}_{2}$ and reduced acid deposition. Scientific Reports 7: 46158.

Lévesque M, Siegwolf R, Saurer M, Eilmann B, Rigling A. 2014. Increased water-use efficiency does not lead to enhanced tree growth under xeric and mesic conditions. New Phytologist 203: 94-109.

Li L, Yu Z, Bebout GE, Stretton T, Allen A, Passaris P. 2010. Tree-ring width and $\delta^{13} \mathrm{C}$ records of industrial stress and recovery in Pennsylvania and New Jersey forests: Implications for $\mathrm{CO}_{2}$ uptake by temperate forests. Chemical Geology 273: 250-257.

Likens GE, Driscoll CT, Buso DC. 1996. Long-Term Effects of Acid Rain: Response and Recovery of a Forest Ecosystem. Science 272: 244-246.

Liu S, Bond-Lamberty B, Hicke JA, Vargas R, Zhao S, Chen J, Edburg SL, Hu Y, Liu J, McGuire AD, et al. 2011. Simulating the impacts of disturbances on forest carbon cycling in North America: Processes, data, models, and challenges. Journal of Geophysical Research 116: G00K08.

Long SP, Ainsworth EA, Rogers A, Ort DR. 2004. Rising atmospheric carbon dioxide: plants FACE the future*. Annual Review of Plant Biology 55: 591-628.

Luo Y, Reynolds JF. 1999. Validity of extrapolating field $\mathrm{CO}_{2}$ experiments to predict carbon sequestration in natural ecosystems. Ecology 80: 1568-1583.

Luo Y, Su B, Currie WS, Dukes JS, Finzi A, Hartwig U, Hungate B, McMurtrie RE, Oren R, Parton WJ, et al. 2004. Progressive Nitrogen Limitation of Ecosystem Responses to Rising Atmospheric Carbon Dioxide. BioScience 54: 731.

McCarroll D, Loader NJ. 2004. Stable isotopes in tree rings. Quaternary Science Reviews 23: 771-801.

Mcdowell NG, Bond BJ, Dickman LT, Ryan MG. 2011. Size- and Age-Related Changes in Tree Structure and Function. 
McLauchlan KK, Gerhart LM, Battles JJ, Craine JM, Elmore AJ, Higuera PE, Mack MC, McNeil BE, Nelson DM, Pederson N, et al. 2017. Centennial-scale reductions in nitrogen availability in temperate forests of the United States. Scientific Reports 7: 7856.

McMahon SM, Parker GG, Miller DR. 2010. Evidence for a recent increase in forest growth. Proceedings of the National Academy of Sciences 107: 3611-3615.

Muggeo VMR. 2008. segmented: an R Package to Fit Regression Models with Broken-Line Relationships. : 20-25.

Nadelhoffer K, Fry B. 1994. Nitrogen isotope studies in forest ecosystems. In: Stable isotopes in ecology and environmental science. 23-44.

National Atmospheric Deposition Program. 2015. NTN Data Access.

NOAA National Centers for Environmental Information, West Virginia climate region 4 meteorological data 1895-2016. 2017.

Norby RJ, DeLucia EH, Gielen B, Calfapietra C, Giardina CP, King JS, Ledford J, McCarthy $\mathrm{HR}$, Moore DJP, Ceulemans R, et al. 2005. Forest response to elevated $\mathrm{CO}_{2}$ is conserved across a broad range of productivity. Proceedings of the National Academy of Sciences 102: 18052-18056.

Pan Y, Birdsey R a, Fang J, Houghton R, Kauppi PE, Kurz W a, Phillips OL, Shvidenko A, Lewis SL, Canadell JG, et al. 2011. A Large and Persistent Carbon Sink in the World's Forests. Science 333: 988-993.

Pardo LH, Hemond HF, Montoya JP, Fahey TJ, Siccama TG. 2002. Response of the natural abundance of $15 \mathrm{~N}$ in forest soils and foliage to high nitrate loss following clear-cutting. Canadian Journal of Forest Research 32: 1126-1136.

Peñuelas J, Canadell JG, Ogaya R. 2011. Increased water-use efficiency during the 20th century did not translate into enhanced tree growth. Global Ecology and Biogeography 20: 597-608.

Piao S, Friedlingstein P, Ciais P, Viovy N, Demarty J. 2007. Growing season extension and its impact on terrestrial carbon cycle in the Northern Hemisphere over the past 2 decades. Global Biogeochemical Cycles 21: 1-11.

Pinheiro J, Bates D, DebRoy S, Sarkar D, Team RC. 2018. nlme: Linear and Nonlinear Mixed Effects Models. R package version 3.1-131.1.

Le Quéré C, Andrew RM, Friedlingstein P, Sitch S, Pongratz J, Korsbakken, Glen P. Peters, Josep G. Canadell, Robert B. Jackson, Thomas A. Boden, Pieter P. Tans, Oliver D. Andrews, Vivek Arora, Dorothee C. E. Bakker, Leticia Barbero, Meike Becker, Richard A. Betts, Laurent Bopp, Frédéric Chevallier, Louise P. Chini, DZZ. 2017. The Global Carbon Budget 2017. Earth Syst. Sci. Data Discussions: 405-448 
Richardson AD, Hollinger DY, Dail DB, Lee JT, Munger JW, O'Keefe J. 2009. Influence of spring phenology on seasonal and annual carbon balance in two contrasting New England forests. Tree Physiology 29: 321-331.

Rinne KTT, Loader NJJ, Switsur VRR, Treydte KSS, Waterhouse JSS. 2010. Investigating the influence of sulphur dioxide $\left(\mathrm{SO}_{2}\right)$ on the stable isotope ratios $\left(\delta^{13} \mathrm{C}\right.$ and $\left.\delta^{18} \mathrm{O}\right)$ of tree rings. Geochimica et Cosmochimica Acta 74: 2327-2339.

Santruckova H, Santrucek J, Setlik J, Svoboda M, Kopacek J. 2007. Carbon isotopes in tree rings of Norway spruce exposed to atmospheric pollution RID E-6860-2010. Environmental science \& technology 41: 5778-5782.

Savard MM, Bégin C, Parent M, Smirnoff A, Marion J. 2004. Effects of Smelter Sulfur Dioxide Emissions. Journal of Environment Quality 33: 13.

Schimel D, Melillo J, Tian H, McGuire AD, Kicklighter D, Kittel T, Rosenbloom N, Running S, Thornton P, Ojima D, et al. 2000. Contribution of increasing $\mathrm{CO}_{2}$ and climate to carbon storage by ecosystems in the United States. Science 287: 2004-2006.

Seibt U, Rajabi A, Griffiths H, Berry JA. 2008. Carbon isotopes and water use efficiency: sense and sensitivity. Oecologia 155: 441-454.

Siccama TG, Bliss M, Vogelmann HW. 1982. Decline of Red Spruce in the Green Mountains of Vermont. Bulletin of the Torrey Botanical Club 109: 162-168.

Siccama TG, Hamburg SP, Arthur MA, Yanai RD, Bormann FH, Likens GE. 1994. Corrections to Allometric Equations and Plant Tissue Chemistry for Hubbard Brook Experimental Forest. Ecology 75: 246-248.

Silva LCR, Anand M, Leithead MD. 2010. Recent Widespread Tree Growth Decline Despite Increasing Atmospheric $\mathrm{CO}_{2}$ (TN Romanuk, Ed.). PLoS ONE 5: e11543.

Smith KR, Mathias JM, McNeil BE, Peterjohn WT, Thomas RB. 2016. Site-level importance of broadleaf deciduous trees outweighs the legacy of high nitrogen $(\mathrm{N})$ deposition on ecosystem N status of Central Appalachian red spruce forests. Plant and Soil.

Soil Survey Geographic (SSURGO) Database for Pocahontas and Randolph Counties, WV.

Sokal RR, Rohlf FJ. 2011. Biometry. W. H. Freeman.

Spiess A-N. 2017. propagate: Propagation of Uncertainty. R package version 1.0-5.

Stokes MA, Smiley TL. 1996. An Introduction to Tree-Ring Dating. Tuscon, AZ: University of Arizona Press. 
Thomas RQ, Canham CD, Weathers KC, Goodale CL. 2010. Increased tree carbon storage in response to nitrogen deposition in the US. Nature Geoscience 3: 13-17.

Thomas RB, Spal SE, Smith KR, Nippert JB. 2013. Evidence of recovery of Juniperus virginiana trees from sulfur pollution after the Clean Air Act. Proceedings of the National Academy of Sciences 110: 15319-15324.

U.S. Environmental Protection Agency, Air Emissions Inventory, Air Pollution Emissions Trends Data. 2015.

University OS. 2004. PRISM Climate Group.

US Geological Survey (1946) Physiographic divisions of the conterminous U.S.

West Virginia Geological Economic Survey, Surface Geology - Rock Units. Online Digitized Map. In: T.U. West Virginia DEP (Ed.), William and Heintz Corporation. 1968.

Whittaker RH, Bormann FH, Likens GE, Siccama TG. 1974. The Hubbard Brook Ecosystem Study: Forest Biomass and Production. Ecological Monographs 44: 233-254.

Wigley TML, Briffa KR, Jones PD. 1984. On the Average Value of Correlated Time Series, with Applications in Dendroclimatology and Hydrometeorology. Journal of Climate and Applied Meteorology 23: 201-213.

Zang C, Biondi F. 2015. treeclim : an R package for the numerical calibration of proxy-climate relationships. : 431-436.

Zeng X, Liu X, Xu G, Wang W, An W. 2014. Tree-ring growth recovers, but $\delta^{13} \mathrm{C}$ and $\delta^{15} \mathrm{~N}$ do not change, after the removal of point-source air pollution: a case study for poplar (Populus cathayana) in northwestern China. Environmental Earth Sciences 72: 2173-2182. 
Chapter 4. Air pollution and climate change interact to influence the growth and water use efficiency of Quercus rubra and Liriodendron tulipifera in the Central Appalachian

Mountains.

In revision at Global Change Biology: Mathias, J.M. and R.B. Thomas. 2020. Air pollution and climate change interact to influence the growth and water use efficiency of Quercus rubra and Liriodendron tulipifera in the Central Appalachian Mountains. 


\subsection{Abstract.}

Many environmental factors, including climate change, increasing atmospheric $\mathrm{CO}_{2}$, and reductions in acidic air pollution, may alter the balance between forest carbon uptake and water loss and will likely have cascading effects on forest ecosystem function. Here, we identify the individual effects of changing environmental factors, and their interactions, on the long-term growth and physiology of two broadleaf deciduous tree species growing in the Central Appalachian Mountains. We collected 84 increment cores from Quercus rubra $(\mathrm{N}=41)$ and Liriodendron tulipifera $(\mathrm{N}=43)$ from two adjacent study locations in the Fernow Experimental Forest, Parsons, WV, USA, from which we developed chronologies of basal area increment (BAI) and intrinsic water use efficiency (iWUE). Sustained increases in BAI of both mature tree species since 1960 were largely driven by reduced acidic sulfur pollution and increasing summer precipitation, while declining acidic nitrogen pollution negatively impacted tree BAI. Increasing atmospheric $\mathrm{CO}_{2}$ largely contributed to increasing iWUE but increases in iWUE were attenuated by acidic nitrogen pollution. Interactive effects between environmental factors reveal that responses to environmental drivers of growth and physiology are complex and do not operate in isolation. Our results underscore the importance of considering the interactive effects of air pollution and climate change and on tree growth and physiology over multi-decadal time scales, and this study highlights the need to include acidic air pollution and acid deposition in Earth System Models. 


\subsection{Introduction.}

Forest ecosystems represent $97 \%$ of the land carbon sink in the conterminous United States, currently sequestering $16 \%$ of national carbon emissions from fossil fuels into trees and soil (Woodbury et al., 2007; Lu et al., 2015). Forests also play a central role in the hydrologic cycle by regulating large fluxes of water through transpiration (Schlesinger \& Jasechko, 2014). Thus, environmental influences over leaf physiology of trees have cascading effects over ecosystem function. Yet, predicting responses to environmental change has been difficult due to the complex, and sometimes counteracting nature of environmental drivers on forest productivity (Fernández-Martínez et al., 2017, 2019; Mathias \& Thomas, 2018). Improving our predictions of forest dynamics in the face of environmental change requires the ability to disentangle the influence of the many factors that affect driving tree growth and physiology.

Invaluable work has documented forest responses to elevated atmospheric $\mathrm{CO}_{2}\left(\mathrm{eCO}_{2}\right)$. Generally, $\mathrm{eCO}_{2}$ results in increased photosynthesis and reduced stomatal conductance (Ainsworth \& Rogers, 2007) that translates to greater productivity (Norby et al., 2005; Fernández-Martínez et al., 2019; Walker et al., 2019) and increased water use efficiency, the ratio of carbon fixed to the amount of water transpired, at the leaf and ecosystem level (Peñuelas et al., 2011; Knauer et al., 2016; Guerrieri et al., 2019). Importantly, environmental factors such as temperature (Way \& Oren, 2010; Wu et al., 2011), precipitation (Beer et al., 2010; Wu et al., 2011), and nitrogen availability (Thomas et al., 2010; Horn et al., 2018) impact these processes and may modify the response to $\mathrm{eCO}_{2}$ (Fernández-Martínez et al., 2019). Often overlooked, however, acidic air pollution and ozone can exert additional controls over leaf physiology, reducing photosynthetic rates (Choi et al., 2014; Lombardozzi et al., 2015) and stomatal conductance (Borer et al., 2005), negatively impacting tree growth (Horn et al., 2018), and offsetting positive effects of $\mathrm{eCO}_{2}$ on productivity (Fernández-Martínez et al., 2017; Mathias \& Thomas, 2018).

Dendroecology has gained substantial traction as an approach to examine the multidecadal response of forest stands to the myriad of changing environmental factors, including in locations experiencing high acid pollutant loads (Boettger, Haupt, Friedrich, \& Waterhouse, 2014; Engel et al., 2016; Kosiba, Schaberg, Rayback, \& Hawley, 2018; Mathias \& Thomas, 2018; Savard, Bégin, \& Marion, 2014; Thomas et al. 2013). For example, tree ring width and stable carbon isotope chronologies provide annual resolution to estimate plot-level biomass (Dye 
et al., 2016) and track ecosystem productivity across large spatial scales (Babst et al., 2014; Belmecheri et al., 2014; Levesque et al., 2019). Furthermore, carbon isotope signatures $\left(\delta^{13} \mathrm{C}\right)$ are directly related to leaf physiological properties during carbon fixation (Farquhar, O'Leary, \& Berry, 1982) and can be used to model reconstructed leaf photosynthesis, stomatal conductance, and intrinsic water use efficiency over time (Battipaglia et al., 2013; Lavergne et al., 2019; Mathias \& Thomas, 2018; Thomas et al., 2013). As such, dendroecology provides an important lens to examine the growth and physiological responses of trees to environmental change over multi-decadal to centurial timescales.

The northeastern United States is one of the most productive, heavily forested areas of the U.S. (Pan et al., 2013). Importantly, this region of the U.S. has experienced significant climate change over the past century as both temperature and precipitation have changed (PRISM Climate Group, 2004). It has also experienced some of the highest levels of acidic air pollution since the rise of industrialization (Driscoll et al., 2001). Dendroecological studies have pointed to the recovery of evergreen conifers following reductions in pollutant emissions after adoption of the Clean Air Act of 1970 as a primary driver of recent tree growth in this region (Kosiba et al., 2018; Mathias \& Thomas, 2018; Thomas et al., 2013). However, the extent to which reductions in acid pollutants affect the growth and physiology of broadleaf deciduous trees is not as clear (Sullivan et al., 2013; Bishop et al., 2015; Levesque et al., 2017).

In this study, we tease apart the combined effects of changing atmospheric $\mathrm{CO}_{2}$, temperature, precipitation, and sulfur (S) and nitrogen $(\mathrm{N})$ acid deposition on the long-term growth and intrinsic water use efficiency (iWUE) of two of the most ecologically important broadleaf tree species in the eastern U.S., northern red oak (Quercus rubra) and tulip poplar (Liriodendron tulipifera). We focus our analysis on 110-year old forest stands located in two small, adjacent watersheds in the Central Appalachian Mountains. These watersheds are downwind from a large number of coal-fired power plants along the Ohio River basin and have experienced moderate changes in climate over the last century. Consistent with experimental observations, one may hypothesize $\mathrm{eCO}_{2}$ will stimulate tree growth and iWUE (Peñuelas et al., 2011; Walker et al., 2019). Alternatively, climate may be a more important driver of tree growth and physiology, as has been shown in the northeastern U.S. (Levesque et al., 2017). Lastly, given the proximity to coal-fired power plants in the Ohio River basin, high acid pollutant loads may moderate, and potentially overwhelm, any positive effects from $\mathrm{eCO}_{2}$ or changing climate as has 
been seen in conifers in this region (Mathias \& Thomas, 2018; Thomas et al., 2013), as well as for other tree species globally (Fernández-Martínez et al., 2017). In this study, we use linear mixed effects models to determine which environmental factors, and their interactive effects, are the most important drivers of the growth and physiology of northern red oak and tulip poplar in the Central Appalachian Mountains since the mid-20 $0^{\text {th }}$ century. 


\subsection{Methods.}

Site descriptions and increment core collection and processing

Two broadleaf deciduous forest stands in the Fernow Experimental Forest, Parsons, WV were selected for this study. Both Watershed 10 (WS10; 39.0566 $\left.{ }^{\circ} \mathrm{N},-79.6789^{\circ} \mathrm{W}\right)$ and Watershed 13 (WS13; $39.0617^{\circ} \mathrm{N},-79.6805^{\circ} \mathrm{W}$ ) are located within the Appalachian Plateau physiographic province (USGS 1946) and are considered reference watersheds for the Fernow; they have remained free from disturbance since the early 1900s. Both watersheds contain the study species northern red oak (hereafter Quru) and tulip poplar (hereafter Litu) as canopy tree species. In addition to the two study species, American beech (Fagus grandifolia), red maple (Acer rubrum), and sugar maple (Acer saccharum) are found between the two locations. Mean elevation of WS10 and WS13 is $\sim 725$ and $\sim 694$ meters above sea level, respectively. The topography at WS10 and WS13 is relatively steep, with 26\% and 25\% slopes, respectively, and while WS10 has a southerly aspect, WS13 has a northerly aspect. Soils at WS10 and WS13 consist of a relatively thin organic layer with litter primarily contributed from the genera Quercus and Liriodendron, as well as Acer and Fagus. Soils at the study locations are classified as Calvin channery silt loam derived from acidic sandstone and shale, being well-drained, and moderately deep (USDA Soil Survey Geographic (SSURGO), 2015). During the study period $\left(1960\right.$ - 2015), mean annual temperature (MAT) at WS10 and WS13 was $9.0^{\circ} \mathrm{C}$ and $9.2^{\circ} \mathrm{C}$, respectively, ranged on average from $2.6^{\circ} \mathrm{C}$ to $20^{\circ} \mathrm{C}$ across the year, and increased by $0.75^{\circ} \mathrm{C}$ at both watersheds. Mean annual precipitation (MAP) at WS10 and WS13 was $1314 \mathrm{~mm}$ and 1310 $\mathrm{mm}$, respectively, with the majority of precipitation occurring in July $(10.2 \pm 0.2 \%$ of total annual precipitation) and the least amount of precipitation occurring in October $(6.8 \pm 0.2 \%$ of total annual precipitation) (PRISM Climate Group, 2004). Mean annual precipitation increased during the study period and was driven largely by precipitation during June and July $(+0.75 \mathrm{~mm}$ $\mathrm{yr}^{-1}$ ) (PRISM Climate Group, 2004).

During the 2016 growing season, $\geq 20$ trees of each species larger than $10 \mathrm{~cm}$ diameter at breast height (1.4 $\mathrm{m}$ aboveground) and older than $\sim 80$ years were cored at each study location using a $5.15 \mathrm{~mm}$ increment borer (Haglöf Inc., Madison, MS). Cores were taken perpendicular to the slope to avoid compression and expansion wood. Following collection, increment cores were returned to the lab where they were air dried and processed according to standard dendrochronological techniques (Stokes \& Smiley, 1996). Increment cores were scanned at 1000 
dpi to create a digital image, after which each growth ring was measured to the nearest $0.001 \mathrm{~mm}$ and assigned at the boundary between earlywood and latewood using WinDENDRO (Regent Instruments, Inc.). Following identification of individual growth rings, chronologies for each respective species within a given watershed were separately crossdated and statistically confirmed using dplR (Bunn et al., 2015), after which a calendar year was assigned to each growth ring. Across both watersheds, the average age of the Quru trees included in this study was $92 \pm 16$ years $(\mathrm{N}=41$, mean $\pm \mathrm{SD})$, while the average age of Litu trees was $100 \pm 21$ years $(\mathrm{N}=43$, mean $\pm \mathrm{SD})$. Across both watersheds, Quru trees ranged from 68 to 154 years in age, while Litu trees ranged from 56 to 154 . The 40 years of juvenile growth preceding 1960 were excluded from our analyses of the influence of environmental factors on the growth and physiology of Quru and Litu. The expressed population signal (EPS), a measure of how well the sampled trees reflect a chronology developed from an infinite population $(\geq 0.85$ is often considered a lower threshold) (Wigley et al., 1984), was 0.91 for Quru and 0.83 for Litu across the two watersheds for the period 1960 - 2015, respectively, with site and species specific EPS values found in Figure 4.1. Chronologies of measured ring widths were converted to basal area increment (BAI), a metric of tree growth that allows for the detection of trends in growth (Peters et al. 2015), using

$$
B A I=\pi *\left(R_{n}^{2}-R_{n-1}^{2}\right)
$$

where $R$ is the radius of the tree at year, $n$. If a missing ring was identified, its value was estimated using the average ring width for its respective year, so as not to influence subsequent calculations of BAI. Individual tree chronologies of BAI were then averaged across all trees $(\mathrm{N} \geq$ 20) for both species within each site.

\section{Carbon isotope analysis of tree rings}

Preparation of samples for $\mathrm{C}$ isotope analysis followed methods from Mathias and Thomas (2018). Within each site, a subset of 5 increment cores were randomly selected from both species for analysis of tree ring $\mathrm{C}$ isotope signatures across the mature phase of the chronology (1960 - 2015). Increment cores were dissected under a stereo zoom microscope into individual growth rings at the boundary of earlywood and latewood, ground to a fine powder, and $1.0 \pm 0.2 \mathrm{mg}$ of ground whole wood from each tree ring was packed into tin capsules (CE Elantech, Lakewood, NJ) for isotope analysis. 
Carbon isotope composition of each tree ring was analyzed using a ThermoFisher Delta $\mathrm{V}+$ isotope ratio mass spectrometer (ThermoFisher, Waltham, MA) interfaced with a Carlo Erba NC 2500 Elemental Analyzer (Carlo Erba, Milan, Italy) at the University of Maryland Center for Environmental Science (UMCES) Appalachian Lab. Tree ring stable C isotope composition was reported in standard delta notation $\delta^{13} \mathrm{C}(\%)$ using

$$
\delta^{13} \mathrm{C}(\% \mathrm{o})=\left(\mathrm{R}_{\text {sample }} / \mathrm{R}_{\text {standard }}-1\right) * 1000,
$$

where $R_{\text {sample }}$ is the ratio of ${ }^{13} \mathrm{C}:{ }^{12} \mathrm{C}$ in the wood sample and $\mathrm{R}_{\text {standard }}$ is the ratio of ${ }^{13} \mathrm{C}:{ }^{12} \mathrm{C}$ in the standard PeeDee belemnite (PDB) from the PeeDee River Formation in Hemingway, South Carolina. To account for the fractionation associated with the conversion of leaf carbohydrate to wood (Leavitt \& Long, 1982; Mathias \& Thomas, 2018; Thomas et al., 2013), wood isotope signatures were corrected using fractionation factors specific to each species (Table S1; Quru: $0.21 \%$, Litu: $-0.62 \%$ ). The resulting leaf-corrected $\mathrm{C}$ isotope signatures $\left(\delta^{13} \mathrm{C}_{\text {leaf }}\right)$ were then converted to leaf $\mathrm{C}$ isotope discrimination $\left(\Delta^{13} \mathrm{C}\right)$ to account for the continuous depletion of atmospheric $\delta^{13} \mathrm{CO}_{2}$ across the chronology due to the burning of isotopically-light fossil fuels using

$$
\Delta^{13} C=\left(\frac{\delta^{13} C_{\text {air }}-\delta^{13} C_{\text {leaf }}}{1+\frac{\delta^{13} C_{\text {leaf }}}{1000}}\right),
$$

where $\delta^{13} \mathrm{C}_{\text {air }}$ is the $\delta^{13} \mathrm{C}$ signature of atmospheric $\mathrm{CO}_{2}$ during the period of tissue formation (Farquhar et al., 1982). Records of $\delta^{13} \mathrm{C}_{\text {air }}$ for the period $1960-2004$ used in the calculation of $\Delta \Delta^{13} \mathrm{C}$ were obtained from Francey et. al (1999) and (McCarroll \& Loader, 2004), with $\delta^{13} \mathrm{C}_{\text {air }}$ for years $2005-2015$ calculated from the average change each year (-0.0199\%) during $1960-$ 2004 (Keeling et al., 2010). We assumed no changes in leaf structure or mesophyll conductance over the study period (Seibt et al., 2008).

Chronologies of leaf internal $\mathrm{CO}_{2}$ concentration $\left(c_{i}\right)$ were calculated from $\Delta^{13} \mathrm{C}$ using

$$
c_{i}=\frac{\Delta^{13} C-a}{b-a} * c_{a},
$$

where $c_{a}$ is the atmospheric $\mathrm{CO}_{2}$ concentration (ppm), $a$ is the fractionation factor (4.4\%) associated with the diffusion of $\mathrm{CO}_{2}$ through the stomata, and $b$ is the fractionation factor (27\%) associated with the preferential utilization of ${ }^{12} \mathrm{CO}_{2}$ over ${ }^{13} \mathrm{CO}_{2}$ by Rubisco during carbon fixation (Farquhar et al., 1982). Values for $c_{a}$ used in the calculation of $c_{i}$ were obtained from the Scripps $\mathrm{CO}_{2}$ Program (Keeling et al., 2015). Intrinsic water use efficiency, the ratio of net 
photosynthesis (A) to stomatal conductance to water $\left(\mathrm{g}_{\mathrm{s}}\right)$, was calculated according to Farquhar et al. (1989) using

$$
i W U E=\frac{A}{g_{s}}=\left(c_{a}-c_{i}\right) * 0.625
$$

where 0.625 is ratio of the diffusivity of $\mathrm{CO}_{2}$ to $\mathrm{H}_{2} \mathrm{O}$ (Farquhar et al., 1989).

Statistical analyses

To explore the relationship between climate variables and tree growth from 1960 - 2015, we first performed bootstrapped Pearson's correlations using the package "treeclim" in R (Bunn et al., 2015). Climate variables examined in this analysis include precipitation, as well as monthly mean, maximum, and minimum temperature spanning May of the year prior to ring formation through August of the year of ring formation (PRISM Climate Group, 2004). In addition to the relationship between single monthly climate variables and tree growth, we also examined climate variables integrated over a range of time, using sums for precipitation and means for temperature (i.e. sum of May - September precipitation, or mean of May - September temperature). We accounted for temporal autocorrelation in these analyses.

Kendall's rank correlation, a nonparametric correlation analysis, was used to examine the nature, and strength of the relationships between single environmental factors, including climate, and each response variable, BAI and iWUE during the 1960 - 2015 period for each species as it does non make a priori assumptions of the distribution of each factor. Non-climatic environmental parameters examined in these analyses include atmospheric $\mathrm{CO}_{2}$ concentration (Keeling et al., 2016), U.S. national emissions of $\mathrm{SO}_{2}$ (Lefohn et al., 1999; EPA, 2015), and U.S. national emissions of $\mathrm{NO}_{\mathrm{x}}(\mathrm{EPA}, 2015)$. We also considered the effects of sulfate $\left(\mathbf{S O}_{\mathbf{4}}^{2-}\right)$ and nitrate $\left(\mathbf{N O}_{3}^{-}\right)$deposition (NADP, 2015) on the growth and physiology of Quru and Litu; however, given the short history of deposition monitoring in this region (unavailable for $>30 \%$ of the mature chronology), the high correlation between emissions and deposition at our study locations (Figure S4.1), and the nature of the relationship between emissions and deposition (deposition largely being a product of emissions), we chose to examine the relationship between $\mathrm{SO}_{2}$ and $\mathrm{NO}_{\mathrm{x}}$ emissions and each response variable (Mathias \& Thomas, 2018). Climate variables examined in these analyses include monthly, growing season, and annual precipitation and temperature (PRISM Climate Group, 2004), as well as other meaningful combinations (i.e. sum of June and July precipitation) informed by the bootstrapped Pearson's correlations.

To identify temporal trends in BAI and iWUE across both study locations, we 
constructed linear mixed effects (LME) models using the package "nlme" in R with 'Year' as the sole fixed effect, and 'Site' as the random effect for each response variable, accounting for temporal autocorrelation with an $\mathrm{AR}(1,0)$ model structure (Pinheiro et al., 2018). To identify temporal trends of each response variable specific to each site and species (i.e. WS10 Quru BAI), we used generalized least squares (GLS) regression using the package "nlme", again with 'Year' as the sole fixed effect, and an $\operatorname{AR}(1,0)$ autocorrelation structure (Pinheiro et al., 2018). We used ANCOVA to determine if the change in each response variable over time was dependent on study location or species. Further, we used ANOVA to test whether mean BAI or iWUE was different between WS10 and WS13 within a given species, or between species within a given study location.

Model averaging of linear mixed effects (LME) models was used to quantitatively assess the temporal contributions of multiple environmental factors and their potential interactions on BAI and iWUE for both Quru and Litu using the packages "nlme" (Pinheiro et al., 2018) and "MuMIn” (Bartoń, 2017) in R (Fernández-Martínez et al., 2017; Mathias \& Thomas, 2018). We first developed a global model of the environmental factors of interest based on the a priori assumption of their physiological importance to BAI and iWUE, in addition to the results of bootstrapped Pearson's correlations and Kendall's rank correlation, including all potential interactions up to order two. For these analyses, the final environmental factors examined include atmospheric $\mathrm{CO}_{2}$, U.S. national emissions of $\mathrm{SO}_{2}$, U.S. national emissions of $\mathrm{NO}_{x}$, average minimum May - September temperature, and the total combined June-July precipitation of the current year (except for Litu BAI, in which case the previous year's total combined JuneJuly precipitation was used; see Supplemental Information). We also examined the contribution of additional environmental factors; however, those factors ultimately included in the model consistently captured the greatest variation in either BAI or iWUE, while minimizing unexplained variance from biotic or abiotic factors, thereby reducing the "Unknown" component in the model. From the global model, we explored all possible model combinations $(1,450$ models for each response variable) fit via maximum likelihood to allow comparison among LME models with different fixed factors, with site as a random effect, and an $\mathrm{AR}(1,0)$ temporal autocorrelation structure. All examined models were ranked by $\mathrm{AIC}_{\mathrm{c}}$, and those with a $\triangle \mathrm{AIC}_{\mathrm{c}}<$ 1 from the best model (Quru BAI: 2 models, Litu BAI: 2 models, Quru iWUE: 4 models, Litu iWUE: 2 models) were averaged resulting in a final average model (hereafter "final model") 
which was then used to assess the temporal contribution of environmental factors to BAI and iWUE (Fernández-Martínez et al., 2017; Mathias \& Thomas, 2018).

To determine the temporal contribution of each environmental factor to BAI and iWUE, we first predicted each response variable separately for Quru and Litu over the 1960 - 2015 time period using the final model. We then iteratively forced the final model to run, holding each respective environmental factor at its median value over the study period, while allowing all other factors change as observed. The temporal contribution of a given factor to BAI and iWUE for each species over the study period was then calculated as the difference between slope of the predicted values over time from the final model letting all environmental factors change as observed and the slope of the predicted values over time from the final model when holding a given environmental parameter constant (Fernández-Martínez et al., 2017; Mathias \& Thomas, 2018).

We used the R package 'visreg' to visualize the averaged LME model interactions among environmental factors and the response variables BAI and iWUE during the study period using the component model with parameter estimates nearest the average model (Breheny \& Burchett, 2017). Significance was assigned at the $\alpha=0.05$ level, and marginal significance at the $\alpha=0.1$ level. Throughout all analyses, propagation of uncertainty was carried out for addition and subtraction using

$$
\varepsilon C=\sqrt{(\varepsilon A)^{2}+(\varepsilon B)^{2}},
$$

while propagation of uncertainty for multiplication and division was calculated using

$$
\varepsilon \mathrm{C}=\mathrm{C} \sqrt{\left(\frac{\varepsilon A}{A}\right)^{2}+\left(\frac{\varepsilon B}{B}\right)^{2}},
$$

where the $\varepsilon$ is the propagated uncertainty from the quantities $A$ and $B$, to the calculated value, $C$ (Fernández-Martínez et al., 2017, 2019; Mathias \& Thomas, 2018). All analyses were performed using R version 3.5.0. (R Core Team, 2018). 


\subsection{Results.}

Changes in tree BAI and iWUE throughout the 55-year chronology

From 1960-2015, BAI of Quru trees in their mature growth phase in WS10 and WS13 in the Fernow Experimental Forest increased by $c a 0.32 \mathrm{~cm}^{2} \mathrm{yr}^{-1}$, while BAI of Litu trees in their mature growth phase increased by ca $0.33 \mathrm{~cm}^{2} \mathrm{yr}^{-1}$, resulting in a $65 \%$ increase in BAI for Quru and a $71 \%$ increase in BAI for Litu across the 55-year chronology (Figure 4.1). Growth rates were not different between species $(\mathrm{F}=1.70, p=0.19)$, nor were growth rates different between the two watersheds for Quru $(\mathrm{F}=1.23, p=0.26)$ or Litu $(\mathrm{F}=2.45, p=0.12)$.

From 1960-2015, leaf-corrected $\Delta^{13} \mathrm{C}$ of Quru trees averaged across both watersheds increased by $c a 0.020 \% \mathrm{yr}^{-2}(p=0.0001$; Figure $4.2 \mathrm{a})$, while leaf-corrected $\Delta^{13} \mathrm{C}$ of Litu trees increased by ca $0.011 \% \mathrm{yr}^{-2}(p=0.008$; Figure $4.2 \mathrm{~b})$, resulting in a $5.9 \%$ increase in leaf $\Delta^{13} \mathrm{C}$ for Quru and a 3.2\% increase in leaf $\Delta^{13} \mathrm{C}$ for Litu. This translated into $10.0 \%$ increase in iWUE for Quru trees ( $p=0.005$; Figure 4.2c) and a 19.6\% increase in iWUE for Litu trees ( $p=$ 0.0001; Figure 4.2d) across the 55-year chronology. Changes across the iWUE chronologies were not different between the two watersheds for Quru $(\mathrm{F}=0.125, p=0.72)$ or Litu $(\mathrm{F}=0.00, p$ $=0.99)$, but iWUE was $1.9 \%$ greater for Quru than in Litu averaged across watersheds $(\mathrm{F}=4.33$, $p=0.04)$.

Contribution of environmental factors to changes in BAI across the 55-year tree ring chronologies

Bootstrapped Pearson's correlations highlight the positive relationship between BAI of Quru and Litu with precipitation, with BAI of Quru being positively correlated to total combined June-July precipitation of the current year $(\mathrm{r}=0.18, p<0.05$; Figure S4.2a,c) and BAI of Litu being most positively related to total combined June-July precipitation of the previous year $(\mathrm{r}=$ $0.15, p<0.05$; Figure S4.2b,d). Additionally, BAI of Quru in WS10 was positively related to previous November precipitation $(\mathrm{r}=0.19, p<0.05)$, current year June precipitation $(\mathrm{r}=0.17, p$ $<0.05)$, and current year July precipitation $(\mathrm{r}=0.24, p<0.05)$, while BAI of Quru in WS13 was positively related to current year July precipitation $(\mathrm{r}=0.24, p<0.05)$ (Figure S4.2a,c). BAI of Litu in WS10 was positively related to previous year October minimum temperature $(\mathrm{r}=0.26, p$ $<0.05)$ and current year February temperature $(\mathrm{r}=0.25, p<0.05)$, while BAI of Litu in WS13 was positively related to previous year July precipitation $(\mathrm{r}=0.21, p<0.05)$ (Figure $\mathrm{S} 4.2 \mathrm{~b}, \mathrm{~d})$. 
Complete Kendall's rank correlation for BAI of Quru and Litu using data combined from WS10 and WS13 is listed in Table S4.2. This analysis revealed that BAI of Quru was most positively related to atmospheric $\mathrm{CO}_{2}(\tau=0.47, p<0.01)$, followed by minimum growing season temperature $(\tau=0.37, p<0.01)$, growing season precipitation $(\tau=0.26, p<0.01)$, and July precipitation $(\tau=0.24, p<0.05)$ (Figure S4.3, Table S4.2). Kendall's rank correlation revealed that BAI of Litu was most positively related to atmospheric $\mathrm{CO}_{2}(\tau=0.49, p<0.01)$, followed by minimum growing season temperature $(\tau=0.33, p<0.01)$ (Figure S4.3, Table S4.2). Kendall's rank correlation indicated a strong negative relationship between BAI and U.S. emissions of $\mathrm{SO}_{2}$ for both Quru $(\tau=-0.26, p<0.01)$ and Litu $(\tau=-0.32, p<0.01)$ (Figure S4.3, Table S4.2).

Linear mixed effects model (LME) summaries for the 55-year BAI chronologies of Quru and Litu are shown in Table S4.3. The final model for BAI of Quru indicated main effects of climate change on tree growth, whereby growth was positively affected by both minimum growing season temperature $(\beta=1.20, p=0.03)$ and total combined June-July precipitation $(\beta=$ $0.08, p<0.01)$. Further, U.S. emissions of $\mathrm{NO}_{\mathrm{x}}(\beta=1.71, p<0.001)$ was found to have a positive effect on BAI of Quru. There was a negative effect of U.S. emissions of $\mathrm{SO}_{2}$ on BAI of Quru $(\beta=-0.83, p<0.01)$ (Table S4.3). However, there were interactive effects between total combined June-July precipitation with U.S. emissions of $\mathrm{SO}_{2}(\beta=-0.002, p=0.04)$ and with $\mathrm{NO}_{\mathrm{x}}(\beta=-0.003, p=0.04)$, where the effects of precipitation on BAI were modulated by acidic air pollution (Figure 4.3a,b). We found no effects of increased atmospheric $\mathrm{CO}_{2}$ on the growth of Quru (Table S4.3).

Over the 1960-2015 period, the average model predicts an increase in Quru BAI of 0.316 $\pm 0.027 \mathrm{~cm}^{2} \mathrm{yr}^{-1}$, in close agreement with the observed BAI $(\mathrm{r}=0.87)$. Of the observed 0.318 $\mathrm{cm}^{2} \mathrm{yr}^{-1}$ increase in Quru BAI, our analysis of temporal contributions of environmental factors indicated that reductions in U.S. emissions of $\mathrm{SO}_{2}$ had the greatest impact on BAI, resulting in an increase of $0.326 \pm 0.145 \mathrm{~cm}^{2} \mathrm{yr}^{-1}$ during the study period. This was followed by reductions in U.S. emissions of $\mathrm{NO}_{x}$, which negatively impacted BAI of Quru by $0.108 \pm 0.03 \mathrm{~cm}^{2} \mathrm{yr}^{-1}$ (Figure 4.4a). Increases in minimum growing season temperature contributed positively to BAI of Quru by $0.033 \pm 0.039 \mathrm{~cm}^{2} \mathrm{yr}^{-1}$, similar to increased total combined June-July precipitation, which contributed positively by $0.047 \pm 0.04 \mathrm{~cm}^{2} \mathrm{yr}^{-1}$. Unknown contributions to BAI of Quru accounted for $0.018 \pm 0.175 \mathrm{~cm}^{2} \mathrm{yr}^{-1}$ (Figure 4.4a). 
For the 55-year BAI chronologies of Litu, LME model results indicated main effects of atmospheric $\mathrm{CO}_{2}(\beta=-0.21, p<0.05)$, U.S. emissions of $\mathrm{SO}_{2}(\beta=-0.87, p=0.04)$, U.S. emissions of $\mathrm{NO}_{\mathrm{x}}(\beta=-5.72, p=0.03)$, as well as the total combined June-July precipitation of the previous year $(\beta=0.018, p<0.001)$ (Table S4.3). Further, there was an interactive effect between atmospheric $\mathrm{CO}_{2}$ and U.S. $\mathrm{NO}_{\mathrm{x}}$ emissions on BAI of Litu $(\beta=0.020, p<0.01)$, where the positive effects of increasing $\mathrm{CO}_{2}$ were diminished under low $\mathrm{NO}_{\mathrm{x}}$ emissions (Figure 4.5a, Table S4.3).

Over the 1960-2015 period, the average model predicts an increase in BAI of Litu of $0.287 \pm 0.073 \mathrm{~cm}^{2} \mathrm{yr}^{-1}$, in close agreement with the observed BAI $(\mathrm{r}=0.88)$. Of the observed $0.329 \mathrm{~cm}^{2} \mathrm{yr}^{-1}$ increase in BAI of Litu, our analysis of the influence of these environmental factors indicated that reductions in U.S. emissions of $\mathrm{SO}_{2}$ had a large positive contribution to increases in BAI of $0.357 \pm 0.186 \mathrm{~cm}^{2} \mathrm{yr}^{-1}$, while reductions in U.S. emissions of $\mathrm{NO}_{\mathrm{x}}$ contributed negatively by $-0.339 \pm 0.158 \mathrm{~cm}^{2} \mathrm{yr}^{-1}$ (Figure $4.4 \mathrm{a}$ ). The total combined June-July precipitation of the previous year positively impacted BAI of Litu by $0.127 \pm 0.131 \mathrm{~cm}^{2} \mathrm{yr}^{-1}$ and atmospheric $\mathrm{CO}_{2}$ had a small, but positive, contribution of $0.068 \pm 0.077 \mathrm{~cm}^{2} \mathrm{yr}^{-1}$. Unknown contributions to BAI of Litu accounted for $0.074 \pm 0.285 \mathrm{~cm}^{2} \mathrm{yr}^{-1}$ (Figure 4.4a).

Contribution of environmental factors to changes in iWUE across the 55-year tree ring chronologies

Kendall's rank correlation revealed that iWUE of Quru was most positively related to atmospheric $\mathrm{CO}_{2}(\tau=0.24, p<0.05)$ and mean July temperature $(\tau=0.24, p<0.05)$, followed by minimum July temperature $(\tau=0.21, p<0.05)$ and maximum July temperature $(\tau=0.20, p<$ 0.05) (Figure S4.3, Table S4.2). Kendall's rank correlation revealed that iWUE of Litu was most positively related to atmospheric $\mathrm{CO}_{2}(\tau=0.47, p<0.01)$ and there was a strong negative correlation with U.S. emissions of $\mathrm{SO}_{2}(\tau=-0.39, p<0.01)$ (Figure S4.3, Table S4.2). Further, iWUE of Litu was positively related to minimum annual temperatures $(\tau=0.21, p<0.05)$, minimum growing season temperatures $(\tau=0.23, p<0.05)$, minimum temperatures in June $(\tau=$ $0.19, p<0.05)$ and July $(\tau=0.24, p<0.05)$, as well as mean July temperature $(\tau=0.22, p<$ 0.05) (Figure S4.3, Table S4.2).

Linear mixed effects model summaries for the 55-year iWUE chronologies of Quru and Litu are shown in Table S4.3. For iWUE of Quru, the final model results showed no significant 
main effects across the chronology (Table S4.3), although there were marginally significant interactions among four of the environmental factors examined (Figure 4.3c,d,e). The average linear mixed effects model indicated a positive interaction between atmospheric $\mathrm{CO}_{2}$ and total combined June-July precipitation ( $\beta=0.0003, p=0.07$ ) (Figure 4.3c) on iWUE of Quru, as well as a negative interaction between atmospheric $\mathrm{CO}_{2}$ and growing season minimum temperature $(\beta$ $=-0.037, p=0.07$ ) (Figure 4.3d). There was also a negative interaction between minimum growing season temperature and U.S. emissions of $\mathrm{NO}_{\mathrm{x}}(\beta=-0.153, p=0.08)$ on iWUE of Quru (Figure 4.3e).

The average model predicted an increase of $0.098 \pm 0.035 \mathrm{mmol} \mathrm{CO}_{2} \mathrm{~mol}^{-1} \mathrm{H}_{2} \mathrm{O} \mathrm{yr}^{-1}$ in iWUE of Quru during the 1960 - 2015 study period, in close agreement with the observed 0.106 $\pm 0.037 \mathrm{mmol} \mathrm{CO}_{2} \mathrm{~mol}^{-1} \mathrm{H}_{2} \mathrm{O} \mathrm{yr}{ }^{-1}$ increase in iWUE of Quru $(\mathrm{r}=0.83, p<0.001)$. Increases in atmospheric $\mathrm{CO}_{2}$ resulted in a positive contribution to iWUE of Quru of $0.193 \pm 0.053 \mathrm{mmol}$ $\mathrm{CO}_{2}$ mol-1 $^{-1} \mathrm{H}_{2} \mathrm{O} \mathrm{yr}^{-1}$ (Figure 4.4b). Reduced U.S. emissions of $\mathrm{NO}_{\mathrm{x}}$ contributed $-0.041 \pm 0.036$ mmol $\mathrm{CO}_{2} \mathrm{~mol}^{-1} \mathrm{H}_{2} \mathrm{O} \mathrm{yr}^{-1}$ to iWUE of Quru and minimum growing season temperature contributed $-0.039 \pm 0.049 \mathrm{mmol} \mathrm{CO}_{2} \mathrm{~mol}^{-1} \mathrm{H}_{2} \mathrm{O} \mathrm{yr}{ }^{-1}$. Total combined June-July precipitation had a positive, but highly variable effect on iWUE of Quru of $0.013 \pm 0.096 \mathrm{mmol} \mathrm{CO}_{2} \mathrm{~mol}^{-1}$ $\mathrm{H}_{2} \mathrm{O} \mathrm{yr}{ }^{-1}$. The unknown contribution of biotic or abiotic factors to the increase in iWUE of Quru was $-0.028 \pm 0.110 \mathrm{mmol} \mathrm{CO}_{2} \mathrm{~mol}^{-1} \mathrm{H}_{2} \mathrm{O} \mathrm{yr}{ }^{-1}$ (Figure 4.4b).

For the 55-year iWUE chronology of Litu, LME model results identified main effects of minimum growing season temperature $(\beta=-3.72, p<0.01)$ and total combined June-July precipitation of the current year $(\beta=-0.16, p<0.01$ ) (Table S4.3). There was a positive interaction between atmospheric $\mathrm{CO}_{2}$ and U.S. emissions of $\mathrm{NO}_{\mathrm{x}}$ on iWUE of Litu $(\beta=0.011, p$ $=0.01)$ (Figure 4.5b, Table S4.3), as well as a negative interaction between U.S. emissions of $\mathrm{SO}_{2}$ and U.S. emissions of $\mathrm{NO}_{\mathrm{x}}(\beta=-0.038, p=0.02)$ (Figure 4.5c, Table S4.3). The effect of minimum growing season temperature on iWUE of Litu depended on the total combined JuneJuly precipitation of the current year $(\beta=0.014, p<0.01)$ (Figure 4.5d, Table S4.3).

The average model predicted an increase of $0.193 \pm 0.018 \mathrm{mmol} \mathrm{CO}_{2} \mathrm{~mol}^{-1} \mathrm{yr}^{-1}$ in iWUE of Litu during the $1960-2015$ study period, similar to the observed $0.195 \pm 0.038 \mathrm{mmol} \mathrm{CO}_{2}$ $\mathrm{mol}^{-1} \mathrm{yr}^{-1}(\mathrm{r}=0.80, p<0.001)$. Increases in atmospheric $\mathrm{CO}_{2}$ made the greatest contribution to increases in iWUE of Litu, resulting in an increase of $0.209 \pm 0.023 \mathrm{mmol} \mathrm{CO}_{2} \mathrm{~mol}^{-1} \mathrm{H}_{2} \mathrm{O} \mathrm{yr}^{-1}$ 
(Figure 4.4b). U.S. emissions of $\mathrm{SO}_{2}$ had a small, but highly variable, positive contribution iWUE of Litu of $0.004 \pm 0.020 \mathrm{mmol} \mathrm{CO}_{2} \mathrm{~mol}^{-1} \mathrm{H}_{2} \mathrm{O} \mathrm{yr}^{-1}$, while reductions in U.S. emissions of $\mathrm{NO}_{\mathrm{x}}$ had a reduced iWUE of Litu by $-0.113 \pm 0.028 \mathrm{mmol} \mathrm{CO}_{2} \mathrm{~mol}^{-1} \mathrm{H}_{2} \mathrm{O} \mathrm{yr}^{-1}$. Minimum growing season temperatures had a small, but highly variable, effect on iWUE of Litu of $0.010 \pm$ $0.027 \mathrm{mmol} \mathrm{CO}_{2} \mathrm{~mol}^{-1} \mathrm{H}_{2} \mathrm{O} \mathrm{yr}$, , while total combined June-July precipitation of the current year contributed positively by $0.068 \pm 0.040 \mathrm{mmol} \mathrm{CO}_{2} \mathrm{~mol}^{-1} \mathrm{H}_{2} \mathrm{O} \mathrm{yr}^{-1}$ over the study period. Unknown contributions to iWUE of Litu accounted for $0.015 \pm 0.053 \mathrm{mmol} \mathrm{CO}_{2} \mathrm{~mol}^{-1} \mathrm{H}_{2} \mathrm{O}$ each year (Figure 4.4b). 


\subsection{Discussion.}

Since ca. 1960, canopy Quru and Litu trees in Watershed 10 and Watershed 13 of the Fernow Experimental Forest have experienced sustained increases in BAI, and moderate increases in iWUE, despite having been in their mature growth phase for $c a$. 55 years (Figure 4.1, Figure 4.2c,d). This persistent increase in tree growth is consistent with observations from Quru and Litu in the eastern U.S. (Johnson \& Abrams, 2009; McMahon et al., 2010) and is similar to recent reports of enhanced tree growth that include conifer species (Engel et al., 2016; Fang et al., 2014; Johnson \& Abrams, 2009; Kosiba et al., 2018; Mathias \& Thomas, 2018; Thomas et al., 2013) and other broadleaf deciduous tree species (Johnson \& Abrams, 2009; McMahon et al., 2010). Further, our results reflect recent studies using tree ring carbon isotopes that show increased iWUE in the eastern U.S. (Levesque et al., 2017; Mathias \& Thomas, 2018; Thomas et al., 2013), as well in other tree species globally (Peñuelas et al., 2011; Leonelli et al., 2012; van der Sleen et al., 2015; Frank et al., 2015; Guerrieri et al., 2019), and are similar in magnitude to the growing body of literature documenting increasing ecosystem WUE from eddy covariance flux observations (Keenan et al., 2013; Knauer et al., 2016). This study on Quru and Litu in the central Appalachian Mountains provides multiple lines of evidence that point to the adverse effect of acidic sulfur pollution on BAI and the positive impact of atmospheric $\mathrm{CO}_{2}$ on iWUE (Figure S4.3, Figure 4.4), but also reveal the importance of considering the simultaneous effects of multiple environmental factors, including interactions with climate, for understanding long-term tree growth and physiology (Figure 4.3, Figure 4.5).

Acidic air pollution from $\mathrm{SO}_{2}$ emissions may reduce radial stem growth (Savva \& Berninger, 2010) and crown volume of trees (Wang et al., 2007) and may also have negative effects on stomatal and photosynthetic physiology (Savard et al., 2004; Choi et al., 2014). Recent work has reinforced findings of the negative impact of $\mathbf{S O}_{4}^{2-}$ deposition on tree growth and survival (Horn et al., 2018), but has also highlighted the ability of forest ecosystems to recover from declining $\mathrm{SO}_{2}$ emissions and $\mathbf{S O}_{4}^{2-}$ deposition (Boettger et al., 2014; Engel et al., 2016; Marcos Fernández-Martínez et al., 2017; Mathias \& Thomas, 2018; Savard et al., 2004; Thomas et al., 2013). Of all of the environmental factors that we examined, national $\mathrm{SO}_{2}$ emissions, which have decreased by about $86 \%$ since 1960 , had the largest effect on BAI of Quru and Litu over the past 55 years. Yet, despite these results, it is clear that the growth of these two broadleaf deciduous tree species is not as sensitive to acidic air pollution as growth of red 
spruce trees in the same region (Mathias \& Thomas, 2018). Levesque et al. (2017) and Maxwell et al. (2019) concluded that precipitation and climatic water balance were more important than reductions in S acidic pollution as a driver of tree growth of Quru and Litu. Indeed, our study found that summer precipitation exerted important contributions to increasing BAI of Quru and Litu in support of research documenting the importance of water availability for the radial growth of Quru and Litu in the eastern U.S. (Brzostek et al., 2014; Helcoski et al., 2019), especially during the early growing season (Tardif et al., 2006; Keyser \& Brown, 2014; Helcoski et al., 2019). For Quru, summer precipitation interacted with acidic sulfur pollution, such that the highest values of BAI were observed when $\mathrm{SO}_{2}$ emissions were low and June and July precipitation was high, and acidic $\mathrm{SO}_{2}$ pollution was most damaging when precipitation was low (Figure 3b). Li et al. (2010) found that red oak trees growing in highly polluted locations in NE Pennsylvania were highly sensitive to acidic deposition, but are now recovering after pollution levels declined after the Clean Air Act. Our study sites in the Fernow Experimental Forest have a history of reductions from pervasively high levels of acidic pollution; a local NADP monitoring station (WV18, Tucker County) has recorded that wet $\mathrm{SO}_{4}{ }^{2}-\mathrm{S}$ deposition has declined $78 \%$ from a high of $44.12 \mathrm{~kg} \mathrm{ha}^{-1}$ in 1979 (Figure S4.1b), reflected by a 17\% drop in S in stream water chemistry in our study site watersheds since monitoring began in 1984 (Figure S4.1d) (Edwards \& Wood, 2011), and the history of acidic S deposition in these locations may help explain why our results differ from those of Levesque et al. (2017) and Maxwell et al. (2019). A first approximation using predicted values from our statistical model of tree growth illustrates that without the observed drastic reductions in $\mathrm{SO}_{2}$ emissions due to the 1990 Clean Air Act Amendments, letting all other environmental factors change as observed, $c a$. 11-15\% less carbon would have been stored in woody biomass of Quru and Litu trees growing in the central Appalachian Mountains over the past 25 years (Figure 4.6a,b).

Nitrogen deposition may act as a source of soil acidity and negatively impact tree growth or it may act as a fertilizer source of $\mathrm{N}$ and positively impact tree growth (Thomas et al., 2010; Jennings et al., 2016). Our results support work that documents enhanced productivity across a range of tree species in U.S. forests experiencing elevated rates of nitrogen deposition, including Litu and Quru (Thomas et al., 2010; Horn et al., 2018). The question remains, however, as to what happens to tree growth when ecosystem $\mathrm{N}$ inputs decline as $\mathrm{N}$ deposition declines (Gilliam et al., 2019), as it has in the Fernow Experimental Forest where wet $\mathrm{NO}_{3}-\mathrm{N}$ deposition has 
decreased by $62 \%$ from a high of $23.03 \mathrm{~kg} \mathrm{ha}^{-1}$ in 1979 to $7.36 \mathrm{~kg} \mathrm{ha}^{-1}$ in 2015 (Figure S4.1a). Stream water $\mathrm{N}$ has decreased by $53 \%$ in the two watersheds across the same time period (Figure S4.1c). Our data indicate that reductions in U.S. emissions of $\mathrm{NO}_{\mathrm{x}}$, and consequently $\mathrm{NO}_{3}^{-}$ deposition (Figure S4.1a), had a negative influence on BAI of both tree species over the past 55 years, although the relative contribution was greater for Litu than for Quru (Figure 4.4a). This finding is in line with work showing a shifts in tree species composition to those functionally more similar to Litu than Quru under high $\mathrm{N}$ deposition (Averill et al., 2018). As with $\mathrm{SO}_{2}$ emissions, our study found an interactive effect of summer precipitation and $\mathrm{NO}_{\mathrm{x}}$ emissions on BAI of Quru, whereby the highest values of BAI were observed when $\mathrm{NO}_{\mathrm{x}}$ emissions and June and July precipitation were both high (Figure 4.3a), again underscoring the importance of water availability for the growth of deciduous hardwood tree species in eastern deciduous forests (Levesque et al., 2017; Maxwell et al., 2019).

Increasing atmospheric $\mathrm{CO}_{2}$ stimulates tree growth in experimental settings (Ainsworth \& Rogers, 2007) and long-term productivity in deciduous broadleaf and coniferous ecosystems (Cernusak et al., 2019; Walker et al., 2019). Yet, isolating the effects of increasing atmospheric $\mathrm{CO}_{2}$ from the myriad environmental factors known to affect tree growth and ecosystem productivity in unmanaged ecosystems has been difficult (Hyvönen et al., 2007b; Gedalof \& Berg, 2010; Fernández-Martínez et al., 2019), and only recently has a positive $\mathrm{CO}_{2}$ effect been documented in conifer tree species growing in the central Appalachian Mountains (Mathias \& Thomas, 2018). This study found differing results for an effect of increasing atmospheric $\mathrm{CO}_{2}$ on BAI of Quru and Litu. While we found no effect of $\mathrm{CO}_{2}$ on BAI of Quru, increasing atmospheric $\mathrm{CO}_{2}$ made a positive contribution to BAI of Litu, although a significant interaction between $\mathrm{CO}_{2}$ and $\mathrm{NO}_{\mathrm{x}}$ deposition indicates that the $\mathrm{CO}_{2}$ fertilization effect for $L i t u$ was diminished as nitrogen deposition declined (Figure 4.5a). This interactive effect adds support for the hypothesis that $\mathrm{N}$ availability constrains the $\mathrm{CO}_{2}$ stimulation of plant growth in many terrestrial ecosystems (Luo et al., 2004; Reich et al., 2006; Schulte-Uebbing \& de Vries, 2018; Terrer et al., 2019), such that continued increases in atmospheric $\mathrm{CO}_{2}$ may only stimulate productivity when $\mathrm{N}$ is sufficiently available.

In both species, increasing atmospheric $\mathrm{CO}_{2}$ exerted the greatest influence on iWUE. Although the rate of increase in iWUE of Litu over the 55-year chronology was approximately twice that of Quru, the magnitude of the positive contribution of atmospheric $\mathrm{CO}_{2}$ was similar 
between the two species (Figure 4.4b), highlighting a consistent leaf-level response of iWUE to increasing atmospheric $\mathrm{CO}_{2}$ that supports previous studies using tree ring chronologies (Frank et al., 2015; Keller et al., 2017; Mathias \& Thomas, 2018; Peñuelas et al., 2011; Saurer, Siegwolf, \& Schweingruber, 2004; Thomas et al., 2013) and is consistent with leaf physiology theory (Frank et al., 2015; Lavergne et al., 2019a). However, we found several environmental factors interacted with $\mathrm{CO}_{2}$ to moderate the integrated response of iWUE in these two species (Figure 4.3, Figure 4.5). Interactions between increasing $\mathrm{CO}_{2}$ and summer precipitation and increasing $\mathrm{CO}_{2}$ and minimum growing season temperature on iWUE of Quru indicated that atmospheric $\mathrm{CO}_{2}$ had its largest effect when summer precipitation was low and minimum growing season temperatures were low (Figure 4.3c,d). For Litu, an interaction between atmospheric $\mathrm{CO}_{2}$ and $\mathrm{NO}_{x}$ emissions on iWUE indicated that the greatest effect of $\mathrm{CO}_{2}$ occurred when $\mathrm{NO}_{\mathrm{x}}$ emissions were at their peak (Figure 4.5b). Nitrogen deposition has been shown to correlate positively with iWUE in several recent dendroisotopic studies (Guerrieri et al., 2011, 2016; Leonardi et al., 2012; Jennings et al., 2016), possibly due to a $\mathrm{N}$ fertilization effect on photosynthesis. We found similar results, with reductions in $\mathrm{N}$ deposition in the Fernow Experimental Forest negatively impacting iWUE of both species. For Quru, iWUE increases with $\mathrm{NO}_{\mathrm{x}}$ emissions, but it increases more when minimum growing season temperatures are lower (Figure 4.3e). $\mathrm{NO}_{\mathrm{x}}$ emissions and $\mathrm{SO}_{2}$ emissions interact such that the positive effect of $\mathrm{NO}_{\mathrm{x}}$ emissions on iWUE of Litu is greatest when $\mathrm{SO}_{2}$ is lowest (Figure 4.5c), and minimum growing season temperature and summer precipitation interact such that iWUE increased with precipitation as temperature increases, but the greatest iWUE occurred at low precipitation and low temperatures (Figure 4.5d). Thus, while our study shows that increasing $\mathrm{CO}_{2}$ is a strong driver of increased water use efficiency in trees, it is clear that one must examine the interactive effects of environmental factors to fully understand the complexity of how iWUE changes over time. To illustrate this, we performed a simple modeling exercise using our final models to simulate iWUE of Quru and Litu through the year 2050, with atmospheric $\mathrm{CO}_{2}$ concentrations increasing according to the RCP 4.5 scenario (IPCC, 2014) and climate factors changing $\pm 25 \%$ from their previous 30 -year averages by the year 2050 (Figure 4.7a,b). While we use our statistical model to force future predictions of iWUE, rather than a mechanistic model, it becomes apparent that future climate change may differentially affect iWUE of the two tree species, with Litu showing less sensitivity 
to changes in climate than Quru, which may be related to Litu being more isohydric through greater stomatal regulation (Roman et al., 2015)

In conclusion, our study presents clear evidence of increases in growth of two broadleaf deciduous tree species in the Central Appalachian Mountains that have been sustained since 1960, and builds upon work documenting recent increases in tree growth and forest ecosystem productivity in the eastern U.S. (Engel et al., 2016; Johnson \& Abrams, 2009; Kosiba et al., 2018; Levesque et al., 2017; Mathias \& Thomas, 2018; McMahon et al., 2010; Thomas et al., 2013) and globally (Fernández-Martínez et al., 2017, 2019) in response to environmental change. Our data from red oak and tulip poplar trees in the Central Appalachian Mountains show the importance of considering the responses of tree growth and physiology to individual environmental factors, but also point to the complexity and consequences of interactions between environmental factors that are driving the responses of trees in forest ecosystems. This study highlights the independent effects of reductions of $\mathrm{S}$ and $\mathrm{N}$ deposition on tree growth in the Fernow Experimental Forest, whereby reductions in S deposition positively affect tree growth through reductions in acidity, but reductions in $\mathrm{N}$ pollution may diminish a source of plant available $\mathrm{N}$ and negatively affect tree growth. Yet, these contrasting effects of acid pollution on vegetation dynamics have largely been overlooked when developing models of plant responses to environmental change. To more accurately predict future forest responses to environmental change, it is crucial that we begin to consider not only the independent, but also the interactive effects of multiple environmental factors on long term tree growth and physiology. 


\subsection{Figures.}

Figure 4.1: Chronologies of basal area increment from 1920 - 2015 for Quercus rubra (a, c) and Liriodendron tulipifera (b, d) from Watershed 10 (a, b) and Watershed 13 (c, d) in the Fernow Experimental Forest, Parsons, West Virginia, USA. Individual tree growth in each panel is denoted by light gray lines, while the average chronology is denoted by the bold purple and orange lines for Quercus rubra and Liriodendron tulipifera, respectively. The vertical dashed lines at 1960 in each panel represent the beginning of the mature growth phase of each chronology. The slope of the average growth trend from 1960 - 2015 (solid black trendline) is denoted for each respective panel below the expressed population signal (eps), a measure of how well the sampled trees reflect a chronology developed from an infinite population (Wigley et al., 1984).
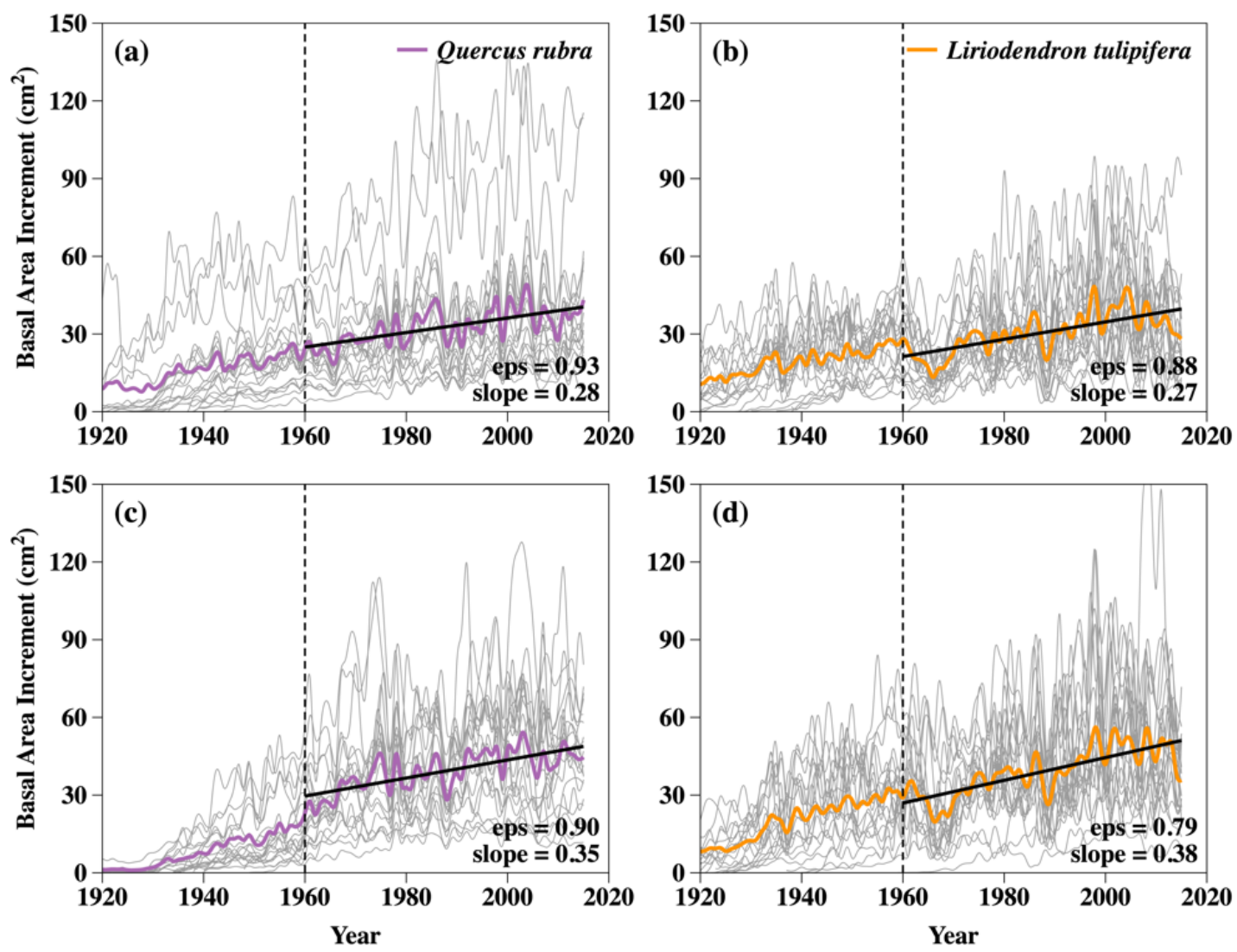
Figure 4.2. Chronologies of leaf-corrected carbon isotope discrimination $(a, b)$ and intrinsic water use efficiency (c,d) for the period 1960 - 2015 for Quercus rubra (a,c; purple) and Liriodendron tulipifera (b,d; orange) in Watershed 10 (circles) and Watershed 13 (triangles) at the Fernow Experimental Forest, Parsons, WV, USA. For each year, iWUE was derived from leaf-corrected $\Delta^{13} \mathrm{C}$ from Quru and Litu trees in each of the two study locations. Data points in gray represent measurements from each tree, while purple and orange represent mean values within a given site for a given year for each chronology. The solid black trendline in each panel is the average trend from $1960-2015$.
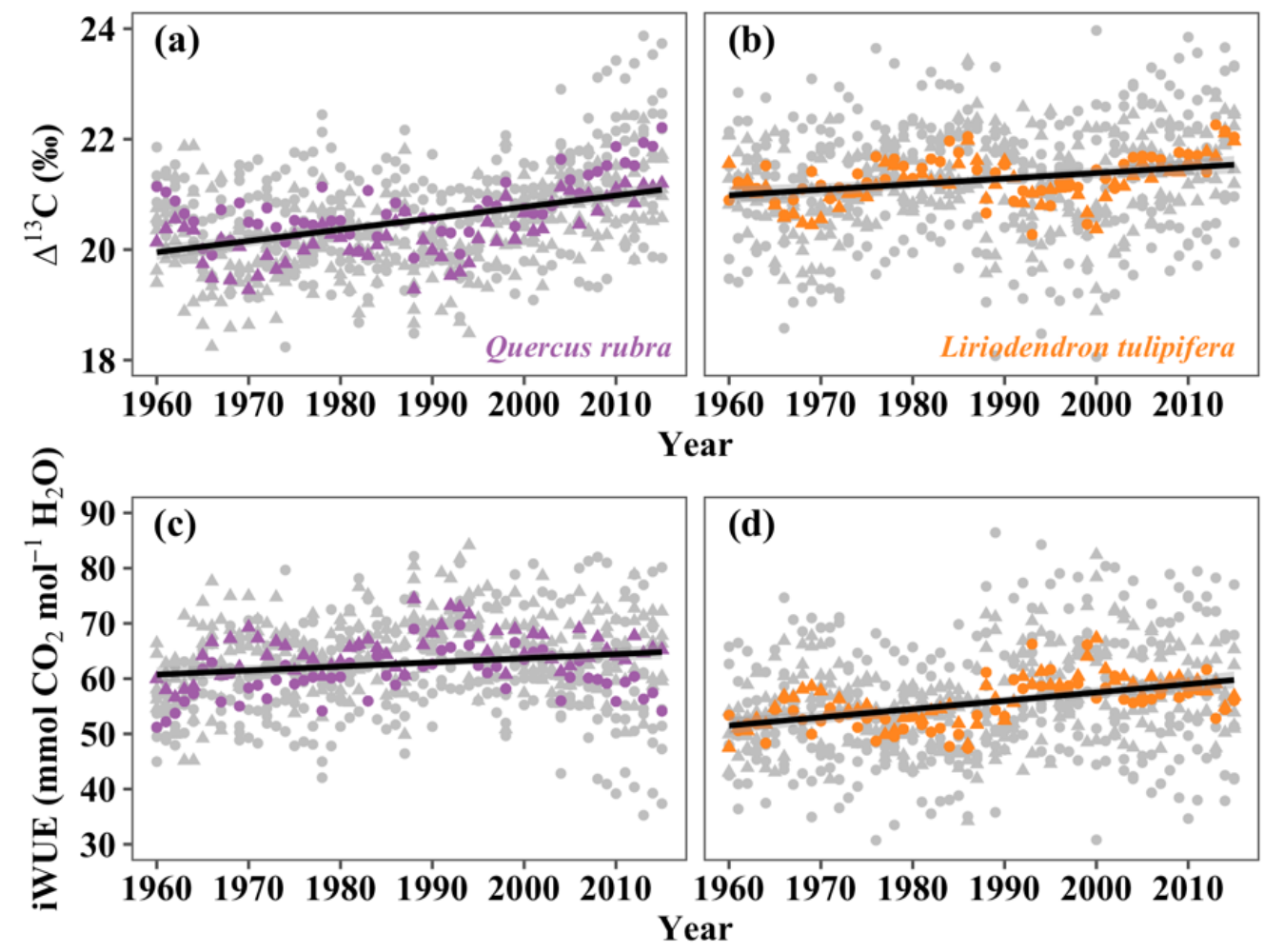
Figure 4.3. Contour plots depicting the interactive effects among environmental factors on BAI $(\mathrm{a}, \mathrm{b})$ and iWUE (c, d, e) of Quercus rubra in the Fernow Experimental Forest, Parsons, WV, U.S during the $1960-2015$ study period. Interactions were determined from the best (lowest $\mathrm{AIC}_{\mathrm{c}}$ ) linear mixed effects model for each response variable and include the sum of June and July precipitation of the current year $\left(\mathrm{JJ}_{\mathrm{ppt}}\right)$, minimum growing season temperature (Growing $\left.{ }_{\mathrm{Tmin}}\right)$, and U.S. emissions of $\mathrm{SO}_{2}\left(\mathrm{SO}_{2}\right.$ Emissions) and $\mathrm{NO}_{\mathrm{x}}\left(\mathrm{NO}_{\mathrm{x}}\right.$ Emissions). Units for $\mathrm{NO}_{\mathrm{x}}$ and $\mathrm{SO}_{2}$ emissions are $10^{6}$ metric tons, while $\mathrm{JJ}_{\mathrm{ppt}}$ are in $\mathrm{mm}$, Growing $\mathrm{Tmin}_{\text {min }}$ in ${ }^{\circ} \mathrm{C}$, and atmospheric $\mathrm{CO}_{2}$ are in ppm. Each interaction is plotted across the range experienced by each respective environmental parameter, with the value of the response variable (BAI or iWUE) corresponding to the respective color hue (moving from light green toward dark blue indicates increasing BAI, while moving from dark blue toward dark red indicates increasing iWUE).
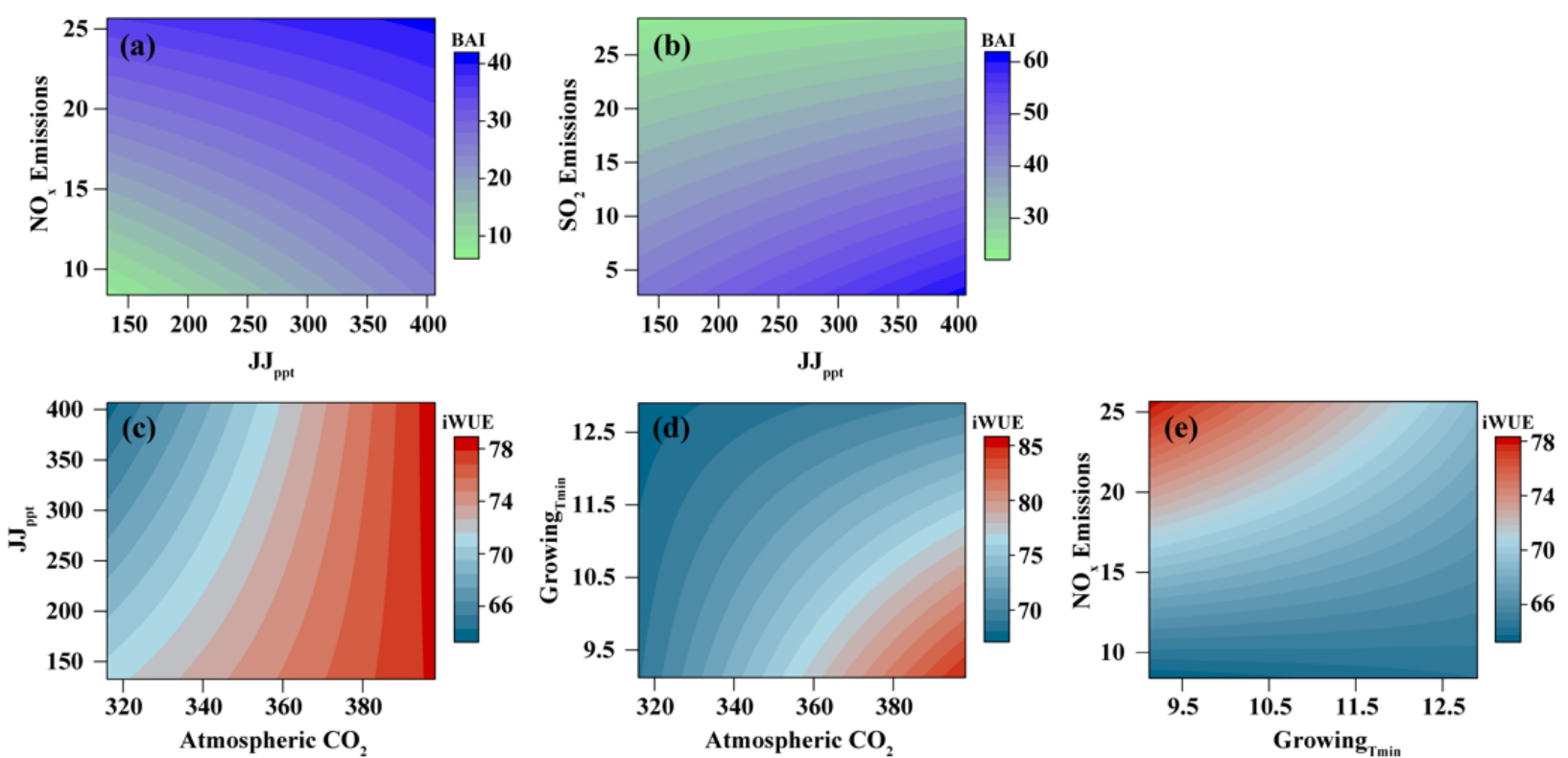
Figure 4.4. Contributions of multiple environmental factors to the observed changes in BAI (A) and iWUE (B) for the period 1960 - 2015 for Quercus rubra (purple) and Liriodendron tulipifera (orange) in Watershed 10 and Watershed 13 in the Fernow Experimental Forest, Parsons, WV, U.S. Numbers in parentheses beside each environmental factor denote the direction and magnitude of the respective average yearly change (i.e. slope) for the period $1960-$ 2015. Units for Atmospheric $\mathrm{CO}_{2}$, Growing ${ }_{\mathrm{Tmin}}$, and $\mathrm{JJ}_{\mathrm{ppt}}$ are $\mathrm{ppm},{ }^{\circ} \mathrm{C}$, and $\mathrm{mm}$, respectively, while units for both $\mathrm{SO}_{2}$ Emissions and $\mathrm{NO}_{\mathrm{x}}$ Emissions are $10^{6}$ metric tons. Unknown contributions were determined by subtracting all known contributions from the observed change during the 1960 - 2015 study period. Model summaries for linear mixed effects models for BAI and iWUE of Quru and Litu used in the calculation of contributions are listed in Table S3.
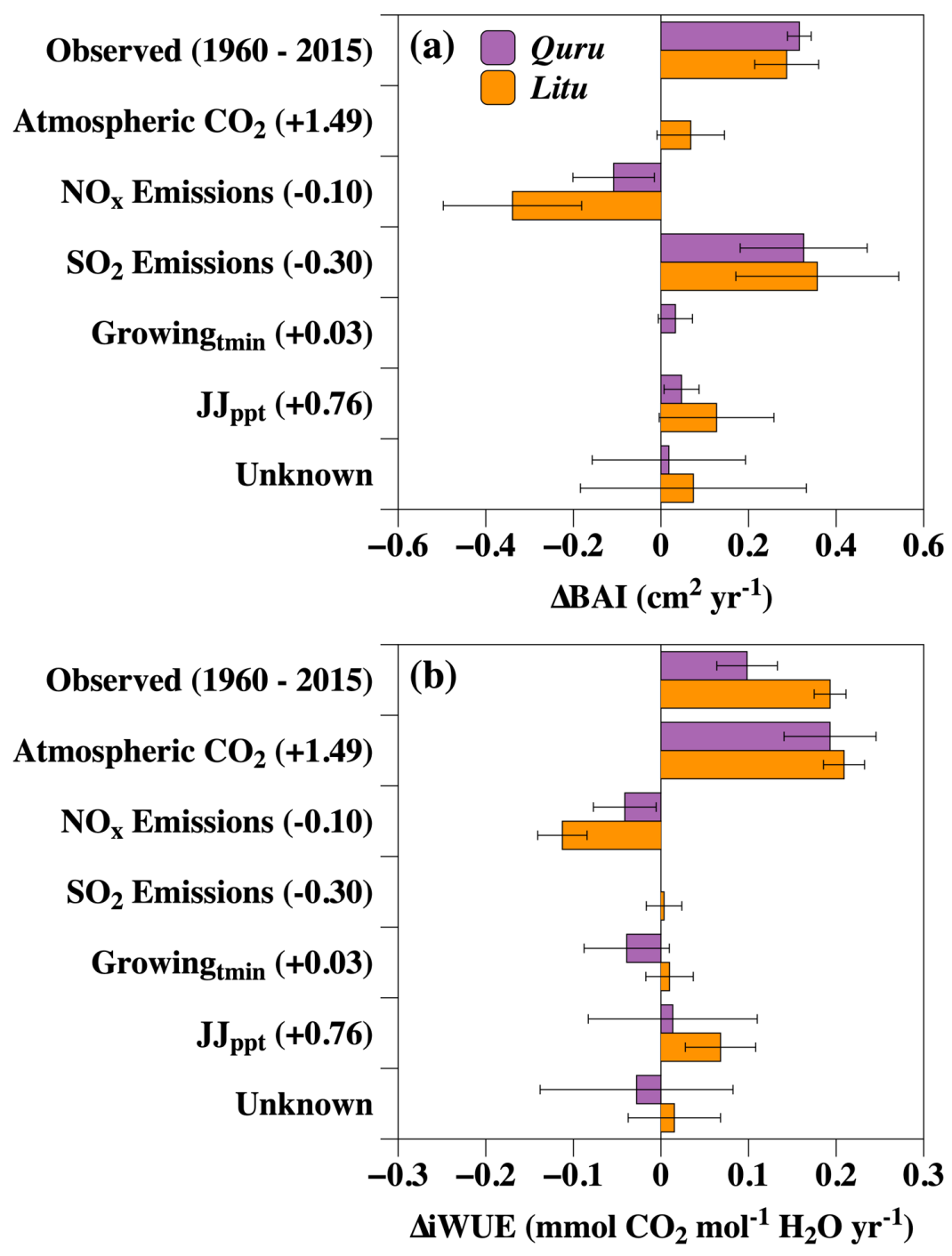
Figure 4.5. Contour plots depicting the nature of the interactions among environmental factors on BAI (A) and iWUE (B, C, D) of Liriodendron tulipifera in the Fernow Experimental Forest, Parsons, WV, U.S during the 1960 - 2015 study period. Interactions were determined from the best $\left(\right.$ lowest $\mathrm{AIC}_{\mathrm{c}}$ ) linear mixed effects model for each response variable and include the sum of June and July precipitation of the current year $\left(\mathrm{JJ}_{\mathrm{ppt}}\right)$, minimum growing season temperature (Growing $\left.{ }_{\mathrm{T} \min }\right)$, and U.S. emissions of $\mathrm{SO}_{2}\left(\mathrm{SO}_{2}\right.$ Emissions) and $\mathrm{NO}_{\mathrm{x}}\left(\mathrm{NO}_{\mathrm{x}}\right.$ Emissions). Units for $\mathrm{NO}_{\mathrm{x}}$ and $\mathrm{SO}_{2}$ emissions are $10^{6}$ metric tons, while $\mathrm{JJ}_{\mathrm{ppt}}$ are in $\mathrm{mm}$, Growing ${ }_{\mathrm{Tmin}}$ are in ${ }^{\circ} \mathrm{C}$, and atmospheric $\mathrm{CO}_{2}$ are in ppm. Each interaction is plotted across the range experienced by each respective environmental parameter, with the value of the response variable (BAI or iWUE) corresponding to the respective color hue (moving from light green toward dark blue indicates increasing BAI, while moving from dark blue toward dark red indicates increasing iWUE).
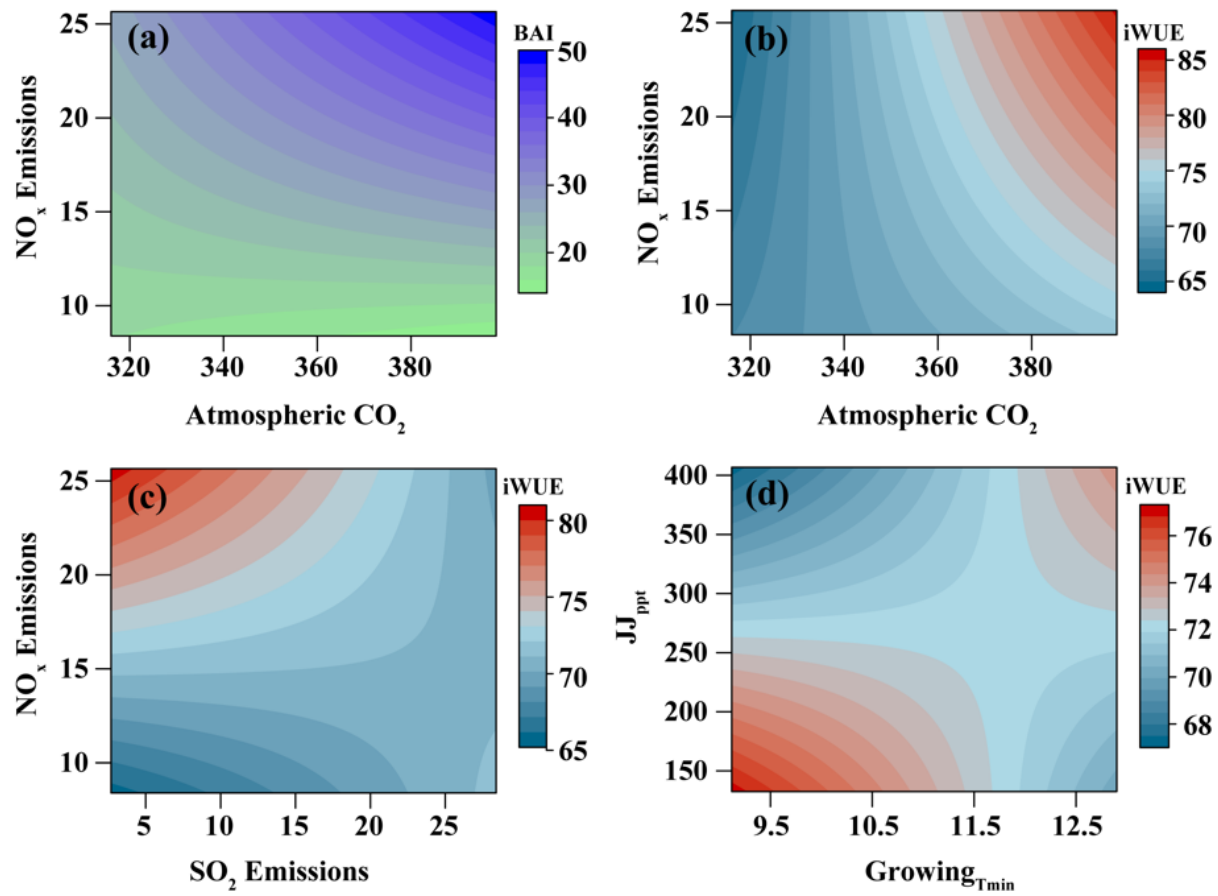
Figure 4.6. Modelled BAI using the final models for Quercus rubra (a) and Liriodendron tulipifera (b) under observed (Quru, purple line; Litu, orange line) and high $\mathrm{SO}_{2}$ emissions (red lines) scenarios. BAI under high $\mathrm{SO}_{2}$ (red lines in a and b) was predicted using the average $\mathrm{SO}_{2}$ emissions level from 1970 - 1990 (24.4 metric tons) forced during the entire period from 1991 to 2015. Cumulative basal area increment for each scenario was then converted to diameter at breast height (DBH), and species specific allometric equations between DBH and aboveground biomass (AGBM) (Chojnacky et al., 2014) were used to determine total aboveground biomass carbon at 2015 for each scenario after accounting for $\% \mathrm{C}$ in wood $\left(\mathrm{AGBM}^{*} 0.5\right)$. The gray shaded area in a and $\mathrm{b}$ represents the calculated integrated difference in basal area between the two scenarios, with the percent difference in carbon stored in AGBM listed in each panel, and the corresponding basal area on the bottom right corner of each panel.
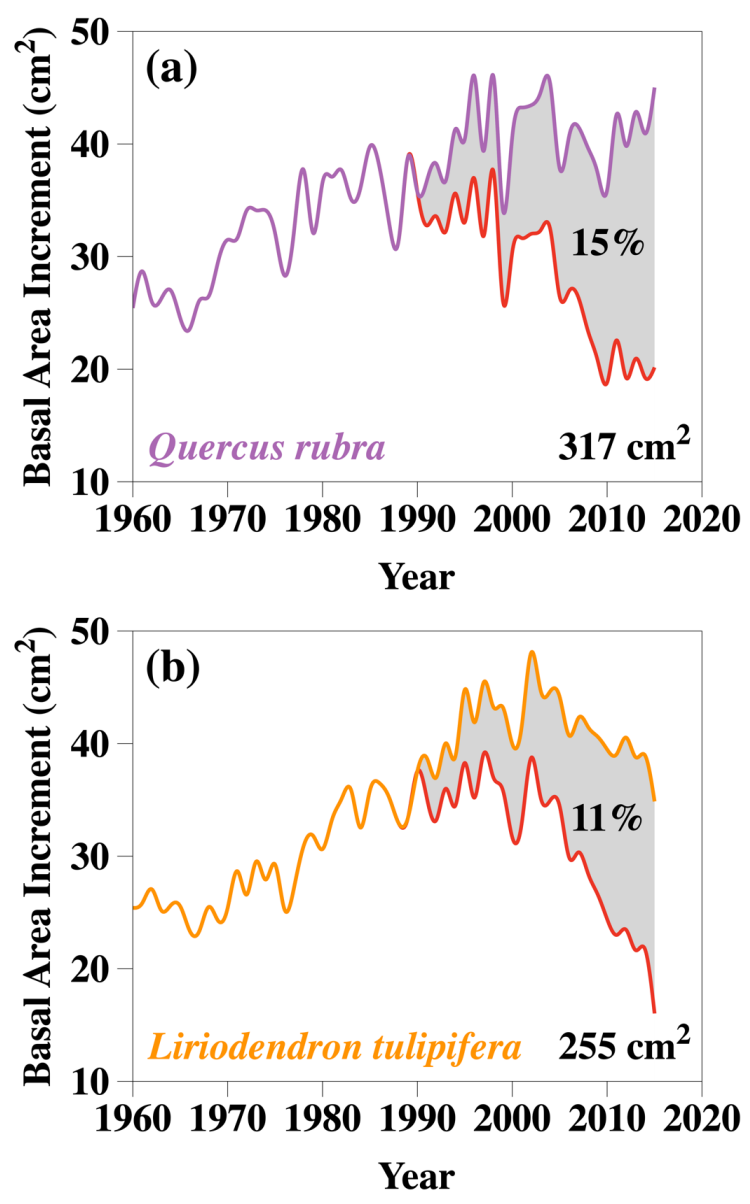
Figure 4.7. Modeled changes of Quercus rubra (a) and Liriodendron tulipifera (b) intrinsic water use efficiency under hypothetical future environmental change predicted using the final model. Data points represent iWUE for each year in the period 2030 - 2050 as climatic factors linearly approach a $\pm 25 \%$ change from their previous 30 -year averages by the year 2050 and atmospheric $\mathrm{CO}_{2}$ concentrations increase according to the RCP 4.5 scenario (IPCC, 2014). Horizontal dashed lines represent observed iWUE in 2015 for each species, respectively.
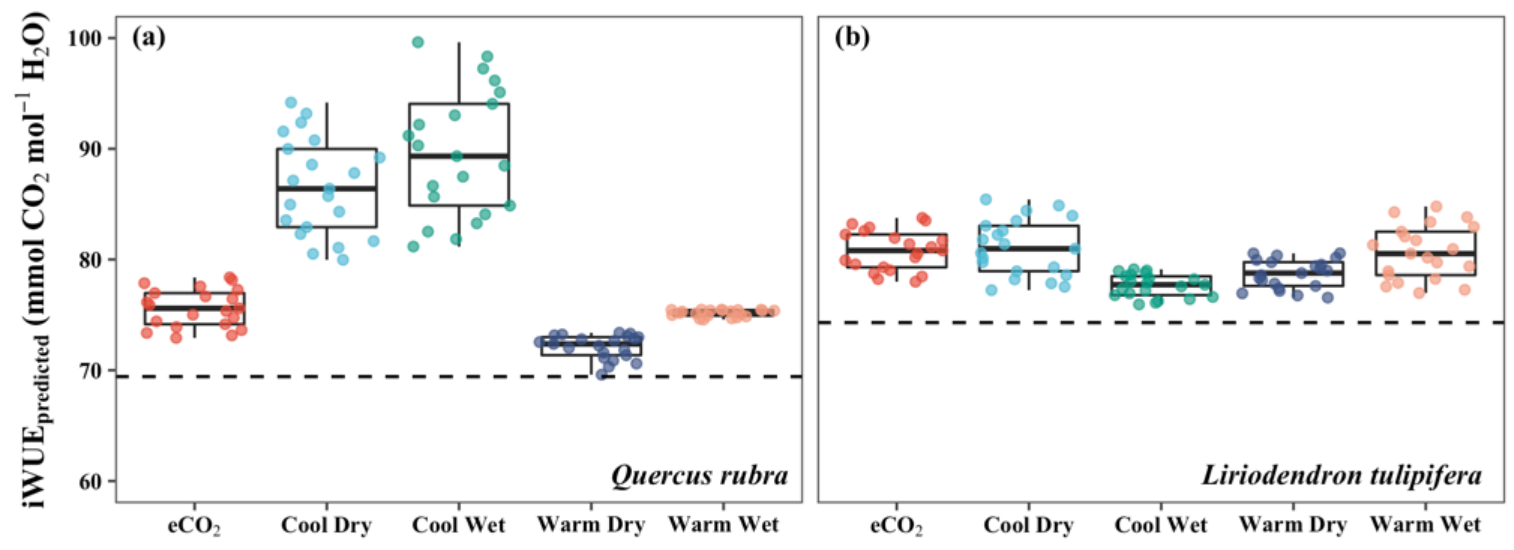


\subsection{Literature Cited.}

Ainsworth EA, Rogers A. 2007. The response of photosynthesis and stomatal conductance to rising $\left[\mathrm{CO}_{2}\right]$ : mechanisms and environmental interactions. Plant, Cell \& Environment 30: $258-270$.

Averill C, Dietze MC, Bhatnagar JM. 2018. Continental-scale nitrogen pollution is shifting forest mycorrhizal associations and soil carbon stocks. Global Change Biology 24: 4544-4553.

Babst F, Bouriaud O, Papale D, Gielen B, Janssens IA, Nikinmaa E, Ibrom A, Wu J, Bernhofer C, Köstner B, et al. 2014. Above-ground woody carbon sequestration measured from tree rings is coherent with net ecosystem productivity at five eddy-covariance sites. New Phytologist 201: 1289-1303.

Bartoń K. 2017. MuMIn: Multi-Model Inference. R package version 1.40.0.

Battipaglia G, Saurer M, Cherubini P, Calfapietra C, McCarthy HR, Norby RJ, Francesca Cotrufo M. 2013. Elevated $\mathrm{CO}_{2}$ increases tree-level intrinsic water use efficiency: insights from carbon and oxygen isotope analyses in tree rings across three forest FACE sites. New Phytologist 197: 544-554.

Beer C, Reichstein M, Tomelleri E, Ciais P, Jung M, Carvalhais N, Rodenbeck C, Arain MA, Baldocchi D, Bonan GB, et al. 2010. Terrestrial Gross Carbon Dioxide Uptake: Global Distribution and Covariation with Climate. Science 329: 834-838.

Belmecheri S, Maxwell RS, Taylor AH, Davis KJ, Freeman KH, Munger WJ. 2014. Tree-ring $\delta^{13} \mathrm{C}$ tracks flux tower ecosystem productivity estimates in a NE temperate forest. Environmental Research Letters 9: 074011.

Bishop DA, Stella JC, Beier CM, Sullivan TJ, Pederson N, Lawrence GB. 2015. Regional growth decline of sugar maple (Acer saccharum) and its potential causes. Ecosphere 6: a179.

Boettger T, Haupt M, Friedrich M, Waterhouse JS. 2014. Reduced climate sensitivity of carbon, oxygen and hydrogen stable isotope ratios in tree-ring cellulose of silver fir (Abies alba Mill.) influenced by background $\mathrm{SO}_{2}$ in Franconia (Germany, Central Europe). Environmental Pollution 185: 281-294.

Borer CH, Schaberg PG, DeHayes DH. 2005. Acidic mist reduces foliar membrane-associated calcium and impairs stomatal responsiveness in red spruce. Tree Physiology 25: 673-680.

Breheny P, Burchett W. 2017. Package 'visreg' : Visualization of Regression Models. The $R$ Journal 9: 56-71.

Brzostek ER, Dragoni D, Schmid HP, Rahman AF, Sims D, Wayson CA, Johnson DJ, Phillips RP. 2014. Chronic water stress reduces tree growth and the carbon sink of deciduous hardwood forests. Global Change Biology 20: 2531-2539. 
Bunn A, Korpela M, Biondi F, Campelo F, Merian P, Qeadan F, Zang C, Buras A, Cecile J, Mudelsee M, et al. 2015. Dendrochronology Program LIbrary in R. R package version 1.6.3.

Cernusak LA, Haverd V, Brendel O, Le Thiec D, Guehl J-M, Cuntz M. 2019. Robust Response of Terrestrial Plants to Rising $\mathrm{CO}_{2}$. Trends in Plant Science: 1-9.

Choi D, Toda H, Kim Y. 2014. Effect of sulfur dioxide $\left(\mathrm{SO}_{2}\right)$ on growth and physiological activity in Alnus sieboldiana at Miyakejima Island in Japan. Ecological Research 29: 103110.

Chojnacky DC, Heath LS, Jenkins JC. 2014. Updated generalized biomass equations for North American tree species. Forestry 87: 129-151.

Core Writing Team RKP and LAM (eds. ). 2014. IPCC, 2014: Climate Change 2014: Synthesis Report. Contribution of Working Groups I, II, and III to the Fifth Assessment Report of the Intergovernmental Panel on Climate Change.

Driscoll CT, Lawrence GB, Bulger AJ, Butler TJ, Cronan CS, Eagar C, Lambert KF, Likens GE, Stoddard JL, Weathers KC. 2001. Acidic Deposition in the Northeastern United States: Sources and Inputs, Ecosystem Effects, and Management Strategies. BioScience 51: 180.

Dye A, Barker Plotkin A, Bishop D, Pederson N, Poulter B, Hessl A. 2016. Comparing tree-ring and permanent plot estimates of aboveground net primary production in three eastern U.S. forests. Ecosphere 7: e01454.

Edwards PJ, Wood F. 2011. Fernow Experimental Forest stream chemistry. Newtown Square, PA: U.S. Department of Agriculture, Forest Service, Northern Research Station. Data publication updated 17 August 2017.

Engel BJ, Schaberg PG, Hawley GJ, Rayback SA, Pontius J, Kosiba AM, Miller EK. 2016. Assessing relationships between red spruce radial growth and pollution critical load exceedance values. Forest Ecology and Management 359: 83-91.

Fang J, Kato T, Guo Z, Yang Y, Hu H, Shen H, Zhao X, Kishimoto-Mo AW, Tang Y, Houghton R a. 2014. Evidence for environmentally enhanced forest growth. Proceedings of the National Academy of Sciences 111: 9527-9532.

Farquhar GD, Ehleringer JR, Hubick KT. 1989. Carbon Isotope Discrimination and Photosynthesis. Annual Review of Plant Physiology and Plant Molecular Biology 40: 503537.

Farquhar G, O'Leary M, Berry J. 1982. On the relationship between carbon isotope discrimination and the intercellular carbon dioxide concentration in leaves. Australian Journal of Plant Physiology 9: 121-137. 
Fernández-Martínez M, Sardans J, Chevallier F, Ciais P, Obersteiner M, Vicca S, Canadell JG, Bastos A, Friedlingstein P, Sitch S, et al. 2019. Global trends in carbon sinks and their relationships with $\mathrm{CO} 2$ and temperature. Nature Climate Change 9: 73-79.

Fernández-Martínez M, Vicca S, Janssens IA, Ciais P, Obersteiner M, Bartrons M, Sardans J, Verger A, Canadell JG, Chevallier F, et al. 2017. Atmospheric deposition, $\mathrm{CO}_{2}$, and change in the land carbon sink. Scientific Reports 7: 9632.

Francey RJ, Allison CE, Etheridge DM, Trudinger CM, Enting IG, Leuenberger M, Langenfelds RL, Michel E, Steele LP. 1999. A 1000-year high precision record of $\delta^{13} \mathrm{C}$ in atmospheric $\mathrm{CO}_{2}$. Tellus B 51: 170-193.

Frank DC, Poulter B, Saurer M, Esper J, Huntingford C, Helle G, Treydte K, Zimmermann NE, Schleser GH, Ahlström A, et al. 2015. Water-use efficiency and transpiration across European forests during the Anthropocene. Nature Climate Change 5: 579-583.

Gedalof Z, Berg AA. 2010. Tree ring evidence for limited direct $\mathrm{CO}_{2}$ fertilization of forests over the 20th century. Global Biogeochemical Cycles 24: 1-6.

Gilliam FS, Burns DA, Driscoll CT, Frey SD, Lovett GM, Watmough SA. 2019. Decreased atmospheric nitrogen deposition in eastern North America: Predicted responses of forest ecosystems. Environmental Pollution 244: 560-574.

Guerrieri R, Belmecheri S, Ollinger S V, Asbjornsen H, Jennings K, Xiao J, Stocker BD, Martin M, Hollinger DY, Bracho-Garrillo R, et al. 2019. Disentangling the role of photosynthesis and stomatal conductance on rising forest water-use efficiency. Proceedings of the National Academy of Sciences: 201905912.

Guerrieri R, Lepine L, Asbjornsen H, Xiao J, Ollinger S V. 2016. Evapotranspiration and water use efficiency in relation to climate and canopy nitrogen in U.S. forests. Journal of Geophysical Research: Biogeosciences 121: 2610-2629.

Guerrieri R, Mencuccini M, Sheppard LJ, Saurer M, Perks MP, Levy P, Sutton MA, Borghetti M, Grace J. 2011. The legacy of enhanced N and S deposition as revealed by the combined analysis of $\delta^{13} \mathrm{C}, \delta^{18} \mathrm{O}$ and $\delta^{15} \mathrm{~N}$ in tree rings. Global Change Biology 17: 1946-1962.

Helcoski R, Tepley AJ, Pederson N, McGarvey JC, Meakem V, Herrmann V, Thompson JR, Anderson-Teixeira KJ. 2019. Growing season moisture drives inter-annual variation in woody productivity of a temperate deciduous forest. New Phytologist: nph.15906.

Horn KJ, Thomas RQ, Clark CM, Pardo LH, Fenn ME, Lawrence GB, Perakis SS, Smithwick EAH, Baldwin D, Braun S, et al. 2018. Growth and survival relationships of 71 tree species with nitrogen and sulfur deposition across the conterminous U.S. (D Loustau, Ed.). PLOS ONE 13: e0205296. 
Hyvönen R, Ågren GI, Linder S, Persson T, Cotrufo MF, Ekblad A, Freeman M, Grelle A, Janssens IA, Jarvis PG, et al. 2007. The likely impact of elevated $\left[\mathrm{CO}_{2}\right]$, nitrogen deposition, increased temperature and management on carbon sequestration in temperate and boreal forest ecosystems: a literature review. New Phytologist 173: 463-480.

Jennings KA, Guerrieri R, Vadeboncoeur MA, Asbjornsen H. 2016. Response of Quercus velutina growth and water use efficiency to climate variability and nitrogen fertilization in a temperate deciduous forest in the northeastern USA. Tree Physiology 36: 428-443.

Johnson SE, Abrams MD. 2009. Age class, longevity and growth rate relationships: protracted growth increases in old trees in the eastern United States. Tree Physiology 29: 1317-1328.

Keeling RF, Piper SC, Bollenbacher AF, Walker SJ. 2010. Monthly atmospheric ${ }^{13} \mathrm{C} /{ }^{12} \mathrm{C}$ isotopic ratios for 11 SIO stations. Trends: A Compendium of Data on Global Change (Carbon Dioxide Information Analysis Center, Oak Ridge National Laboratory, US Department of Energy, Oak Ridge, TN).

Keeling RF, Piper SC, Bollenbacher AF, Walker SJ. 2015. Scripps $\mathrm{CO}_{2}$ Program. Scripps Institution of Oceanography, University of California - San Diego, USA 92093-0244.

Keenan TF, Hollinger DY, Bohrer G, Dragoni D, Munger JW, Schmid HP, Richardson AD. 2013. Increase in forest water-use efficiency as atmospheric carbon dioxide concentrations rise. Nature 499: 324-327.

Keller KM, Lienert S, Bozbiyik A, Stocker TF, Churakova (Sidorova) O V., Frank DC, Klesse S, Koven CD, Leuenberger M, Riley WJ, et al. 2017. 20th century changes in carbon isotopes and water-use efficiency: tree-ring-based evaluation of the CLM4.5 and LPX-Bern models. Biogeosciences 14: 2641-2673.

Keyser TL, Brown PM. 2014. Climate-growth relationships for yellow-poplar across structural and site quality gradients in the southern Appalachian Mountains. Forest Ecology and Management 329: 158-165.

Knauer J, Zaehle S, Reichstein M, Medlyn BE, Forkel M, Hagemann S, Werner C. 2016. The response of ecosystem water-use efficiency to rising atmospheric $\mathrm{CO}_{2}$ concentrations: sensitivity and large-scale biogeochemical implications. New Phytologist: n/a-n/a.

Kosiba AM, Schaberg PG, Rayback SA, Hawley GJ. 2018. Science of the Total Environment The surprising recovery of red spruce growth shows links to decreased acid deposition and elevated temperature. Science of the Total Environment 637-638: 1480-1491.

Lavergne A, Graven HD, De Kauwe MG, Keenan TF, Medlyn BE, Prentice IC. 2019. Observed and modelled historical trends in water use efficiency of plants and ecosystems. Global Change Biology. 
Leavitt SW, Long A. 1982. Evidence for ${ }^{13} \mathrm{C} /{ }^{12} \mathrm{C}$ fractionation between tree leaves and wood. Nature 298: 742-744.

Lefohn AS, Husar JD, Husar RB. 1999. Estimating historical anthropogenic global sulfur emission patterns for the period 1850-1990. Atmospheric Environment 33: 3435-3444.

Leonardi S, Gentilesca T, Guerrieri R, Ripullone F, Magnani F, Mencuccini M, Noije T V., Borghetti M. 2012. Assessing the effects of nitrogen deposition and climate on carbon isotope discrimination and intrinsic water-use efficiency of angiosperm and conifer trees under rising $\mathrm{CO}_{2}$ conditions. Global Change Biology 18: 2925-2944.

Leonelli G, Battipaglia G, Siegwolf RTW, Saurer M, Morra di Cella U, Cherubini P, Pelfini M. 2012. Climatic isotope signals in tree rings masked by air pollution: A case study conducted along the Mont Blanc Tunnel access road (Western Alps, Italy). Atmospheric Environment 61: 169-179.

Levesque M, Andreu-Hayles L, Pederson N. 2017. Water availability drives gas exchange and growth of trees in northeastern US, not elevated $\mathrm{CO}_{2}$ and reduced acid deposition. Scientific Reports 7: 46158.

Levesque M, Andreu-hayles L, Smith WK, Allred BW, Pederson N, Williams AP, Hobi ML. 2019. productivity dynamics at the biome scale. Nature Communications: 1-10.

Li L, Yu Z, Bebout GE, Stretton T, Allen A, Passaris P. 2010. Tree-ring width and $\delta 13 \mathrm{C}$ records of industrial stress and recovery in Pennsylvania and New Jersey forests: Implications for $\mathrm{CO}_{2}$ uptake by temperate forests. Chemical Geology 273: 250-257.

Lombardozzi D, Levis S, Bonan G, Hess PG, Sparks JP. 2015. The Influence of Chronic Ozone Exposure on Global Carbon and Water Cycles. Journal of Climate 28: 292-305.

Lu X, Kicklighter DW, Melillo JM, Reilly JM, Xu L. 2015. Land carbon sequestration within the conterminous United States: Regional- and state-level analyses. Journal of Geophysical Research: Biogeosciences 120: 379-398.

Luo Y, Su B, Currie WS, Dukes JS, Finzi A, Hartwig U, Hungate B, McMurtrie RE, Oren R, Parton WJ, et al. 2004. Progressive Nitrogen Limitation of Ecosystem Responses to Rising Atmospheric Carbon Dioxide. BioScience 54: 731.

Mathias JM, Thomas RB. 2018. Disentangling the effects of acidic air pollution, atmospheric $\mathrm{CO}_{2}$, and climate change on recent growth of red spruce trees in the Central Appalachian Mountains. Global Change Biology. 
Maxwell JT, Harley GL, Mandra TE, Yi K, Kannenberg SA, Au TF, Robeson SM, Pederson N, Sauer PE, Novick KA. 2019. Higher CO2 Concentrations and Lower Acidic Deposition Have Not Changed Drought Response in Tree Growth But Do Influence iWUE in Hardwood Trees in the Midwestern United States. Journal of Geophysical Research: Biogeosciences: 2019JG005298.

McCarroll D, Loader NJ. 2004. Stable isotopes in tree rings. Quaternary Science Reviews 23: 771-801.

McMahon SM, Parker GG, Miller DR. 2010. Evidence for a recent increase in forest growth. Proceedings of the National Academy of Sciences 107: 3611-3615.

National Atmospheric Deposition Program. 2015. NTN Data Access.

Norby RJ, DeLucia EH, Gielen B, Calfapietra C, Giardina CP, King JS, Ledford J, McCarthy HR, Moore DJP, Ceulemans R, et al. 2005. Forest response to elevated $\mathrm{CO}_{2}$ is conserved across a broad range of productivity. Proceedings of the National Academy of Sciences 102: $18052-18056$.

Pan Y, Birdsey R a., Phillips OL, Jackson RB. 2013. The Structure, Distribution, and Biomass of the World's Forests. Annual Review of Ecology, Evolution, and Systematics 44: 593-622.

Peñuelas J, Canadell JG, Ogaya R. 2011. Increased water-use efficiency during the 20th century did not translate into enhanced tree growth. Global Ecology and Biogeography 20: 597-608.

Peters RL, Groenendijk P, Vlam M, Zuidema PA. 2015. Detecting long-term growth trends using tree rings: a critical evaluation of methods. Global Change Biology 21: 2040-2054.

Pinheiro J, Bates D, DebRoy S, Sarkar D, Team RC. 2018. nlme: Linear and Nonlinear Mixed Effects Models. R package version 3.1-131.1.

PRISM Climate Group, Oregon State University. 2004. : http://prism.oregonstate.edu.

R Core Team. 2018. R: A language and environment for Statistical Computing.

Reich PB, Hobbie SE, Lee T, Ellsworth DS, West JB, Tilman D, Knops JMH, Naeem S, Trost J. 2006. Nitrogen limitation constrains sustainability of ecosystem response to $\mathrm{CO}_{2}$. Nature 440: 922-925.

Roman DT, Novick KA, Brzostek ER, Dragoni D, Rahman F, Phillips RP. 2015. The role of isohydric and anisohydric species in determining ecosystem-scale response to severe drought. Oecologia 179: 641-654.

Saurer M, Siegwolf RTW, Schweingruber FH. 2004. Carbon isotope discrimination indicates improving water-use efficiency of trees in northern Eurasia over the last 100 years. Global Change Biology 10: 2109-2120. 
Savard MM, Bégin C, Marion J. 2014. Modelling carbon isotopes in spruce trees reproduces air quality changes due to oil sands operations. Ecological Indicators 45: 1-8.

Savard MM, Bégin C, Parent M, Smirnoff A, Marion J. 2004. Effects of Smelter Sulfur Dioxide Emissions. Journal of Environment Quality 33: 13.

Savva Y, Berninger F. 2010. Sulphur deposition causes a large-scale growth decline in boreal forests in Eurasia. Global Biogeochemical Cycles 24: 1-14.

Schlesinger WH, Jasechko S. 2014. Transpiration in the global water cycle. Agricultural and Forest Meteorology 189-190: 115-117.

Schulte-Uebbing L, de Vries W. 2018. Global-scale impacts of nitrogen deposition on tree carbon sequestration in tropical, temperate, and boreal forests: A meta-analysis. Global Change Biology 24: e416-e431.

Seibt U, Rajabi A, Griffiths H, Berry JA. 2008. Carbon isotopes and water use efficiency: sense and sensitivity. Oecologia 155: 441-454.

van der Sleen P, Groenendijk P, Vlam M, Anten NPR, Boom A, Bongers F, Pons TL, Terburg G, Zuidema PA. 2015. No growth stimulation of tropical trees by 150 years of $\mathrm{CO}_{2}$ fertilization but water-use efficiency increased. Nature Geoscience 8: 24-28.

Soil Survey Geographic (SSURGO) Database for Pocahontas and Randolph Counties, WV.

Stokes MA, Smiley TL. 1996. An Introduction to Tree-Ring Dating. Tuscon, AZ: University of Arizona Press.

Sullivan TJ, Lawrence GB, Bailey SW, McDonnell TC, Beier CM, Weathers KC, McPherson GT, Bishop DA. 2013. Effects of acidic deposition and soil acidification on sugar maple trees in the Adirondack Mountains, New York. Environmental Science and Technology 47: 12687-12694.

Tardif JC, Conciatori F, Nantel P, Gagnon D. 2006. Radial growth and climate responses of white oak (Quercus alba) and northern red oak (Quercus rubra) at the northern distribution limit of white oak in Quebec, Canada. Journal of Biogeography 33: 1657-1669.

Terrer C, Jackson RB, Prentice IC, Keenan TF, Kaiser C, Vicca S, Fisher JB, Reich PB, Stocker $\mathrm{BD}$, Hungate $\mathrm{BA}$, et al. 2019. Nitrogen and phosphorus constrain the $\mathrm{CO}_{2}$ fertilization of global plant biomass. Nature Climate Change.

Thomas RQ, Canham CD, Weathers KC, Goodale CL. 2010. Increased tree carbon storage in response to nitrogen deposition in the US. Nature Geoscience 3: 13-17. 
Thomas RB, Spal SE, Smith KR, Nippert JB. 2013. Evidence of recovery of Juniperus virginiana trees from sulfur pollution after the Clean Air Act. Proceedings of the National Academy of Sciences 110: 15319-15324.

U.S. Environmental Protection Agency, Air Emissions Inventory, Air Pollution Emissions Trends Data. 2015.

US Geological Survey (1946) Physiographic divisions of the conterminous U.S.

Walker AP, De Kauwe MG, Medlyn BE, Zaehle S, Iversen CM, Asao S, Guenet B, Harper A, Hickler T, Hungate BA, et al. 2019. Decadal biomass increment in early secondary succession woody ecosystems is increased by $\mathrm{CO}_{2}$ enrichment. Nature Communications 10: 454.

Wang Y, Solberg S, Yu P, Myking T, Vogt RD, Du S. 2007. Assessments of tree crown condition of two Masson pine forests in the acid rain region in south China. Forest Ecology and Management 242: 530-540.

Way DA, Oren R. 2010. Differential responses to changes in growth temperature between trees from different functional groups and biomes: a review and synthesis of data. Tree Physiology 30: 669-688.

Wigley TML, Briffa KR, Jones PD. 1984. On the Average Value of Correlated Time Series, with Applications in Dendroclimatology and Hydrometeorology. Journal of Climate and Applied Meteorology 23: 201-213.

Woodbury PB, Smith JE, Heath LS. 2007. Carbon sequestration in the U.S. forest sector from 1990 to 2010. Forest Ecology and Management 241: 14-27.

Wu Z, Dijkstra P, Koch GW, Peñuelas J, Hungate BA. 2011. Responses of terrestrial ecosystems to temperature and precipitation change: A meta-analysis of experimental manipulation. Global Change Biology 17: 927-942. 
Chapter 5. General conclusions about the trends and drivers of tree growth and intrinsic water use efficiency during the $20^{\text {th }}$ century 


\subsection{General Conclusions.}

My dissertation examines the trends and drivers of tree growth and intrinsic water use efficiency (iWUE) during the $20^{\text {th }}$ century. Since the onset of the industrial revolution, there have been drastic increases in atmospheric $\mathrm{CO}_{2}$ concentrations $\left(\mathrm{C}_{\mathrm{a}}\right)$ (Keeling et al., 2016), significant changes in climate (Dai, 2012; Trenberth et al., 2014), and pronounced changes in acidic air pollution (WHO, 2016) across the globe. While increasing atmospheric $\mathrm{C}_{\mathrm{a}}$ is spatially consistent, climate and acidic air pollution are highly variable across both space and time. Importantly, as trees dynamically respond to environmental change, there will be cascading effects throughout the Earth-climate system at local to continental scales (Swann et al., 2016; Kooperman et al., 2018). Given the central role of trees in linking the carbon and water cycles, the overall aim of this research project was to 1) identify those factors most important in driving global scale changes in tree iWUE, 2) determine at a regional scale how environmental change and reductions in acid pollution affect the growth and physiology of an environmentally sensitive tree species and 3) examine the drivers of long term growth and physiology of two broadleaf tree species in the Central Appalachian Mountains where moderate changes in climate and large reductions in acid pollution have occurred.

In Chapter 2, I synthesized annually-resolved tree ring carbon and oxygen isotope data from 49 published articles to 1) examine the global trends and environmental drivers of tree ring $\delta^{13} \mathrm{C}$ derived iWUE and 2) investigate whether trends in tree iWUE are overwhelmingly driven by changes in leaf photosynthesis or stomatal conductance through a combined analysis of tree ring $\delta^{13} \mathrm{C}$ and $\delta^{18} \mathrm{O}$. For this chapter, I compiled 113 unique tree ring $\delta^{13} \mathrm{C}$ and $\delta^{18} \mathrm{O}$ chronologies that represent 34 tree species across 84 sites in 10 biomes that span a spectrum of leaf and wood types. Based on experimental (Battipaglia et al., 2013) and long-term observational studies (Frank et al., 2015; Giguère-Croteau et al., 2019; Guerrieri et al., 2019), I hypothesized iWUE would increase across all tree species, regardless of plant functional type and would be driven primarily by increasing atmospheric $\mathrm{CO}_{2}$. Further, I expected reductions in stomatal conductance $\left(g_{s}\right)$ to overwhelm potential increases in photosynthesis $\left(A_{n e t}\right)$ in cases where iWUE increased. I used a model selection approach to determine the importance and contribution of the environmental factors atmospheric $\mathrm{CO}_{2}$, growing season precipitation, growing season temperature, and growing season vapor pressure deficit to changes in iWUE for the period 1901 
- 2015. To do this, I compared 1,450 unique linear mixed effect model structures, examining every fixed effect combination, including second order interactions, after which models were ranked by the corrected Akaike's Information Criterion $\left(\mathrm{AIC}_{\mathrm{c}}\right)$. The best model, as characterized by having the lowest $\mathrm{AIC}_{\mathfrak{c}}$, revealed tree-level iWUE increased, on average, by $c a .40 \%$ over the twentieth century. I identified a breakpoint in the combined iWUE chronology at 1963, after which iWUE increased linearly at a rate of $1.67 \%$ per year, approximately 3.9 times faster than the previous 63 years. Across all species and study locations since 1963, model results indicated increasing iWUE was strongly, positively related to atmospheric $\mathrm{CO}_{2}$, supporting my hypothesis. However, I also found iWUE was also positively related to growing season vapor pressure deficit and was negatively related to growing season precipitation. Of all chronologies examined since the 1963 breakpoint, $18.6 \%$ showed decreasing $\Delta^{18} \mathrm{O}_{\mathrm{lw}}, 71.7 \%$ showed constant $\Delta^{18} \mathrm{O}_{\mathrm{lw}}$, and 9.7\% showed increasing $\Delta^{18} \mathrm{O}_{\mathrm{lw}}$, despite consistent increases in iWUE. This points to enhanced $A_{\text {net }}$ overwhelming increases in $g_{s}$ where $\Delta^{18} \mathrm{O}_{\mathrm{lw}}$ declined, as well as driving increasing iWUE under constant $g_{s}$ where $\Delta^{18} \mathrm{O}_{\mathrm{lw}}$ remained constant, such that increasing iWUE was driven by stimulated $A_{n e t}$ in $c a .90 \%$ of chronologies examined. These data highlight the complexity of tree responses to environmental change and reinforce the importance of increased photosynthesis, and not reductions in leaf $g_{s}$, as the primary driver in widespread iWUE increases.

In Chapter 3, I focused my analysis of the drivers of tree-level iWUE to red spruce in the Central Appalachian Mountains, which experienced some of the highest levels of acidic pollution in the eastern United States prior to the Clean Air Act Amendments of 1990 (EPA 2015). Reductions in acidic pollution since $c a$. 1990 , coupled with increasing atmospheric $\mathrm{CO}_{2}$ and moderate changes in climate, provide a unique opportunity to disentangle how multiple environmental factors simultaneously influence the growth and physiology of red spruce. Given the previously documented negative effects of acid deposition on red spruce function (Borer $e t$ al., 2005; Engel et al., 2016), I hypothesized growth would be negatively influenced by acidic deposition, and would modulate any $\mathrm{CO}_{2}$ effect on iWUE. To test this hypothesis, I collected increment cores for growth and carbon and nitrogen isotope analysis from three study locations spanning 100 kilometers in the Monongahela National Forest, West Virginia where red spruce are co-dominant canopy trees. I developed site-level growth chronologies using at least 20 individual trees at each site, after which five randomly sampled cores were analyzed for annual 
tree ring $\delta^{13} \mathrm{C}$ and $\delta^{15} \mathrm{~N}$. While tree ring $\delta^{13} \mathrm{C}$ can be used to calculate tree-level iWUE, tree ring $\delta^{15} \mathrm{~N}$ serves as an index of ecosystem nitrogen $(\mathrm{N})$ status, whereby higher $\delta^{15} \mathrm{~N}$ signatures correspond to increased nitrogen supply relative to demand. Last, I collected physiological measurements on the red spruce trees (A- $\mathrm{C}_{\mathrm{i}}$ curves) in order to reconstruct historical seasonallyintegrated photosynthesis and stomatal conductance. I found growth declined at each of the red spruce stands from 1940 to 1989, after which growth increased through 2014. The rates of decline between 1940 and $c a$. 1989 were not different between sites; nor was the rate of recovery after $c a$. 1989. I found the enhanced growth of red spruce after 1989 was driven by increasing atmospheric $\mathrm{CO}_{2}$, warmer April temperatures, and reductions in acidic sulfur pollution, highlighting the positive effects of increasing atmospheric $\mathrm{CO}_{2}$ on tree growth in a period of rapidly declining acidic pollution. Using a robust statistical model, I calculated, as a first approximation, the potential consequences of acid pollution on carbon sequestration in forests of the northeastern United States by coupling land cover, biomass, and acid pollution data products and showed since 1940, $c a .0 .75 \mathrm{Pg} \mathrm{C}$ may not have been sequestered in aboveground woody biomass due to high levels of acidic pollution.

Red spruce tree ring carbon isotope analysis showed iWUE increased from 1940 to $c a$. 2005, after which iWUE partially declined, resulting in an overall ca. 51\% increase in iWUE over the 75-year period. A simple modeling exercise showed $\mathrm{CO}_{2}$ effects alone correctly predicted iWUE at 2014, following the downturn in iWUE in 2005. Importantly, I found acidic pollution had a larger effect on iWUE of the red spruce trees than did atmospheric $\mathrm{CO}_{2}$ over the same time period, likely through reductions in stomatal conductance (Borer et al., 2005). Nitrogen isotope analysis showed $\delta^{15} \mathrm{~N}$ signatures did not change from 1940 to 1989, after which they sharply declined at all three study locations, suggesting a decrease in ecosystem nitrogen supply relative to demand. Together, this multiproxy analysis shows high acid pollution led to reduced tree growth and $\mathrm{N}$ demand from 1940 to 1989, after which tree growth increased as inputs declined, leading to lower $\mathrm{N}$ supply relative to demand. In summary, this chapter documents the complex environmental interactions that have contributed to the recovery of red spruce forest ecosystems from pervasive acidic air pollution beginning in 1989, about 15 years after acidic pollutants started to decline in the United States. 
In Chapter 4 of this research project, I examined the historical environmental drivers of northern red oak (Quercus rubra) and tulip poplar (Liriodendron tulipifera) in two reference watersheds in the Fernow Experimental Forest (FEF), West Virginia. Furthermore, I extended my analysis by performing a simple modelling exercise to examine the potential effects of the Clean Air Act on carbon sequestration in eastern U.S. forests, as well as how iWUE may be expected to change under future climate scenarios. While Chapter 2 provided insight over the broad-scale controls over tree iWUE and Chapter 3 underscored the influence of acidic pollution on a highly sensitive tree species, Chapter 4 provides a highly localized investigation of the controls over growth and iWUE of two tree species largely representative of the ecology of forests of the eastern U.S. in the context of historical and future environmental change. I hypothesized the broadleaf deciduous trees may be sensitive to acidic pollution but will also be highly sensitive to climate. Furthermore, I hypothesized red oak and tulip poplar trees will show increasing iWUE over since 1960, driven primarily by increasing atmospheric $\mathrm{CO}_{2}$. I conducted this experiment in two adjacent watersheds, WS10 and WS13, in the FEF where I cored approximately twenty trees of each species, northern red oak and tulip poplar. I randomly selected a subset of five trees of each species within each watershed for physiological measurements ( $\mathrm{A}-\mathrm{C}_{\mathrm{i}}$ curves), in addition to $\delta^{13} \mathrm{C}$ analysis to calculate iWUE. I found sustained increases in basal area increment (BAI) of both mature tree species since 1960 that were mainly driven by reduced acidic sulfur pollution and increasing summer precipitation, while declining acidic nitrogen pollution negatively impacted tree BAI. Increasing atmospheric $\mathrm{CO}_{2}$ largely contributed to increasing iWUE but increases in iWUE were attenuated by declining acidic nitrogen pollution. Interactive effects between environmental factors reveal that responses to environmental drivers of growth and physiology are complex and do not operate in isolationfor example, I found no evidence of $\mathrm{CO}_{2}$ stimulating growth of red oak trees, but an interaction between $\mathrm{N}$ emissions and $\mathrm{CO}_{2}$ showed tulip poplar growth was stimulated under elevated $\mathrm{CO}_{2}$, but only when $\mathrm{N}$ was sufficient to sustain growth. As such, an important finding from this chapter is how environmental factors interact to influence the growth and physiology of broadleaf deciduous trees over multi-decadal time scales. Given the negative impact of acidic sulfur pollution on tree growth, I used a statistical model to examine the potential impact of having not implemented the Clean Air Act and subsequent amendments on both species. My results show since 1990, both tree species would have stored $c a .13 \%$ less carbon in 
aboveground biomass without this landmark environmental legislation in the absence of $\mathrm{NO}_{\mathrm{x}}$ effects that showed species-specific positive associations with growth . I further examined how future climate change may be expected to influence iWUE of both tree species and showed iWUE will continue to increase as atmospheric $\mathrm{CO}_{2}$ rises, but climate may modulate iWUE much more for red oak trees than for tulip poplar trees. Overall, results from this chapter showcase the importance of considering the interactive effects of air pollution and climate change and on tree growth and physiology over multi-decadal time scales and highlights the need to include acidic air pollution and acid deposition in Earth System Models.

During this research project I found evidence for consistent increases in tree iWUE ( $c a$. $+40 \%$ since 1901) through a global meta-analysis of 34 unique tree species, as well as two observational studies conducted in the Central Appalachian Mountains in the eastern United States. In each study, increasing iWUE was largely driven by increasing atmospheric $\mathrm{CO}_{2}$, though climate factors such as precipitation and vapor pressure deficit modulate this response, which may be particularly important under future climate scenarios (Figure 4.7). Furthermore, a global meta-analysis using a dual isotope approach showed in approximately $90 \%$ of cases examined, increasing iWUE resulted from stimulated leaf photosynthesis overwhelming changes in stomatal conductance (Figure 2.4). These findings are in line with observations of enhanced leaf photosynthesis (Haverd et al., 2020) and vegetation productivity (Cernusak et al., 2019) at the global scale and underscore the dynamic response of leaf physiology over a range of atmospheric $\mathrm{CO}_{2}$.

A focused analysis of temporal iWUE changes in a region with a history of acidic deposition also showed iWUE may also be modulated by non-climatic factors. For example, iWUE of tulip poplar increased with atmospheric $\mathrm{CO}_{2}$, but this effect was exacerbated under high $\mathrm{N}$ levels (Figure 4.5b), likely through enhanced photosynthesis under increasing $\mathrm{N}$ availability (Jennings et al., 2016). Furthermore, I found red spruce trees that had experienced high acidic pollution loads generally showed increasing iWUE over the late twentieth century, although acidic pollution effects on the underlying component parts, photosynthesis and stomatal conductance, altered this response (Figure 3.3). Together, these results underscore the general influence of atmospheric $\mathrm{CO}_{2}$ and climate on tree iWUE across large spatial scales, but also 
highlight the complexity of this response when additional factors such as acidic pollution are considered.

A regional analysis of historical growth of three tree species in the Central Appalachian Mountains reinforces the importance of considering the controls of multiple environmental factors over tree growth and productivity. While we did find evidence for a stimulatory $\mathrm{CO}_{2}$ effect on growth of two of the three tree species examined, climate also played an important role. Importantly, reductions in sulfur pollution had large, persistent effects on the growth of all three species, and negatively impacted total carbon sequestration in these forest stands as shown through simple modeling exercises (Figure 4.6, Figure S3.7). Further, this research highlights a spectrum of sensitivity to acidic pollution among different tree species.

In conclusion, the results of this research project showcase the dynamic regulation of tree growth and physiology under environmental change. Importantly, I have shown acidic pollution negatively impacts tree growth, and modulates tree iWUE responses to increasing $\mathrm{CO}_{2}$ and climate change, yet cutting-edge process-based models do not consider these processes. This will introduce uncertainty in projections of forest responses to environmental change, potentially overestimating carbon sequestration especially in areas where acidic pollution is high. However, this research also underscores the ability of forests to recover from the negative impacts of acidic pollution and may provide a promising outlook under future scenarios with stringent environmental legislation. 


\subsection{Literature Cited.}

Battipaglia G, Saurer M, Cherubini P, Calfapietra C, McCarthy HR, Norby RJ, Francesca Cotrufo M. 2013. Elevated $\mathrm{CO}_{2}$ increases tree-level intrinsic water use efficiency: insights from carbon and oxygen isotope analyses in tree rings across three forest FACE sites. New Phytologist 197: 544-554.

Borer CH, Schaberg PG, DeHayes DH. 2005. Acidic mist reduces foliar membrane-associated calcium and impairs stomatal responsiveness in red spruce. Tree Physiology 25: 673-680.

Cernusak LA, Haverd V, Brendel O, Le Thiec D, Guehl J-M, Cuntz M. 2019. Robust Response of Terrestrial Plants to Rising $\mathrm{CO}_{2}$. Trends in Plant Science: 1-9.

Dai A. 2012. Increasing drought under global warming in observations and models. Nature Climate Change 3: 52-58.

Engel BJ, Schaberg PG, Hawley GJ, Rayback SA, Pontius J, Kosiba AM, Miller EK. 2016. Assessing relationships between red spruce radial growth and pollution critical load exceedance values. Forest Ecology and Management 359: 83-91.

Frank DC, Poulter B, Saurer M, Esper J, Huntingford C, Helle G, Treydte K, Zimmermann NE, Schleser GH, Ahlström A, et al. 2015. Water-use efficiency and transpiration across European forests during the Anthropocene. Nature Climate Change 5: 579-583.

Giguère-Croteau C, Girardin MP, Bergeron Y, Drobyshev I, Hélie J-F, Boucher É, Silva LCR, Garneau M. 2019. North America's oldest boreal trees are more efficient water users due to increased $\left[\mathrm{CO}_{2}\right]$, but do not grow faster . Proceedings of the National Academy of Sciences 116: 201816686.

Guerrieri R, Belmecheri S, Ollinger S V, Asbjornsen H, Jennings K, Xiao J, Stocker BD, Martin M, Hollinger DY, Bracho-Garrillo R, et al. 2019. Disentangling the role of photosynthesis and stomatal conductance on rising forest water-use efficiency. Proceedings of the National Academy of Sciences: 201905912.

Haverd V, Smith B, Canadell JG, Cuntz M, Mikaloff-Fletcher S, Farquhar G, Woodgate W, Briggs PR, Trudinger CM. 2020. Higher than expected $\mathrm{CO}_{2}$ fertilization inferred from leaf to global observations. Global Change Biology: gcb.14950.

Jennings KA, Guerrieri R, Vadeboncoeur MA, Asbjornsen H. 2016. Response of Quercus velutina growth and water use efficiency to climate variability and nitrogen fertilization in a temperate deciduous forest in the northeastern USA. Tree Physiology 36: 428-443.

Keeling RF, Piper SC, Bollenbacher AF, Walker SJ. 2016. Scripps $\mathrm{CO}_{2}$ Program. 
Kooperman GJ, Fowler MD, Hoffman FM, Koven CD, Lindsay K, Pritchard MS, Swann ALS, Randerson JT. 2018. Plant Physiological Responses to Rising $\mathrm{CO}_{2}$ Modify Simulated Daily Runoff Intensity With Implications for Global-Scale Flood Risk Assessment. Geophysical Research Letters 45: 12,457-12,466.

Swann ALS, Hoffman FM, Koven CD, Randerson JT. 2016. Plant responses to increasing $\mathrm{CO}_{2}$ reduce estimates of climate impacts on drought severity. Proceedings of the National Academy of Sciences 113: 10019-10024.

Trenberth KE, Dai A, van der Schrier G, Jones PD, Barichivich J, Briffa KR, Sheffield J. 2014. Global warming and changes in drought. Nature Clim. Change 4: 17-22.

U.S. Environmental Protection Agency, Air Emissions Inventory, Air Pollution Emissions Trends Data. 2015.

WHO. 2016. Global Health Observatory data repository. 


\section{Appendix. Supplementary Tables and Figures}

Table S2.1. List of sites and species and their associated attributes included in the examination of changes in iWUE and $\Delta^{18} \mathrm{O}^{1 \mathrm{w}}$ for the periods 1901 - 2015 and 1963 - 2015. For a given published study, information regarding the location all sites (latitude/longitude) and the number of trees of each species used in this analysis are listed, along with wood type, leaf type, biome, and the trend in iWUE and $\Delta^{18} \mathrm{O}_{\mathrm{lw}}$ for the time periods $1901-2015$ and $1963-2015$, respectively. Significance of trends in are denoted by ${ }^{* *}$ for $\mathrm{p}<0.05,{ }^{*}$ for $\mathrm{p}$ $<0.01$, and ${ }^{\mathrm{ns}}$ where no significant trend was detected.

\begin{tabular}{|c|c|c|c|c|c|c|c|c|c|c|c|}
\hline Citation & Latitude & Longitude & $\begin{array}{c}\text { Latin } \\
\text { binomial }\end{array}$ & $\mathrm{N}$ & Wood Type & Leaf Type & Biome & $\begin{array}{l}\text { iWUE trend } \\
1901-2015\end{array}$ & $\begin{array}{l}\text { iWUE trend } \\
1963-2015\end{array}$ & $\begin{array}{l}\Delta^{18} \mathrm{O}_{\mathrm{lw}} \text { trend } \\
1901-2015\end{array}$ & $\begin{array}{l}\Delta^{18} \mathrm{O}_{\mathrm{lw}} \text { trend } \\
1963-2015 \\
\end{array}$ \\
\hline Awada et al. 2019 & 40.25 & -100.27 & $\begin{array}{l}\text { Populus } \\
\text { deltoides }\end{array}$ & 4 & $\begin{array}{l}\text { Diffuse } \\
\text { Porous }\end{array}$ & $\begin{array}{l}\text { Broadleaf } \\
\text { Deciduous }\end{array}$ & $\begin{array}{l}\text { Temperate Grasslands, } \\
\text { Savannas \& Shrublands }\end{array}$ & $1.066^{* *}$ & $1.066^{* *}$ & $0.020^{\mathrm{ns}}$ & $0.020^{\mathrm{ns}}$ \\
\hline $\begin{array}{l}\text { Colombaroli et al. } \\
2016\end{array}$ & 0.23 & 25.25 & $\begin{array}{l}\text { Pericopsis } \\
\quad \text { elata }\end{array}$ & 4 & $\begin{array}{l}\text { Diffuse } \\
\text { Porous }\end{array}$ & $\begin{array}{l}\text { Broadleaf } \\
\text { Deciduous }\end{array}$ & $\begin{array}{c}\text { Tropical \& Subtropical Moist } \\
\text { Broadleaf Forests }\end{array}$ & $0.412^{* *}$ & $0.483^{* *}$ & $0.037^{* *}$ & $0.036^{* *}$ \\
\hline Hartl-Meier et al. 2014 & 47.90 & 14.44 & $\begin{array}{l}\text { Fagus } \\
\text { sylvatica }\end{array}$ & 8 & $\begin{array}{l}\text { Diffuse } \\
\text { Porous }\end{array}$ & $\begin{array}{l}\text { Broadleaf } \\
\text { Deciduous }\end{array}$ & $\begin{array}{l}\text { Temperate Broadleaf \& } \\
\text { Mixed Forests }\end{array}$ & $0.429^{* *}$ & $0.429^{* *}$ & $0.045^{*}$ & $0.045^{*}$ \\
\hline Hartl-Meier et al. 2014 & 47.80 & 14.44 & $\begin{array}{l}\text { Fagus } \\
\text { sylvatica }\end{array}$ & 8 & $\begin{array}{l}\text { Diffuse } \\
\text { Porous }\end{array}$ & $\begin{array}{r}\text { Broadleaf } \\
\text { Deciduous }\end{array}$ & Temperate Conifer Forests & $0.344^{* *}$ & $0.344^{* *}$ & $0.039^{\text {ns }}$ & $0.039^{\text {ns }}$ \\
\hline Hartl-Meier et al. 2014 & 47.70 & 14.44 & $\begin{array}{l}\text { Fagus } \\
\text { sylvatica }\end{array}$ & 8 & $\begin{array}{l}\text { Diffuse } \\
\text { Porous }\end{array}$ & $\begin{array}{l}\text { Broadleaf } \\
\text { Deciduous }\end{array}$ & Temperate Conifer Forests & $0.371^{* *}$ & $0.371^{* *}$ & $0.031^{\text {ns }}$ & $0.031^{\mathrm{ns}}$ \\
\hline Lavergne et al. 2017 & -41.19 & -71.62 & $\begin{array}{l}\text { Nothofagus } \\
\text { pumilio }\end{array}$ & 12 & $\begin{array}{l}\text { Diffuse } \\
\text { Porous }\end{array}$ & $\begin{array}{r}\text { Broadleaf } \\
\text { Deciduous }\end{array}$ & $\begin{array}{l}\text { Temperate Broadleaf \& } \\
\text { Mixed Forests }\end{array}$ & $0.366^{* *}$ & $0.459^{* *}$ & $0.022^{* *}$ & $0.024^{* *}$ \\
\hline Levesque et al. 2019 & 41.42 & -74.01 & $\begin{array}{l}\text { Liriodendron } \\
\text { tulipifera }\end{array}$ & 5 & $\begin{array}{l}\text { Diffuse } \\
\text { Porous }\end{array}$ & $\begin{array}{l}\text { Broadleaf } \\
\text { Deciduous }\end{array}$ & $\begin{array}{l}\text { Temperate Broadleaf \& } \\
\text { Mixed Forests }\end{array}$ & $0.043^{\text {ns }}$ & $0.014^{\mathrm{ns}}$ & $-0.020^{* *}$ & $-0.031^{* *}$ \\
\hline Levesque et al. 2019 & 37.07 & -89.60 & $\begin{array}{l}\text { Liriodendron } \\
\text { tulipifera }\end{array}$ & 5 & $\begin{array}{l}\text { Diffuse } \\
\text { Porous }\end{array}$ & $\begin{array}{l}\text { Broadleaf } \\
\text { Deciduous }\end{array}$ & $\begin{array}{l}\text { Temperate Grasslands, } \\
\text { Savannas \& Shrublands }\end{array}$ & $0.255^{* *}$ & $0.255^{* *}$ & $-0.040^{* *}$ & $-0.040^{* *}$ \\
\hline Levesque et al. 2019 & 34.67 & -84.18 & $\begin{array}{l}\text { Liriodendron } \\
\text { tulipifera }\end{array}$ & 5 & $\begin{array}{l}\text { Diffuse } \\
\text { Porous }\end{array}$ & $\begin{array}{l}\text { Broadleaf } \\
\text { Deciduous }\end{array}$ & $\begin{array}{l}\text { Temperate Broadleaf \& } \\
\text { Mixed Forests }\end{array}$ & $0.220^{* *}$ & $0.269^{* *}$ & $-0.012^{\mathrm{ns}}$ & $-0.006^{\mathrm{ns}}$ \\
\hline Liu et al. 2014 & 40.95 & 100.18 & $\begin{array}{l}\text { Populus } \\
\text { euphratica }\end{array}$ & 5 & $\begin{array}{l}\text { Diffuse } \\
\text { Porous }\end{array}$ & $\begin{array}{l}\text { Broadleaf } \\
\text { Deciduous }\end{array}$ & Deserts \& Xeric Shrublands & $0.119^{* *}$ & $0.161^{* *}$ & $0.004^{\text {ns }}$ & $0.044^{* *}$ \\
\hline Sladden et al. 2018 & 51.31 & -0.84 & $\begin{array}{l}\text { Fagus } \\
\text { sylvatica }\end{array}$ & 1 & $\begin{array}{l}\text { Diffuse } \\
\text { Porous }\end{array}$ & $\begin{array}{l}\text { Broadleaf } \\
\text { Deciduous }\end{array}$ & $\begin{array}{l}\text { Temperate Broadleaf \& } \\
\text { Mixed Forests }\end{array}$ & $0.503^{* *}$ & $0.490^{* *}$ & $0.012^{*}$ & $0.010^{\mathrm{ns}}$ \\
\hline Awada et al. 2019 & 40.25 & -100.27 & $\begin{array}{l}\text { Elaeagnus } \\
\text { angustifolia }\end{array}$ & 3 & Ring Porous & $\begin{array}{l}\text { Broadleaf } \\
\text { Deciduous }\end{array}$ & $\begin{array}{l}\text { Temperate Grasslands, } \\
\text { Savannas \& Shrublands }\end{array}$ & $0.401^{\mathrm{ns}}$ & $0.401^{\mathrm{ns}}$ & $0.029^{\text {ns }}$ & $0.029^{\text {ns }}$ \\
\hline Danis et al. 2006 & 45.71 & 6.15 & Quercus $R$ & 6 & Ring Porous & $\begin{array}{l}\text { Broadleaf } \\
\text { Evergreen }\end{array}$ & Temperate Conifer Forests & $0.416^{* *}$ & $0.416^{* *}$ & $0.001^{\mathrm{ns}}$ & $0.001^{\mathrm{ns}}$ \\
\hline Danis et al. 2006 & 45.75 & 6.19 & Quercus $R$ & 9 & Ring Porous & $\begin{array}{l}\text { Broadleaf } \\
\text { Evergreen }\end{array}$ & Temperate Conifer Forests & $0.400^{* *}$ & $0.400^{* *}$ & $-0.010^{\text {ns }}$ & $-0.010^{\text {ns }}$ \\
\hline Etien et al. 2009 & 48.38 & 2.67 & $\begin{array}{l}\text { Quercus } \\
\text { petraea }\end{array}$ & 15 & Ring Porous & $\begin{array}{l}\text { Broadleaf } \\
\text { Deciduous }\end{array}$ & $\begin{array}{l}\text { Temperate Broadleaf \& } \\
\text { Mixed Forests }\end{array}$ & $0.202^{* *}$ & $0.412^{*}$ & $-0.002^{\mathrm{ns}}$ & $0.007^{\mathrm{ns}}$ \\
\hline Granda et al. 2018 & 42.68 & -2.49 & $\begin{array}{l}\text { Quercus } \\
\text { pyrenaica }\end{array}$ & 5 & Ring Porous & $\begin{array}{l}\text { Broadleaf } \\
\text { Deciduous }\end{array}$ & $\begin{array}{l}\text { Temperate Broadleaf \& } \\
\text { Mixed Forests }\end{array}$ & $0.598^{* *}$ & $0.639^{* *}$ & $0.029^{* *}$ & $0.029^{* *}$ \\
\hline Granda et al. 2018 & 42.68 & -2.49 & $\begin{array}{l}\text { Quercus } \\
\text { robur }\end{array}$ & 5 & Ring Porous & $\begin{array}{r}\text { Broadleaf } \\
\text { Deciduous }\end{array}$ & $\begin{array}{l}\text { Temperate Broadleaf \& } \\
\text { Mixed Forests }\end{array}$ & $0.519^{* *}$ & $0.550^{* *}$ & $0.038^{* *}$ & $0.042^{* *}$ \\
\hline Granda et al. 2018 & 43.15 & -1.60 & $\begin{array}{c}\text { Quercus } \\
\text { pyrenaica }\end{array}$ & 5 & Ring Porous & $\begin{array}{l}\text { Broadleaf } \\
\text { Deciduous }\end{array}$ & $\begin{array}{l}\text { Temperate Broadleaf \& } \\
\text { Mixed Forests }\end{array}$ & $0.338^{* *}$ & $0.363^{* *}$ & $0.025^{* *}$ & $0.024^{* *}$ \\
\hline
\end{tabular}




\begin{tabular}{|c|c|c|c|c|c|c|c|c|c|c|c|}
\hline Granda et al. 2018 & 43.15 & -1.60 & $\begin{array}{l}\text { Quercus } \\
\text { robur }\end{array}$ & 5 & Ring Porous & $\begin{array}{l}\text { Broadleaf } \\
\text { Deciduous }\end{array}$ & $\begin{array}{l}\text { Temperate Broadleaf \& } \\
\text { Mixed Forests }\end{array}$ & $0.329^{* *}$ & $0.341^{* *}$ & $0.004^{\text {ns }}$ & $0.002^{\mathrm{ns}}$ \\
\hline Haupt et al. 2011 & 48.19 & 16.21 & $\begin{array}{l}\text { Quercus } \\
\text { petraea }\end{array}$ & 7 & Ring Porous & $\begin{array}{l}\text { Broadleaf } \\
\text { Deciduous }\end{array}$ & $\begin{array}{l}\text { Temperate Broadleaf \& } \\
\text { Mixed Forests }\end{array}$ & $0.239^{* *}$ & $0.278^{*}$ & $0.005^{\text {ns }}$ & $0.047^{* *}$ \\
\hline $\begin{array}{l}\text { Hilasvuori and } \\
\text { Berninger } 2010\end{array}$ & 60.00 & 23.08 & $\begin{array}{l}\text { Quercus } \\
\text { robur }\end{array}$ & 4 & Ring Porous & $\begin{array}{l}\text { Broadleaf } \\
\text { Deciduous }\end{array}$ & $\begin{array}{l}\text { Temperate Broadleaf \& } \\
\text { Mixed Forests }\end{array}$ & $0.222^{* *}$ & $0.300^{* *}$ & $0.004^{\text {ns }}$ & $-0.042^{*}$ \\
\hline Levesque et al. 2019 & 41.42 & -74.01 & $\begin{array}{l}\text { Quercus } \\
\text { rubra }\end{array}$ & 5 & Ring Porous & $\begin{array}{l}\text { Broadleaf } \\
\text { Deciduous }\end{array}$ & $\begin{array}{l}\text { Temperate Broadleaf \& } \\
\text { Mixed Forests }\end{array}$ & $0.121^{* *}$ & $0.135^{* *}$ & $-0.031^{* *}$ & $-0.040^{* *}$ \\
\hline Levesque et al. 2019 & 34.67 & -84.18 & $\begin{array}{l}\text { Quercus } \\
\text { rubra }\end{array}$ & 5 & Ring Porous & $\begin{array}{l}\text { Broadleaf } \\
\text { Deciduous }\end{array}$ & $\begin{array}{l}\text { Temperate Broadleaf \& } \\
\text { Mixed Forests }\end{array}$ & $0.128^{* *}$ & $0.082^{*}$ & $-0.004^{\text {ns }}$ & $-0.005^{\text {ns }}$ \\
\hline Levesque et al. 2019 & 34.68 & -94.63 & $\begin{array}{l}\text { Quercus } \\
\text { rubra }\end{array}$ & 5 & Ring Porous & $\begin{array}{l}\text { Broadleaf } \\
\text { Deciduous }\end{array}$ & $\begin{array}{l}\text { Temperate Broadleaf \& } \\
\text { Mixed Forests }\end{array}$ & $0.311^{* *}$ & $0.326^{* *}$ & $-0.016^{\mathrm{ns}}$ & $-0.027^{\mathrm{ns}}$ \\
\hline Loader et al. 2008 & 55.67 & -3.95 & $\begin{array}{l}\text { Quercus } \\
\text { robur }\end{array}$ & 4 & Ring Porous & $\begin{array}{l}\text { Broadleaf } \\
\text { Deciduous }\end{array}$ & $\begin{array}{l}\text { Temperate Broadleaf \& } \\
\text { Mixed Forests }\end{array}$ & $0.132^{* *}$ & $0.022^{\mathrm{ns}}$ & $0.000^{\text {ns }}$ & $0.002^{\mathrm{ns}}$ \\
\hline $\begin{array}{l}\text { Raffalli-Delerce et al. } \\
2004\end{array}$ & 48.10 & -1.68 & $\begin{array}{l}\text { Quercus } \\
\text { robur }\end{array}$ & 4 & Ring Porous & $\begin{array}{l}\text { Broadleaf } \\
\text { Deciduous }\end{array}$ & $\begin{array}{l}\text { Temperate Broadleaf \& } \\
\text { Mixed Forests }\end{array}$ & $0.148^{* *}$ & $0.307^{* *}$ & $0.004^{\mathrm{ns}}$ & $0.025^{\mathrm{ns}}$ \\
\hline Sladden et al. 2018 & 51.31 & -0.84 & $\begin{array}{l}\text { Castanea } \\
\text { sativa }\end{array}$ & 1 & Ring Porous & $\begin{array}{l}\text { Broadleaf } \\
\text { Deciduous }\end{array}$ & $\begin{array}{l}\text { Temperate Broadleaf \& } \\
\text { Mixed Forests }\end{array}$ & $0.713^{* *}$ & $0.817^{* *}$ & $0.026^{* *}$ & $0.020^{* *}$ \\
\hline Sladden et al. 2018 & 51.31 & -0.84 & $\begin{array}{l}\text { Quercus } \\
\text { robur }\end{array}$ & 1 & Ring Porous & $\begin{array}{l}\text { Broadleaf } \\
\text { Deciduous }\end{array}$ & $\begin{array}{l}\text { Temperate Broadleaf \& } \\
\text { Mixed Forests }\end{array}$ & $0.465^{* *}$ & $0.546^{* *}$ & $0.025^{* *}$ & $0.024^{*}$ \\
\hline Szczepanek et al. 2006 & 50.04 & 20.34 & $\begin{array}{l}\text { Quercus } \\
\text { robur }\end{array}$ & 4 & Ring Porous & $\begin{array}{l}\text { Broadleaf } \\
\text { Deciduous }\end{array}$ & $\begin{array}{l}\text { Temperate Broadleaf \& } \\
\text { Mixed Forests }\end{array}$ & $0.162^{* *}$ & $0.297^{\mathrm{ns}}$ & $0.004^{\mathrm{ns}}$ & $0.019^{\mathrm{ns}}$ \\
\hline Anderson et al. 1998 & 47.18 & 8.26 & Picea abies & 4 & Tracheids & $\begin{array}{l}\text { Needleleaf } \\
\text { Evergreen }\end{array}$ & $\begin{array}{l}\text { Temperate Broadleaf \& } \\
\text { Mixed Forests }\end{array}$ & $0.661^{* *}$ & $0.634^{* *}$ & $-0.041^{* *}$ & $-0.025^{\text {ns }}$ \\
\hline Awada et al. 2019 & 40.25 & -100.27 & $\begin{array}{l}\text { Juniperus } \\
\text { virginiana }\end{array}$ & 3 & Tracheids & $\begin{array}{l}\text { Needleleaf } \\
\text { Evergreen }\end{array}$ & $\begin{array}{l}\text { Temperate Grasslands, } \\
\text { Savannas \& Shrublands }\end{array}$ & $1.455^{* *}$ & $1.455^{* *}$ & $-0.046^{\mathrm{ns}}$ & $-0.046^{\mathrm{ns}}$ \\
\hline Battipaglia et al. 2009 & 41.13 & 14.58 & Abies alba & 4 & Tracheids & $\begin{array}{l}\text { Needleleaf } \\
\text { Evergreen }\end{array}$ & $\begin{array}{l}\text { Mediterranean Forests, } \\
\text { Woodlands \& Scrub }\end{array}$ & $0.212^{* *}$ & $0.290^{*}$ & $0.041^{*}$ & $0.049^{\mathrm{ns}}$ \\
\hline Battipaglia et al. 2009 & 41.13 & 14.58 & Picea abies & 4 & Tracheids & $\begin{array}{l}\text { Needleleaf } \\
\text { Evergreen }\end{array}$ & $\begin{array}{l}\text { Mediterranean Forests, } \\
\text { Woodlands \& Scrub }\end{array}$ & $0.391^{\text {ns }}$ & $0.184^{\text {ns }}$ & $0.021^{\text {ns }}$ & $0.016^{\mathrm{ns}}$ \\
\hline Boettger et al. 2014 & 49.15 & 9.53 & Abies alba & 6 & Tracheids & $\begin{array}{l}\text { Needleleaf } \\
\text { Evergreen }\end{array}$ & $\begin{array}{l}\text { Temperate Broadleaf \& } \\
\text { Mixed Forests }\end{array}$ & $0.312^{* *}$ & $-0.050^{\text {ns }}$ & $0.005^{\text {ns }}$ & $0.004^{\mathrm{ns}}$ \\
\hline Churakova et al. 2016 & 46.68 & 10.17 & $\begin{array}{l}\text { Larix } \\
\text { decidua }\end{array}$ & 4 & Tracheids & $\begin{array}{l}\text { Needleleaf } \\
\text { Deciduous }\end{array}$ & Temperate Conifer Forests & $0.354^{* *}$ & $0.699^{* *}$ & $0.001^{\mathrm{ns}}$ & $0.007^{\text {ns }}$ \\
\hline Churakova et al. 2016 & 46.68 & 10.17 & Pinus mugo & 4 & Tracheids & $\begin{array}{l}\text { Needleleaf } \\
\text { Evergreen }\end{array}$ & Temperate Conifer Forests & $0.295^{* *}$ & $0.695^{* *}$ & $-0.010^{*}$ & $-0.049^{*}$ \\
\hline Churakova et al. 2016 & 46.67 & 10.17 & $\begin{array}{c}\text { Larix } \\
\text { decidua }\end{array}$ & 4 & Tracheids & $\begin{array}{l}\text { Needleleaf } \\
\text { Deciduous }\end{array}$ & Temperate Conifer Forests & $0.338^{* *}$ & $0.657^{* *}$ & $-0.011^{*}$ & $-0.017^{\mathrm{ns}}$ \\
\hline Churakova et al. 2016 & 46.67 & 10.17 & Pinus mugo & 4 & Tracheids & $\begin{array}{l}\text { Needleleaf } \\
\text { Evergreen }\end{array}$ & Temperate Conifer Forests & $0.280^{* *}$ & $0.608^{* *}$ & $-0.011^{*}$ & $-0.022^{\mathrm{ns}}$ \\
\hline $\begin{array}{l}\text { Cullen and Grierson } \\
\qquad 2007\end{array}$ & -22.85 & 118.63 & $\begin{array}{c}\text { Callitris } \\
\text { columellaris }\end{array}$ & 11 & Tracheids & $\begin{array}{l}\text { Needleleaf } \\
\text { Evergreen }\end{array}$ & Deserts \& Xeric Shrublands & $0.033^{\text {ns }}$ & $-0.089^{\text {ns }}$ & $-0.060^{* *}$ & $-0.112^{\mathrm{ns}}$ \\
\hline Esper et al. 2017 & 45.71 & 6.15 & Picea abies & 4 & Tracheids & $\begin{array}{l}\text { Needleleaf } \\
\text { Evergreen }\end{array}$ & Temperate Conifer Forests & $0.235^{* *}$ & $0.246^{\mathrm{ns}}$ & $0.03^{* *}$ & $0.019^{\mathrm{ns}}$ \\
\hline Esper et al. 2018 & 67.95 & 20.03 & $\begin{array}{l}\text { Pinus } \\
\text { sylvestris }\end{array}$ & 4 & Tracheids & $\begin{array}{l}\text { Needleleaf } \\
\text { Evergreen }\end{array}$ & Tundra & $0.074^{* *}$ & $0.046^{\text {ns }}$ & $-0.020^{* *}$ & $-0.026^{\mathrm{ns}}$ \\
\hline Esper et al. 2018 & 68.00 & 20.03 & $\begin{array}{l}\text { Pinus } \\
\text { sylvestris }\end{array}$ & 4 & Tracheids & $\begin{array}{l}\text { Needleleaf } \\
\text { Evergreen }\end{array}$ & Tundra & $0.071^{* *}$ & $0.041^{\text {ns }}$ & $-0.016^{* *}$ & $-0.013^{\text {ns }}$ \\
\hline Esper et al. 2018 & 59.44 & 18.00 & $\begin{array}{l}\text { Pinus } \\
\text { sylvestris }\end{array}$ & 4 & Tracheids & $\begin{array}{l}\text { Needleleaf } \\
\text { Evergreen }\end{array}$ & $\begin{array}{l}\text { Temperate Broadleaf \& } \\
\text { Mixed Forests }\end{array}$ & $0.196^{* *}$ & $0.184^{* *}$ & $-0.017^{* *}$ & $-0.046^{* *}$ \\
\hline
\end{tabular}




\begin{tabular}{|c|c|c|c|c|c|c|c|c|c|c|c|}
\hline Esper et al. 2018 & 59.55 & 18.00 & $\begin{array}{c}\text { Pinus } \\
\text { sylvestris }\end{array}$ & 4 & Tracheids & $\begin{array}{l}\text { Needleleaf } \\
\text { Evergreen }\end{array}$ & $\begin{array}{l}\text { Temperate Broadleaf \& } \\
\text { Mixed Forests }\end{array}$ & $0.174^{* *}$ & $0.150^{*}$ & $-0.009^{*}$ & $-0.027^{*}$ \\
\hline Gennaretti et al. 2017 & 54.23 & -71.39 & $\begin{array}{l}\text { Picea } \\
\text { mariana }\end{array}$ & 5 & Tracheids & $\begin{array}{l}\text { Needleleaf } \\
\text { Evergreen }\end{array}$ & Boreal Forests/Taiga & $0.235^{* *}$ & $0.335^{*}$ & $0.002^{\mathrm{ns}}$ & $0.019^{\mathrm{ns}}$ \\
\hline $\begin{array}{l}\text { Giguére-Croteau et al. } \\
2019\end{array}$ & 48.47 & -79.33 & $\begin{array}{c}\text { Thuja } \\
\text { occidentalis }\end{array}$ & 11 & Tracheids & $\begin{array}{l}\text { Needleleaf } \\
\text { Evergreen }\end{array}$ & Boreal Forests/Taiga & $0.262^{* *}$ & $0.401^{* *}$ & $-0.018^{* *}$ & $0.010^{\mathrm{ns}}$ \\
\hline Gori et al. 2013 & 46.08 & 11.05 & Picea abies & 10 & Tracheids & $\begin{array}{l}\text { Needleleaf } \\
\text { Evergreen }\end{array}$ & Temperate Conifer Forests & $0.444^{* *}$ & $0.369^{* *}$ & $0.018^{\text {ns }}$ & $-0.016^{\mathrm{ns}}$ \\
\hline Gori et al. 2013 & 46.25 & 11.50 & Picea abies & 10 & Tracheids & $\begin{array}{l}\text { Needleleaf } \\
\text { Evergreen }\end{array}$ & Temperate Conifer Forests & $0.228^{* *}$ & $0.301^{\mathrm{ns}}$ & $-0.011^{\text {ns }}$ & $-0.059^{* *}$ \\
\hline Gori et al. 2013 & 46.29 & 11.61 & Picea abies & 10 & Tracheids & $\begin{array}{l}\text { Needleleaf } \\
\text { Evergreen }\end{array}$ & Temperate Conifer Forests & $0.310^{* *}$ & $0.362^{* *}$ & $0.023^{* *}$ & $0.022^{\mathrm{ns}}$ \\
\hline Granda et al. 2017 & 42.65 & 0.83 & $\begin{array}{c}\text { Pinus } \\
\text { uncinata }\end{array}$ & 4 & Tracheids & $\begin{array}{l}\text { Needleleaf } \\
\text { Evergreen }\end{array}$ & $\begin{array}{l}\text { Temperate Broadleaf \& } \\
\text { Mixed Forests }\end{array}$ & $0.180^{* *}$ & $0.296^{*}$ & $-0.012^{\mathrm{ns}}$ & $-0.048^{*}$ \\
\hline Granda et al. 2017 & 42.66 & 0.02 & $\begin{array}{c}\text { Pinus } \\
\text { uncinata }\end{array}$ & 4 & Tracheids & $\begin{array}{l}\text { Needleleaf } \\
\text { Evergreen }\end{array}$ & $\begin{array}{l}\text { Temperate Broadleaf \& } \\
\text { Mixed Forests }\end{array}$ & $0.039^{\text {ns }}$ & $0.330^{\mathrm{ns}}$ & $-0.012^{\mathrm{ns}}$ & $-0.080^{\text {ns }}$ \\
\hline Granda et al. 2017 & 42.35 & 1.96 & $\begin{array}{c}\text { Pinus } \\
\text { uncinata }\end{array}$ & 4 & Tracheids & $\begin{array}{l}\text { Needleleaf } \\
\text { Evergreen }\end{array}$ & $\begin{array}{l}\text { Temperate Broadleaf \& } \\
\text { Mixed Forests }\end{array}$ & $0.266^{\mathrm{ns}}$ & $0.544^{* *}$ & $0.004^{\text {ns }}$ & $0.001^{\mathrm{ns}}$ \\
\hline Grießinger et al. 2019 & 31.08 & 96.98 & $\begin{array}{l}\text { Juniperus } \\
\text { tibetica }\end{array}$ & 5 & Tracheids & $\begin{array}{l}\text { Needleleaf } \\
\text { Evergreen }\end{array}$ & Temperate Conifer Forests & $0.176^{* *}$ & $0.465^{* *}$ & $0.031^{* *}$ & $-0.007^{\mathrm{ns}}$ \\
\hline Grießinger et al. 2019 & 31.08 & 96.98 & $\begin{array}{c}\text { Picea } \\
\text { balfouriana }\end{array}$ & 5 & Tracheids & $\begin{array}{l}\text { Needleleaf } \\
\text { Evergreen }\end{array}$ & Temperate Conifer Forests & $0.062^{* *}$ & $0.241^{* *}$ & $0.009^{\text {ns }}$ & $0.020^{\mathrm{ns}}$ \\
\hline Hafner et al. 2011 & 46.39 & 14.22 & $\begin{array}{c}\text { Larix } \\
\text { decidua }\end{array}$ & 9 & Tracheids & $\begin{array}{l}\text { Needleleaf } \\
\text { Deciduous }\end{array}$ & Temperate Conifer Forests & $0.155^{* *}$ & $0.291^{* *}$ & $-0.028^{* *}$ & $-0.003^{\text {ns }}$ \\
\hline Hartl-Meier et al. 2014 & 47.90 & 14.44 & $\begin{array}{l}\text { Larix } \\
\text { decidua }\end{array}$ & 8 & Tracheids & $\begin{array}{l}\text { Needleleaf } \\
\text { Deciduous }\end{array}$ & $\begin{array}{l}\text { Temperate Broadleaf \& } \\
\text { Mixed Forests }\end{array}$ & $0.512^{* *}$ & $0.512^{* *}$ & $0.010^{\mathrm{ns}}$ & $0.010^{\mathrm{ns}}$ \\
\hline Hartl-Meier et al. 2014 & 47.90 & 14.44 & Picea abies & 8 & Tracheids & $\begin{array}{l}\text { Needleleaf } \\
\text { Evergreen }\end{array}$ & $\begin{array}{l}\text { Temperate Broadleaf \& } \\
\text { Mixed Forests }\end{array}$ & $0.570^{* *}$ & $0.570^{* *}$ & $-0.026^{\mathrm{ns}}$ & $-0.026^{\mathrm{ns}}$ \\
\hline Hartl-Meier et al. 2014 & 47.80 & 14.44 & $\begin{array}{l}\text { Larix } \\
\text { decidua }\end{array}$ & 8 & Tracheids & $\begin{array}{l}\text { Needleleaf } \\
\text { Deciduous }\end{array}$ & Temperate Conifer Forests & $0.561^{* *}$ & $0.561^{* *}$ & $0.031^{\text {ns }}$ & $0.031^{\text {ns }}$ \\
\hline Hartl-Meier et al. 2014 & 47.80 & 14.44 & Picea abies & 8 & Tracheids & $\begin{array}{l}\text { Needleleaf } \\
\text { Evergreen }\end{array}$ & Temperate Conifer Forests & $0.475^{* *}$ & $0.475^{* *}$ & $-0.001^{\mathrm{ns}}$ & $-0.001^{\mathrm{ns}}$ \\
\hline Hartl-Meier et al. 2014 & 47.70 & 14.44 & Picea abies & 8 & Tracheids & $\begin{array}{l}\text { Needleleaf } \\
\text { Evergreen }\end{array}$ & Temperate Conifer Forests & $0.682^{* *}$ & $0.682^{* *}$ & $-0.013^{\text {ns }}$ & $-0.013^{\text {ns }}$ \\
\hline Hilasvuori et al. 2009 & 68.93 & 28.32 & $\begin{array}{c}\text { Pinus } \\
\text { sylvestris }\end{array}$ & 4 & Tracheids & $\begin{array}{l}\text { Needleleaf } \\
\text { Evergreen }\end{array}$ & Boreal Forests/Taiga & $0.109^{* *}$ & $0.240^{* *}$ & $-0.017^{* *}$ & $-0.025^{\text {ns }}$ \\
\hline Hilasvuori et al. 2009 & 62.98 & 31.27 & $\begin{array}{l}\text { Pinus } \\
\text { sylvestris }\end{array}$ & 4 & Tracheids & $\begin{array}{l}\text { Needleleaf } \\
\text { Evergreen }\end{array}$ & Boreal Forests/Taiga & $0.104^{* *}$ & $0.212^{* *}$ & $-0.009^{\mathrm{ns}}$ & $-0.079^{* *}$ \\
\hline Knorre et al. 2010 & 54.40 & 89.95 & $\begin{array}{l}\text { Larix } \\
\text { sibirica }\end{array}$ & 5 & Tracheids & $\begin{array}{l}\text { Needleleaf } \\
\text { Deciduous }\end{array}$ & Temperate Conifer Forests & $0.140^{* *}$ & $0.149^{\text {ns }}$ & $-0.026^{* *}$ & $-0.081^{* *}$ \\
\hline Konter et al. 2014 & 42.58 & -0.97 & $\begin{array}{c}\text { Pinus } \\
\text { uncinata }\end{array}$ & 5 & Tracheids & $\begin{array}{l}\text { Needleleaf } \\
\text { Evergreen }\end{array}$ & $\begin{array}{l}\text { Mediterranean Forests, } \\
\text { Woodlands \& Scrub }\end{array}$ & $0.223^{* *}$ & $0.459^{* *}$ & $-0.015^{* *}$ & $-0.022^{\mathrm{ns}}$ \\
\hline Kress et al. 2010 & 46.41 & 7.79 & $\begin{array}{c}\text { Larix } \\
\text { decidua }\end{array}$ & 5 & Tracheids & $\begin{array}{l}\text { Needleleaf } \\
\text { Deciduous }\end{array}$ & Temperate Conifer Forests & $0.168^{* *}$ & $0.353^{* *}$ & $-0.012^{*}$ & $0.001^{\text {ns }}$ \\
\hline Lavergne et al. 2017 & -41.16 & -71.78 & $\begin{array}{l}\text { Fitzroya } \\
\text { cupressoides }\end{array}$ & 12 & Tracheids & $\begin{array}{l}\text { Needleleaf } \\
\text { Evergreen }\end{array}$ & $\begin{array}{c}\text { Temperate Broadleaf \& } \\
\text { Mixed Forests }\end{array}$ & $0.432^{* *}$ & $0.523^{* *}$ & $0.019^{* *}$ & $0.022^{*}$ \\
\hline Levesque et al. 2014 & 45.78 & 7.55 & $\begin{array}{l}\text { Larix } \\
\text { decidua }\end{array}$ & 4 & Tracheids & $\begin{array}{l}\text { Needleleaf } \\
\text { Deciduous }\end{array}$ & Temperate Conifer Forests & $0.348^{* *}$ & $0.347^{* *}$ & $-0.025^{\mathrm{ns}}$ & $-0.020^{\mathrm{ns}}$ \\
\hline Levesque et al. 2014 & 45.78 & 7.55 & Picea abies & 4 & Tracheids & $\begin{array}{l}\text { Needleleaf } \\
\text { Evergreen }\end{array}$ & Temperate Conifer Forests & $0.531^{* *}$ & $0.499^{* *}$ & $-0.006^{\mathrm{ns}}$ & $-0.006^{\mathrm{ns}}$ \\
\hline
\end{tabular}




\begin{tabular}{|c|c|c|c|c|c|c|c|c|c|c|c|}
\hline Levesque et al. 2014 & 45.78 & 7.55 & Pinus nigra & 4 & Tracheids & $\begin{array}{l}\text { Needleleaf } \\
\text { Evergreen }\end{array}$ & Temperate Conifer Forests & $0.387^{* *}$ & $0.372^{* *}$ & $-0.033^{\mathrm{ns}}$ & $-0.037^{\mathrm{ns}}$ \\
\hline Levesque et al. 2014 & 45.78 & 7.55 & $\begin{array}{c}\text { Pinus } \\
\text { sylvestris }\end{array}$ & 4 & Tracheids & $\begin{array}{l}\text { Needleleaf } \\
\text { Evergreen }\end{array}$ & Temperate Conifer Forests & $0.130^{* *}$ & $0.086^{\mathrm{ns}}$ & $-0.055^{\mathrm{ns}}$ & $-0.061^{\text {ns }}$ \\
\hline Levesque et al. 2014 & 45.78 & 7.55 & $\begin{array}{l}\text { Pseudotsuga } \\
\text { menziesii }\end{array}$ & 4 & Tracheids & $\begin{array}{l}\text { Needleleaf } \\
\text { Evergreen }\end{array}$ & Temperate Conifer Forests & $0.432^{* *}$ & $0.396^{* *}$ & $-0.020^{\mathrm{ns}}$ & $-0.016^{\mathrm{ns}}$ \\
\hline Levesque et al. 2014 & 47.17 & 7.27 & $\begin{array}{l}\text { Larix } \\
\text { decidua }\end{array}$ & 4 & Tracheids & $\begin{array}{l}\text { Needleleaf } \\
\text { Deciduous }\end{array}$ & $\begin{array}{l}\text { Temperate Broadleaf \& } \\
\text { Mixed Forests }\end{array}$ & $0.353^{* *}$ & $0.370^{* *}$ & $-0.011^{\mathrm{ns}}$ & $-0.015^{\text {ns }}$ \\
\hline Levesque et al. 2014 & 47.17 & 7.27 & Picea abies & 4 & Tracheids & $\begin{array}{l}\text { Needleleaf } \\
\text { Evergreen }\end{array}$ & $\begin{array}{l}\text { Temperate Broadleaf \& } \\
\text { Mixed Forests }\end{array}$ & $0.471^{* *}$ & $0.468^{* *}$ & $0.001^{\text {ns }}$ & $-0.002^{\text {ns }}$ \\
\hline Levesque et al. 2014 & 47.17 & 7.27 & Pinus nigra & 4 & Tracheids & $\begin{array}{l}\text { Needleleaf } \\
\text { Evergreen }\end{array}$ & $\begin{array}{l}\text { Temperate Broadleaf \& } \\
\text { Mixed Forests }\end{array}$ & $0.282^{* *}$ & $0.341^{* *}$ & $-0.010^{\mathrm{ns}}$ & $-0.009^{\text {ns }}$ \\
\hline Levesque et al. 2014 & 47.17 & 7.27 & $\begin{array}{l}\text { Pinus } \\
\text { sylvestris }\end{array}$ & 4 & Tracheids & $\begin{array}{l}\text { Needleleaf } \\
\text { Evergreen }\end{array}$ & $\begin{array}{l}\text { Temperate Broadleaf \& } \\
\text { Mixed Forests }\end{array}$ & $0.282^{* *}$ & $0.279^{* *}$ & $-0.014^{\mathrm{ns}}$ & $-0.018^{\text {ns }}$ \\
\hline Levesque et al. 2014 & 47.17 & 7.27 & $\begin{array}{l}\text { Pseudotsuga } \\
\text { menziesii }\end{array}$ & 4 & Tracheids & $\begin{array}{l}\text { Needleleaf } \\
\text { Evergreen }\end{array}$ & $\begin{array}{l}\text { Temperate Broadleaf \& } \\
\text { Mixed Forests }\end{array}$ & $0.246^{*}$ & $0.198^{\text {ns }}$ & $-0.024^{\mathrm{ns}}$ & $-0.026^{\mathrm{ns}}$ \\
\hline Liu et al. 2014 & 30.28 & 99.47 & $\begin{array}{l}\text { Abies } \\
\text { georgei }\end{array}$ & 5 & Tracheids & $\begin{array}{l}\text { Needleleaf } \\
\text { Evergreen }\end{array}$ & $\begin{array}{l}\text { Montane Grasslands \& } \\
\text { Shrublands }\end{array}$ & $0.210^{* *}$ & $0.255^{* *}$ & $0.013^{\text {ns }}$ & $0.021^{\mathrm{ns}}$ \\
\hline Liu et al. 2018 & 51.39 & 123.34 & $\begin{array}{l}\text { Larix } \\
\text { gmelinii }\end{array}$ & 5 & Tracheids & $\begin{array}{l}\text { Needleleaf } \\
\text { Deciduous }\end{array}$ & Temperate Conifer Forests & $0.181^{* *}$ & $0.432^{* *}$ & $-0.014^{* *}$ & $-0.010^{\text {ns }}$ \\
\hline Liu et al. 2018 & 51.45 & 122.76 & $\begin{array}{l}\text { Pinus } \\
\text { sylvestris }\end{array}$ & 5 & Tracheids & $\begin{array}{l}\text { Needleleaf } \\
\text { Evergreen }\end{array}$ & Temperate Conifer Forests & $0.127^{* *}$ & $0.439^{* *}$ & $-0.029^{* *}$ & $-0.054^{* *}$ \\
\hline $\begin{array}{l}\text { Loader et al. } \\
\quad 2010\end{array}$ & 50.40 & 87.55 & $\begin{array}{l}\text { Pinus } \\
\text { sibirica }\end{array}$ & 4 & Tracheids & $\begin{array}{l}\text { Needleleaf } \\
\text { Evergreen }\end{array}$ & $\begin{array}{l}\text { Montane Grasslands \& } \\
\text { Shrublands }\end{array}$ & $0.154^{* *}$ & $0.238^{\mathrm{ns}}$ & $-0.016^{* *}$ & $-0.077^{* *}$ \\
\hline Porter et al. 2009 & 64.40 & -133.81 & Picea glauca & 3 & Tracheids & $\begin{array}{l}\text { Needleleaf } \\
\text { Evergreen }\end{array}$ & Tundra & $0.192^{* *}$ & $0.402^{* *}$ & $0.003^{\text {ns }}$ & $-0.010^{\mathrm{ns}}$ \\
\hline $\begin{array}{c}\text { Roden and Ehleringer } \\
2007\end{array}$ & 44.40 & -121.67 & $\begin{array}{c}\text { Pinus } \\
\text { ponderosa }\end{array}$ & 3 & Tracheids & $\begin{array}{l}\text { Needleleaf } \\
\text { Evergreen }\end{array}$ & Temperate Conifer Forests & $0.361^{* *}$ & $0.361^{* *}$ & $-0.042^{\mathrm{ns}}$ & $-0.042^{\text {ns }}$ \\
\hline $\begin{array}{c}\text { Roden and Ehleringer } \\
2007\end{array}$ & 38.43 & -119.43 & $\begin{array}{l}\text { Pinus } \\
\text { ponderosa }\end{array}$ & 3 & Tracheids & $\begin{array}{l}\text { Needleleaf } \\
\text { Evergreen }\end{array}$ & Deserts \& Xeric Shrublands & $0.569^{* *}$ & $0.569^{* *}$ & $-0.002^{\mathrm{ns}}$ & $-0.002^{\text {ns }}$ \\
\hline $\begin{array}{c}\text { Roden and Ehleringer } \\
2007\end{array}$ & 36.27 & -110.00 & $\begin{array}{l}\text { Pinus } \\
\text { ponderosa }\end{array}$ & 3 & Tracheids & $\begin{array}{l}\text { Needleleaf } \\
\text { Evergreen }\end{array}$ & Deserts \& Xeric Shrublands & $0.412^{* *}$ & $0.412^{* *}$ & $-0.032^{\mathrm{ns}}$ & $-0.032^{\mathrm{ns}}$ \\
\hline Roden et al. 2011 & 40.87 & -124.05 & $\begin{array}{c}\text { Sequoia } \\
\text { sempervirens }\end{array}$ & 4 & Tracheids & $\begin{array}{l}\text { Needleleaf } \\
\text { Evergreen }\end{array}$ & Temperate Conifer Forests & $0.387^{* *}$ & $0.43^{* *}$ & $-0.017^{\mathrm{ns}}$ & $-0.017^{\text {ns }}$ \\
\hline Roden et al. 2011 & 41.80 & -124.10 & $\begin{array}{c}\text { Sequoia } \\
\text { sempervirens }\end{array}$ & 4 & Tracheids & $\begin{array}{l}\text { Needleleaf } \\
\text { Evergreen }\end{array}$ & Temperate Conifer Forests & $0.383^{* *}$ & $0.304^{* *}$ & $0.004^{\text {ns }}$ & $0.003^{\mathrm{ns}}$ \\
\hline Roden et al. 2011 & 41.40 & -124.03 & $\begin{array}{c}\text { Sequoia } \\
\text { sempervirens }\end{array}$ & 4 & Tracheids & $\begin{array}{l}\text { Needleleaf } \\
\text { Evergreen }\end{array}$ & Temperate Conifer Forests & $0.221^{* *}$ & $0.268^{* *}$ & $-0.003^{\mathrm{ns}}$ & $-0.006^{\mathrm{ns}}$ \\
\hline Roden et al. 2011 & 38.40 & -122.99 & $\begin{array}{c}\text { Sequoia } \\
\text { sempervirens }\end{array}$ & 4 & Tracheids & $\begin{array}{l}\text { Needleleaf } \\
\text { Evergreen }\end{array}$ & Temperate Conifer Forests & $0.276^{* *}$ & $0.249^{* *}$ & $-0.010^{\text {ns }}$ & $-0.017^{\mathrm{ns}}$ \\
\hline Seftigen et al. 2011 & 63.17 & 13.50 & $\begin{array}{c}\text { Pinus } \\
\text { sylvestris }\end{array}$ & 7 & Tracheids & $\begin{array}{l}\text { Needleleaf } \\
\text { Evergreen }\end{array}$ & Boreal Forests/Taiga & $0.062^{* *}$ & $0.117^{* *}$ & $-0.008^{\mathrm{ns}}$ & $-0.051^{* *}$ \\
\hline $\begin{array}{c}\text { Sensula and } \\
\text { Wilczynski. } 2018\end{array}$ & 50.24 & 19.25 & $\begin{array}{l}\text { Pinus } \\
\text { sylvestris }\end{array}$ & 10 & Tracheids & $\begin{array}{l}\text { Needleleaf } \\
\text { Evergreen }\end{array}$ & $\begin{array}{l}\text { Temperate Broadleaf \& } \\
\text { Mixed Forests }\end{array}$ & $0.564^{* *}$ & $0.564^{* *}$ & $0.059^{\text {ns }}$ & $0.059^{\mathrm{ns}}$ \\
\hline $\begin{array}{c}\text { Sensula and } \\
\text { Wilczynski. } 2018\end{array}$ & 50.20 & 18.19 & $\begin{array}{l}\text { Pinus } \\
\text { sylvestris }\end{array}$ & 10 & Tracheids & $\begin{array}{l}\text { Needleleaf } \\
\text { Evergreen }\end{array}$ & $\begin{array}{l}\text { Temperate Broadleaf \& } \\
\text { Mixed Forests }\end{array}$ & $0.525^{* *}$ & $0.525^{* *}$ & $0.006^{\text {ns }}$ & $0.006^{\mathrm{ns}}$ \\
\hline $\begin{array}{c}\text { Sensula and } \\
\text { Wilczynski. } 2018\end{array}$ & 50.90 & 18.56 & $\begin{array}{l}\text { Pinus } \\
\text { sylvestris }\end{array}$ & 10 & Tracheids & $\begin{array}{l}\text { Needleleaf } \\
\text { Evergreen }\end{array}$ & $\begin{array}{l}\text { Temperate Broadleaf \& } \\
\text { Mixed Forests }\end{array}$ & $0.647^{* *}$ & $0.647^{* *}$ & $0.054^{\text {ns }}$ & $0.054^{\mathrm{ns}}$ \\
\hline Shestakova et al. 2017 & 54.26 & 89.62 & $\begin{array}{l}\text { Pinus } \\
\text { sylvestris }\end{array}$ & 5 & Tracheids & $\begin{array}{l}\text { Needleleaf } \\
\text { Evergreen }\end{array}$ & Temperate Conifer Forests & $0.293^{* *}$ & $0.339^{* *}$ & $-0.021^{*}$ & $-0.031^{*}$ \\
\hline
\end{tabular}




\begin{tabular}{|c|c|c|c|c|c|c|c|c|c|c|c|}
\hline Shestakova et al. 2017 & 53.72 & 91.84 & $\begin{array}{c}\text { Pinus } \\
\text { sylvestris }\end{array}$ & 5 & Tracheids & $\begin{array}{l}\text { Needleleaf } \\
\text { Evergreen }\end{array}$ & $\begin{array}{l}\text { Temperate Grasslands, } \\
\text { Savannas \& Shrublands }\end{array}$ & $0.222^{* *}$ & $0.266^{* *}$ & $-0.035^{* *}$ & $-0.059^{* *}$ \\
\hline Sidorova et al. 2009 & 64.53 & 100.23 & $\begin{array}{l}\text { Larix } \\
\text { gmelinii }\end{array}$ & 8 & Tracheids & $\begin{array}{l}\text { Needleleaf } \\
\text { Deciduous }\end{array}$ & Boreal Forests/Taiga & $0.299^{* *}$ & $0.416^{* *}$ & $-0.018^{* *}$ & $-0.056^{* *}$ \\
\hline Sidorova et al. 2013 & 72.00 & 102.00 & $\begin{array}{l}\text { Larix } \\
\text { gmelinii }\end{array}$ & 4 & Tracheids & $\begin{array}{l}\text { Needleleaf } \\
\text { Deciduous }\end{array}$ & Tundra & $0.212^{* *}$ & $0.404^{*}$ & $0.008^{\mathrm{ns}}$ & $-0.006^{\mathrm{ns}}$ \\
\hline Sladden et al. 2018 & 51.31 & -0.84 & $\begin{array}{l}\text { Pinus } \\
\text { sylvestris }\end{array}$ & 1 & Tracheids & $\begin{array}{l}\text { Needleleaf } \\
\text { Evergreen }\end{array}$ & $\begin{array}{l}\text { Temperate Broadleaf \& } \\
\text { Mixed Forests }\end{array}$ & $0.420^{* *}$ & $0.371^{* *}$ & $-0.002^{\mathrm{ns}}$ & $-0.013^{\text {ns }}$ \\
\hline Sohn et al. 2014 & 35.27 & -111.74 & $\begin{array}{c}\text { Pinus } \\
\text { ponderosa }\end{array}$ & 3 & Tracheids & $\begin{array}{l}\text { Needleleaf } \\
\text { Evergreen }\end{array}$ & Temperate Conifer Forests & $0.254^{\mathrm{ns}}$ & $0.034^{\mathrm{ns}}$ & $0.106^{\text {ns }}$ & $0.200^{\mathrm{ns}}$ \\
\hline Szczepanek et al. 2006 & 50.04 & 20.34 & $\begin{array}{l}\text { Pinus } \\
\text { sylvestris }\end{array}$ & 4 & Tracheids & $\begin{array}{l}\text { Needleleaf } \\
\text { Evergreen }\end{array}$ & $\begin{array}{l}\text { Temperate Broadleaf \& } \\
\text { Mixed Forests }\end{array}$ & $0.097^{\mathrm{ns}}$ & $0.253^{\text {ns }}$ & $0.001^{\mathrm{ns}}$ & $-0.004^{\text {ns }}$ \\
\hline Szejner et al. 2016 & 35.27 & -107.62 & $\begin{array}{c}\text { Pinus } \\
\text { ponderosa }\end{array}$ & 4 & Tracheids & $\begin{array}{l}\text { Needleleaf } \\
\text { Evergreen }\end{array}$ & Temperate Conifer Forests & $0.449^{* *}$ & $0.524^{* *}$ & $-0.037^{\mathrm{ns}}$ & $-0.023^{\text {ns }}$ \\
\hline Szejner et al. 2016 & 32.72 & -109.97 & $\begin{array}{c}\text { Pinus } \\
\text { ponderosa }\end{array}$ & 4 & Tracheids & $\begin{array}{l}\text { Needleleaf } \\
\text { Evergreen }\end{array}$ & $\begin{array}{l}\text { Tropical \& Subtropical } \\
\text { Coniferous Forests }\end{array}$ & $0.446^{* *}$ & $0.482^{* *}$ & $-0.005^{\mathrm{ns}}$ & $-0.006^{\mathrm{ns}}$ \\
\hline Szejner et al. 2016 & 34.24 & -105.79 & $\begin{array}{c}\text { Pinus } \\
\text { ponderosa }\end{array}$ & 4 & Tracheids & $\begin{array}{l}\text { Needleleaf } \\
\text { Evergreen }\end{array}$ & Temperate Conifer Forests & $0.68^{* *}$ & $0.694^{* *}$ & $0.003^{\text {ns }}$ & $0.013^{\mathrm{ns}}$ \\
\hline Szejner et al. 2016 & 36.76 & -112.26 & $\begin{array}{l}\text { Pinus } \\
\text { ponderosa }\end{array}$ & 4 & Tracheids & $\begin{array}{l}\text { Needleleaf } \\
\text { Evergreen }\end{array}$ & Temperate Conifer Forests & $0.484^{* *}$ & $0.574^{* *}$ & $-0.041^{*}$ & $-0.046^{*}$ \\
\hline Szejner et al. 2016 & 35.36 & -111.62 & $\begin{array}{c}\text { Pinus } \\
\text { ponderosa }\end{array}$ & 4 & Tracheids & $\begin{array}{l}\text { Needleleaf } \\
\text { Evergreen }\end{array}$ & Temperate Conifer Forests & $0.270^{* *}$ & $0.316^{* *}$ & $0.002^{\text {ns }}$ & $0.009^{\mathrm{ns}}$ \\
\hline Szejner et al. 2016 & 39.36 & -111.26 & $\begin{array}{c}\text { Pinus } \\
\text { ponderosa }\end{array}$ & 4 & Tracheids & $\begin{array}{l}\text { Needleleaf } \\
\text { Evergreen }\end{array}$ & Temperate Conifer Forests & $0.431^{* *}$ & $0.485^{* *}$ & $-0.008^{\text {ns }}$ & $-0.003^{\text {ns }}$ \\
\hline Szejner et al. 2016 & 40.54 & -110.64 & $\begin{array}{c}\text { Pinus } \\
\text { ponderosa }\end{array}$ & 4 & Tracheids & $\begin{array}{l}\text { Needleleaf } \\
\text { Evergreen }\end{array}$ & Temperate Conifer Forests & $0.381^{* *}$ & $0.462^{* *}$ & $-0.014^{\mathrm{ns}}$ & $-0.008^{\text {ns }}$ \\
\hline Szejner et al. 2016 & 33.81 & -110.91 & $\begin{array}{c}\text { Pinus } \\
\text { ponderosa }\end{array}$ & 4 & Tracheids & $\begin{array}{l}\text { Needleleaf } \\
\text { Evergreen }\end{array}$ & Temperate Conifer Forests & $0.501^{* *}$ & $0.570^{* *}$ & $-0.005^{\mathrm{ns}}$ & $-0.005^{\mathrm{ns}}$ \\
\hline Szejner et al. 2016 & 32.75 & -105.77 & $\begin{array}{c}\text { Pinus } \\
\text { ponderosa }\end{array}$ & 4 & Tracheids & $\begin{array}{l}\text { Needleleaf } \\
\text { Evergreen }\end{array}$ & Temperate Conifer Forests & $0.526^{* *}$ & $0.564^{* *}$ & $-0.025^{\mathrm{ns}}$ & $-0.021^{\mathrm{ns}}$ \\
\hline Szejner et al. 2016 & 35.21 & -106.42 & $\begin{array}{l}\text { Pinus } \\
\text { ponderosa }\end{array}$ & 4 & Tracheids & $\begin{array}{l}\text { Needleleaf } \\
\text { Evergreen }\end{array}$ & Temperate Conifer Forests & $0.669^{* *}$ & $0.802^{* *}$ & $-0.132^{* *}$ & $-0.131^{* *}$ \\
\hline Szejner et al. 2016 & 32.41 & -110.70 & $\begin{array}{c}\text { Pinus } \\
\text { ponderosa }\end{array}$ & 4 & Tracheids & $\begin{array}{l}\text { Needleleaf } \\
\text { Evergreen }\end{array}$ & $\begin{array}{l}\text { Tropical \& Subtropical } \\
\text { Coniferous Forests }\end{array}$ & $0.327^{* *}$ & $0.368^{* *}$ & $-0.077^{\text {ns }}$ & $-0.085^{\mathrm{ns}}$ \\
\hline Szymczak et al. 2012 & 42.00 & 9.00 & Pinus nigra & 5 & Tracheids & $\begin{array}{l}\text { Needleleaf } \\
\text { Evergreen }\end{array}$ & $\begin{array}{l}\text { Mediterranean Forests, } \\
\text { Woodlands \& Scrub }\end{array}$ & $0.307^{* *}$ & $0.344^{* *}$ & $-0.029^{*}$ & $-0.040^{* *}$ \\
\hline $\mathrm{Xu}$ et al. 2018 & 44.00 & 87.00 & $\begin{array}{c}\text { Picea } \\
\text { schrenkiana }\end{array}$ & 10 & Tracheids & $\begin{array}{l}\text { Needleleaf } \\
\text { Evergreen }\end{array}$ & Deserts \& Xeric Shrublands & $0.206^{* *}$ & $0.219^{* *}$ & $-0.050^{* *}$ & $-0.052^{* *}$ \\
\hline Zeng et al. 2017 & 29.50 & 94.00 & $\begin{array}{l}\text { Abies } \\
\text { georgei }\end{array}$ & 6 & Tracheids & $\begin{array}{l}\text { Needleleaf } \\
\text { Evergreen }\end{array}$ & $\begin{array}{c}\text { Montane Grasslands \& } \\
\text { Shrublands }\end{array}$ & $0.411^{* *}$ & $0.472^{* *}$ & $0.010^{\text {ns }}$ & $-0.023^{\text {ns }}$ \\
\hline
\end{tabular}


Table S2.2. Trends in iWUE and the associated standard error across all sites and species within a given biome for the period $1963-2015$. Those biomes with the same letter in the third column, group, have temporal trends that are not significantly different from one another.

\begin{tabular}{|c|c|c|c|}
\hline Biome & $\begin{array}{c}\Delta \mathrm{iWUE}\left(\mu \mathrm{mol} \mathrm{CO}{ }_{2}\right. \\
\left.\mathrm{mol}^{-1} \mathrm{H}_{2} \mathrm{O} \mathrm{yr}^{-1}\right)\end{array}$ & S.E. & Group \\
\hline Mediterranean Forests, Woodlands \& Scrub & 0.611 & 0.074 & $\mathrm{a}$ \\
\hline Temperate Conifer Forests & 0.482 & 0.021 & $\mathrm{a}$ \\
\hline Tropical \& Subtropical Moist Broadleaf Forests & 0.472 & 0.136 & $\mathrm{abc}$ \\
\hline Tropical \& Subtropical Coniferous Forests & 0.426 & 0.085 & $\mathrm{abc}$ \\
\hline Montane Grasslands \& Shrublands & 0.422 & 0.083 & $\mathrm{abc}$ \\
\hline Boreal Forests/Taiga & 0.412 & 0.058 & $\mathrm{ab}$ \\
\hline Temperate Broadleaf \& Mixed Forests & 0.409 & 0.022 & $\mathrm{ab}$ \\
\hline Temperate Grasslands, Savannas \& Shrublands & 0.182 & 0.082 & $\mathrm{bc}$ \\
\hline Tundra & 0.111 & 0.069 & $\mathrm{c}$ \\
\hline Deserts \& Xeric Shrublands & 0.101 & 0.070 & $\mathrm{c}$ \\
\hline
\end{tabular}


Table S2.3. Linear mixed effect model results and attributes for the best model (lowest AICc) examining the drivers of tree ring derived iWUE for the period $1963-2015$ when considering factors climate, $\mathrm{CO}_{2}$, and wood ( $2^{\text {nd }}$ column), or leaf type ( $3^{\text {rd }}$ column) in the model, including interactions with wood and leaf type. Intercept values for each model represent the value of iWUE when each numerical environmental factor included in the model is at its mean value during the study period. Leaf and wood type parameter estimates indicate the difference from the original intercept value for each respective variable, with comparisons made with "tracheids" at the base level for wood type and "needleleaf evergreen" as the base level for leaf type. Parameter estimates for interactions between wood and leaf type and environmental factors indicate the change from the slope of the original estimate for that parameter and when considering the respective leaf or wood type. The marginal $\mathrm{R}^{2}$ describes the goodness of model fit given fixed effects only, while the conditional $\mathrm{R}^{2}$ describes the goodness of model fit including fixed and random effects (tree species nested within site). Model parameter significance is denoted by an asterisk where $\sim$ denotes $\mathrm{p}<0.06, *$ denotes $\mathrm{p}<0.05, * *$ denotes $\mathrm{p}<0.01$, and $* * *$ denotes $\mathrm{p}<$ 0.001 , while ${ }^{\text {ns }}$ denotes not significant.

\begin{tabular}{|c|c|c|}
\hline Attribute & $1963-2015_{\text {wood }}$ & $1963-2015_{\text {leaf }}$ \\
\hline Intercept $\left(\mu \mathrm{mol} \mathrm{mol}{ }^{-1}\right)$ & $87.338 \pm 1.293^{* * *}$ & $87.584 \pm 1.327^{* * *}$ \\
\hline $\mathrm{CO}_{2}(\mathrm{ppm})$ & $0.248 \pm 0.008^{* * *}$ & $0.244 \pm 0.008^{* * *}$ \\
\hline $\mathrm{PPT}_{\text {grw }}(\mathrm{mm})$ & $-0.010 \pm 0.001^{* * *}$ & $-0.009 \pm 0.001^{* * *}$ \\
\hline $\mathrm{TMP}_{\text {grw }}\left({ }^{\circ} \mathrm{C}\right)$ & $0.288 \pm 0.157^{\mathrm{ns}}$ & $0.148 \pm 0.155^{\mathrm{ns}}$ \\
\hline $\operatorname{VPD}_{\text {grw }}(\mathrm{kPa})$ & $13.523 \pm 1.761^{* * *}$ & $14.292 \pm 1.506^{* * *}$ \\
\hline Diffuse Porous & $-17.656 \pm 2.854^{* * *}$ & - \\
\hline Ring Porous & $-18.340 \pm 2.729^{* * *}$ & - \\
\hline Needleleaf Deciduous & - & $-3.068 \pm 2.669^{\mathrm{ns}}$ \\
\hline Broadleaf Evergreen & - & $-10.760 \pm 7.960^{\mathrm{ns}}$ \\
\hline Broadleaf Deciduous & - & $-18.946 \pm 2.286^{* * *}$ \\
\hline $\mathrm{CO}_{2}: \mathrm{VPD}_{\text {grw }}$ & $-0.094 \pm 0.054^{\mathrm{ns}}$ & $-0.161 \pm 0.073^{*}$ \\
\hline $\mathrm{CO}_{2}: \mathrm{TMP}_{\mathrm{grw}}$ & - & $0.011 \pm 0.007^{\mathrm{ns}}$ \\
\hline $\mathrm{CO}_{2}$ :Diffuse Porous & $-0.056 \pm 0.021^{* *}$ & - \\
\hline $\mathrm{CO}_{2}:$ Ring Porous & $-0.017 \pm 0.018^{\mathrm{ns}}$ & - \\
\hline $\mathrm{CO}_{2}$ :Needleleaf Deciduous & - & $0.013 \pm 0.021^{\mathrm{ns}}$ \\
\hline $\mathrm{CO}_{2}:$ Broadleaf Evergreen & - & $-0.100 \pm 0.084^{\mathrm{ns}}$ \\
\hline $\mathrm{CO}_{2}$ :Broadleaf Deciduous & - & $-0.030 \pm 0.015^{*}$ \\
\hline $\mathrm{PPT}_{\text {grw }}: \mathrm{TMP}_{\text {grw }}$ & - & $0.001 \pm 0.001^{\mathrm{ns}}$ \\
\hline $\mathrm{TMP}_{\text {grw }}: \mathrm{VPD}_{\text {grw }}$ & $2.123 \pm 0.901^{*}$ & $2.485 \pm 1.004^{*}$ \\
\hline $\mathrm{TMP}_{\text {grw:Diffuse Porous }}$ & $-0.996 \pm 0.452^{*}$ & - \\
\hline $\mathrm{TMP}_{\text {grw: }}$ Ring Porous & $0.058 \pm 0.365^{\mathrm{ns}}$ & - \\
\hline TMP grw:Needleleaf Deciduous & - & $0.822 \pm 0.289^{* *}$ \\
\hline $\mathrm{TMP}_{\text {grw }}$ :Broadleaf Evergreen & - & $1.618 \pm 0.790^{*}$ \\
\hline $\mathrm{TMP}_{\text {grw:Broadleaf Deciduous }}$ & - & $-0.340 \pm 0.207^{\mathrm{ns}}$ \\
\hline VPD $_{\text {grw:Diffuse Porous }}$ & $7.019 \pm 3.832^{\mathrm{ns}}$ & - \\
\hline VPD grw:Ring Porous & $-5.151 \pm 3.541^{\mathrm{ns}}$ & - \\
\hline Marginal $\mathrm{R}^{2}$ & 0.38 & 0.39 \\
\hline Conditional $\mathrm{R}^{2}$ & 0.89 & 0.89 \\
\hline
\end{tabular}


Table S2.4. Linear mixed effect model results and attributes for the best model (lowest AICc) examining the drivers of tree ring derived iWUE for the period $1901-2015$ when only considering environmental factors climate and $\mathrm{CO}_{2}\left(2^{\text {nd }}\right.$ column $)$, including wood type as a fixed effect in the model ( $3^{\text {rd }}$ column), and when including leaf type as a fixed effect in the model ( $4^{\text {th }}$ column). Intercept values for each model represent the value of iWUE when each numerical environmental factor included in the model is at its mean value during the study period. Leaf and wood type parameter estimates indicate the difference from the original intercept value for each respective variable, with comparisons made with " $100 \%$ tracheids" at the base level for wood type and "needleleaf evergreen" as the base level for leaf type. The marginal $\mathrm{R}^{2}$ describes the goodness of model fit given fixed effects only, while the conditional $\mathrm{R}^{2}$ describes the goodness of model fit including fixed and random effects (tree species nested within site). Model parameter significance is denoted by an asterisk where $\sim$ denotes $p<0.06,{ }^{*}$ denotes $p<0.05$, $* *$ denotes $\mathrm{p}<0.01$, and ${ }^{* * *}$ denotes $\mathrm{p}<0.001$, while ${ }^{\text {ns }}$ denotes not significant.

\begin{tabular}{cccc}
\hline Attribute & $1901-2015$ & $1901-2015_{\text {wood }}$ & $1901-2015_{\text {leaf }}$ \\
\hline Intercept $\left.(\mu \mathrm{mol} \mathrm{mol})^{-1}\right)$ & $80.242 \pm 1.437^{* * *}$ & $84.373 \pm 1.361^{* * *}$ & $84.821 \pm 1.379^{* * *}$ \\
$\mathrm{CO}_{2}(\mathrm{ppm})$ & $0.251 \pm 0.005^{* * *}$ & $0.251 \pm 0.005^{* * *}$ & $0.251 \pm 0.005^{* * *}$ \\
$\mathrm{PPT}_{\text {grw }}(\mathrm{mm})$ & $-0.010 \pm 0.001^{* * *}$ & $-0.010 \pm 0.001^{* * *}$ & $-0.010 \pm 0.001^{* * *}$ \\
$\mathrm{TMP}_{\text {grw }}\left({ }^{\circ} \mathrm{C}\right)$ & $0.190 \pm 0.099^{\sim}$ & $0.190 \pm 0.099^{\sim}$ & $0.190 \pm 0.099^{\sim}$ \\
$\mathrm{VPD}_{\text {grw }}(\mathrm{kPa})$ & $14.509 \pm 1.187^{* * *}$ & $14.503 \pm 1.187^{* * *}$ & $14.504 \pm 1.187^{* * *}$ \\
$\mathrm{CO}_{2}: \mathrm{TMP}$ grw & $0.011 \pm 0.005^{*}$ & $0.010 \pm 0.005^{*}$ & $0.010 \pm 0.005^{*}$ \\
$\mathrm{CO}_{2}:$ VPD grw & $-0.121 \pm 0.051^{*}$ & $-0.120 \pm 0.051^{*}$ & $-0.120 \pm 0.051^{*}$ \\
Diffuse Porous & - & $-17.159 \pm 2.831^{* * *}$ & - \\
Ring Porous & - & $-18.543 \pm 2.780^{* * *}$ & - \\
Needleleaf Deciduous & - & - & $-4.835 \pm 2.584^{\mathrm{ns}}$ \\
Broadleaf Evergreen & - & - & $-7.874 \pm 8.359^{\text {ns }}$ \\
Broadleaf Deciduous & - & - & $-19.246 \pm 2.274^{* * *}$ \\
Marginal R & 0.15 & 0.37 & 0.38 \\
Conditional R & 0.89 & 0.89 & 0.89 \\
\hline
\end{tabular}


Table S3.1. Kendall's rank correlation coefficients $(\tau)$ between environmental parameters and the regional chronologies from 1940 to 2014 of basal area increment (BAI), $\Delta{ }^{13} \mathrm{C}$, seasonally integrated net photosynthesis $(A)$, and seasonally integrated stomatal conductance $\left(g_{c}\right)$ of red spruce trees from three locations in the central Appalachian Mountains. Environmental parameters included national $\mathrm{SO}_{2}$ and $\mathrm{NO}_{\mathrm{x}}$ emissions (Lefohn et al., 1999; EPA, 2015), atmospheric $\mathrm{CO}_{2}$ concentrations (Keeling et al., 2015), and monthly, growing season, and annual precipitation and temperatures (WV Climate Division 4, NOAA, 2017). $\tau$ is shown for significant correlations only, and ${ }^{*}$ denotes $\mathrm{p}<0.01,{ }^{* *}$ denotes $\mathrm{p}<0.001$, while ${ }^{* * *}$ denotes $\mathrm{p}<$ 0.0001 .

\begin{tabular}{ccccc}
\hline Environmental Parameter & $\mathrm{BAI}$ & $\Delta^{13} \mathrm{C}$ & $A$ & $g_{c}$ \\
\hline $\mathrm{NO}_{\mathrm{x}}$ & $-0.341^{* * *}$ & $-0.498^{* * *}$ & $-0.265^{* * *}$ & $-0.659^{* * *}$ \\
$\mathrm{SO}_{2}$ & -0.116 & & $-0.386^{* * *}$ & \\
Atmospheric $\mathrm{CO}_{2}$ & $-0.142^{*}$ & $-0.416^{* * *}$ & $0.202^{* * *}$ & $-0.426^{* * *}$ \\
MAT & & $0.223^{* * *}$ & \\
MGT & & $0.146^{* *}$ & 0.119 \\
January temperature & & 0.103 & \\
March temperature & & & -0.107 \\
April temperature & & & $0.1068^{* *}$ & \\
May temperature & & 0.094 & & $0.126^{*}$ \\
June temperature & 0.105 & $0.142^{*}$ & $0.146^{*}$ \\
August temperature & & 0.095 & $0.135^{*}$ \\
October temperature & & 0.103 & & -0.104 \\
November temperature & -0.099 & & \\
December temperature & & & & $0.140^{*}$ \\
May precipitation & & 0.103 & 0.110 & \\
June precipitation & & & & \\
\hline
\end{tabular}


Table S3.2. Bootstrapped Pearson's correlation coefficients between tree growth and maximum annual temperature $\left(\mathrm{T}_{\max }\right)$, minimum annual temperature $\left(\mathrm{T}_{\min }\right)$, and the Palmer Drought Severity Index (PDSI) for months of the current (capital letters) and previous year (lowercase letters). There were no significant relationships detected at the $\alpha=0.05$ level for each of the climate variables listed.

\begin{tabular}{cccccccccc}
\hline & \multicolumn{3}{c}{ MCG } & \multicolumn{3}{c}{ SOR } & & \multicolumn{3}{c}{ CGL } \\
\hline Month & $\mathrm{T}_{\max }$ & $\mathrm{T}_{\min }$ & PDSI & $\mathrm{T}_{\max }$ & $\mathrm{T}_{\min }$ & PDSI & $\mathrm{T}_{\max }$ & $\mathrm{T}_{\min }$ & PDSI \\
\hline Jun & 0.062 & -0.044 & -0.025 & -0.039 & 0.058 & 0.148 & -0.06 & 0.143 & 0.043 \\
Jul & -0.071 & -0.04 & -0.043 & -0.054 & 0.108 & 0.097 & -0.013 & 0.119 & 0.042 \\
Aug & 0.033 & -0.013 & -0.048 & -0.008 & 0.045 & 0.081 & 0.122 & 0.056 & 0.018 \\
Sep & -0.118 & 0.066 & -0.013 & 0.115 & 0.158 & -0.076 & 0.084 & 0.016 & -0.005 \\
Oct & 0.089 & -0.005 & -0.029 & -0.077 & 0.054 & -0.088 & 0.037 & 0.052 & -0.041 \\
Nov & 0.068 & -0.051 & -0.003 & 0.039 & 0.026 & -0.056 & 0.097 & 0.019 & -0.053 \\
Dec & 0.02 & -0.096 & 0.058 & -0.05 & -0.04 & 0.014 & -0.115 & -0.107 & -0.104 \\
JAN & 0.075 & 0.056 & 0.062 & -0.141 & -0.092 & 0.07 & -0.071 & -0.056 & -0.103 \\
FEB & -0.04 & -0.058 & -0.055 & -0.085 & -0.129 & -0.028 & 0.04 & 0.023 & -0.064 \\
MAR & -0.041 & -0.046 & -0.034 & -0.092 & -0.047 & -0.111 & -0.095 & -0.058 & -0.013 \\
APR & -0.036 & 0.145 & 0.008 & 0.017 & 0.001 & -0.086 & 0.023 & 0.126 & 0.035 \\
MAY & 0.051 & 0.089 & 0.018 & 0.046 & -0.069 & 0.037 & 0.034 & -0.012 & 0.029 \\
JUN & 0.134 & 0.04 & -0.026 & -0.01 & 0.107 & 0.097 & 0.008 & -0.058 & 0.036 \\
JUL & 0.066 & 0.138 & -0.059 & -0.055 & -0.01 & 0.109 & 0.033 & -0.098 & -0.002 \\
AUG & 0.031 & 0.04 & -0.077 & 0.125 & -0.008 & 0.075 & 0.207 & 0.087 & -0.01 \\
SEP & 0.029 & -0.031 & -0.095 & 0.032 & -0.099 & -0.102 & -0.059 & -0.064 & 0.009 \\
\hline
\end{tabular}


Table S3.3. Summary of the average model (generated from models with $\Delta \mathrm{AICc}<4$ from the best model) used to determine the contribution of each environmental parameter to changes in BAI each year. The saturated model included April temperature (WV Climate Division 4, NOAA, 2017), atmospheric $\mathrm{CO}_{2}$ (Keeling et al., 2015), $\mathrm{SO}_{2}$ emissions (Lefohn et al., 1999; EPA, 2015), and $\mathrm{NO}_{\mathrm{x}}$ emissions (EPA, 2015), as well as all possible combinations. Significance at the $\mathrm{p}=0.001$ level is denoted by ${ }^{* *}$, while ${ }^{* * *}$ denotes significance at the $\mathrm{p}<0.0001$ level.

\begin{tabular}{ccccc}
\hline Model Parameter & Estimate & Std.Error & z-value & $\mathrm{p}$ \\
\hline (Intercept) & -8.683 & 62.15 & 0.139 & 0.889 \\
April temperature & 0.509 & 0.15 & 3.284 & $0.001^{* *}$ \\
$\mathrm{SO}_{2}$ emissions & -0.243 & 1.89 & 0.129 & 0.898 \\
$\mathrm{NO}_{\mathrm{x}}$ emissions & -1.066 & 3.62 & 0.294 & 0.769 \\
$\mathrm{NO}_{\mathrm{x}}$ emissions: $\mathrm{SO}_{2}$ emissions & -0.060 & 0.02 & 3.853 & $0.000^{* * *}$ \\
Atmospheric CO & 0.078 & 0.22 & 0.348 & 0.728 \\
Atmospheric $\mathrm{CO}_{2}: \mathrm{NO}_{\mathbf{x}}$ emissions & 0.022 & 0.01 & 3.511 & $0.000^{* * *}$ \\
Atmospheric $\mathrm{CO}_{2}: \mathrm{SO}_{2}$ emissions & 0.016 & 0.00 & 4.323 & $0.000^{* * *}$ \\
\hline
\end{tabular}


Table S3.4. Estimates of the reduction in carbon sequestration for each respective zone outlined in the Multi-Resolution Land Characteristics Consortium's 2011 National Land Cover Database. Values represent the average reduction over the 75-year chronology and are given for each land cover class (evergreen, deciduous, and mixed) for each zone. To determine this, we first calculated the cumulative basal area over the 75-year chronology for an average red spruce tree at our study locations with $\left(1177 \mathrm{~cm}^{2}\right)$, and without $\left(1446 \mathrm{~cm}^{2}\right)$, the influence of acid pollution (assuming BAI at 1940 would approach BAI at 2014 linearly without pollution effects). Each respective cumulative basal area was converted to diameter at breast height, used to predict aboveground biomass (AGBM) (Siccama et al., 1994), and converted to kilograms C tree ${ }^{-1}$ in AGBM using the $\% \mathrm{C}$ of our red spruce samples $(48 \pm 0.05 \%)$. The predicted difference in C storage ( $+25.3 \%$ without pollution) was then applied to zones 53, 57, and 61-66 outlined in the MRLC's Land Cover Data Base for Land cover estimates for (Homer et al., 2015) using biomass estimates from the National Biomass and Carbon Dataset for the Year 2000 (Kellndorfer et al., 2012). Columns 2-4 indicate the $C$ reduction on a mass basis, whereas columns 5-7 indicate reductions on a mass per area basis. Total sink reduction due to pollution $(\mathrm{Pg} \mathrm{C})$ for each land cover class was taken as the sum of all zones examined; total sink reduction per land area due to pollution for each land cover class $\left(\mathrm{kg} \mathrm{C} \mathrm{m}^{-2}\right)$ was taken as the average of all zones examined. Summing the total sink reduction for each land cover class (evergreen, deciduous, and mixed) provided the total sink reduction estimate of $0.79 \mathrm{Pg} \mathrm{C}$.

\begin{tabular}{ccccccc}
\hline \multirow{2}{*}{ Zone } & \multicolumn{2}{c}{$\begin{array}{c}1940-2014 \text { Carbon Sink Reduction } \\
\text { for Land Cover Class (Pg C) }\end{array}$} & \multicolumn{3}{c}{$\begin{array}{c}1940-2014 \text { Carbon Sink Reduction } \\
\text { for Land Cover Class }\left(\mathrm{kg} \mathrm{C}^{-2}\right)\end{array}$} \\
\cline { 2 - 6 } & Evergreen & Deciduous & Mixed & Evergreen & Deciduous & Mixed \\
\hline 53 & 0.002 & 0.093 & 0.005 & 1.37 & 1.73 & 1.56 \\
57 & 0.006 & 0.077 & 0.003 & 1.66 & 1.99 & 1.64 \\
61 & 0.008 & 0.128 & 0.006 & 1.62 & 1.80 & 1.72 \\
62 & 0.002 & 0.084 & 0.001 & 1.90 & 1.76 & 1.97 \\
63 & 0.007 & 0.057 & 0.017 & 1.96 & 1.82 & 1.99 \\
64 & 0.017 & 0.066 & 0.013 & 1.83 & 1.86 & 1.93 \\
65 & 0.015 & 0.049 & 0.013 & 2.12 & 1.88 & 2.07 \\
66 & 0.032 & 0.038 & 0.050 & 1.41 & 1.64 & 1.54 \\
Total & 0.090 & 0.591 & 0.108 & 1.66 & 1.81 & 1.71 \\
\hline
\end{tabular}


Table S4.1. Leaf and wood carbon isotope signatures $\delta^{13} \mathrm{C}(\%)$ for Quercus rubra and Liriodendron tulipifera used to determine the fractionation associated with the conversion of leaf to wood carbohydrate (Leavitt \& Long, 1982). Leaf isotope signatures integrate sun and shade leaves. Leaf and wood samples were collected at WS10 and WS13 throughout June, July, and August of 2016.

\begin{tabular}{cccc}
\hline Species & Tissue & $\delta^{13}$ C \pm S.E. (\%) & $\mathrm{N}$ \\
\hline Quercus rubra & Wood & $-28.08 \pm 0.34$ & 10 \\
Quercus rubra & Leaf & $-28.29 \pm 0.16$ & 38 \\
Liriodendron tulipifera & Wood & $-27.39 \pm 0.31$ & 10 \\
Liriodendron tulipifera & Leaf & $-28.80 \pm 0.25$ & 29 \\
\hline
\end{tabular}


Table S4.2. Complete table for Kendall's rank correlation coefficients between all considered environmental factors and BAI and iWUE for Quru and Litu in Watershed 10 and Watershed 13 in the Fernow Experimental Forest, Parsons, WV, U.S for the period 1960 - 2015. Climate variables include minimum, mean, and maximum monthly, growing season, and annual temperature, as well as monthly, growing season and annual precipitation (PRISM Climate Group, 2004). Non-climatic environmental factors include $\mathrm{SO}_{2}$ and $\mathrm{NO}_{x}$ emissions (EPA, 2015), as well as atmospheric $\mathrm{CO}_{2}$ concentrations (Keeling et al., 2015). Significance at the $\alpha=0.05$ level is denoted by the presence of one asterisk (*), while significance at the $\alpha=0.01$ level is denoted by the presence of two asterisks $(* *)$.

\begin{tabular}{|c|c|c|c|c|}
\hline & \multicolumn{2}{|c|}{ Quercus rubra } & \multicolumn{2}{|c|}{ Liriodendron tulipifera } \\
\hline Environmental Factor & BAI & iWUE & BAI & iWUE \\
\hline Atmospheric $\mathrm{CO}_{2}$ & $0.47 * *$ & $0.24 *$ & $0.49 * *$ & $0.47 * *$ \\
\hline $\mathrm{SO}_{2}$ Emissions & $-0.26 * *$ & -0.06 & $-0.32 * *$ & $-0.39 * *$ \\
\hline $\mathrm{NO}_{\mathrm{x}}$ Emissions & 0.00 & 0.16 & -0.04 & -0.15 \\
\hline Januaryppt & 0.01 & 0.01 & 0.10 & 0.12 \\
\hline January $_{\text {tmin }}$ & 0.05 & 0.04 & 0.14 & 0.15 \\
\hline Januarytmean & 0.00 & 0.05 & 0.08 & 0.12 \\
\hline Januarytmax & -0.04 & 0.05 & 0.02 & 0.08 \\
\hline Februaryppt & 0.04 & -0.06 & 0.00 & 0.00 \\
\hline Februarytmin & 0.13 & 0.13 & $0.20 *$ & 0.08 \\
\hline February tmean & 0.12 & 0.16 & $0.20 *$ & 0.08 \\
\hline February tmax & 0.08 & 0.17 & 0.17 & 0.08 \\
\hline March $_{\mathrm{ppt}}$ & 0.03 & 0.02 & -0.03 & 0.05 \\
\hline March $_{\text {tmin }}$ & 0.09 & -0.01 & 0.09 & 0.00 \\
\hline $\mathrm{March}_{\text {tmean }}$ & 0.05 & -0.01 & 0.04 & -0.04 \\
\hline $\operatorname{March}_{\text {tmax }}$ & 0.02 & 0.01 & 0.00 & -0.04 \\
\hline April $_{p p t}$ & -0.07 & -0.06 & -0.05 & -0.04 \\
\hline April $_{\text {tmin }}$ & 0.07 & 0.02 & 0.10 & 0.07 \\
\hline April $1_{\text {tmean }}$ & 0.06 & 0.02 & 0.11 & 0.10 \\
\hline April $_{\operatorname{tmax}}$ & 0.03 & 0.04 & 0.08 & 0.10 \\
\hline Mayppt $_{\text {pat }}$ & 0.15 & 0.06 & 0.11 & 0.10 \\
\hline Maytmin $_{\text {tm }}$ & $0.21 *$ & -0.06 & 0.15 & 0.08 \\
\hline Maytmean $_{\text {ta }}$ & 0.12 & -0.07 & 0.08 & 0.04 \\
\hline Maytmax & 0.02 & -0.07 & 0.01 & -0.02 \\
\hline June $_{p p t}$ & 0.17 & -0.13 & 0.12 & -0.13 \\
\hline June $_{\text {tmin }}$ & $0.28 * *$ & 0.03 & $0.23 *$ & $0.19 *$ \\
\hline June $_{\text {tmean }}$ & 0.12 & 0.03 & 0.08 & 0.14 \\
\hline June $_{\text {tmax }}$ & -0.08 & 0.03 & -0.08 & 0.03 \\
\hline Julyppt & $0.24 *$ & -0.03 & 0.10 & -0.01 \\
\hline July $_{\text {tmin }}$ & $0.22 *$ & $0.21 *$ & $0.23 *$ & $0.24^{*}$ \\
\hline
\end{tabular}




\begin{tabular}{|c|c|c|c|c|}
\hline Julytmean $_{\text {tme }}$ & 0.08 & $0.24 *$ & 0.13 & $0.22 *$ \\
\hline Julytmax $_{\text {tmax }}$ & -0.05 & $0.20 *$ & 0.02 & 0.14 \\
\hline August $_{\mathrm{ppt}}$ & 0.08 & -0.06 & -0.02 & -0.06 \\
\hline August $_{\text {tmin }}$ & 0.18 & 0.11 & $0.19 *$ & 0.17 \\
\hline August $_{\text {tmean }}$ & 0.08 & 0.11 & 0.16 & 0.17 \\
\hline August $t_{\text {tmax }}$ & -0.06 & 0.08 & 0.07 & 0.13 \\
\hline September ${ }_{p p t}$ & -0.06 & 0.03 & -0.12 & -0.02 \\
\hline September ${ }_{\text {tmin }}$ & 0.15 & -0.09 & 0.11 & -0.03 \\
\hline September $_{\text {tmean }}$ & 0.09 & -0.10 & 0.09 & -0.02 \\
\hline September $_{\text {tmax }}$ & 0.01 & -0.08 & 0.05 & -0.01 \\
\hline October $_{\mathrm{ppt}}$ & -0.01 & -0.05 & 0.03 & -0.08 \\
\hline October $_{\text {tmin }}$ & $0.21 *$ & -0.05 & 0.14 & -0.01 \\
\hline October $_{\text {tmean }}$ & 0.16 & -0.04 & 0.09 & -0.02 \\
\hline October $_{\text {tmax }}$ & 0.07 & 0.00 & -0.01 & -0.02 \\
\hline November $_{\mathrm{ppt}}$ & 0.01 & 0.00 & 0.02 & -0.07 \\
\hline November $_{\text {tmin }}$ & 0.04 & -0.03 & 0.01 & -0.10 \\
\hline November $_{\text {tmean }}$ & 0.04 & 0.01 & 0.04 & -0.05 \\
\hline November $_{\text {tmax }}$ & 0.02 & 0.03 & 0.04 & -0.02 \\
\hline December $_{\mathrm{ppt}}$ & 0.11 & -0.06 & 0.01 & -0.01 \\
\hline December $_{\text {tmin }}$ & $0.20^{*}$ & 0.09 & 0.11 & 0.11 \\
\hline December $_{\text {tmean }}$ & 0.15 & 0.10 & 0.07 & 0.09 \\
\hline December $_{\text {tmax }}$ & 0.11 & 0.09 & 0.05 & 0.07 \\
\hline Annual $_{\mathrm{ppt}}$ & 0.23 & -0.09 & 0.07 & -0.07 \\
\hline Annual $_{\text {tmin }}$ & $0.38 * *$ & 0.13 & $0.37 * *$ & $0.21^{*}$ \\
\hline Annual tmean $_{\text {to }}$ & $0.25 * *$ & 0.14 & $0.27 * *$ & 0.18 \\
\hline Annual $_{\text {tmax }}$ & 0.07 & 0.13 & 0.11 & 0.09 \\
\hline Growing $_{\mathrm{ppt}}$ & $0.26^{* *}$ & -0.03 & 0.11 & 0.00 \\
\hline Growing $_{\text {tmin }}$ & $0.37 * *$ & 0.04 & $0.33 * *$ & $0.23 *$ \\
\hline Growing $_{\text {tmean }}$ & 0.16 & 0.04 & 0.17 & 0.15 \\
\hline Growing $_{\text {tmax }}$ & -0.05 & 0.02 & 0.01 & 0.06 \\
\hline
\end{tabular}


Table S4.3. Model summaries for the average models used to determine the temporal contribution of each environmental parameter on the growth (BAI) and physiology (iWUE) of Quercus rubra (Quru) and Liriodendron tulipifera (Litu) in Watershed 10 and Watershed 13 at the Fernow Experimental Forest in Parsons, WV, U.S. for the period $1960-2015$. Environmental factors included in the saturated model included atmospheric $\mathrm{CO}_{2}$, minimum growing season temperatures (May - September; Growing ${ }_{\text {tmin }}$ ), the sum of June and July precipitation $\left(\mathrm{JJ}_{\mathrm{ppt}}\right)$, U.S. emissions of $\mathrm{SO}_{2}$, and U.S. emissions of $\mathrm{NO}_{\mathrm{x}}$. All possible combinations of models were examined using the previously mentioned parameters, including interactions up to order two, resulting in a total of 1,450 models examined for each response variable. Models with $\triangle \mathrm{AICc}<1$ from the best model were averaged resulting in the final model. Significance at the $p<0.05$ level is denoted by *, while significance at the $p<0.09$ level is denoted by ${ }^{\circ}$.

\begin{tabular}{|c|c|c|c|c|c|}
\hline Model & Model Parameter & Estimate & Adjusted SE & $\mathrm{z}$ value & $\mathrm{P}$ \\
\hline \multirow{7}{*}{ Quru BAI } & (Intercept) & -4.879 & 10.406 & 0.469 & 0.639 \\
\hline & Growing $_{\text {tmin }}$ & 1.200 & 0.556 & 2.158 & $0.031 *$ \\
\hline & $\mathrm{JJ}_{\mathrm{ppt}}$ & 0.077 & 0.028 & 2.775 & $0.006^{*}$ \\
\hline & $\mathrm{NO}_{\mathrm{x}}$ Emissions & 1.706 & 0.477 & 3.579 & $0.000 *$ \\
\hline & $\mathrm{SO}_{2}$ Emissions & -0.829 & 0.317 & 2.615 & $0.009^{*}$ \\
\hline & $\mathrm{JJ}_{\mathrm{ppt}} * \mathrm{NO}_{\mathrm{x}}$ Emissions & -0.003 & 0.001 & 2.049 & $0.040^{*}$ \\
\hline & $\mathrm{JJ}_{\mathrm{ppt}} * \mathrm{SO}_{2}$ Emissions & -0.002 & 0.001 & 2.011 & $0.044 *$ \\
\hline \multirow{8}{*}{ Quru iWUE } & (Intercept) & -61.200 & 111.000 & 0.553 & 0.580 \\
\hline & $\mathrm{CO}_{2}$ & 0.364 & 0.273 & 1.337 & 0.181 \\
\hline & Growing $_{\text {tmin }}$ & 9.810 & 9.980 & 0.983 & 0.326 \\
\hline & $\mathrm{JJ}_{\mathrm{ppt}}$ & -0.113 & 0.078 & 1.443 & 0.149 \\
\hline & $\mathrm{NO}_{\mathrm{x}}$ Emissions & 1.410 & 1.050 & 1.342 & 0.180 \\
\hline & $\mathrm{CO}_{2} *$ Growing $_{\text {tmin }}$ & -0.037 & 0.021 & 1.803 & $0.071^{\bullet}$ \\
\hline & $\mathrm{CO}_{2} * \mathrm{JJ}_{\mathrm{ppt}}$ & 0.0003 & 0.000 & 1.826 & $0.068^{\circ}$ \\
\hline & Growing $_{\operatorname{tmin}} * \mathrm{NO}_{\mathrm{x}}$ Emissions & -0.153 & 0.089 & 1.724 & $0.085^{\circ}$ \\
\hline \multirow{7}{*}{ Litu BAI } & (Intercept) & 95.838 & 38.919 & 2.463 & $0.014 *$ \\
\hline & $\mathrm{CO}_{2}$ & -0.214 & 0.108 & 1.977 & $0.048 *$ \\
\hline & $\mathrm{JJ}_{\mathrm{ppt}}$ & 0.018 & 0.005 & 3.711 & $0.000 *$ \\
\hline & $\mathrm{NO}_{\mathrm{x}}$ Emissions & -5.725 & 2.600 & 2.202 & $0.028 *$ \\
\hline & $\mathrm{SO}_{2}$ Emissions & -0.867 & 0.431 & 2.011 & $0.044^{*}$ \\
\hline & $\mathrm{CO}_{2}{ }^{*} \mathrm{NOx}$.Emissions & 0.020 & 0.007 & 2.855 & $0.004 *$ \\
\hline & Growing $_{\text {tmin }}$ & 0.756 & 0.594 & 1.273 & 0.203 \\
\hline \multirow{5}{*}{ Litu iWUE } & (Intercept) & 78.186 & 44.216 & 1.768 & $0.077^{\bullet}$ \\
\hline & $\mathrm{CO}_{2}$ & 0.078 & 0.102 & 0.764 & 0.445 \\
\hline & Growing $_{\text {tmin }}$ & -3.723 & 1.340 & 2.778 & $0.005^{*}$ \\
\hline & $\mathrm{JJ}_{\mathrm{ppt}}$ & -0.163 & 0.054 & 3.018 & $0.003 *$ \\
\hline & $\mathrm{NO}_{\mathrm{x}}$ Emissions & -0.741 & 2.386 & 0.311 & 0.756 \\
\hline
\end{tabular}




\begin{tabular}{|c|c|c|c|c|}
\hline $\mathrm{SO}_{2}$ Emissions & 0.541 & 0.533 & 1.015 & 0.310 \\
\hline Growing $_{\mathrm{tmin}} * \mathrm{JJ}_{\mathrm{ppt}}$ & 0.014 & 0.005 & 2.818 & $0.004 *$ \\
\hline $\begin{array}{c}\mathrm{NO}_{\mathrm{x}} \text { Emissions } * \mathrm{SO}_{2} \\
\text { Emissions }\end{array}$ & -0.038 & 0.016 & 2.366 & $0.018^{*}$ \\
\hline $\mathrm{CO}_{2}$ :NOx.Emissions & 0.011 & 0.004 & 2.439 & $0.015^{*}$ \\
\hline
\end{tabular}


Figure S2.1. Chronologies of iWUE for each biome over time (a) and mean iWUE for each biome (b) for the period $1963-2015$, representing the part of the chronology following the breakpoint where iWUE began rapidly, and linearly increasing. Biomes were determined according to Dinerstein et al.(Dinerstein et al., 2017) with biome numbers in panel (b) classified as follows: 1) temperate conifer forests, 2) montane grasslands and shrublands, 3) tropical and subtropical coniferous forests, 4) deserts and xeric shrublands, 5) temperate grasslands savannas, and shrublands, 6) boreal forests/taiga, 7) temperate broadleaf and mixed forests, 8) tundra, 9) Mediterranean forests, woodlands, and scrub, and 10) tropical and subtropical moist broadleaf forests. Solid lines in (a) represent the average trend for each biome over the chronology. Center lines in boxplots in (b) represent the median value of iWUE for each group, while upper and lower box borders represent the $75^{\text {th }}$ and $25^{\text {th }}$ percentile values, respectively. Within each panel in (b) different letters indicate groups with means that are significantly different.

a

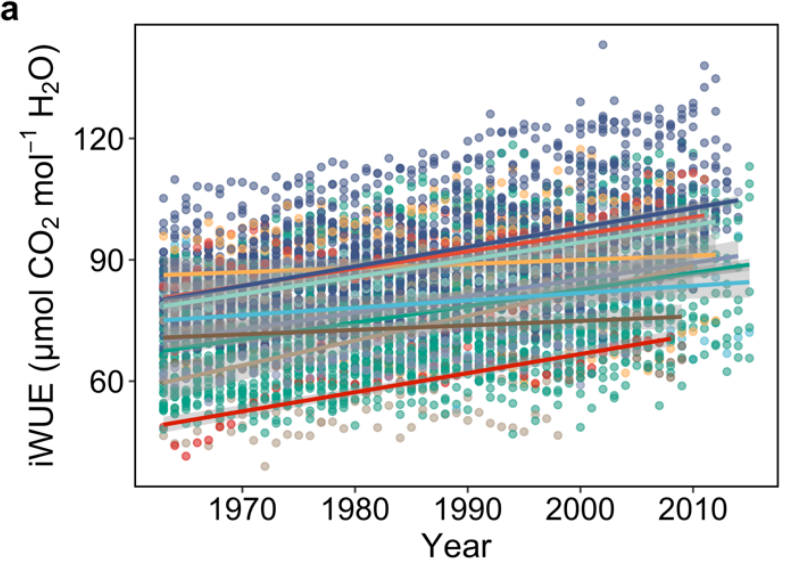

b

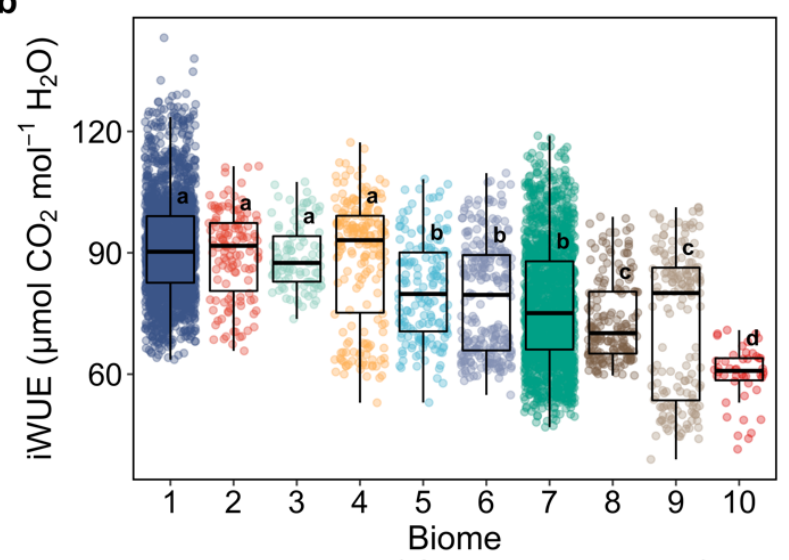

$\rightarrow$ Boreal Forests/Taiga $\quad \rightarrow$ Temperate Broadleaf \& Mixed Forests

Deserts \& Xeric Shrublands $\rightarrow$ Temperate Conifer Forests

- Mediterranean Forests, Woodlands \& Scrub - Temperate Grasslands, Savannas \& Shrublands

$\sim$ Montane Grasslands \& Shrublands $\sim$ Tropical \& Subtropical Coniferous Forests

$\rightarrow$ Tropical \& Subtropical Moist Broadleaf Forests 
Figure S2.2. Chronologies of iWUE for each wood type (a), mean iWUE for each wood type (b), chronologies of iWUE for each leaf type (c), and mean iWUE for each leaf type (d) for the period $1963-2015$, representing the part of the chronology following the breakpoint where iWUE began rapidly, and linearly increasing. Solid lines in (a) and (c) represent the average trend for each wood or leaf type over the chronology, respectively. Center lines in boxplots in (b) and (d) represent the median value of iWUE for each group, while upper and lower box borders represent the $75^{\text {th }}$ and $25^{\text {th }}$ percentile values, respectively. Within each panel in (b) and (d) different letters indicate groups with means that are significantly different.
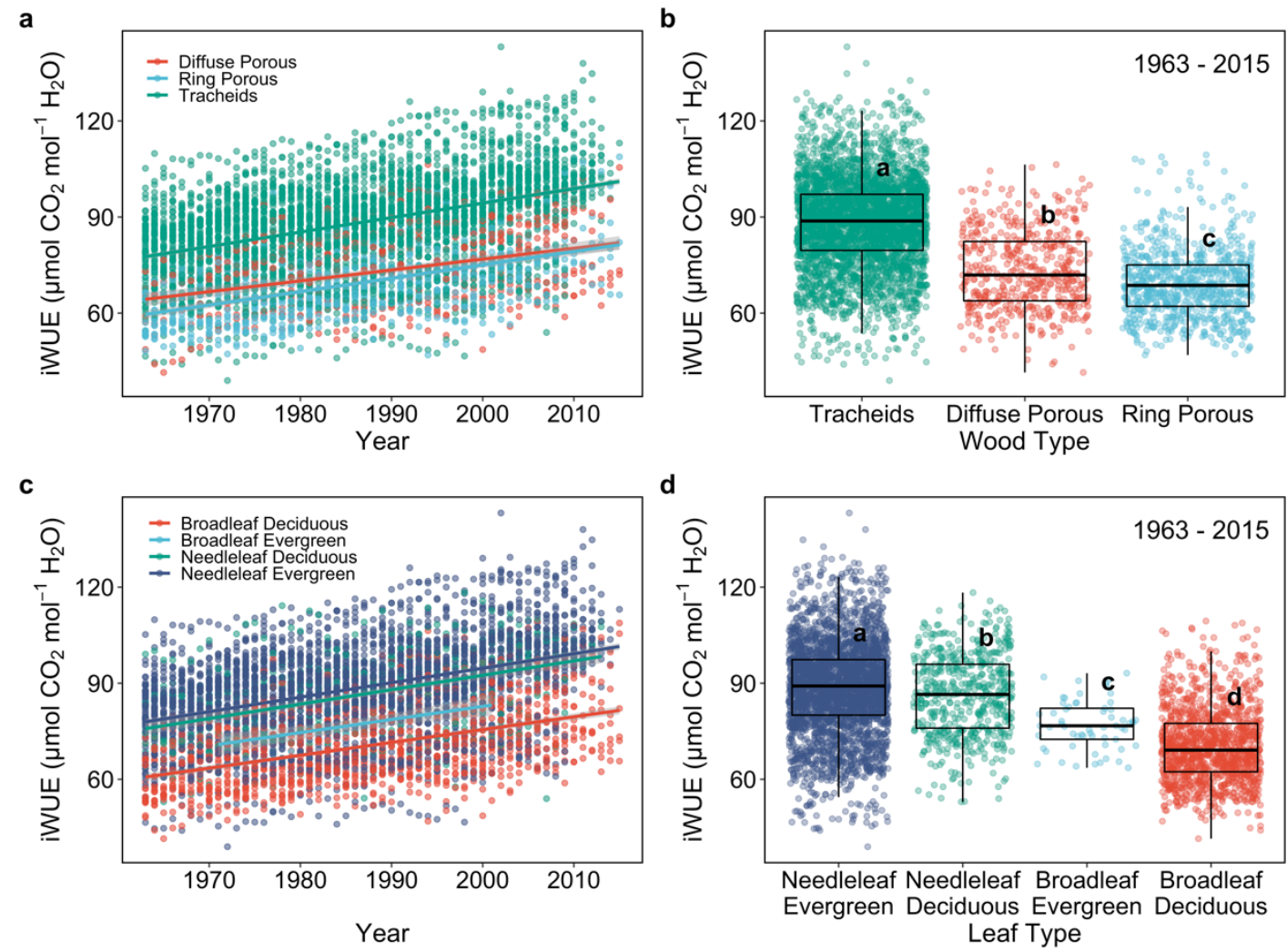
Figure S2.3. Visualization of the nature of the interaction between growing season vapor pressure deficit and atmospheric $\mathrm{CO}_{2}$ (a) and growing season temperature and $\mathrm{CO}_{2}$ (b) on iWUE during the period $1901-2015$. The interactions shown represent a given predicted value of iWUE throughout the range experienced by each group mean-centered environmental factor over the $1901-2015$ period. Values listed for each environmental factor represent its value with respect to the mean during the study period. Parameter estimates for each interaction are listed in Table 2.1.

a

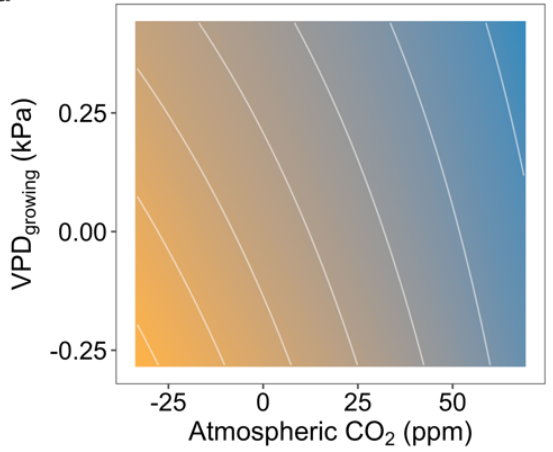

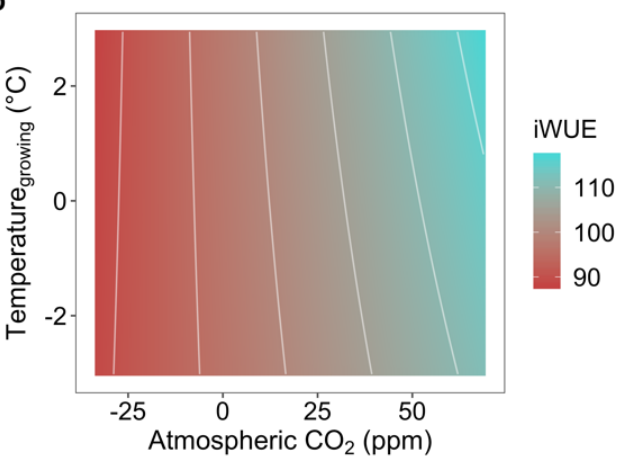


Figure S2.4. Visualization of the nature of the interaction between growing season temperature (TMP growing) and growing season precipitation ( $\mathrm{PPT}_{\text {growing }}$ ) on those tree species with $100 \%$ tracheids (a) and diffuse porous trees (b), and between growing season vapor pressure deficit (VPD growing) and $\mathrm{PPT}_{\text {growing }}$ for ring porous trees (c). The interactions shown represent a given predicted value of iWUE throughout the range experienced by each group mean-centered environmental factor over the $1963-2015$ period. Values listed for each environmental factor represent its value with respect to the mean during the study period.

a

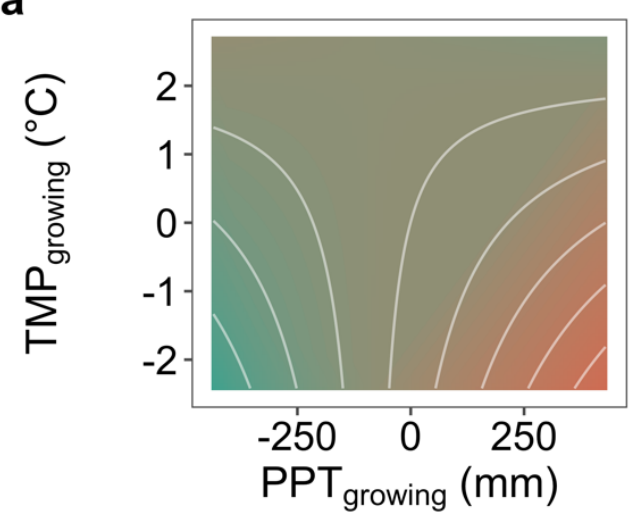

C

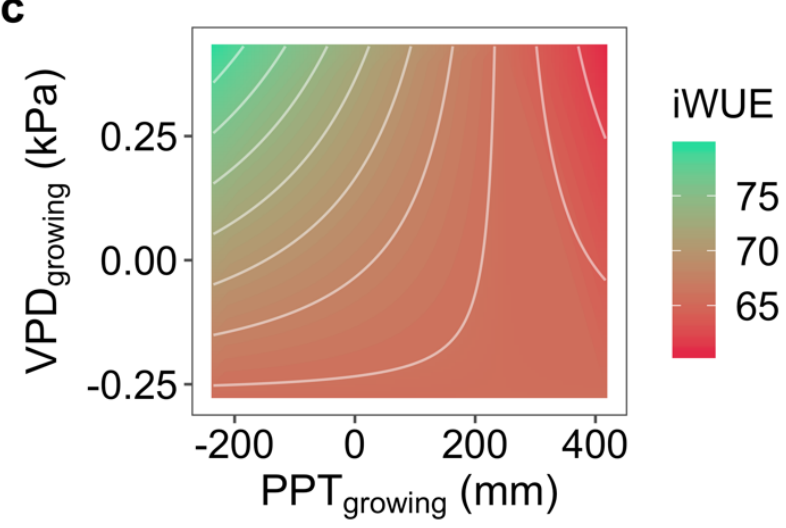

b

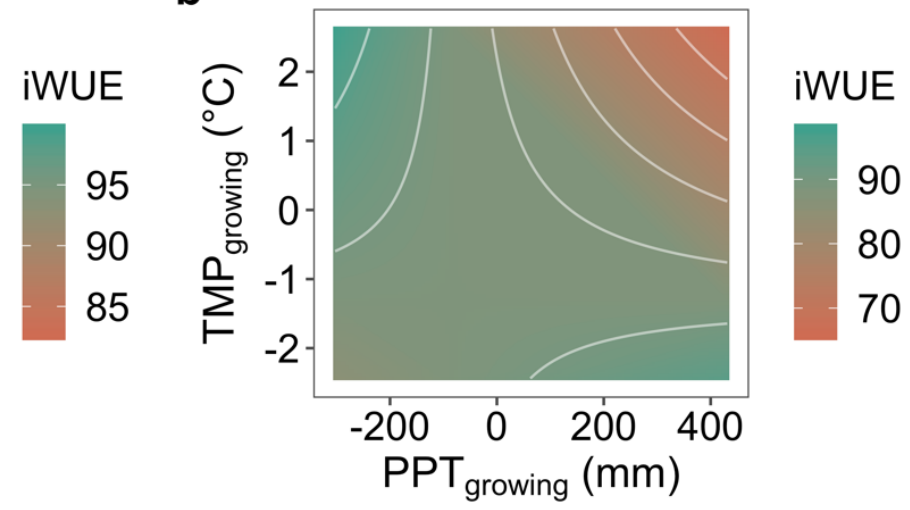


Figure S2.5. Trends in $\Delta^{18} \mathrm{O}_{\mathrm{lw}}$ for each leaf ring type (a) and leaf type (b) across all tree species and sites for the period $1963-2015$. The bold lines each panel represent, in turn, the average trend in $\Delta^{18} \mathrm{O}_{\mathrm{lw}}$ for each ring type or leaf type. The F-statistic and $\mathrm{p}$-value associated with ANCOVA testing for differences in the rate of change among each trait within each panel are listed.
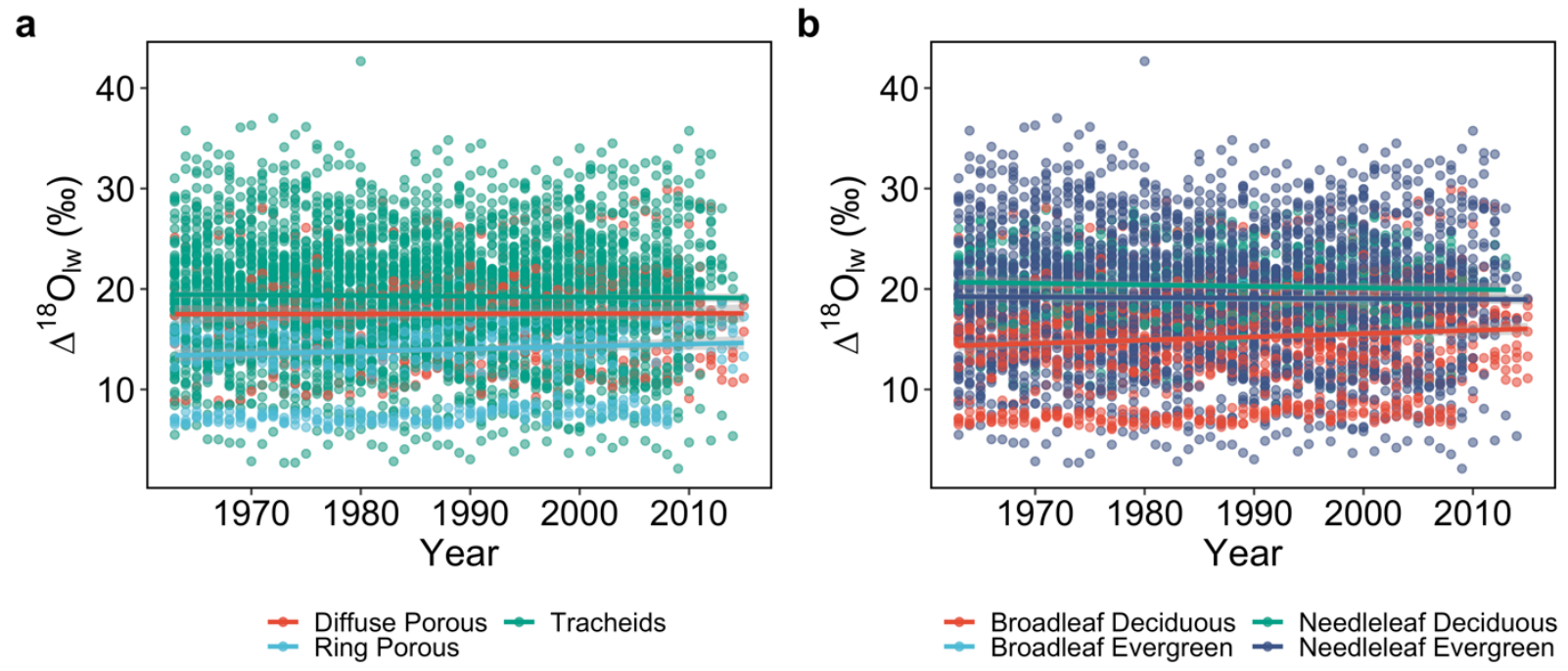
Figure S2.6. Trends in $\Delta^{18} \mathrm{O}_{\mathrm{lw}}$ for each of the 113 unique chronologies examined in this study as a function of mean $\mathrm{TMP}_{\text {grw }}(\mathrm{a}), \mathrm{PPT}_{\text {grw }}(\mathrm{b})$, and $\mathrm{VPD}_{\text {grw }}(\mathrm{c})$, and as a function of the average trend in $\mathrm{TMP}_{\text {grw }}(\mathrm{d}), \mathrm{PPT}_{\text {grw }}(\mathrm{e})$, and $\mathrm{VPD}_{\text {grw }}$ (f) for the period $1963-2015$. The slope ( \pm s.e.) and $p$-value for the linear relationship between the trend in $\Delta^{18} \mathrm{O}_{\mathrm{lw}}$ and each respective environmental factor is listed in each panel. Trends in $\Delta^{18} \mathrm{O}_{\mathrm{lw}}$, as well as each environmental factor, were determined using generalized least squares regression, including an $\operatorname{AR}(1,0)$ autocorrelation structure.
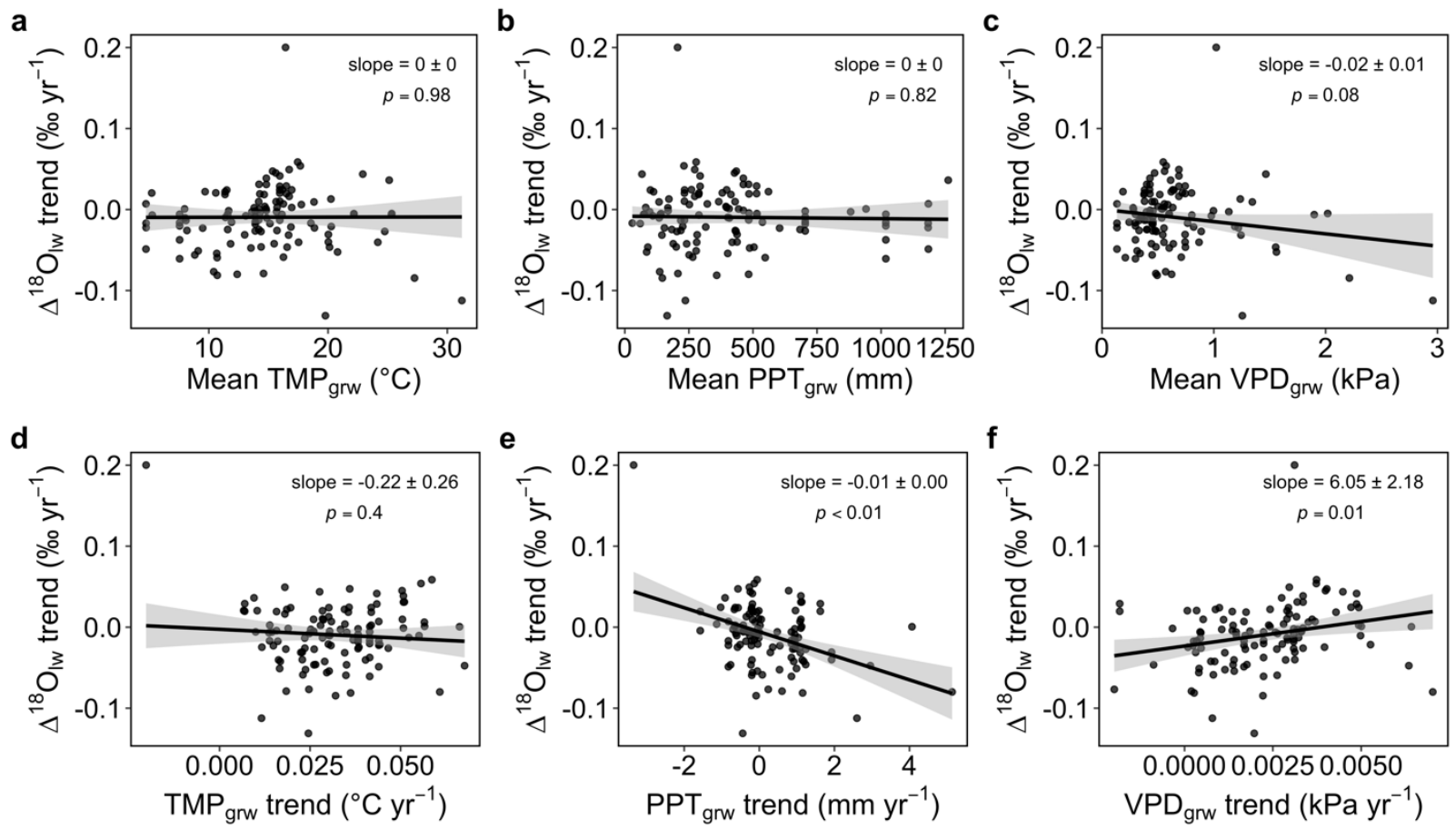
Figure S2.7. Global concentrations of annual atmospheric $\mathrm{CO}_{2}$ from $1901-2015$. The vertical blue dashed line at 1963 represents the breakpoint where iWUE averaged across all 113 chronologies began to rapidly increase, while the vertical red dashed line at 1969 represents the breakpoint where concentrations of atmospheric $\mathrm{CO}_{2}$ began increasing more rapidly than the 69 years prior.

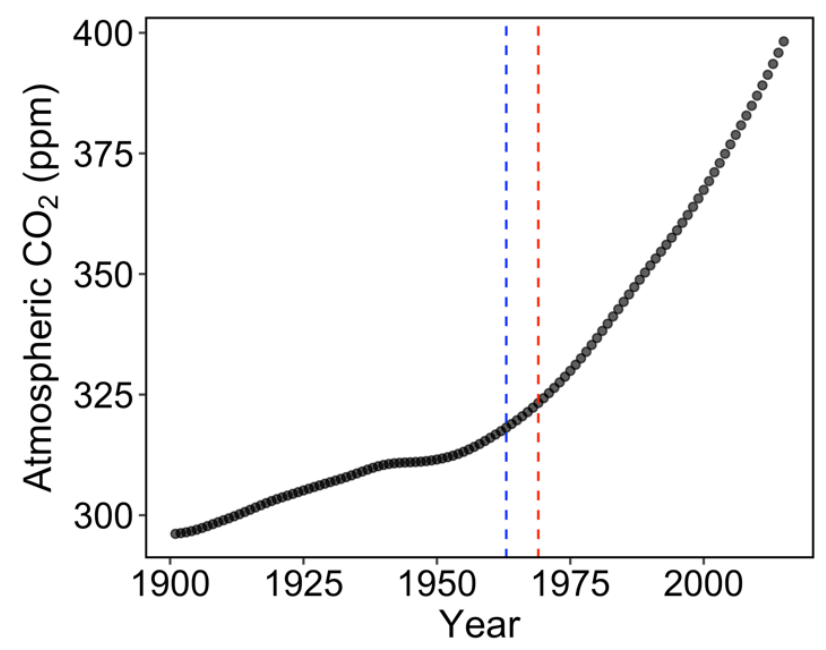


Figure S3.1. National emissions of sulfur dioxide $\left(\mathrm{SO}_{2}\right)$ estimated by the EPA (2015) and regional sulfate $\left(\mathrm{SO}_{4}{ }^{2-}\right)$ deposition measured at the NADP's WV18 site in Parsons, WV (a) (NADP 2015), national emissions of nitrogen oxides $\left(\mathrm{NO}_{\mathrm{x}}\right)$ estimated by the EPA (2015) and regional deposition of nitrate $\left(\mathrm{NO}_{3}^{-}\right)$measured at the NADP's WV18 site in Parsons, WV (b) (NADP 2015), atmospheric $\mathrm{CO}_{2}$ concentrations measured at the Mauna Loa Observatory (c) (Keeling et al. 2015), and mean April temperatures for WV Climate Division 4 (d) (NOAA, 2017). The unshaded region indicates the time period after the critical year when a directional shift in BAI, $\Delta^{13} \mathrm{C}$, and $\delta^{15} \mathrm{~N}$ occurs. Coefficients of determination for the relationship between emissions and deposition of oxidized forms of $\mathrm{S}$ and $\mathrm{N}$ are shown for the unshaded region in panels (a) and (b), respectively. For mean April temperatures (d), trend lines are for each period (1940-1989 and 1989-2014).
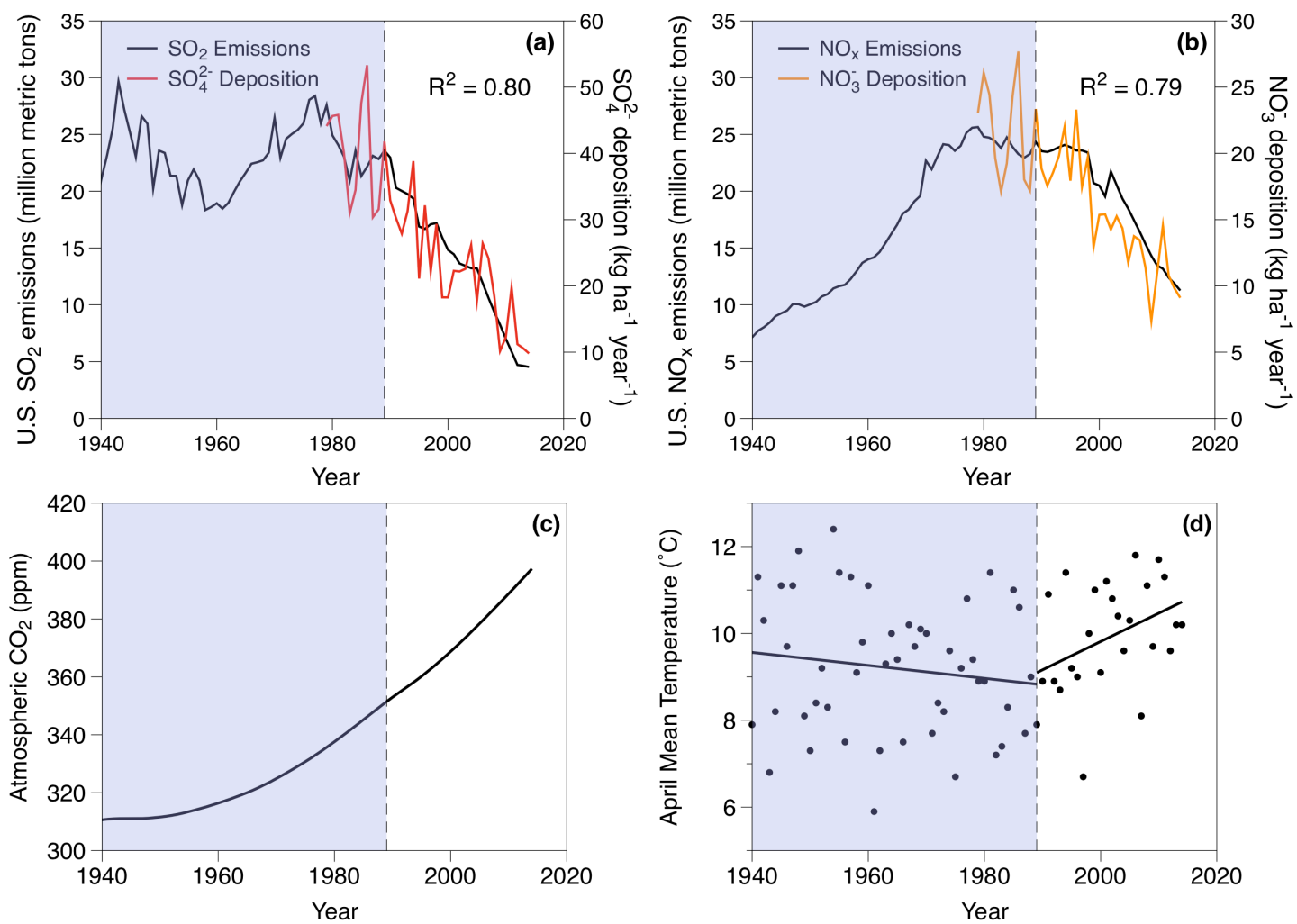
Figure S3.2. Temporal trends in mean annual temperature (a), mean annual precipitation (b), mean growing temperature (c), and mean growing precipitation (d) for WV Climate Division 4. Vertical dashed lines are at 1989, regional critical year, and trend lines for each period (19401989 and 1989-2014) are displayed on each panel. ANCOVA indicated that rates of change before and after the 1989 critical year were not different for these climate parameters. Climate data are from West Virginia Division 4, which is the region that contains the three red spruce stands in this study (NOAA 2017). Over the entire 75 year chronology, (a) yearly temperature (T $=-3.81+0.007 *$ year, $\left.\mathrm{R}^{2}=0.04, \mathrm{p}=0.04\right)$, (b) yearly precipitation $\left(\mathrm{y}=-686.15+0.97 *\right.$ year; $\mathrm{R}^{2}=$ $0.02, p=0.22)$, (c) growing season temperature $\left(y=14.69+0.002 *\right.$ year; $\left.R^{2}=0.003, p=0.65\right)$, and $(\mathrm{d})$ growing season precipitation $\left(\mathrm{y}=8.37+0.29 *\right.$ year; $\left.\mathrm{R}^{2}=0.004, \mathrm{p}=0.58\right)$. The only significant change has been a $0.50^{\circ} \mathrm{C}$ increase in mean annual temperature over $1940-2014$. ANOVA comparing the means before and after 1989 indicates that annual temperature was $0.54^{\circ} \mathrm{C}$ greater after 1989 than for the annual temperature during 1940-1989 $(\mathrm{F}=14.99, \mathrm{p}<$ $0.01)$.
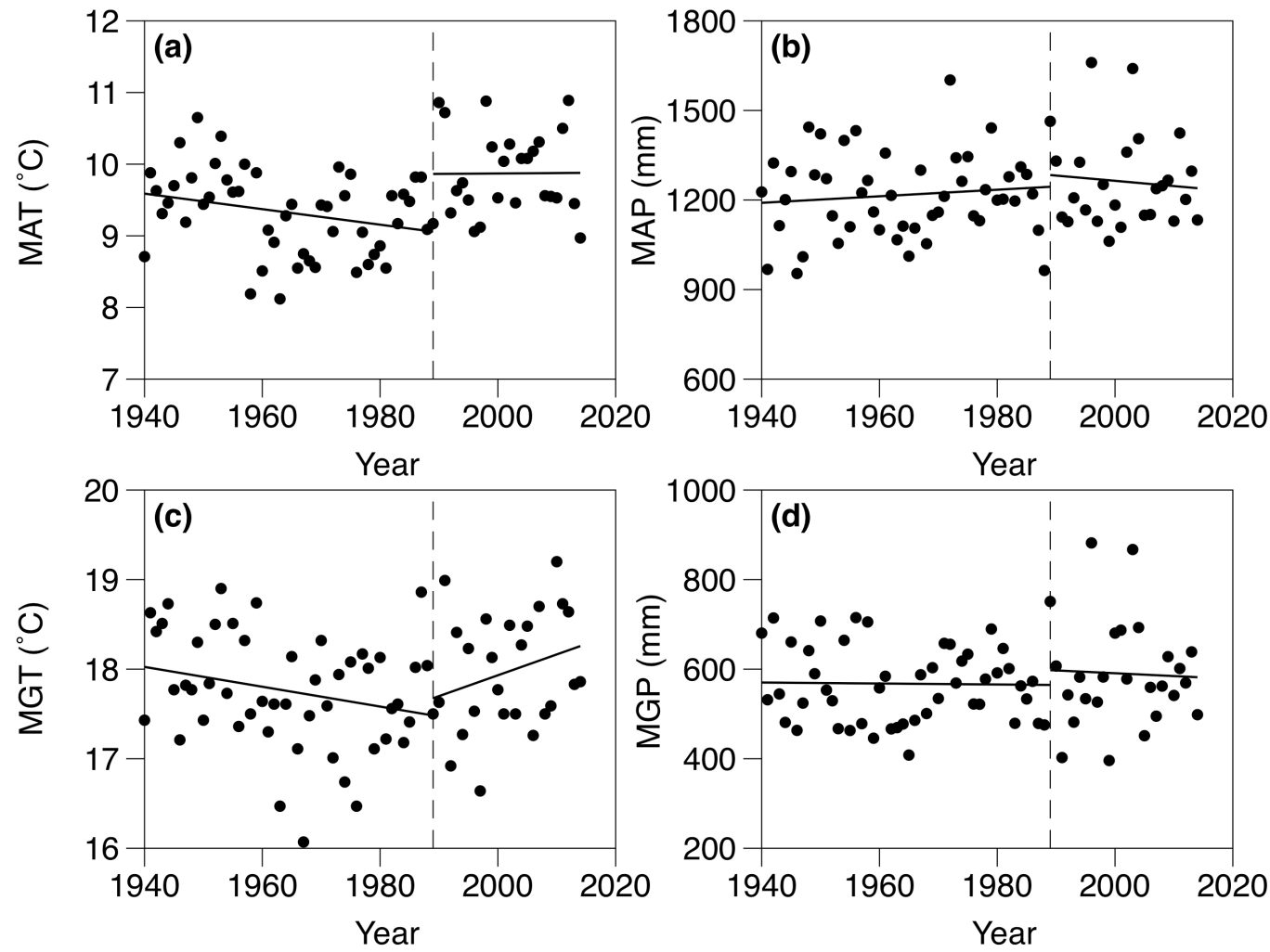
Figure S3.3. Wood $\delta^{15} \mathrm{~N}$ as a function of U.S. $\mathrm{NO}_{\mathrm{x}}$ emissions during 1989-2013 (a), and wood $\delta^{15} \mathrm{~N}$ as a function of $\mathrm{NO}_{3}{ }^{-}$wet deposition during 1989-2013 (b). The three red spruce forest sites are McGowan Mountain (MCG), Span Oak Run (SOR), and Cranberry Glades (CGL). $\mathrm{NO}_{\mathrm{x}}$ emissions are from the EPA (2015) and $\mathrm{NO}_{3}{ }^{-}$wet deposition are from (NADP 2015).
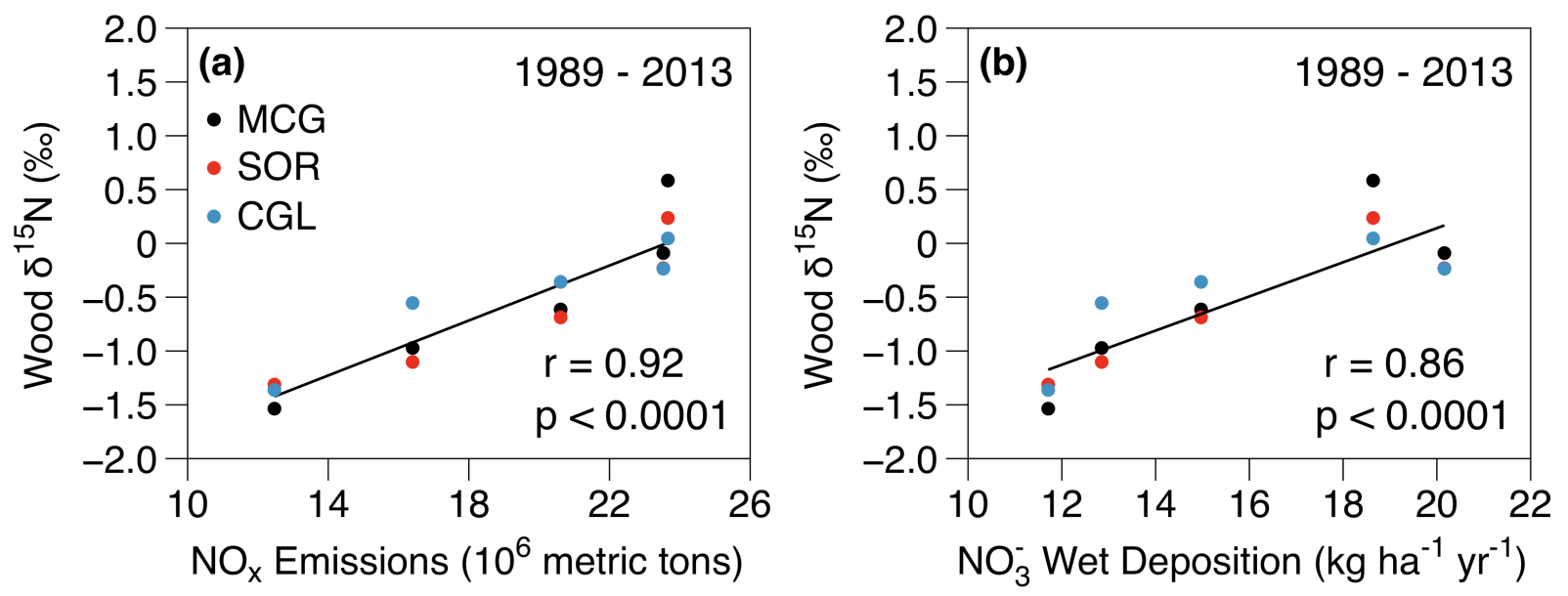
Figure S3.4. Bootstrapped Pearson's correlations calculated between tree ring indices and current year's (months in all capital letters) and previous year's (months in lowercase) climate predictor variables for MCG (a), SOR (b), and CGL (c) for the period 1940-2014. Correlations between tree ring indices and mean monthly temperatures are in blue, while correlations between tree ring indices and monthly precipitation sums are in red. A solid vertical line indicates a significant relationship at the $\alpha=0.05$ level, while dashed lines indicate a non-significant relationship.
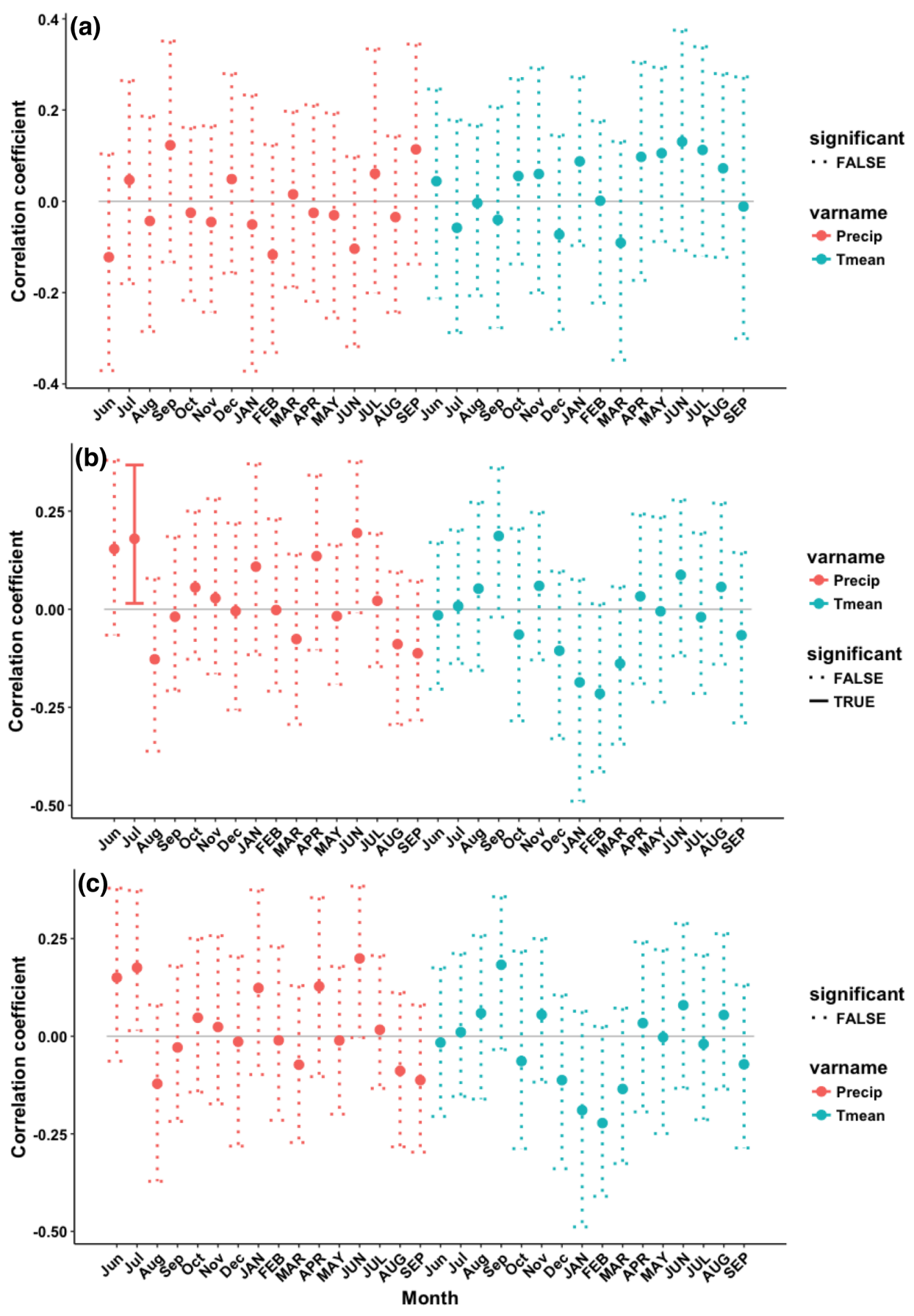
Figure S3.5. Predicted BAI from the GLMM average model as a function of observed BAI across all red spruce forest sites (MCG, SOR, and CGL) for the 1989-2014 period. Models with $\triangle \mathrm{AICc}<4$ were included in the average model. Average model structure can be found in Table S3.

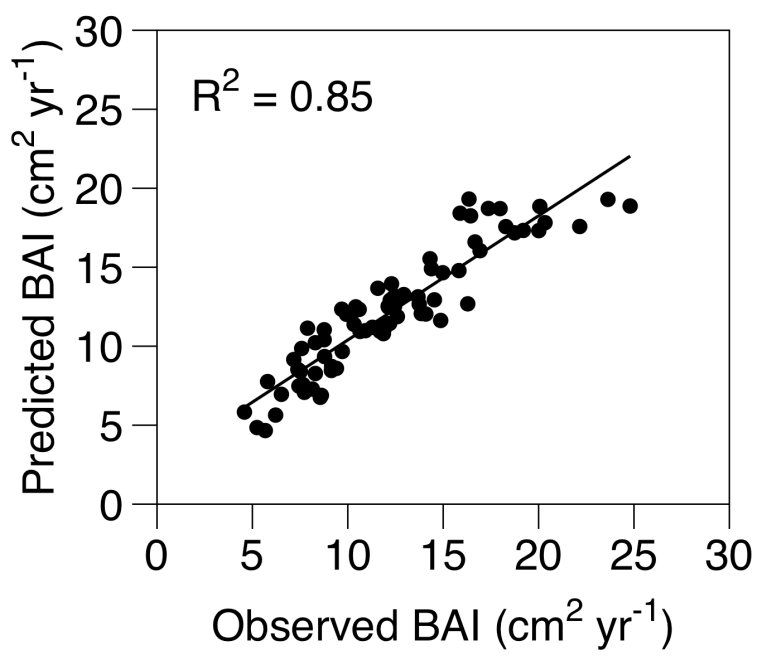


Figure S3.6. Chronology of stomatal conductance to $\mathrm{CO}_{2}(\mathrm{a})$, and observed and modeled intrinsic water use efficiency (b) from 1940 to 2014 for each red spruce site ( $\mathrm{N}=5$ per site). In panel (a), if we assume a complete recovery of $g_{c}$ after 1989 , the $15 \%$ decline in $g_{c}$ that occurred between 1940 and 2014 can be attributed to the effect of increasing $\mathrm{CO}_{2}$ (dashed line). The 47\% decline in $g_{c}$ can be partitioned with $10 \%$ attributed to increasing $\mathrm{CO}_{2}$ and $37 \%$ attributed to acid deposition $(47 \%-10 \%=37 \%)$. In panel (b), modeled $i$ WUE was calculated assuming a constant $\mathrm{C}_{\mathrm{i}} / \mathrm{C}_{\mathrm{a}}(0.72,1940$ mean) using the Ball-Berry model (solid line) (Knauer et al., 2016) and changes in leaf physiology predicted from $\mathrm{CO}_{2}$ enrichment studies (Ainsworth \& Rogers, 2007), combined with changes in $g_{c}$ attributed to increasing $\mathrm{CO}_{2}$ (dashed line). The three red spruce forest sites are McGowan Mountain (MCG), Span Oak Run (SOR), and Cranberry Glades (CGL).
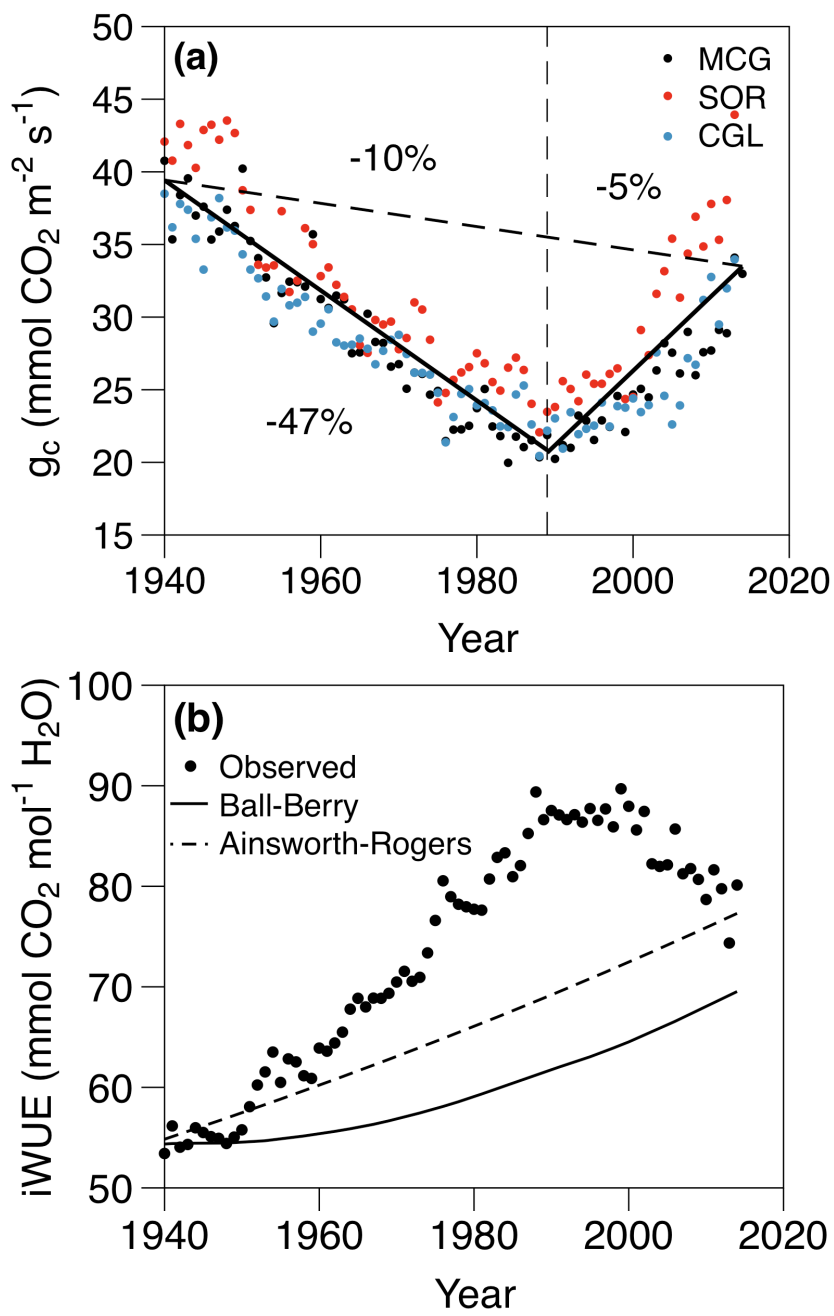
Figure S3.7. Map of the U.S. regions $(53,57$, and $61-66)$ used in estimation of the reduction in carbon sequestration due to pollution (Table S4), from the National Biomass and Carbon Dataset (Kellndorfer et al., 2012). Forest land cover estimates from the Multi-Resolution Land Characteristics Consortium's 2011 Land Cover Database (Homer et al., 2015) were coupled with biomass estimates from the National Biomass and Carbon Dataset for the year 2000. Map was made using ArcMap 10.3.1 (http://desktop.arcgis.com/en/arcmap/).

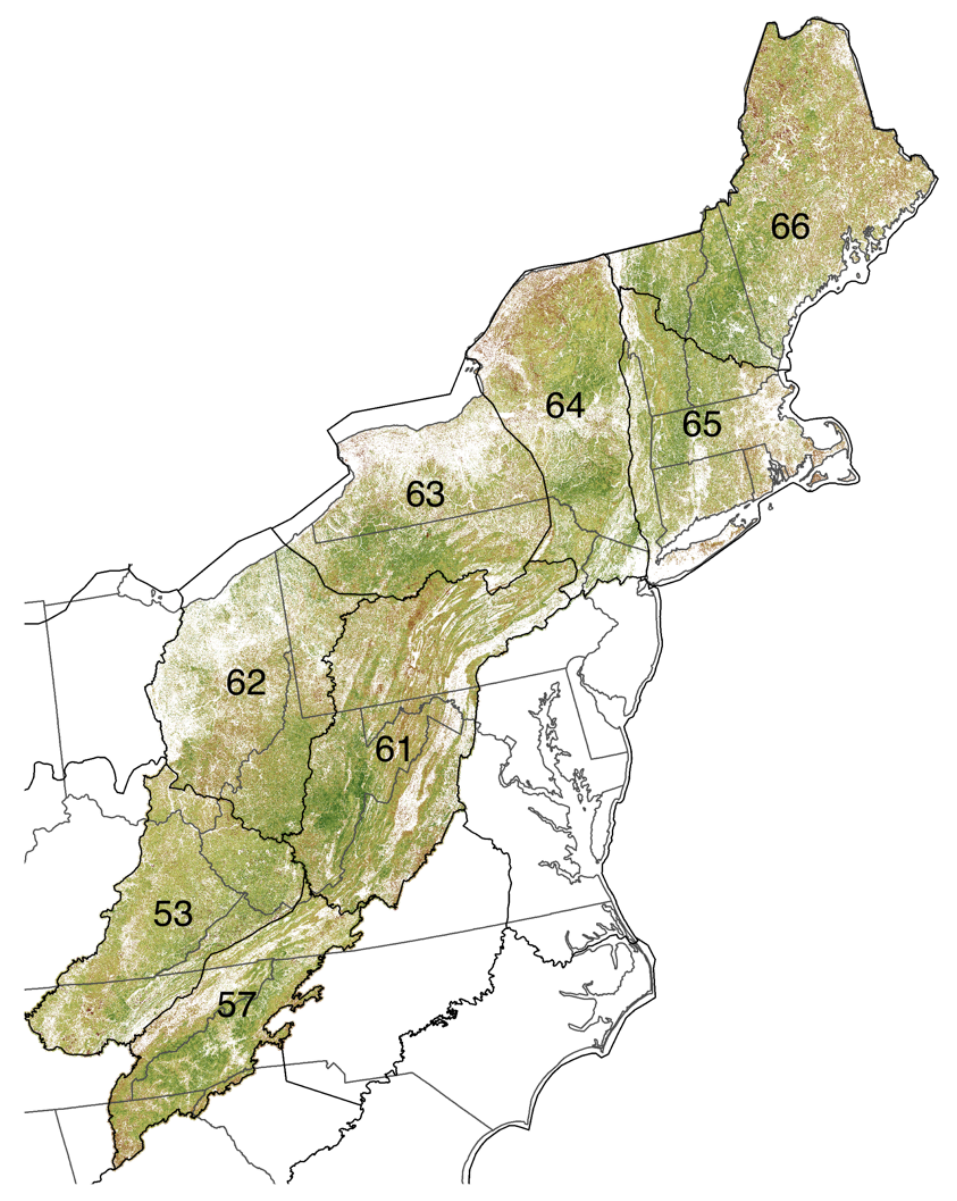


Figure S4.1. U.S. national emissions of $\mathrm{NO}_{x}$ and local deposition of $\mathrm{NO}_{3}{ }^{-}$(a) national emissions of $\mathrm{SO}_{2}$ and local deposition of $\mathrm{SO}_{4}{ }^{2-}(\mathrm{b})$, national emissions of $\mathrm{NO}_{\mathrm{x}}$ and stream water $\mathrm{NO}_{3}{ }^{-}$in WS10 and WS13 (c), and national emissions of $\mathrm{SO}_{2}$ and stream water $\mathrm{SO}_{4}{ }^{2-}$ in $\mathrm{WS} 10$ and $\mathrm{WS} 13$ in the Fernow Experimental Forest, Parsons, WV (d). Emissions of $\mathrm{NO}_{\mathrm{x}}$ (black line in a and c) and $\mathrm{SO}_{2}$ (black solid line in $\mathrm{b}$ and d) are available for the entire $1960-2015$ study period (EPA, 2015), while deposition of $\mathrm{NO}_{3}{ }^{-}$(green solid line in a) and $\mathrm{SO}_{4}{ }^{2-}$ (blue solid line in b) are shown beginning in 1979 NADP, 2015), and stream water chemistry available beginning in 1984 (Edwards \& Wood, 2011). The Pearson's correlation coefficient between emissions and deposition of $\mathrm{N}$ and $\mathrm{S}$ for the period $1979-2015$ is denoted in the lower left corner $\mathrm{a}$ and $\mathrm{b}$. Concentrations of stream water $\mathrm{NO}_{3}^{-}\left(\mathrm{c}\right.$, red lines) and $\mathrm{SO}_{4}{ }^{2-}(\mathrm{d}$, brown lines) for WS10 and WS13 are shown in dashed and solid lines, respectively.
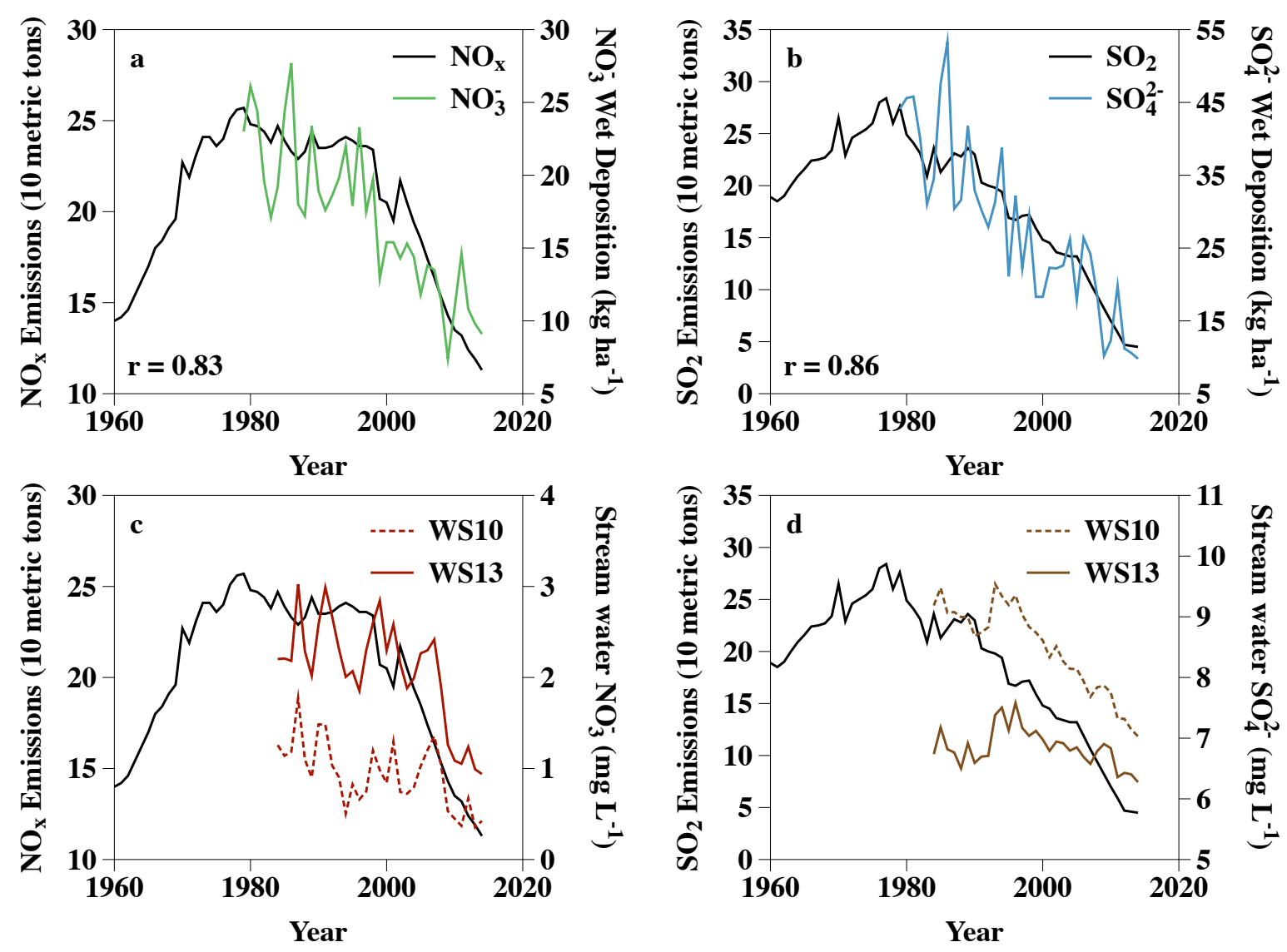
Figure S4.2. Bootstrapped Pearson's correlations between climate variables and basal area increment for the period 1960 - 2015 for Quercus rubra $(\mathrm{a}, \mathrm{c})$ and Liriodendron tulipifera $(\mathrm{b}, \mathrm{d})$ in Watershed $10(\mathrm{a}, \mathrm{b})$ and Watershed $13(\mathrm{c}, \mathrm{d})$ in the Fernow Experimental Forest, Parsons, WV, U.S. Green bars represent correlations between temperature and BAI, while blue bars represent correlations between precipitation and BAI. Solid bars indicate a significant correlation between either previous year's (lowercase months) or current year's (uppercase months) climate variable and BAI at the $\alpha=0.05$ level, while dashed bars indicate a non-significant correlation at the $\alpha=$ 0.05 level. For precipitation, $\mathrm{JJ}_{\mathrm{ppt}}$ is the sum of the current year's June and July precipitation, while $\mathrm{jj}_{\mathrm{ppt}}$ is the sum of the previous June and July's precipitation. $\mathrm{G}_{\mathrm{tmin}}$ represents the mean of May - September minimum temperatures.
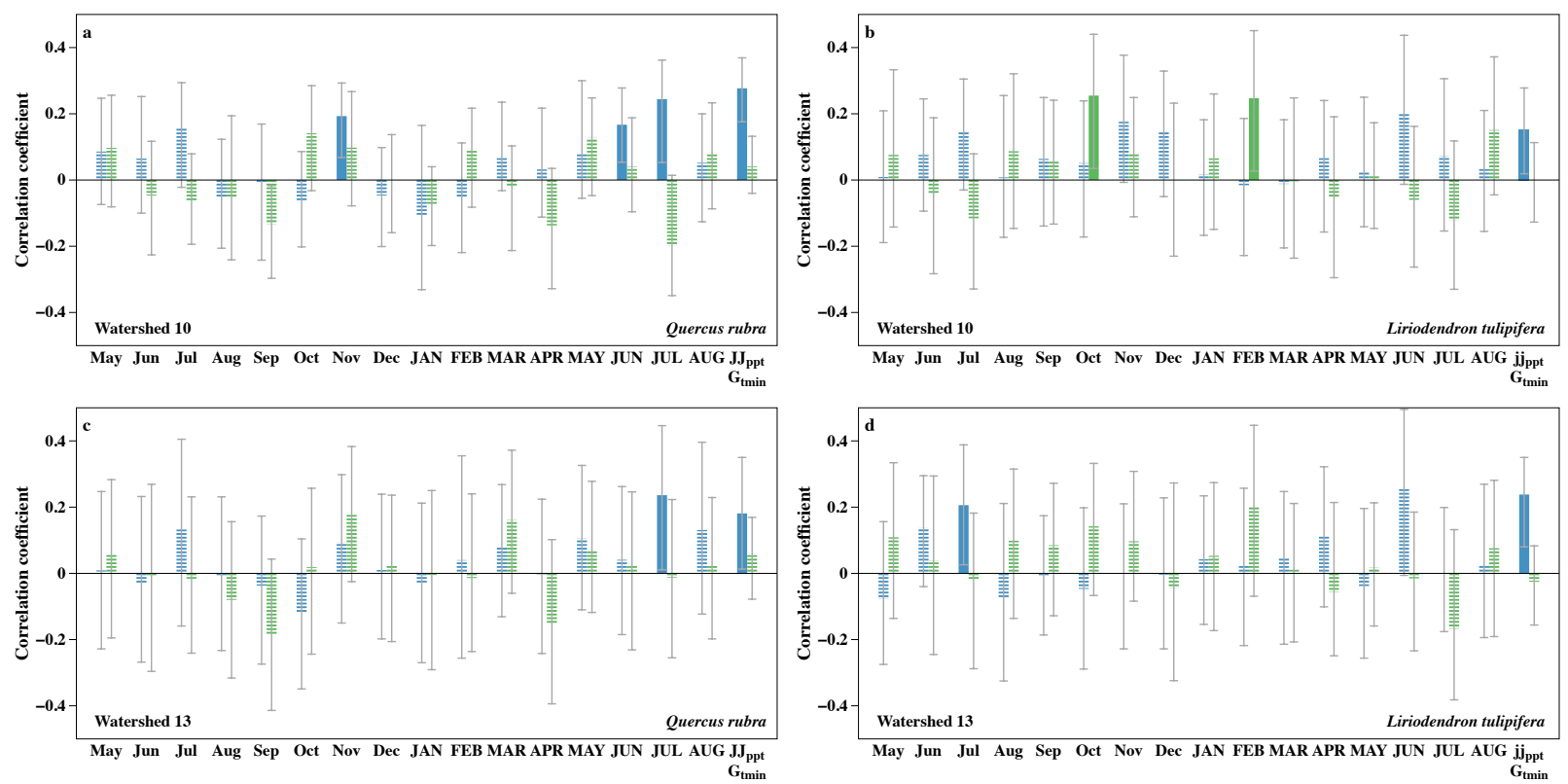
Figure S4.3. Heatmap of Kendall's rank correlation coefficients between environmental factors and BAI and iWUE for Quru and Litu for the period 1960 - 2015 across WS10 and WS13 in the Fernow Experimental Forest, Parsons, WV, U.S. Climate variables included in the analysis are temperature and precipitation (PRISM Climate Group, 2004), while non-climatic environmental factors are atmospheric $\mathrm{CO}_{2}$ (Keeling et al., 2015), $\mathrm{SO}_{2}$ emissions, and $\mathrm{NO}_{\mathrm{x}}$ emissions (EPA, 2015). Minimum, mean, and maximum temperatures are denoted by $T_{\min }, T_{\text {mean }}$, and $T_{\max }$, respectively. Significant correlations $(\mathrm{p} \leq 0.05)$ between a given environmental factor and response variable are denoted by the presence of an asterisk, with the cell hue corresponding to the correlation coefficient, with blue being positive and red being negative. Environmental parameters with at least one significant relationship with a given response variable are shown. A full correlation summary can be found in Table S2.

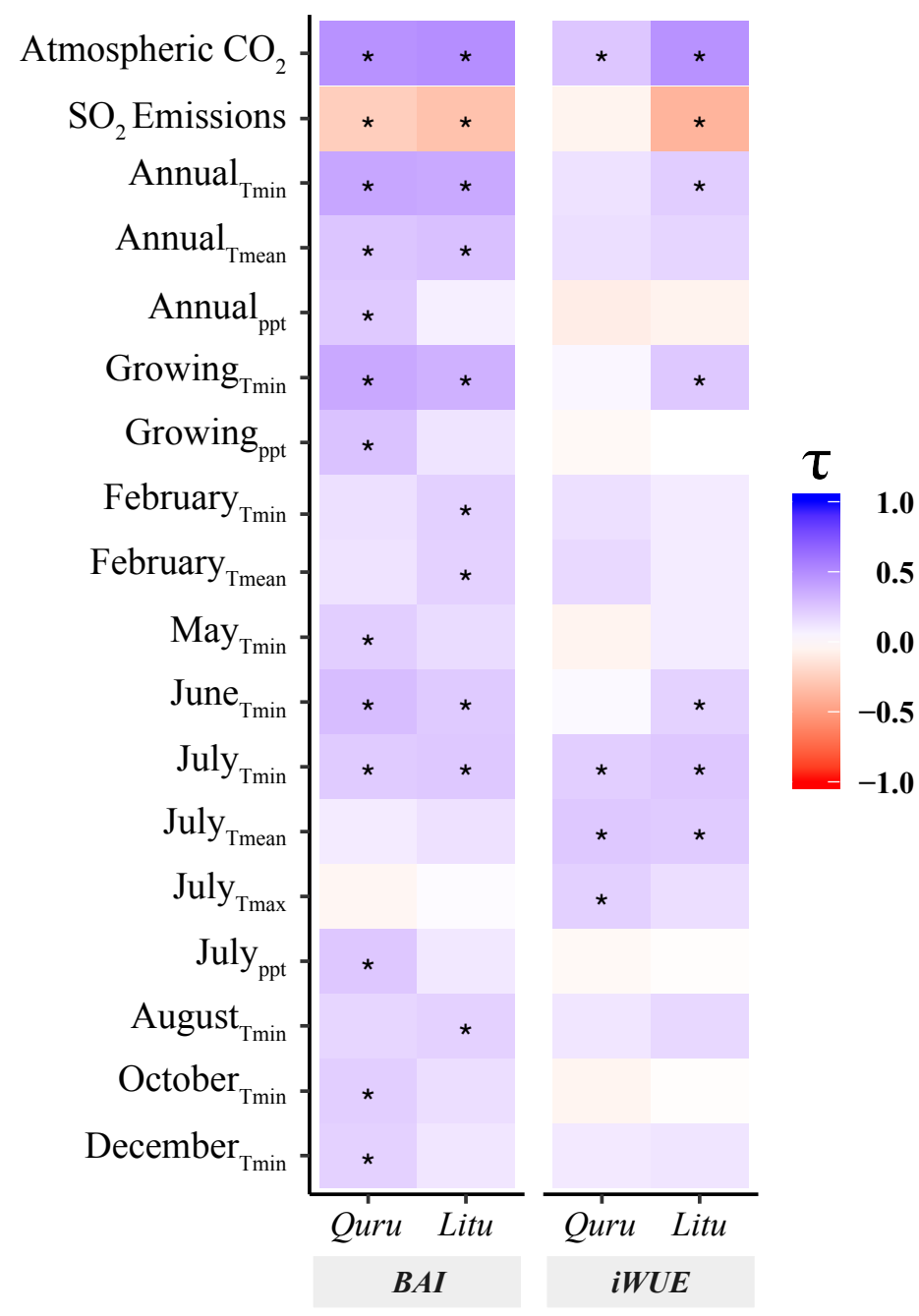

